ISSN: 2707-7365

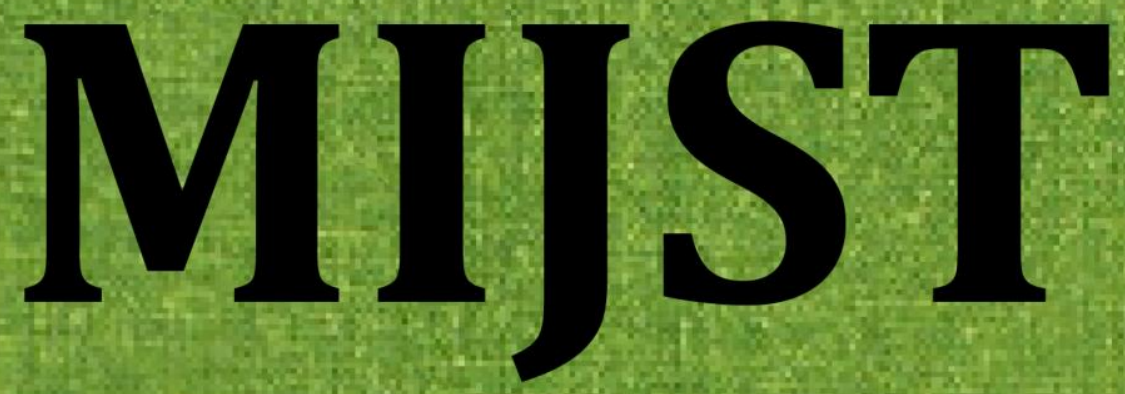

MIST International Journal of Science and Technology A Peer Reviewed Online Open Access Journal

Volume 08 June 2020

Military Institute of Science and Technology (MIST) 
MIST International Journal of Science and Technology 



\section{CHIEF PATRON}

Major General Md Wahid-Uz-Zaman, ndc, aowc, psc, te

Commandant

Military Institute of Science and Technology (MIST)

Dhaka, Bangladesh

\section{EDITOR-IN-CHIEF}

\section{Dr. Firoz Alam}

Professor

Offshore Mechanical Engineering, School of Engineering, RMIT University

Melbourne, Australia

\section{EXECUTIVE EDITOR}

\section{Dr. A.K.M. Nurul Amin}

Professor, Industrial and Production Engineering, Military Institute of Science and Technology

Dhaka, Bangladesh

\section{ASSOCIATE EDITORS}

\section{Lt Col Md Altab Hossain, PhD, EME}

Assoc. Professor, Nuclear Science and Engineering, Military Institute of Science and Technology Dhaka, Bangladesh

\section{Lt Col Muhammad Nazrul Islam, PhD, Sigs}

Assoc. Professor, Computer Science and Engineering, Military Institute of Science and Technology Dhaka, Bangladesh

\section{COPY EDITOR}

\section{Dr. Md Enamul Hoque}

Professor, Biomedical Engineering, Military Institute of Science and Technology

Dhaka, Bangladesh

\section{EDITORIAL ADVISOR}

Col Molla Md. Zubaer, te

Military Institute of Science and Technology

Dhaka, Bangladesh

\section{SECTION EDITORS}

\section{Dr G. M Jahid Hasan}

Professor (CE), MIST,

Dhaka, Bangladesh

Lt Col Khondaker Sakil Ahmed, PhD Assoc. Professor (CE), MIST,

Dhaka, Bangladesh

\section{Dr. Md. Mahbubur Rahman}

Professor (CSE), MIST,

Dhaka, Bangladesh

\section{Brig Gen A K M Nazrul Islam, PhD}

Professor (EECE), MIST,

Dhaka, Bangladesh

\section{Mr. Tariq Mahbub}

Assist. Professor (ME), MIST,

Dhaka, Bangladesh
Dr. M A Taher Ali

Professor (AE), MIST,

Dhaka, Bangladesh

Dr M A Rashid Sarker

Professor (NSE), MIST,

Dhaka, Bangladesh

Maj Osman Md Amin, PhD, Engrs Assoc. Professor (NAME), MIST,

Dhaka, Bangladesh

Maj Kazi Shamima Akter, PhD, Engrs Assoc. Professor (EWCE), MIST,

Dhaka, Bangladesh

Md. Sazzad Hossain

Assoc. Professor (Arch), MIST,

Dhaka, Bangladesh
Dr. Md Enamul Hoque Professor (BME), MIST, Dhaka, Bangladesh

Dr. Muammer Din Arif Assist. Professor (IPE), MIST, Dhaka, Bangladesh

\section{Dr. AKM Badrul Alam}

Assoc. Professor (PME), MIST, Dhaka, Bangladesh

Lt Col Brajalal Sinha, PhD, AEC Assoc. Professor (Sc \& Hum), MIST, Dhaka, Bangladesh

Maj Palash Kumar Sarker, PhD, Sigs Assoc. Professor (Sc \& Hum), MIST, Dhaka, Bangladesh 


\section{PROOF/LANGUAGE SUPPORT GROUP}

Maj Md. Manwarul Haq, PhD, AEC

Associate Professor

Science \& Humanities, Military Institute of Science and Technology

Dhaka, Bangladesh

\section{Selin Yasmin}

Associate Professor

Science \& Humanities, Military Institute of Science and Technology

Dhaka, Bangladesh

\section{Md Moslem Uddin}

Librarian, Military Institute of Science and Technology

Dhaka, Bangladesh

\section{RESEARCH COORDINATOR}

Lt Col Muhammad Sanaullah, psc, Engrs

Military Institute of Science and Technology

Dhaka, Bangladesh

\section{WEB CONSULTANT}

\section{Dr. Md Akhtaruzzaman}

MIJST, Military Institute of Science and Technology

Dhaka Bangladesh

\section{EDITORIAL BOARD MEMBERS (EXTERNAL)}

\section{Dr. Md Hadiuzzaman}

Professor,

Bangladesh University of Engineering \&

Technology (BUET),

Bangladesh

\section{Dr. M. Kaykobad}

Professor,

Bangladesh University of Engineering \&

Technology (BUET),

Bangladesh

\section{Dr. A.B.M. Harun-ur Rashid}

Professor,

Bangladesh University of Engineering \&

Technology (BUET),

Bangladesh

\section{Dr. Abdul Hasib Chowdhury}

Professor,

Bangladesh University of Engineering \&

Technology (BUET)

Bangladesh

\section{Dr. Mohammad Ali}

Professor,

Bangladesh University of Engineering \&

Technology (BUET),

Bangladesh

\section{Dr. Nikhil Ranjan Dhar}

Professor,

Bangladesh University of Engineering \&

Technology (BUET),

Bangladesh

\section{Dr. Shahjada Tarafder}

Professor,

Bangladesh University of Engineering \&

Technology (BUET),

Bangladesh

\section{Dr. Tanvir Ahmed}

Professor,

Bangladesh University of Engineering \&

Technology (BUET),

Bangladesh

\section{Dr. Khandaker Shabbir Ahmed}

Professor,

Bangladesh University of Engineering \&

Technology (BUET),

Bangladesh

\section{Dr. Nahrizul Adib Bin Kadri}

Assoc. Professor

University of Malaya,

Malaysia

\section{Dr. Sunil S. Chirayath}

Assoc. Professor,

Texas A\&M University, USA

\section{Dr. A.K.M. Masud}

Professor,

Bangladesh University of Engineering \&

Technology (BUET),

Bangladesh

\section{Dr. ASM Woobaidullah}

Professor,

Dhaka University,

Bangladesh

\section{Dr. Abdul Basith}

Professor,

Bangladesh University of Engineering \& Technology (BUET),

Bangladesh

\section{Dr. Md Abdul Jabbar}

Professor,

Dhaka University,

Bangladesh 


\section{Dr. Mahmud Ashraf}

Assoc. Professor, Deakin University, Australia

\section{Dr. Mohammed A Quddus}

Professor, Loughborough University, UK

\section{Dr. A. K. M. Najmul Islam}

Adjunct Professor, University of Turku, Finland

\section{Dr. Chanchal Roy}

Professor, University of Saskatchewan, Canada

\section{Dr. Muhammad H. Rashid}

Professor, University of West Florida, USA

\section{Dr. Md. Azizur Rahman}

Adjunct Professor, Memorial University of Newfoundland, Canada

\section{Dr. Ing. Bhuiyan Shameem}

Mahmood Ebna Hai

Scientific Researcher, Helmut-SchmidtUniversitat, Germany

Dr. Naoya Umeda

Professor, Osaka University, Japan

\section{Dr. Easir Arafat Papon}

University of Alabania, Alabania
Dr. Kawamura Yasumi

Professor, Yokohama National

University, Japan

\section{Dr. Navid Saleh}

Assoc. Professor, The University of Texas at Austin, USA

\section{Dr. Soumyen Bandyopadhyay}

Professor, Liverpool University, UK

\section{Dr. Hafizur Rahman}

Research Fellow, Curtin University, Australia

\section{Dr. Rezaul Karim Begg}

Professor, University of Victoria, Australia

\section{Dr. Subramani Kanagaraj \\ Professor, \\ IIT, Guwahati, India}

Dr. Mohamed H. M. Hassan

Professor,

Alexandria University,

Egypt

Dr. Ahmad Faris Ismail

Professor, International Islamic University Malaysia (IIUM),

Malaysia

\section{Dr. Azizur Rahman}

Assistant Professor, Texas A\&M

University, Qatar

\section{Dr. Stephen Butt}

Professor, Memorial University of Newfoundland Canada

\section{Dr. Basir Ahmmad}

Professor, Yamagata University, Japan.

\section{D-T. Ngo}

Technical University of Denmark, Denmark

\section{Dr. Kobayahsi Kensei}

Professor, Yokohama National

University, Japan

\section{Dr. Md Ataur Rahman}

Professor, International Islamic University Malaysia (IIUM),

Malaysia

\section{Dr. Cheol-Gi Kim}

Professor,

Daegu Gyeongbuk Institute of Science \& Technology, Korea

\section{Dr. Bashir Khoda}

Assistant Professor,

The University of MAINE, USA

\section{DISCLAIMER}

The analysis, opinions, and conclusions expressed or implied in this Journal are those of the authors and do not necessarily represent the views of the MIST, Bangladesh Armed Forces, or any other agencies of Bangladesh Government. Statements of fact or opinion appearing in MIJST Journal are solely those of the authors and do not imply endorsement by the editors or publisher.

ISSN: 2707-7365

\section{QUERIES ON SUBMISSION}

For any query on submission the author(s) should contact: MIST, Mirpur Cantonment, Dhaka-1216, Bangladesh; Tel: 8802 8034194, FAX: 8802 9011311, email: mijst@mist.ac.bd. For detailed information on submission of articles, the author(s) should refer to the Call for Papers and About MIJST at the back cover of the MIJST Journal. Authors must browse MIJST website through the journal link (https://mijst.mist.ac.bd/mijst) for electronic submission of their manuscripts.

\section{PUBLISHER}

\section{Military Institute of Science and Technology (MIST), Dhaka, Bangladesh}

All rights reserved. No part of this publication may be reproduced, stored in retrieval system, or transmitted in any form, or by any means, electrical, photocopying, recording, or otherwise, without the prior permission of the publisher.

\section{DESIGN AND PRINTING}

\section{Research and Development Wing}

Military Institute of Science and Technology (MIST)

Dhaka, Bangladesh 



\section{F OREWORD}

Bismillahir Rahmanir Rahim.

The Military Institute of Science and Technology (MIST) being a growing academic institution, remains focused on enhancing its vision through professional excellence in the field of science, engineering and technology with quality education and cutting-edge research. The 'MIST Journal of Science and Technology' had been the institution's Flagship journal since 2009 presenting the research outputs mainly of the institution. The idea of having a truly international journal was conceived less than a year back. A vibrant international team comprising of globally renowned members of the international advisory board, experts from around the world in the Editorial Board along with a network of experienced reviewers, has made that dream come true within a short period under the new transformed title 'MIST International Journal of Science and Technology (MIJST)'. Virtually this journal is the first truly online international journal in the country and aims to be one of the leading journals of the country and region, and to be enlisted in the major Journal Indexing Databases of the world. It gives me immense pleasure to welcome you to the First Issue of the MIJST published in July 2020 and to be published henceforth on time biannually.

At this special occasion for the publication of the first issue, I would like to thank all whose tireless contributions and efforts have made the MIJST a reality. The list includes the Editorial Board under the Leadership of the Editor in Chief, Professor Firoz Alam of RMIT University of Australia, and the Executive Editor Professor AKM Nurul Amin, of MIST, for without their dedication and hard work the dream would not have been materialized. Very special thanks to all the Members of the International Advisory Board for their constant support and guidance. Heartfelt thanks are also to the panel of Reviewers, who provided invaluable peer review to ensure the high standard of the articles. The articles, published in this issue, would determine the face of the journal, and set the stage for the subsequent issues. I am deeply grateful to all the authors for their remarkable contributions to this promising journal. I firmly believe, the MIJST will be a well sought and recognized platform for the publication of high-quality cutting-edge research outputs of authors from home and abroad.

I wish all the success to the MIJST for its future issues!

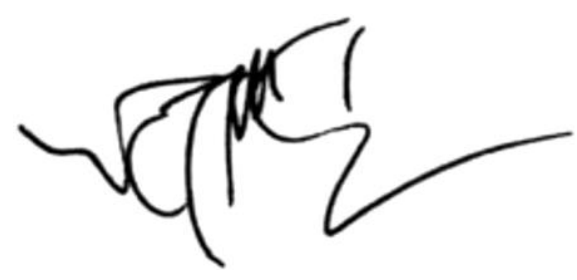

Major General Md Wahid-Uz-Zaman, ndc, aowc, psc, te Commandant, MIST, Bangladesh Chief Patron, MIJST, Bangladesh 

It is my immense pleasure to present the First Issue of MIST International Journal of Science and Technology (MIJST) published in July 2020. This journal humbly started in 2009 with the title "MIST Journal of Science and Technology" and continued with this title till 2019. Then the journal has undergone an epoch-making transformation in 2020 and started its new global journey with a new title "MIST International Journal of Science and Technology" encompassing greater scope and global relevance. The journal commits to publishing contemporary innovation, theoretical and applied research findings in the field of science, engineering, and technology as a true interdisciplinary platform.

The priority of the MIJST is to conduct speedy review and production of each issue on time through the collaborative efforts of the globally renowned and experienced international advisory board, editorial team, production team and most importantly a pool of experienced and expert reviewers who have wholehearted commitment, synergy, love and vision for this journal.

Currently, MIJST is published biannually in June and December. However, the increase in frequency is planned in the future. To make the journal more visible, globally accessible, facilitating diffusion and higher impact of new knowledge, innovation and technology for mankind, environment, and sustainable planet, the journal is kept open access without incurring any cost for the authors. Furthermore, our sincere efforts are being undertaken to make the Journal indexed under Scopus, Web of Science (WoS), Creative Common and Open Journal System databases through Google Scholar, Emerging Source Citation Indexing (ESCI), Directory of Open Access Journals (DOAJ), Asian Citation Indexing, Bangladesh Journal Online, and other citation platforms.

We have a strict policy to publish high quality innovative and latest original as well as review articles. Researchers are highly encouraged to submit their unpublished works in any branch of Science, Engineering and Technology. As per the Journal's policy, the submitted manuscripts undergo a double-blind peer-review process. The MIJST gives especial emphasis on the contributions that deal with life-changing solutions for the betterment of emerging and developing nations.

The inaugural issue of this newly transformed journal includes a distinct selection of stimulating five research articles encompassing the strength of construction material brick aggregates, river water contamination evaluation, application of link budget tool in defense satellite communication reliability assessment, evaluation of land use and land cover change on surface runoff, and application of the performance of design method for enhancing the effectiveness of information-intensive website design. All five articles are original, innovative and have notable implications in science, engineering, and technology fields. The research findings of each article deal with real-world problems.

Although this issue did not include any review article, we aim to publish at least one review article in each issue. I wholeheartedly encourage the experts to submit review articles summarising the latest development, state of knowledge and applications in contemporary science, engineering, and technology fields with especial emphasis on economic viability, safety, efficiency, and environmental sustainability. We particularly encourage submissions from scholars around the world.

Last but not the least, I express my profound gratitude and thanks to our Chief Patron, Executive Editor, Associate Editors, Section Editors, Copyeditors, Reviewers, other Editors and Proof Readers, Editorial/Advisory Board members (national and international), and web production consultant for their hard work, unwavering support, commitment and enthusiasm. Without their heartfelt effort, this collective 
achievement could not be materialised. I request all our reviewers, readers, and patrons to promote the MIST International Journal of Science and Technology to their colleagues and library databases across the globe.

I cordially welcome your advice, suggestion, and feedback for the betterment of the Journal. Please feel free to contact me at firoz.alam@rmit.edu.au or mijst@mist.ac.bd with any queries or ideas you might have.

Sincerely,

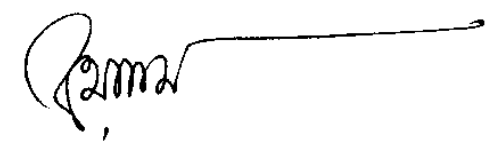

Prof. Dr. Firoz Alam

Editor in Chief 
1. Comparative Study of Physical and Mechanical Properties of Machine and Manually Crushed Brick Aggregate Concrete

Md Jahidul Islam, Jesika Rahman, Sadia Nawshin, Mohammad M. Islam

2. Assessment of Hexavalent Chromium Pollution in Buriganga and Dhaleshwari River Waterbodies Adjacent to Tannery Estates in Bangladesh

Hafizur Rahman, Nabila Hoque, Palash Kumar Sarker, Ashrafus Safa

3. Link Budget Analysis in Designing a Web-application Tool for Military X-Band Satellite Communication

M. Akhtaruzzaman, S. M. Sadakatul Bari, Syed Akhter Hossain, Md. Mahbubur Rahman

4. Land-Use and Land-Cover Change in Dhaka Eastern Region and Its Impact on Surface Run-off

Md. Habibul Huq, Md. Mafizur Rahman

5. Exploring and Comparing the Performance of Design Methods Used for Information Intensive Websites

Tarannum Zaki, Zinia Sultana, S M Anisur Rahman, Muhammad Nazrul Islam 



\title{
Comparative Study of Physical and Mechanical Properties of Machine and Manually Crushed Brick Aggregate Concrete
}

\author{
Md J. Islam1, Jesika Rahman², Sadia Nawshin³, and Mohammad M. Islam4 \\ 1,2,3 Department of Civil Engineering, Military Institute of Science and Technology, Dhaka, Bangladesh \\ ${ }^{4} \mathrm{GPH}$ Ispat Ltd., Chattagram, Bangladesh \\ emails: *1mjislam@ce.mist.ac.bd; 2jesikanmn@gmail.com; ${ }^{3 n a w s h i n 95 @ g m a i l . c o m ; ~ a n d ~}{ }^{4}$ mmi124@yahoo.com
}

\section{ARTICLE INFO}

Article History:

Received: 08th April 2020

Revised: 05th May 2020

Accepted: 07th May 2020

Published online: 21 $1^{\text {st }}$ July 2020

\section{Keywords:}

Brick Aggregate

Manually Crushed

Machine Crushed

Coarse Aggregate Properties

Concrete Compressive Strength

\begin{abstract}
A B S T RAC T
With technological advancement on the rise, manual crushing of bricks is gradually being replaced by machine crushing to obtain coarse aggregates for construction. However, properties of the brick aggregates obtained from these two methods vary which in turn, may affect the properties of the concrete matrix as well. This study represents a comparison between the machine crushed and manually crushed brick aggregates to be used as coarse aggregates in preparation of concrete. Four types of bricks, namely first class, second class, picket (over burnt) and ceramic were investigated, and each was crushed both manually and mechanically to a usable form of aggregates. The physical and mechanical properties of the brick aggregates derived from the two methods were tested and compared. In all types of brick, aggregates size, shape and strength properties such as flakiness and elongation indices, aggregate impact and crushing values and Los Angeles abrasion value showed lower values for manually crushed aggregate indicating better properties compare to machine crushed aggregates. This was evident while comparing compressive and tensile strength of concrete prepared with both manually and machine crushed first class and picket brick aggregates. Concrete with manually crushed brick aggregates showed marginally higher compressive and tensile strength in both types of brick aggregates.
\end{abstract}

\section{INTRODUCTION}

There is a growing concern that urges a sustainable construction practice to be undertaken because concrete is one of the largest consumers of natural resources worldwide. About $60 \%$ to $75 \%$ of the volume of concrete is composed of aggregates and the primary source of such are the natural stone reserves. As concrete is the second largest consumed material after water, it is imperative that a suitable substitute for natural stone aggregates is introduced. Brick aggregate concrete is an effective alternative to natural stone aggregate concrete in regions like Bangladesh where scarcity of stone reserves exists. In addition, to allow considerable savings in non-renewable resources, bricks are widely available and a cost-effective solution to the ever-increasing demand for concrete construction. The use of brick chips as coarse aggregates dates back to the Second World War (Hansen, 1992). After concrete, brick remains as the second most important building material around the world (RMIT University, 2006). The damaged or broken bricks during its production can be reused as coarse aggregates in concrete which can alleviate the excessive waste disposal problems into the landfills (Lennon, 2005).

Despite the common disadvantages that include high porosity and absorption capacity along with lower compressive strength than its stone counterpart (Afroz et al., 2015), brick chips are used as aggregates in different parts of the world including Bangladesh. As reported by Cachim (2009), crushed bricks can be utilized as coarse aggregates by up to $15 \%$ replacement of the conventional stone aggregates without affecting the strength of concrete keeping all other factors constant. Studies also reported that high strength concrete can be achieved using crushed well-burned brick as aggregates of proper gradation (Akhtaruzzaman et al., 1983). When proper gradation of brick chips is obtained, their performance as aggregates is excellent in both lightweight and high strength concrete structures (Rashid et al., 2009). In a study by Khalaf and DeVenny (2004) it is seen that brick aggregate concrete can perform well or even superior to conventional stone aggregate concrete when subjected to high temperatures. The properties of crushed clinker brick aggregates and recycled brick aggregates are investigated by Khaloo (1994) and Hansen (1992) respectively where it is reported that both the types of brick aggregates increase the tensile strength of the concrete. Adamson et al. (2015) studied the durability properties of concrete where brick aggregates were partially replaced by natural stone aggregates. Their results revealed that brick aggregates can be used in place of stone aggregates without prominent changes in the durability of concrete provided no steel reinforcement are present.

The properties of concrete including compressive and tensile strength are highly dependent upon the properties of the 
constituent aggregates (Ayub et al., 2012). Therefore, it is of prime importance that the strength and physical characteristics of the brick chips are tested before being used as coarse aggregates in concrete. The effects of parameters related to the shape and strength of coarse aggregates on the properties of the resulting concrete are studied by many researchers. A higher proportion of flaky and elongated aggregates tend to reduce the impermeability, workability, and compressive strength of the concrete (Islam et al., 2020; Yu et al., 2015). Crushing and impact value of aggregates are very helpful in estimating the compressive strength of the concrete especially when the performance of the aggregates being used in the concrete is not known (Neville, 1995). In addition to the above-mentioned properties, void content, absorption capacity, unit weight and toughness of the aggregates do play vital roles in indicating the quality of concrete.

Crushing of bricks can be done in two ways, by machine and by hand. In Bangladesh, both the processes are incorporated whichever appears to comply within the constraints of a project. One of the main reasons for using a machine to crush bricks is that it requires less time than crushing the bricks manually. Therefore, when time is a constraint and labor cost not a significant issue, the developers often opt for machine crushed brick aggregates for concrete construction. However, such a choice made during the production of concrete does not always take account of the fact whether machine crushed aggregates provide the desired quality concrete over the manually crushed ones. The properties of the brick aggregates obtained by manual crushing vary significantly to that produced by machine crushing and in turn, are expected to affect the properties of concrete. There is hardly any literature that addressed this phenomenon enlightening the comparison of the properties of the machine and manually crushed brick aggregates. To the authors' best knowledge, no research has yet to be reported that compared the properties of concrete prepared with machine crushed brick aggregate to that with manually crushed brick aggregate as coarse aggregates. The choice of aggregate crushing method may vary on many factors, such as labor cost, project duration, availability, and affordability of the technology, and many more. However, in terms of only concrete properties, it is important to carry out this comparative study to develop a plan that helps to decide which method of crushing bricks shall be followed during construction.

\section{MATERIALS}

\section{A. Cement}

As a binding material, Type I Portland cement conforming to ASTM C150 (2015e) specification was used in this study. Physical properties were tested according to ASTM C204 $(2011 b)$ for fineness using Blaine air-permeability apparatus, ASTM C430 (2015h) for fineness by $45 \mu \mathrm{m}$ sieve, ASTM C191 (2013c) for initial and final setting time, ASTM C187 (2011a) for normal consistency, ASTM 151 (2015f) for soundness by autoclave expansion method and ASTM C109 (2013a) for compressive strengths. The specific gravity was recorded as 3.15. The physical properties of the cement are presented in Table 1.

\section{B. Fine Aggregates (Sand)}

Local Sylhet sands were used as fine aggregates for the present study. The sample was first collected from a local supplier. It was then cleaned from different debris and other organic materials. Its physical properties, like gradation, specific gravity, and absorption capacity, were determined according to ASTM standards (ASTM C128 (2015c) and ASTM C136 (2014)). Table 2 represents the physical properties of the sand, whereas Figure 1 shows the gradation of the sand along with ASTM upper and lower limits. As shown in the figure, the particle size distribution of the sand falls well within the ASTM limits. Fineness modulus of 2.89 also falls within the recommended range of 2.3 to 3.1 according to ASTM C33 (2013b) standard.

Table 1

Physical properties of cement

\begin{tabular}{|c|c|c|c|c|}
\hline \multicolumn{2}{|l|}{ Physical Properties } & Unit & Specification & Test Results \\
\hline \multicolumn{2}{|c|}{ Fineness (Specific Surface) } & $\left(m^{2} / K g\right)$ & $\begin{array}{l}260 \text { min } \\
430 \text { max }\end{array}$ & 370 \\
\hline \multicolumn{2}{|l|}{ Fineness (By 45 Micron) } & $(\%)$ & - & 97.9 \\
\hline \multicolumn{2}{|l|}{ Initial Setting Time } & Minutes & 45 minutes (min.) & 182 \\
\hline \multicolumn{2}{|l|}{ Final Setting Time } & Minutes & 375 minutes (max.) & 374 \\
\hline \multicolumn{2}{|l|}{ Normal consistency } & $(\%)$ & - & 27.5 \\
\hline \multicolumn{2}{|c|}{ Soundness (By Autoclave method) } & $(\%)$ & Maximum 0.80 & 0.01 \\
\hline \multirow{3}{*}{ Compressive Strength } & 3 days & MPa (psi) & $12(1740)$ & $22.4(3240)$ \\
\hline & 7 days & MPa (psi) & $19(2760)$ & $29.8(4320)$ \\
\hline & 28 days & $\mathrm{MPa}(\mathrm{psi})$ & $28(4060)$ & $39.2(5690)$ \\
\hline
\end{tabular}

\section{Properties of Bricks}

Four types of brick specimens commercially available in Bangladesh were used in this study namely first class, second class, picket (over burnt) and ceramic. Among these first class, second class and picket bricks are handmade bricks. However, ceramic bricks are machine made bricks. Figure 2 displays the four different types of bricks. As shown in Figure 2(a) and 2(b), first class brick has the well-defined shape with dimension tolerance within 3\% and deep red; whereas, second class brick has shown with under burnt physical appearance with irregular shape and size with dimension tolerance within 8\% (Sahu et al., 2015). Picket brick, as shown in Figure 2(c), has an irregular shape with dark color and rough surfaces (Sahu et al., 2015). Finally, ceramic brick, also known as perforated brick, has a well-defined size and shape, glassy surface, and uniform reddish color (Sahu et al., 2015). These four types of brick have distinctive compressive strength as shown in Table 3. Picket brick, has the highest compressive strength of $29.67 \mathrm{MPa}$; whereas, ceramic brick has the second highest compressive strength (23.90 MPa) and the 
first class brick has the third highest compressive strength (18.38 $\mathrm{MPa}$ ). However, second class brick has the lowest compressive strength $(9.84 \mathrm{MPa})$. Unit weights of all four types of bricks have been also measured as described in Table 3. Similar to compressive strength, picket showed the highest unit weight of $1989 \mathrm{~kg} / \mathrm{m}^{3}$; whereas second class brick displayed the lowest unit weight of $1603 \mathrm{~kg} / \mathrm{m}^{3}$.

Table 2

Physical properties of fine aggregate

\begin{tabular}{lc}
\hline \hline Components Name & Fine Aggregate (Sand) \\
\hline Maximum size & $4.75 \mathrm{~mm}$ \\
Minimum size & $0.15 \mathrm{~mm}$ \\
Fineness modulus & 2.89 \\
Bulk specific gravity & 2.43 \\
Apparent specific gravity & 2.62 \\
Water absorption Capacity & $3.00 \%$ \\
\hline \hline
\end{tabular}

All types of brick specimens were crushed both manually and mechanically to produce brick aggregates. In the case of manual crushing, two labors with comparable strength crushed bricks using hammer over a period of 2 days as shown in Figure 3(a). For the machine crushing of bricks, a heavy-duty crushing machine is used as depicted in Figure 3(b). The portable (3 wheels) crusher has a set of mild steel jaw crusher and attached sieve. It can crush $1000-15000$ bricks per hour. Prior to brick crushing, bricks were soaked with water to reduce the production of dust during the crushing process. Larger particle sizes were separated using the sieve and put into the jaw crusher again. However, the machine crusher creates a larger quantity of finer particles. Figure 4 presents the comparison of cumulative percentages of finer particles passing the sieve opening of $2.36 \mathrm{~mm}$ for all four types, such as first class brick aggregate (FCA), second class brick aggregate (SCA), picket brick aggregate (PBA), ceramic brick aggregate (CBA), of manual and machine crushed bricks. As shown in the figure, machine crushing produces as high as $14.49 \%$ finer particles compare to a maximum of $2.98 \%$ of finer particles for manually crushed bricks. Thus, it can be said that machine crushing is uneconomical as it produces an average of 5 times more wastage than that produced in manual crushing.
For the machine crushing process, the production of finer particles is highest for the first-class bricks and lowest for the ceramic bricks. During the machine crushing procedure, first class bricks initially produced a high percentage of aggregate larger than $25 \mathrm{~mm}$ sieve opening and those aggregate went through the crusher one more time compared to the secondclass bricks. Because of this additional crushing, first class bricks produced higher percentages of finer particles than the second-class bricks. These finer particles have very low mechanical properties, and thus, discarded from the next phase of the study, that is, material testing and concrete preparation.

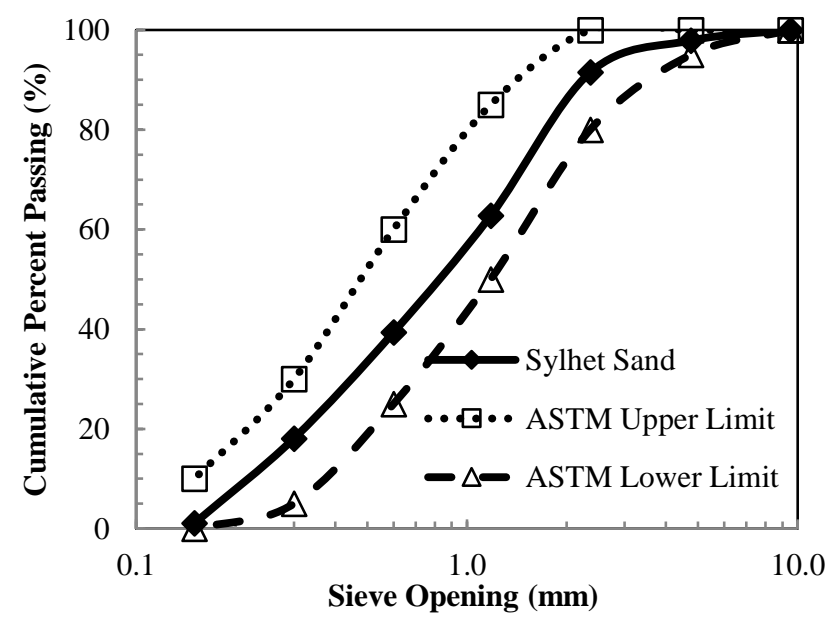

Figure 1: Particle size distribution of fine aggregates (sand)
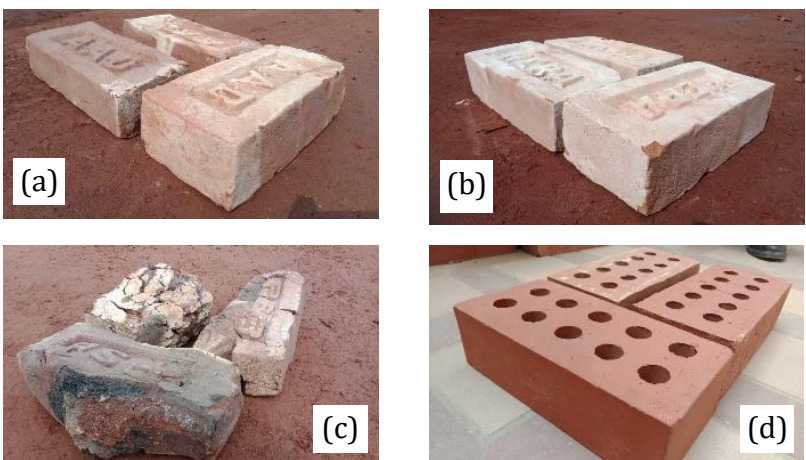

Figure 2: Pictures of four types of bricks: (a) first class; (b) second class; (c) picket and (d) ceramic

Table 3

Strength of brick specimens

\begin{tabular}{ccccc}
\hline \hline Types of Bricks & $\begin{array}{c}\text { Unit weight } \\
\left(\mathbf{k g} / \mathbf{m}^{\mathbf{3}}\right)\end{array}$ & $\begin{array}{c}\text { Standard Deviation } \\
\left(\mathbf{k g} / \mathbf{m}^{\mathbf{3}}\right)\end{array}$ & $\begin{array}{c}\text { Average Compressive Strength } \\
(\mathbf{M P a})\end{array}$ & $\begin{array}{c}\text { Standard Deviation } \\
(\boldsymbol{M P a})\end{array}$ \\
\hline First Class (FC) & 1797 & 44 & 18.38 & 2.21 \\
Second Class (SC) & 1603 & 16 & 9.84 & 0.38 \\
Picket Brick (PB) & 1989 & 84 & 29.67 & 0.64 \\
Ceramic Brick (CB) & 1771 & 31 & 23.90 & 2.48 \\
\hline
\end{tabular}



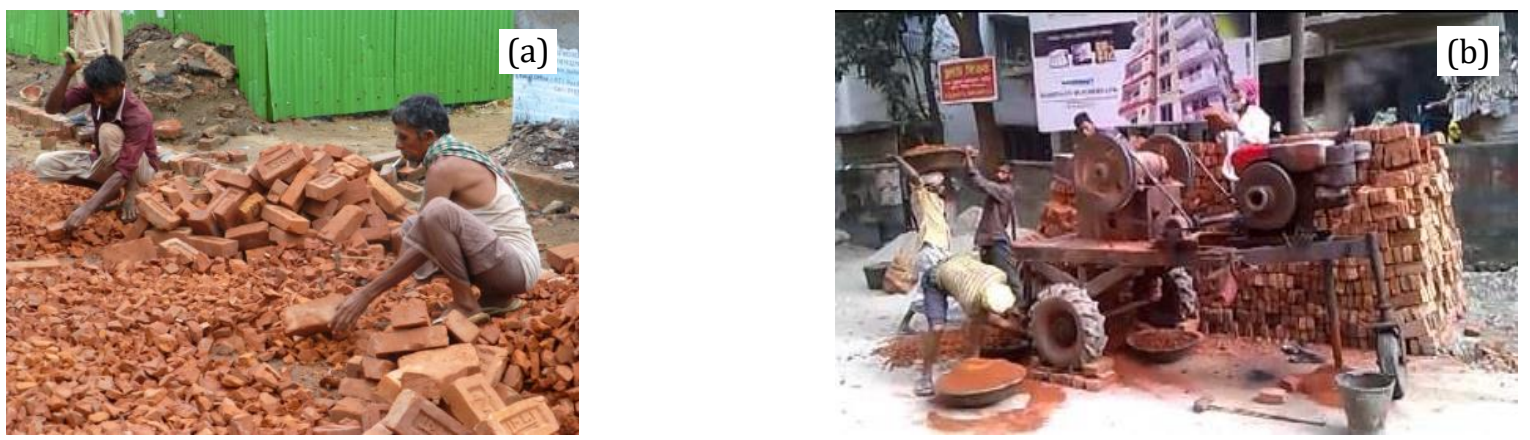

Figure 3: Brick crushing method: (a) manual process, (b) machine crushing

\section{Physical Properties of Brick Aggregates}

The particle size distribution of aggregate is an important factor for properties of concrete, such as workability, density, and strengths. Therefore, sieve analysis of all the brick aggregates were performed following ASTM C 136 (2014). Figure 5 displays the particle size distribution of both manually and machine crushed brick aggregates after discarding particles those passing through the $2.36 \mathrm{~mm}$ sieve. The figure also includes the upper and lower limits for cumulative percent passing proposed by ASTM C 33 (2013b) for concrete aggregate. As shown in the figure, manually crushed brick aggregates are coarser than the machine crushed brick aggregates. Especially, FCA and PBA are coarser among all the aggregate types. Furthermore, all the curves fall outside the ASTM lower limit indicating coarser aggregate types. Fineness modulus of brick aggregates have also showed similar phenomenon. Figure 6 compared the fineness modulus of both manually and machine crushed brick aggregates. These results are also consistent with the previous findings.

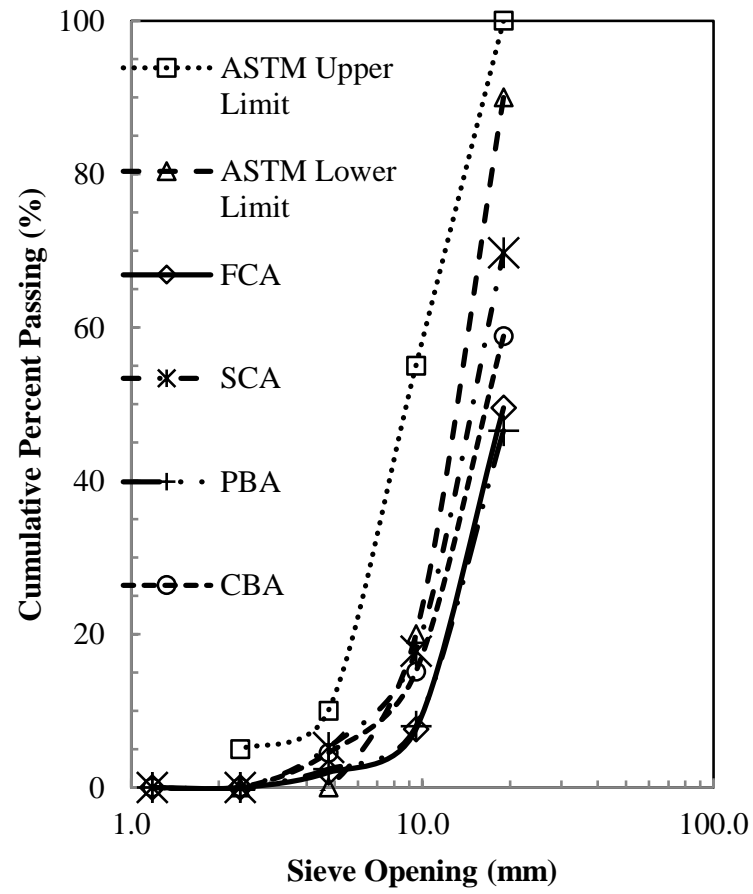

(a)

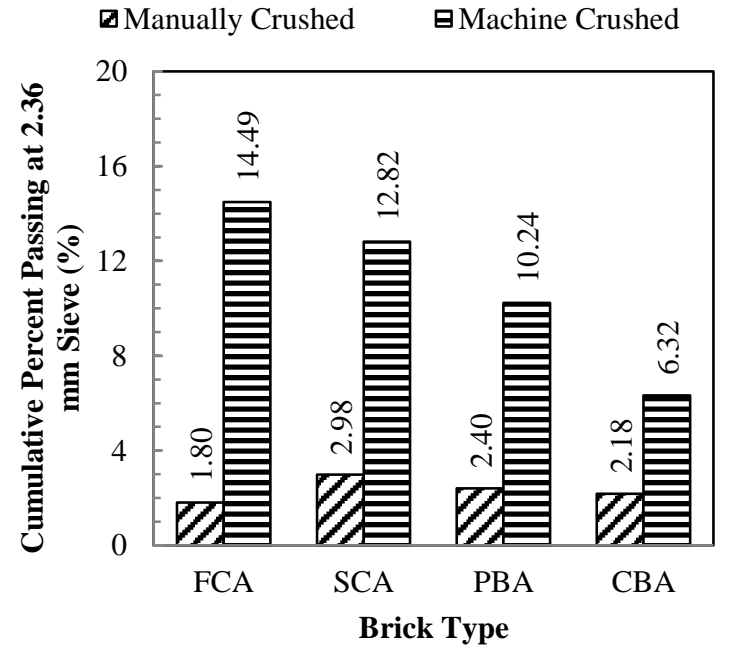

Figure 4: Cumulative percent passing at $2.36 \mathrm{~mm}$ sieve for four types of manually and machine crushed brick aggregates

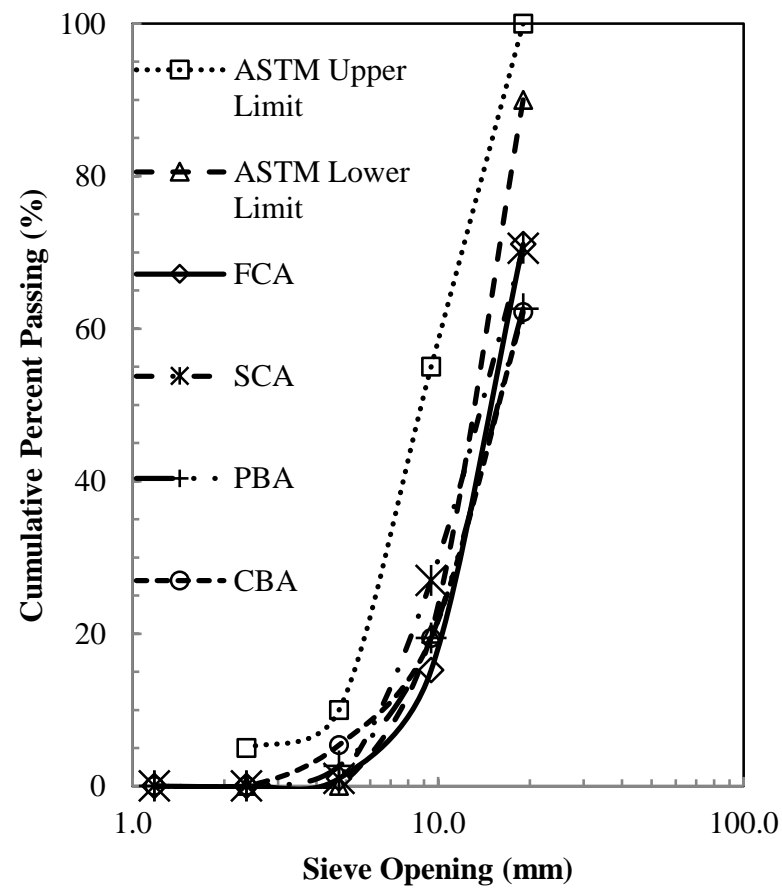

(b)

Figure 5: Particle size distribution of (a) manually crushed brick aggregates (b) machine crushed brick aggregates 


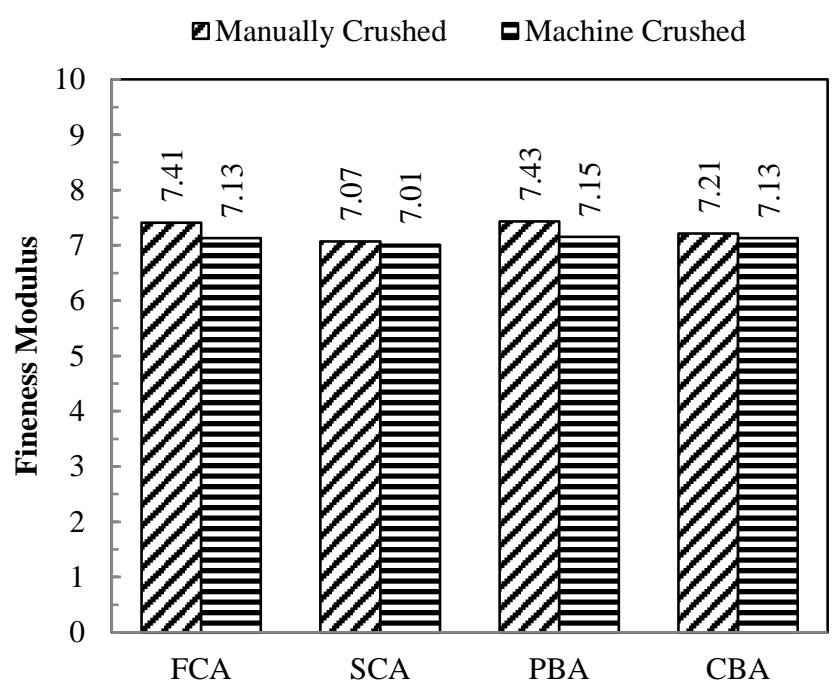

Figure 6: Fineness modulus for four types of manually and machine crushed brick aggregates

Unit weights and void ratios of brick aggregates were measured following the ASTM C29 (2009) standard. The results are presented in Table 4 . Table 4 also includes the ACI recommended values for aggregate used in concrete (ACI,
2016). The unit weight of manually crushed brick aggregate varies between 1039 to $1112 \mathrm{~kg} / \mathrm{m}^{3}$. On the other hand, for machine crushes brick aggregate, unit weight ranges between 1015 to $1102 \mathrm{~kg} / \mathrm{m}^{3}$. In both cases, second class brick aggregates show the lowest unit weight and ceramic brick aggregate shows the highest unit weight. However, unit weight for all four types of bricks with different crushing methods below the ACI recommended value $\left(1280 \mathrm{~kg} / \mathrm{m}^{3}\right)$ for the dry rodded unit weight. It is seen that the unit weight of ceramic bricks derived by both machine and manual crushing processes is the highest. Void percentages were also measured. The test results indicate that picket aggregate has the least void percentage $(42.6 \%)$ among the four aggregate types.

Bulk specific gravity and absorption capacity of the aggregates are determined by the standard procedure of ASTM C127 (2015b). ACI E-16 recommended value for bulk specific gravity for coarse aggregate is a range between 2.30 to 2.90 (ACI, 2016). Although CBA has the highest specific gravity (2.06) for all aggregates it is still below the ACI E-16 recommended value. The absorption capacities of aggregates are well within the recommended value. It should be noted that all the aggregates have similar absorption capacity ranging between 4.4 to $5.8 \%$.

Table 4

Brick aggregate properties

\begin{tabular}{ccccccccccc}
\hline \hline \multirow{2}{*}{ Parameters } & \multicolumn{4}{c}{ Machine-crushed } & \multicolumn{3}{c}{ Manually crushed } & \multicolumn{2}{c}{ ACI E1-16 } \\
\cline { 2 - 8 } & FCA & SCA & PBA & CBA & FCA & SCA & PBA & CBA & (2016) \\
\hline Unit Weight $\left(\mathrm{kg} / \mathrm{m}^{3}\right)$ & 1018 & 1015 & 1087 & 1102 & 1062 & 1039 & 1108 & 1112 & $1280-1920$ \\
Voids (\%) & 45.6 & 46.3 & 42.6 & 45.5 & 45.9 & 45.0 & 43.1 & 49.0 & - \\
Specific Gravity (OD) & 1.97 & 1.89 & 1.93 & 2.04 & 1.96 & 1.89 & 1.91 & 2.06 & $2.30-2.90$ \\
Absorption (\%) & 4.9 & 5.3 & 5.8 & 4.4 & 4.7 & 5.3 & 5.7 & 4.6 & $0.0-8.0$ \\
\hline \hline
\end{tabular}

The flakiness and elongation indices of the brick chips are determined as per the standards BS 812-105.1 (1990a) and BS 812-105.2 (1990b) respectively. Figure 7 shows the variation in flakiness and elongation Indices among the different classes and crushing methods. Both the indices of the manually crushed brick aggregates are less than that of the machine crushed brick aggregates. The flakiness index of machine crushed brick aggregates is $21.4 \%, 6 \%, 25 \%$, and $15.7 \%$ higher than manually crushed brick aggregates of FCA, SCA, PBA and $\mathrm{CBA}$, respectively. Flakiness index of machine crushed FCA and SCA is found to be the same whereas the value for manually crushed SCA and PBA are observed to be

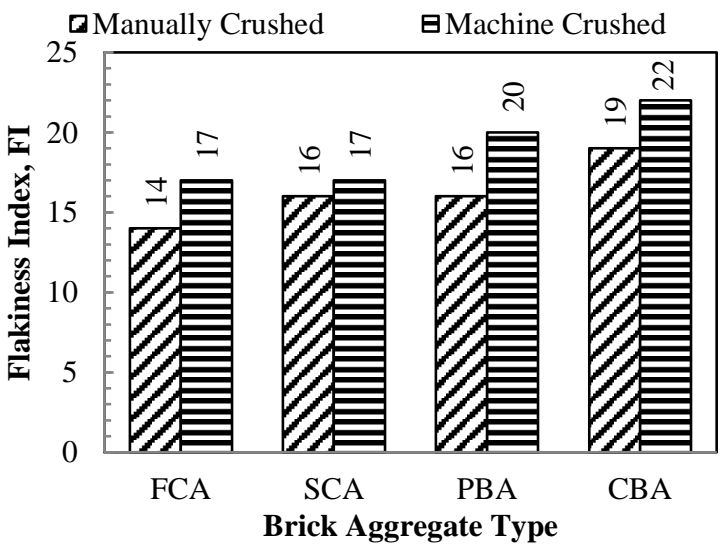

(a) similar. Interestingly, the flakiness index of the machine crushed ceramic brick aggregate is found to be the highest (22). The orientation of these flaky aggregates play an important role in the strength of the concrete samples. Flakier nature of machine crushed brick aggregates might lead to lower workability and strength in concrete. The Elongation Indices of machine crushed FCA, SCA, PBA and CBA are $10.7 \%, 13.3 \%, 16.2 \%$, and $9.3 \%$ greater than the same aggregates produced by manual crushing, respectively. It is seen that both PBA and CBA provided the highest elongation index at 43 ; whereas, manually crushed FCA shows the lowest index at 28.

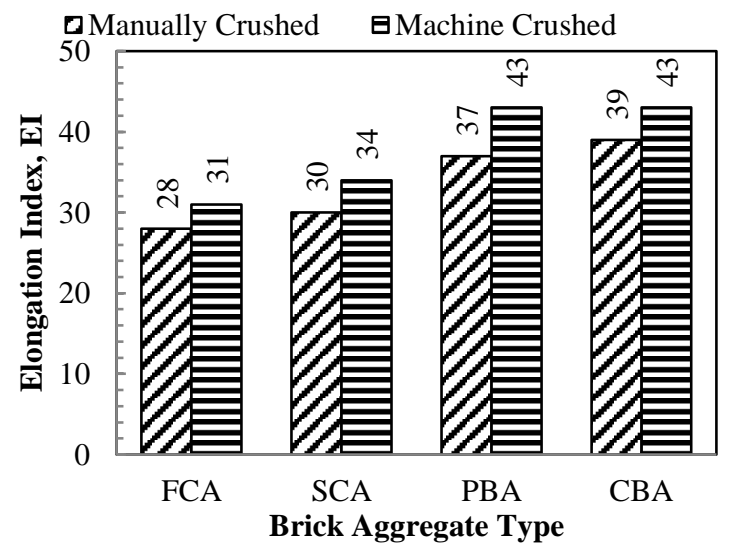

(b)

Figure 7: (a) Flakiness and (b) elongation indexes of four types of manually and machine crushed brick aggregates 


\section{E. Mechanical Properties of Brick Aggregates}

The strength of concrete is highly dependent on the mechanical properties of its constituent aggregates (Islam $e t$ al., 2020; Neville, 1995). Figure 8 illustrates the mechanical properties, such as aggregate impact value (AIV), aggregate crushing value (ACV) and Los Angeles abrasion (LAA) value of brick chips as aggregates. The resistance to impact loading (aggregate impact value, AIV) and gradual crushing (aggregate crushing value, ACV) of the brick chips were measured following the specifications of BS 812-112 (1990d) and BS 812-110 (1990c) respectively. On the other hand, to determine the resistance of the brick chips against abrasion, the LA Abrasion test was carried out following the standard procedure of ASTM C131 (2015d).

As seen in Figure 8(a) and (b), both the AIV and ACV of manually crushed brick aggregates are less than that of the machine crushed brick aggregates. Variations in AIV mount up to an average of $6 \%$ among the machine and manually crushed brick aggregates. On the other hand, the difference in ACV among the machine and manually crushed brick aggregates is about $4 \%$ on average. A higher AIV and ACV signify that machine crushed brick aggregates have inferior quality compare to manually crushed brick aggregates. Among both the manual and machine crushed brick aggregates, the SCA has the highest ACV and AIV whereas the CBA has the lowest ACV and AIV. Among the four different types of brick aggregate CBA has the best mechanical properties and PBA has almost similar values. This is consistent with the brick crushing strength properties of $\mathrm{PB}$ and $\mathrm{CB}$, two of the highest compressive strength brick types. As expected, the machine crushed brick aggregates had higher LAA value compared to manually crushed brick aggregates among all types of brick aggregates, as shown in Figure 8(c). However, the differences are negligible with a maximum of $5.4 \%$ for FCA. Among the four aggregate types, PBA showed the lowest LAA value whereas the variation of LAA values for manually crushed FCA, SCA and CBA are $12 \%, 30 \%$, and $21 \%$, respectively.

\section{F. Selection of Brick Aggregate}

The physical and mechanical properties of aggregates have a notable effect on the strength properties of concrete (Islam $e t$ al., 2020). Based on the size, shape, and strength properties study, it is evident that FCA, PBA and CBA have good properties and can be used as coarse aggregate in concrete. However, CBA has higher flakiness, elongation and LAA values compare to FCA and PBA for manually and machine crushing processes. Therefore, for the present study only FCA and PBA were used for the preparation of concrete.

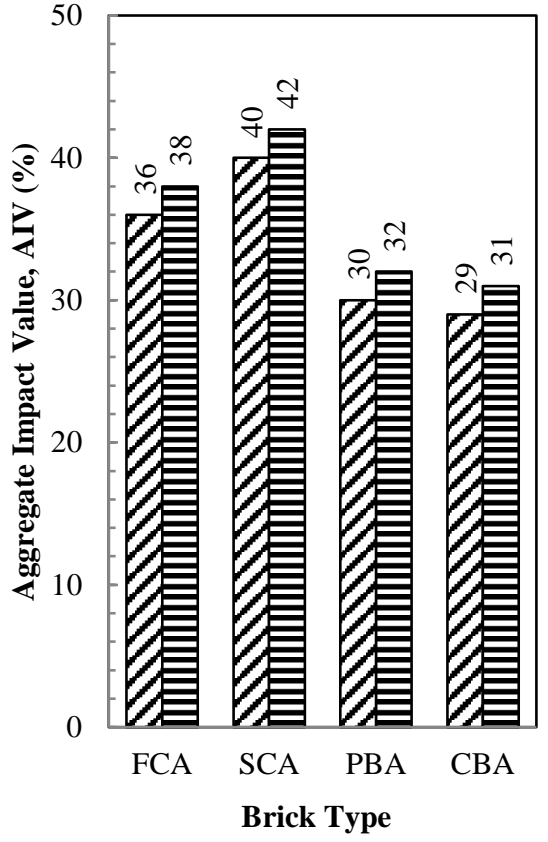

口Manually Crushed घMachine Crushed (a)

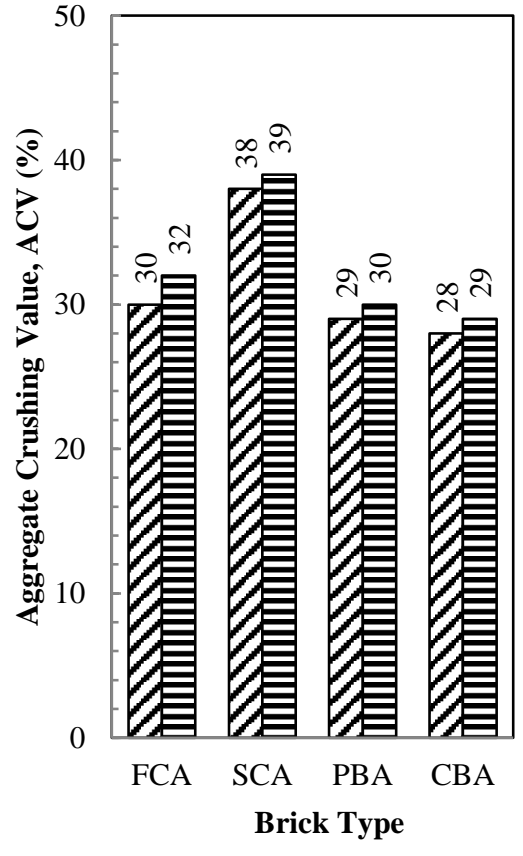

๑Manually Crushed $\boxminus$ Machine Crushed

(b)

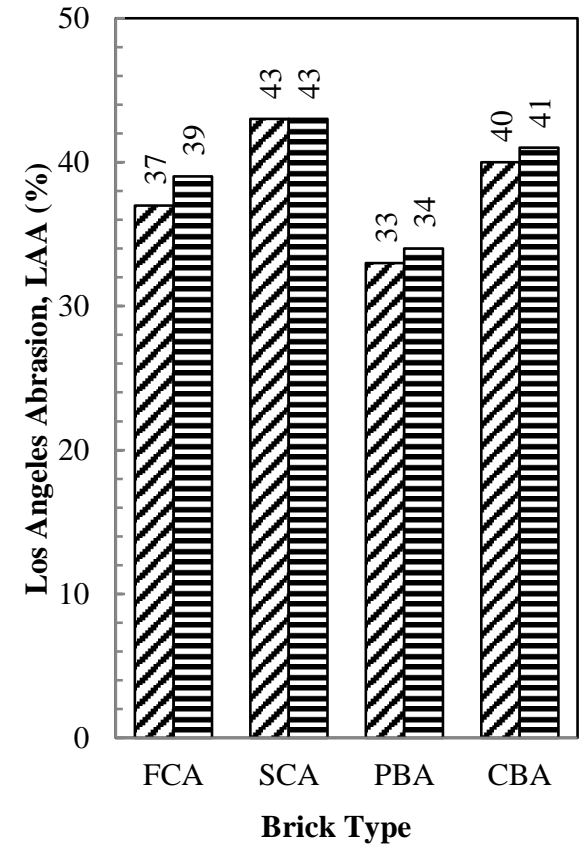

ఐManually Crushed 曰Machine Crushed

(c)

Figure 8: Mechanical properties comparison of four types of manually and machine crushed brick aggregates: (a) aggregate impact value (AIV), (b) aggregate crushing value (ACV), and (c) Los Angeles abrasion (LAA) value

\section{CONCRETE PREPARATION}

Concrete cylinders of a target strength of $25 \mathrm{MPa}$ were prepared to investigate the compressive and tensile strength imparted by the brick aggregates derived from the two said methods of crushing in the previous sections. The concrete mix was designed using ordinary Portland cement, Sylhet sand and the number of mix designs followed the number of variations in the coarse aggregates. Four types of aggregates, namely FCA - machine crushed, FCA - manually crushed,
PBA - machine crushed and PBA - manually crushed were adopted as coarse aggregate for the present study. In all four mix designs, the water-cement ratio was kept constant to 0.5 . Mix proportions were performed according to ACI 211.1 (1994). Table 5 describes the mix proportions for 1 cum of concrete with four different aggregate types. ASTM C192 $(2015 \mathrm{~g})$ was followed during the mixing and curing of concrete cylinders having $100 \mathrm{~mm}$ diameter and $200 \mathrm{~mm}$ height. For each combination 12 cylinders were prepared. 
Table 5

Mix proportion for 1 cum of concrete (by weight)

\begin{tabular}{cccccc}
\hline \hline Designation & $\boldsymbol{w} / \boldsymbol{c}$ ratio & Water $(\boldsymbol{k g})$ & Cement $(\boldsymbol{k g})$ & Fine aggregate $(\boldsymbol{k g})$ & Coarse aggregate $(\boldsymbol{k g})$ \\
\hline FCA-Manual & 0.5 & 200 & 400 & 773 & 658 \\
FCA-Machine & 0.5 & 200 & 400 & 777 & 729 \\
PBA-Manual & 0.5 & 200 & 400 & 752 & 687 \\
PBA-Machine & 0.5 & 200 & 400 & 674 \\
\hline \hline
\end{tabular}

\section{COMPARISON OF CONCRETE STRENGTH}

Concrete cylinders were prepared with four different types of aggregates. Strength tests were conducted at 14 and 28 days after 14 and 28 days curing, respectively. Just before the test, samples were gathered from the curing tank. Samples were then surface dried, measured and weighed. Compressive and tensile strengths were measured in a $2000 \mathrm{kN}$ capacity ELE 36-4150/01 compression testing machine. Compressive strength of concrete was obtained following ASTM C39 (2015a) and split tensile strength was performed according to ASTM C496 (2011c).

\section{A. Compressive Strength}

The compressive strength of concrete with FCA and PBA was determined at 14 and 28 days. At each of the $14^{\text {th }}$ and $28^{\text {th }}$ days, three samples per combination were tested and their average was calculated. Compressive strength results are presented in Figure 9 for both manually and machine crushed brick aggregate concrete. As shown in the figure all the specimens have compressive strength greater than $25 \mathrm{MPa}$ at 28 days of age. Moreover, concrete with manually crushed FCA produced the highest compressive strength (26.7 $\mathrm{MPa}$ at 28 days) and it was only 1\% higher than the manually crushed PBA concrete. As discussed in the previous section, PBA has better strength properties, lower AIV, ACV and LAA values, compare to FCA. However, FCA has better shape properties, lower flakiness, and elongation values, compare to PBA. Therefore, it can be summarized that the better shape properties of FCA concrete compensate for the inferior strength properties while considering the concrete compressive strength.

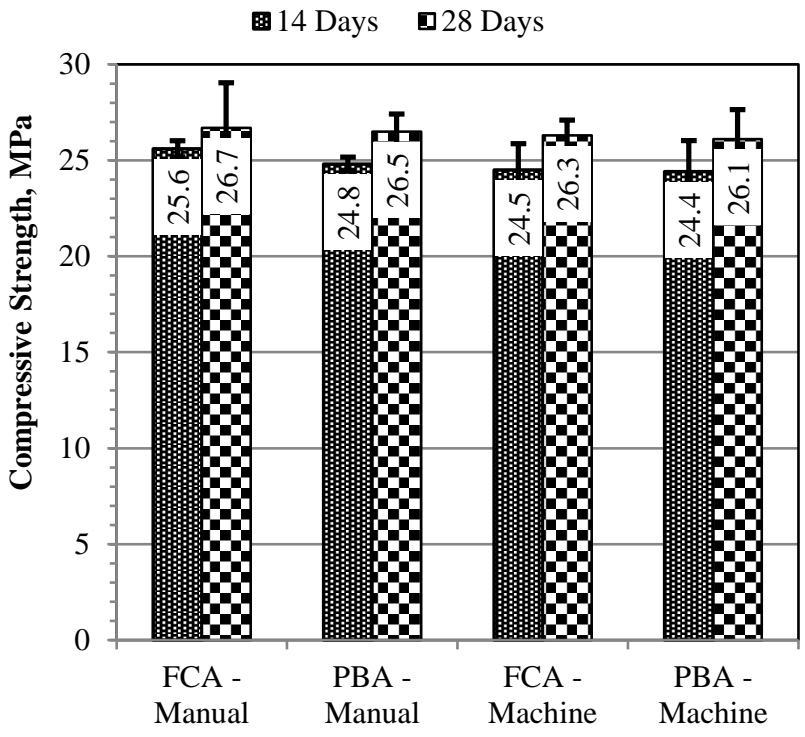

Figure 9: Variation of compressive strength with different concrete types
In both the types of bricks studied for compressive strength, manual crushing of the aggregates yields higher strength compared to the machine crushed ones. A possible reason for this may be due to the difference in the quality of the aggregates. It is observed in Figure 7 that machine-crushed aggregates have higher flakiness and elongation Indices. As a higher number of flaky and elongated particles leads to lower strength of the aggregate, this could be one of the main reason for lower compressive strength of concrete specimens made with machine crushed brick aggregates compare to the manually crushed brick aggregate. The maximum decrease $(2.2 \%)$ in compressive strength is found in PBA - Machine concrete at 28 days when compared between manual and machine crushing.

\section{B. Tensile Strength}

Splitting tensile strength of concrete was measured at 14 and 28 days and the results are presented in Figure 10. Both manually crushed FCA and PBA concrete had similar tensile strength at both 14 and 28 days, and higher tensile strength compared to the machine crushed brick aggregate concrete. Although the reduction in tensile strength at 28 days for FCA - Machine is $3.7 \%$ the reduction is found to be the largest (18.5\% at 28 days) for PBA - Machine when it is compared between manually and machine crushed. Higher values of flakiness and elongation indices for PBA results in lower compressive strength for machine crushed brick aggregate concrete.

\section{Comparison of Strengths with Standard Codes}

There is a strong correlation between the compressive and splitting tensile strengths of concrete. Various codes, such as ACI 318-14 (2014) and fib (2010), proposed equations and guidelines to predict splitting tensile strengths from the compressive strengths, as shown in Table 6. However, these equations are heavily influenced by the density of the concrete. ACI 318-14 defines concrete to be normal weight and lightweight if the density of concrete is within 2155 to $2560 \mathrm{~kg} / \mathrm{m}^{3}$ and 1440 to $1840 \mathrm{~kg} / \mathrm{m}^{3}$, respectively (ACI, 2014). On the other hand, according to fib (2010), density of normal weight concrete ranges between 2000 to $2600 \mathrm{~kg} /$ $\mathrm{m}^{3}$. In the present study, densities of FCA and PBA concrete are $2035 \mathrm{~kg} / \mathrm{m}^{3}$ and $2025 \mathrm{~kg} / \mathrm{m}^{3}$, respectively. Therefore, the FCA and PBA concrete can be categorized as normal weight concrete for fib (2010) and the equation proposed in Table 6 can be used for predicting tensile strength. However, these concretes are not either normal weight or lightweight concrete according to ACI 318-14. Hence, the equation proposed by ACI $318-14$ has a modification factor $(\lambda)$ to consider the effect of lightweight concrete. For a normal weight fine aggregate and blended (lightweight and normal weight) coarse aggregate, modification factor may vary between 0.85 to 1 (ACI, 2014). 


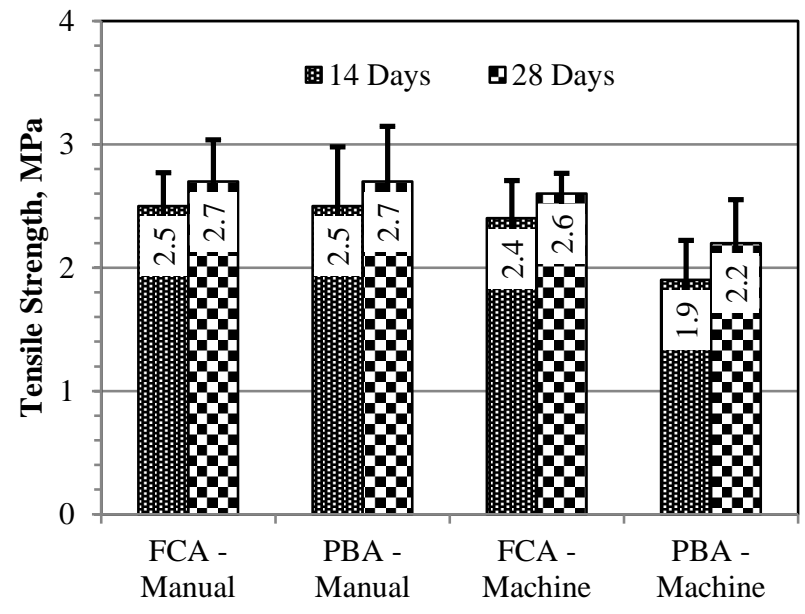

Figure 10: Variation of tensile strength with age for different concrete types

Using equations mentioned in Table 6, splitting tensile strength of concrete can be predicted from the experimental compressive strength as displayed in Figure 11. As observed from the figure, using a modification factor of 0.94 , ACI 318 14 equation gives a very good prediction $(-0.4 \%$ to $3.1 \%)$ of the experimental tensile strength data for all concrete types except for the machine crushed PBA concrete. For the machine crushed PBA concrete the variation is $21.4 \%$. On the other hand, fib (2010) underestimates (1\%) the tensile strength for manually crushed concrete and overestimate (2-20\%) for machine crushed concrete.

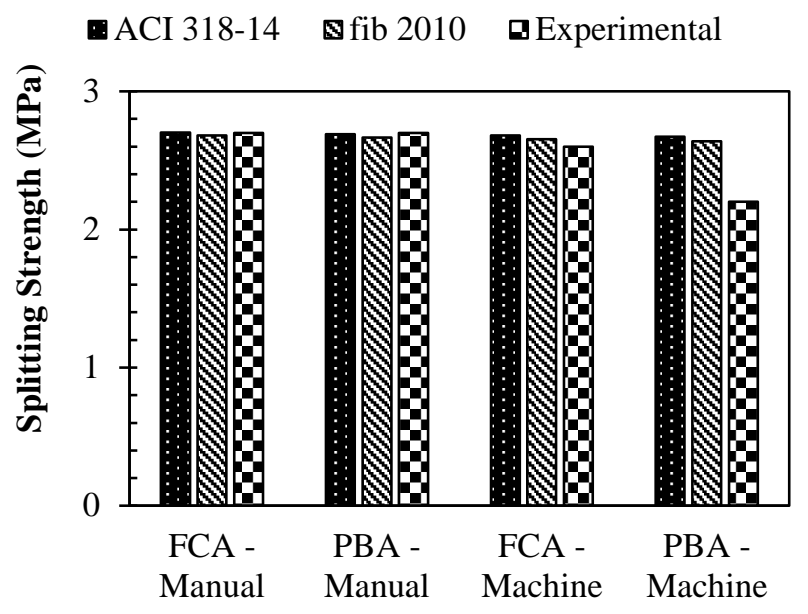

Figure 11: Comparison of splitting tensile strength with different equations

Table 6

Proposed equations and guidelines by various codes

\begin{tabular}{ccc}
\hline \hline Code & Proposed Equations & Description \\
\hline ACI 318-14 (2014) & $f_{c t s}=0.556 \lambda \sqrt{ } f_{C}^{\prime}$ & $\begin{array}{l}\text { Where, } f_{c t s}=\text { mean splitting tensile strength in } M P a, \\
f_{C}^{\prime}=\text { the compressive strength of concrete in } M P a \text { and } \\
\lambda=\text { modification factor }\end{array}$ \\
fib (2010) & $\begin{array}{c}\text { Where, } f_{c t u}=\text { mean uniaxial tensile strength in } M P a, \text { and } \\
f_{c t u}^{\prime}=0.3\left(f_{C}^{\prime}\right)^{\frac{2}{3}}\end{array}$ & $f_{C}=$ compressive strength in $M P a$ \\
\hline \hline
\end{tabular}

\section{CONCLUSIONS}

The results of this present study have led to the following conclusions.

- The strength of the brick has no apparent effect on the strength of concrete specimens. Compressive strengths of picket brick (PB) and ceramic brick (CB) are $61 \%$ and $30 \%$ higher than the first class (FC) brick, respectively. Whereas compressive and tensile strengths of concrete casted with manually crushed FCA and PBA are varied up to $1 \%$.

- In terms of wastage production (cumulative percent passing $2.36 \mathrm{~mm}$ sieve) during brick crushing, the manual crushing procedure is found to be more economical than machine crushing as evidenced by as high as $14.5 \%$ of wastage for FC brick after machine crushing. On the contrary, manual crushing for $\mathrm{FC}$ results in as low as $1.8 \%$ wastage.

- The machine crushed brick aggregates have a substandard size, shape, and strength properties compared to the manually crushed ones as indicated by the higher flakiness index $(6-25 \%)$, elongation index $(10-16 \%)$, aggregate impact value ( $5-$ $7 \%)$, aggregate crushing value $(3-7 \%)$, and LA abrasion value $(0-6 \%)$.

- Higher-strength PB has produced better aggregate in terms of aggregate strength. Compared to FCA, PBA has $17 \%$ lower AIV, 3\% lower ACV and $11 \%$ lower LAA value for the manually crushing process. However, higher strength bricks produce flakier and elongated aggregates. In comparison to manually crushed FCA, PBA has a 14\% higher flakiness index and a $32 \%$ higher elongation index. Although CBA has better strength properties it has $36 \%$ and $39 \%$ higher flakiness and elongation indices, respectively.

- In general, for high-performance concrete both physical and mechanical properties of aggregate is one of the major conditions for achieving higher strength. However, in the present study for concrete with compressive strength of $27 \mathrm{MPa}$ or less, physical properties (such as size and shape) are found to be more defining factors than the strength properties of aggregates. At 28 days, the compressive strength of concrete made with manually crushed aggregate showed better results than the machine crushed aggregate concrete. Furthermore, manually crushed FCA concrete showed a $1 \%$ higher compressive strength than the manually crushed PBA concrete. Machine crushed aggregate concrete showed up to $18.5 \%$ lower split tensile strength compares to the manually crushed aggregate concrete and it was significant for machine crushed PBA concrete.

- The available design guidelines and equations can predict the splitting tensile strength of brick aggregate concrete. Except for machine crushed PBA 
concrete, both ACI 318 and fib (2010) can predict the splitting tensile strength with good accuracy from the compressive strength of concrete.

\section{ACKNOWLEDGEMENTS}

The authors would like to thank the Military Institute of Science and Technology (MIST) for supporting this work.

\section{REFERENCES}

ACI. (1994). ACI 211.1.91: Standard Practice of Selecting Proportions for Normal, Heavy-weight, and Mass Concrete. Detroit: ACI Committee 211.

ACI. (2014). ACI 318-14: Building Code Requirements for Structural Concrete and Commentary. Detroit: American Concrete Institute.

ACI. (2016). E1-16: Aggregates for Concrete ACI Education Bulletin E1-16. 38800 Country Club Drive, Farmington Hills, MI 48331: ACI Committee E-701.

Adamson, M., Razmjoo, A., \& Poursaee, A. (2015). Durability of concrete incorporating crushed brick as coarse aggregate. Construction and Building Materials, 94, 426-432.

Afroz, S., Rahman, F., Iffat, S., \& Manzur, T. (2015). Sorptivity and strength characteristics of commonly used concrete mixes of Bangladesh. International Conference on Recent Innovation in Civil Engineering for Sustainable Development (IICSD2015), Gazipur, Bangladesh.

Akhtaruzzaman, A. A., \& Hasnat, A. (1983). Properties of concrete using crushed brick as aggregate. Concrete International, 5(2), 58-63.

ASTM. (2009). ASTM C29/C29M-09 Standard Test Method for Bulk Density ("Unit Weight") and Voids in Aggregate (2009 ed., Vol. PA 19428-2959). West Conshohocken: ASTM International.

ASTM. (2011a). ASTM C187-11 Standard Test Method for Amount of Water Required for Normal Consistency of Hydraulic Cement Paste (2010 ed., Vol. PA 19428-2959). West Conshohocken: ASTM International.

ASTM. (2011b). ASTM C204-11 Standard Test Methods for Fineness of Hydraulic Cement by Air-Permeability Apparatus (2011 ed., Vol. PA 19428-2959). West Conshohocken: ASTM International.

ASTM. (2011c). ASTM C496/C496M Standard Test Method for Splitting Tensile Strength of Cylindrical Concrete Specimens (2011 ed., Vol. PA 19428-2959). West Conshohocken ASTM International.

ASTM. (2013a). ASTM 109/109M-13 Standard Test Method for Compressive Strength of Hydraulic Cement Mortars (Using 2in. or [50-mm] Cube Specimens) (2013 ed., Vol. Pennsylvania). West Conshohocken ASTM International.

ASTM. (2013b). ASTM C33-13 Standard Specification for Concrete Aggregates (2013 ed., Vol. PA 19428-2959). West Conshohocken: ASTM International.

ASTM. (2013c). ASTM C191-13 Standard Test Methods for Time of Setting of Hydraulic Cement by Vicat Needle (2013 ed., Vol. PA 19428-2959). West Conshohocken: ASTM International.

ASTM. (2014). ASTM C136/C136M-14 Standard Test Method for Sieve Analysis of Fine and Coarse Aggregates (2014 ed., Vol. PA 19428-2959). West Conshohocken: ASTM International.

ASTM. (2015a). ASTM C39/C39M Standard Test Method for Compressive Strength of Cylindrical Concrete Specimens (2015A ed., Vol. PA 19428-2959). West Conshohocken ASTM International.

ASTM. (2015b). ASTM C127-15 Standard Test Method for Relative Density (Specific Gravity), and Absorption of Coarse Aggregate (Vol. PA 19428-2959). West Conshohocken: ASTM International.

ASTM. (2015c). ASTM C128-15 Standard Test Method for Relative Density (Specific Gravity), and Absorption of Fine
Aggregate (Vol. PA 19428-2959). West Conshohocken: ASTM International.

ASTM. $(2015 d)$. ASTM C131-15 Standard Test Method for Resistance to Degradation of Small-Size Coarse Aggregate by Abrasion and Impact in the Los Angeles Machine (Vol. PA 19428-2959). West Conshohocken: ASTM International.

ASTM. (2015e). ASTM C150/C150M-15 Standard Specification for Portland Cement (2015 ed., Vol. PA 19428-2959). West Conshohocken ASTM International.

ASTM. (2015f). ASTM C151/C151M-15 Standard Test Method for Autoclave Expansion of Hydraulic Cement (2015 ed., Vol. PA 19428-2959). West Conshohocken ASTM International.

ASTM. (2015g). ASTM C192/C192M Standard Practice for Making and Curing Concrete Test Specimens in the Laboratory (2015 ed., Vol. PA 19428-2959). West Conshohocken ASTM International.

ASTM. (2015h). ASTM C430-08 Standard Test Methods for Fineness of Hydraulic Cement by the 45- $\mu \mathrm{m}$ (No. 325) Sieve (2015 ed., Vol. PA 19428-2959). West Conshohocken: ASTM International.

Ayub, M., Ali, Q., Shahzada, K., Naseer, A., Shoaib, M., \& Ayub, U. (2012). Engineering assessment of coarse aggregates used in Peshawar. International Journal of Advanced Structures and Geotechnical Engineering, 1(2), 61-64.

BSI. (1990a). BS 812-105.1: 1989 Testing aggregates — Part 105: Methods for determination of particle shape - Section 105.1 Flakiness index: BSI.

BSI. (1990b). BS 812-105.2: 1990 Testing aggregates - Part 105: Methods for determination of particle shape - Section 105.2 Elongation index of coarse aggregate: BSI.

BSI. (1990c). BS 812-110: 1990 Testing aggregates - Part 110: Methods for determination of aggregate crushing value (ACV): BSI

BSI. (1990d). BS 812-112: 1990 Testing aggregates - Part 112: Methods for determination of aggregate impact value (AIV): BSI.

Cachim, P. B. (2009). Mechanical properties of brick aggregate concrete. Construction and Building Materials, 23(3), 12921297.

fib. (2010). fib Model Code for Concrete Structures: International Federation for Structural Concrete.

Hansen, T. (1992). Recycling of demolished concrete and masonry, RILEM Report 6. Methods. SPON Press, London, UK.

Islam, M. J., Alam, M. R., Islam, M. R., \& Hasanuzzaman, M. (2020). Evaluation of Commonly Used Aggregates for Sustainable Infrastructure Development in Bangladesh. International Journal of GEOMATE, 18(66), 98-104. doi: https://doi.org/10.21660/2020.66.9464

Khalaf, F. M., \& DeVenny, A. S. (2004). Performance of brick aggregate concrete at high temperatures. Journal of Materials in Civil Engineering, 16(6), 556-565.

Khaloo, A. R. (1994). Properties of concrete using crushed clinker brick as coarse aggregate. Materials Journal, 91(4), 401-407.

Lennon, M. (2005). Recycling construction and demolition wastes: a guide for architects and contractors.

Neville, A. M. (1995). Properties of concrete (4 ed.): Longman Scientific and Technical, London.

Rashid, M. A., Hossain, T., \& Islam, M. A. (2009). Properties of higher strength concrete made with crushed brick as coarse aggregate. Journal of Civil Engineering (IEB), 37(1), 43-52.

RMIT University, (2006). Scoping Study to Investigate Measures for Improving the Environmental Sustainability of Building Materials. Department of the Environment, Water, Heritage, and the Arts, Canberra, Australia.

Sahu, G. C., \& Jena, J. (2015). Building Materials and Construction (4 ed.): McGraw Hill Education (India) Private Limited.

Yu, J., Cai, X., Ge, Y., \& Yu, Y. (2015). Effect of elongated and flaky particles content on the durability of concrete. Fifth International Conference on Transportation Engineering (ICTE), Dailan, China. 



\title{
Assessment of Hexavalent Chromium Pollution in Buriganga and Dhaleshwari River Waterbodies Adjacent to Tannery Estates in Bangladesh
}

\author{
Hafizur Rahman ${ }^{1 *}$, Nabila Hoque ${ }^{2}$, Palash K. Sarker³ ${ }^{3}$ and Ashrafus Safa ${ }^{4}$ \\ 1,2Department of Environmental Science, SESM, Independent University, Bangladesh (IUB), Dhaka, Bangladesh \\ ${ }^{3}$ Department of Science and Humanities, Military Institute of Science and Technology (MIST), Dhaka, Bangladesh \\ ${ }^{4}$ School of Life Sciences, Independent University, Bangladesh (IUB), Bangladesh \\ emails: ${ }^{*}$ hrahman@iub.edu.bd; ${ }^{2 n a b i l a h o q 111 @ g m a i l . c o m ; ~}{ }^{3}$ sarker@sh.mist.ac.bd; and ${ }^{4}$ asafa@iub.edu.bd
}

\section{ARTICLE INFO}

Article History:

Received: 22 2 fe Fruary 2020

Revised: $18^{\text {th }}$ March 2020

Accepted: $31^{\text {st }}$ March 2020

Published online: $21^{\text {st }}$ July 2020

\section{Keywords:}

Chromium

Tannery

Effluent

Buriganga

Dhaleshwari

\begin{abstract}
A B S T RAC T
Recently, in Bangladesh, all tannery industries have been relocated to a new location exclusively established for leather processing industries with modern manufacturing facilities and effluent treatment plants with standard probations. Effluents generated from the tannery industries are now being disposed of into the surrounding river water bodies. In this study, our goal was to investigate the presence of chemical contaminants like hexavalent chromium $\left(\mathbf{C r}^{6+}\right)$ in the water bodies surrounding tannery industries and to understand the possible role played by the tannery effluents in contaminating the river water bodies with $\boldsymbol{C r}^{6+}$. Result analysis revealed the presence of an amount of $\boldsymbol{C r}^{6+}$ (ranging from $\mathbf{0 . 0 1} \mathbf{~ m g} / \mathbf{L}$ to $3.54 \mathrm{mg} / \mathrm{L}$ ) in the surrounding water bodies, which was far above the maximum permissible limit of $\boldsymbol{C r}^{\mathbf{6}+}(\mathbf{0 . 0 5} \mathbf{m g} / \boldsymbol{L}$ for surface water), set by the Environmental Protection Agency. It is, therefore, plausible to assume that effluents from the tanneries play an important role in hexavalent chromium contamination of water bodies surrounding tannery industries.
\end{abstract}

\section{INTRODUCTION}

Leather industry is one of the key export sectors in Bangladesh. Currently, $>270$ registered tanneries are operating in Bangladesh (Rouf et al., 2013; Blacksmith Institute and Green Cross Switzerland, 2013; Hashem et al., 2014). Majority tanneries are situated at Hazaribagh area, located one and a half kilometer northeast to the river Buriganga in Dhaka, as shown in Figure 1 (Shams et al., 2009). A portion of the effluents from tanneries in Hazaribagh are transported to the lagoon while the other portion discharged into nearby low-lying areas through drain, which eventually falls into the Buriganga and introducing significant hazards in the surrounding environment (Hashem et al., 2015). It has already been reported that these tanneries discharge 1.6 tons of chromium per day, of which 0.35 tons are deposited into the lagoons and the remaining amount end up in the Buriganga (Karim et al., 2013). Generally, tannery waste contains both hexavalent and trivalent forms of chromium which are most stable and exist in the aqueous system. The hexavalent chromium is more toxic than its trivalent form and it is of particular concern for being carcinogenic and mutagenic to living organisms (Holmes et al., 2008; Saha et al., 2011; Zewdu \& Amare, 2018). In addition, highly toxic heavy metals such as copper, zinc, arsenic, cadmium, lead and organic compounds such as phenols, hydrocarbons and other toxic chemicals are found in Hazaribagh tannery area. (Shams et al., 2009; Karim et al., 2012; Tinni et al., 2014; Sarkar et al., 2015; Asaduzzaman et al., 2016; Juel et al., 2016). Exposure to these chemicals causes adverse health effects when they are not metabolized by the body and accumulated in the soft tissues. (Singh et al., 2004; Wilson and Pyatt, 2007). A number of residents in Hazaribagh were affected by pollution resulted from toxic chemicals, particularly chromium (Blacksmith Institute \& Green Cross Switzerland, 2013; Hossain \& Islam, 2016).

Considering the hazardous impact of tannery wastes on human and environment in Hazaribagh, Bangladesh government has planned a new strategy to resettle the tannery factories from their contemporary location to a new spot in Savar, which is known as 'Hazaribagh Tannery Relocation Project (HTRP)' (Jolly et al., 2012, Mahmood et al., 2017). The main focus of this relocation is to modernize the tanneries, and to treat the effluents through a modern common effluent treatment plant (CETP) before disposing of in the river water, which would finally evolve an appropriate waste management system for tannery industry. It is mentionable that Savar is an Upazila of Dhaka District, 
which is bounded to the west and south by the river Dhaleshwari, a linked river of Buriganga and the CETP is 20 kilometers far from Hazaribagh tannery area (RPMC, 2008; Islam et al., 2015). Therefore, contaminants might be transported with the water flow between these two rivers.

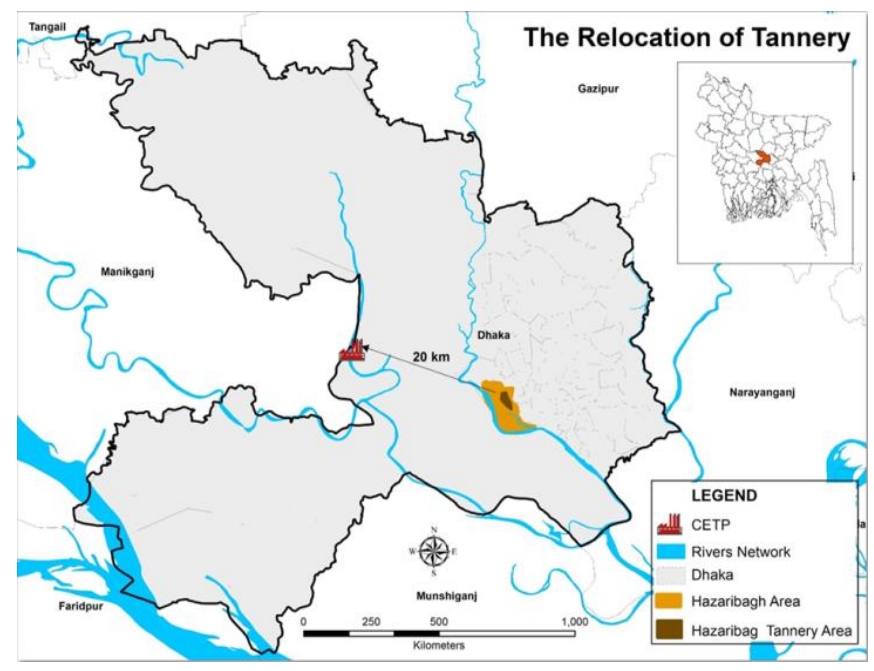

Figure 1: Map of tanneries in Hazaribagh and newly established estate in Savar

In the present study, we aim to determine the concentration of $\mathrm{Cr}^{6+}$ in the Buriganga and Dhaleshwari rivers from Hazaribagh and Savar tannery estates, respectively. The obtained data from this study will be helpful to understand the contamination level of the water bodies, that will facilitate to create people's awareness of chromium contamination from tannery waste disposal. Moreover, this study will be beneficial for the newly relocated tannery estate to make it more sustainable.

\section{METHODOLOGY}

\section{A. Sampling Site}

All the samples were collected from different categorized locations that are representative of the river flow, water source, drainage points, and treatment plant as shown in Figure 2 (a) and (b). There are two different study areas as shown in Figure 3 (a) and (b) for this project. All the samplings have been taken from the mentioned two areas, i.e., the Buriganga riverine area in Hazaribagh tannery estate and the Dhaleshwari riverine area in Savar tannery estate. The water samples were collected from 20 feet depth in each point which was marked by a global positioning system (Garmin eTrex 10) for future reference. It is mentionable that all the samples were taken at the rainy season between June and July while the water dilution of the rivers was much higher than the dry season.

\section{B. Reagents and Solutions}

All chemicals were of analytical-reagent grade and purchased from Sigma-Aldrich. Deionized water was used in the preparation of various solutions. A stock solution of potassium dichromate $\left(\mathrm{K}_{2} \mathrm{Cr}_{2} \mathrm{O}_{7}\right)$ of $1000 \mathrm{mg} / \mathrm{L}$ was prepared by weighing out an appropriate amount and dissolving it in deionized water. Working standards were prepared by consecutive dilution. Diphenylcarbazide solution was prepared by dissolving $1 \mathrm{~g}$ of 1,5-diphenylcarbazide (DPC), $\mathrm{CO}\left(\mathrm{NHNHC}_{6} \mathrm{H}_{5}\right)_{2}$, in $100 \mathrm{~mL}$ acetone and acidified with a drop of acetic acid.

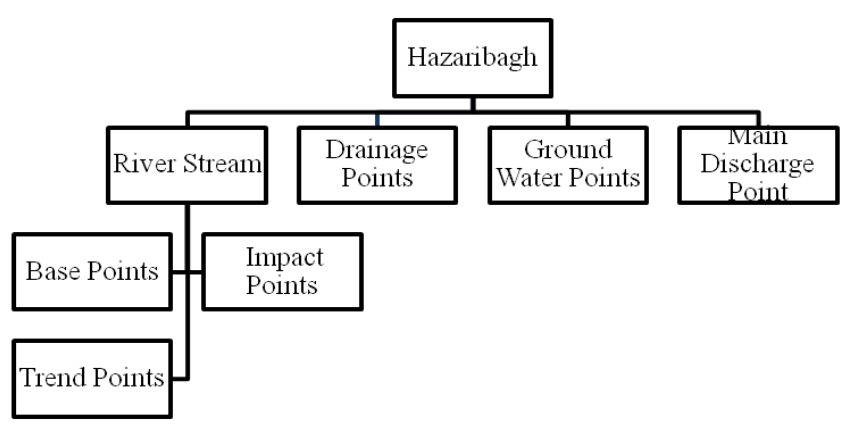

(a)

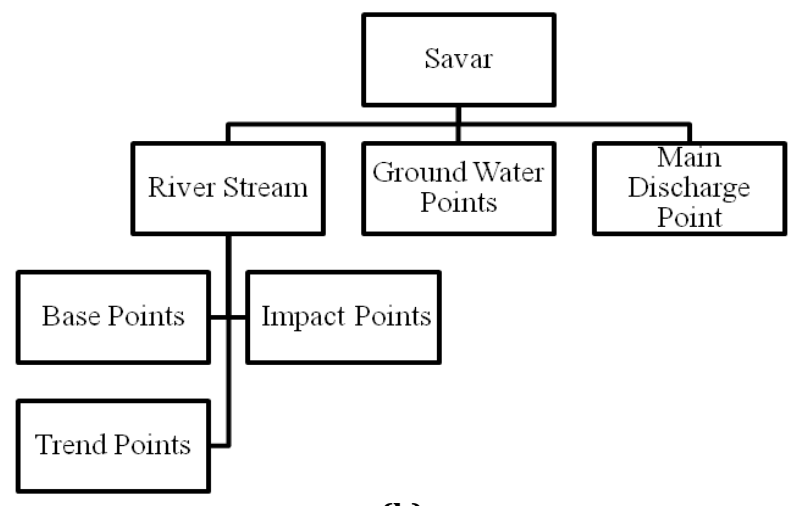

(b)

Figure 2: Categorized water samples collection points: (a) at Hazaribagh, and (b) at Savar

\section{UV Absorbance Measurement}

In this process, $20 \mathrm{~mL}$ of the sample was acidified with $1 \mathrm{~mL}$ of sulfuric acid and $1 \mathrm{~mL}$ of nitric acid. Then the sample was boiled properly for 10 minutes followed by cooling. The sample was then filtered with filter paper. Then the filtrate was taken into a volumetric flask and it was diluted with deionized water to adjust the volume into $20 \mathrm{~mL}$. After that, 2 drops of methyl orange were added in that adjusted $20 \mathrm{~mL}$ sample solution and the sample solution became orange in colour. Then the sample solution was titrated consecutively, firstly with a $28 \%$ ammonia solution until the colour turned yellow and secondly with 1: 1 sulfuric acid solution until the colour turned back into orange. After that the sample was boiled and cooled down, 2 drops of potassium dichromate was added to it followed by boiling. The colour of the sample turned into purple at this time. Then $1 \mathrm{~mL}$ of sodium azide was added followed by boiling again. All the colour had to disappear properly after the boil. If the colour did not disappear, another $1 \mathrm{~mL}$ of sodium azide was added to make the sample entirely colourless. The sample was properly cooled down to room temperature and $0.25 \mathrm{~mL}$ of orthophosphoric acid was added into the sample solution. The $p H$ level of the solution was found between $1.7-1.3$. Then, $20 \mathrm{~mL}$ of this solution was taken into another volumetric flask followed by the addition of $2 \mathrm{~mL}$ of sulfuric acid $(0.2 \mathrm{~N})$ and $2 \mathrm{~mL}$ of DPC solution. The volume of the solution was adjusted again to $50 \mathrm{~mL}$ with deionized water. In this method, $\operatorname{Cr}(V I)$ was reacted with DPC in acidic conditions and formed a purple-coloured species. As a result of a redox reaction, $\operatorname{Cr}(V I)$ was reduced to $C r(I I I)$, and DPC was oxidized to 1,5-diphenylcarbazone as shown in Figure 4. Finally, the wavelength of UV-Vis spectrophotometer (HACH, DR2800) was adjusted at $540 \mathrm{~nm}$ to measure the absorbance of the samples (Onchoke \& Sasu, 2016). 

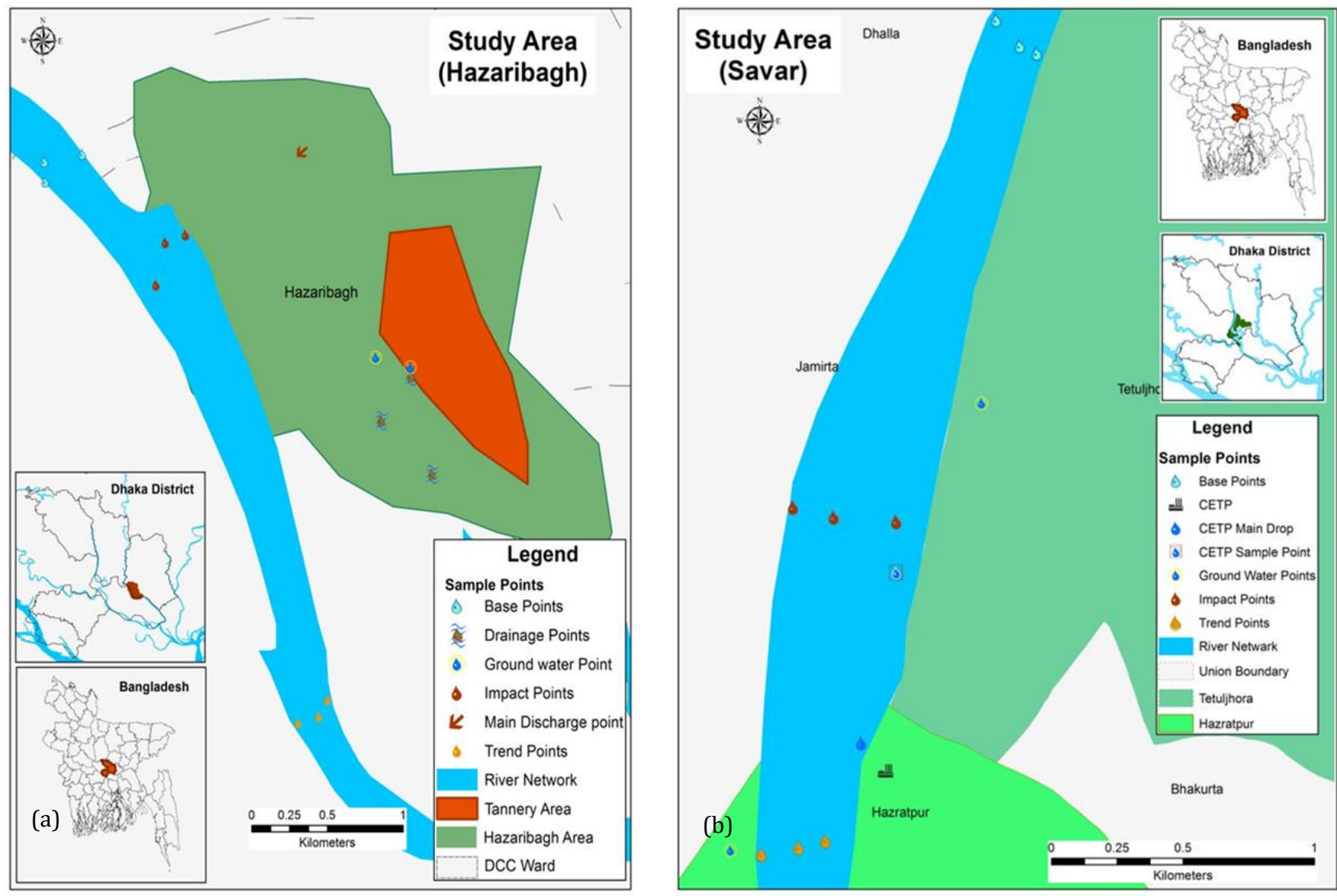

Figure 3: Map showing, (a) the study area at Hazaribagh, and (b) the study area at Savar

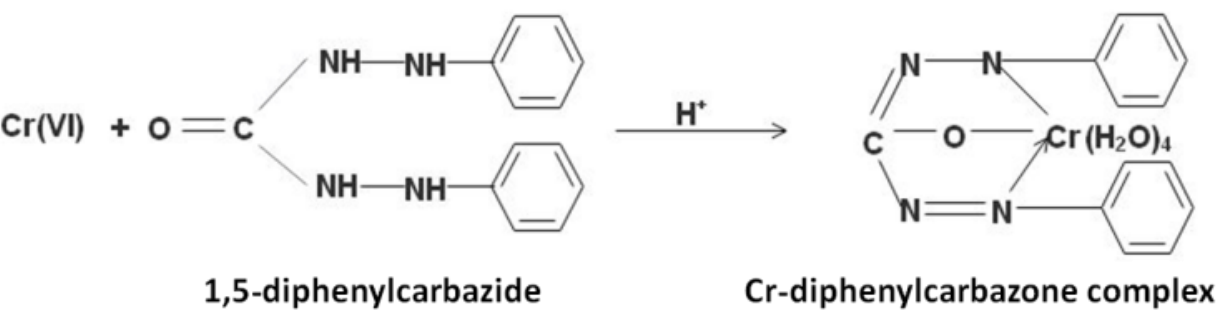

Figure 4: The chemical reaction between chromium (VI) and diphenylcarbazide to form chromium-diphenylcarbazone

\section{RESULTS AND DISCUSSION}

$\mathrm{Cr}^{6+}$ was detected in both study areas. However, the concentration was alarming in the drainage streams of Hazaribagh, because of the huge amount of basic chromium sulfate which is discharged from the adjacent leather processing and tanning industries. The effluents generated from those tanneries are dumped either directly into the nearby Buriganga river without any treatment or through drainage system. Sometimes, the industries use small lagoons to keep their effluents temporarily. Solid wastes are managed through open dumping methods near the industries or river and leachate comes in the environment very often. However, all the effluents discharged from the tanneries somehow end up in the Buriganga river through point and non-point sources.

The detected concentration of $\mathrm{Cr}^{6+}$ in the samples collected from Hazaribagh area were ranging from $0.01 \mathrm{mg} / \mathrm{L}$ to $3.54 \mathrm{mg} / \mathrm{L}$ as shown in Table 1 and Table 2.
Table 1

Chromium level at trend, impact and base points in Hazaribagh and Savar

\begin{tabular}{lcc}
\hline \hline \multirow{2}{*}{$\begin{array}{l}\text { pampling } \\
\text { points }\end{array}$} & $\begin{array}{c}\text { Hazaribagh } \\
\text { area }\end{array}$ & $\begin{array}{c}\text { Savar } \\
\text { area }\end{array}$ \\
\cline { 2 - 3 } Chromium $(\mathbf{m g} / \boldsymbol{L})$ \\
\hline Trend FS & 0.055 & 0.044 \\
Trend MS & 0.174 & 0.030 \\
Trend OS & 0.192 & 0.034 \\
Impact FS & 0.032 & 0.022 \\
Impact MS & 0.100 & 0.029 \\
Impact OS & 0.017 & 0.050 \\
Base FS & 0.052 & 0.038 \\
Base MS & 0.051 & 0.035 \\
Base OS & 0.010 & 0.029 \\
\hline \hline
\end{tabular}


Table 2

Chromium level at main discharge, drainage stream, groundwater, and CETP main drop points in Hazaribagh and Savar

\begin{tabular}{lcc}
\hline \hline $\begin{array}{l}\text { Sampling } \\
\text { points }\end{array}$ & $\begin{array}{c}\text { Hazaribagh } \\
\text { area }\end{array}$ & $\begin{array}{c}\text { Savar } \\
\text { area }\end{array}$ \\
\cline { 2 - 3 } $\begin{array}{l}\text { Chromium }(\mathbf{m g} / \mathbf{L}) \\
\text { (switch gate) }\end{array}$ & 3.460 & - \\
Drainage Stream 1 & 1.700 & - \\
Drainage Stream 2 & 3.540 & - \\
Drainage Stream 3 & 0.163 & - \\
Ground Water 1 & 0.028 & - \\
Ground Water 2 & 0.031 & - \\
CETP Main Drop Point & - & 0.032 \\
Ground FS & - & 0.029 \\
Ground OS & - & 0.033 \\
\hline \hline
\end{tabular}

Note: Trend means the point where the river Buriganga meets Dhaka city and around $2 \mathrm{~km}$ away from the tannery site. Impact is the river site adjacent to tanneries. Base is the point again $2 \mathrm{~km}$ away from the factory sites but when the discharge is taken away from the factory sites. FS means factory side of the river, MS means middle side of the river; OS means other side of the river.

Among them, the highest and the lowest concentration of $\mathrm{Cr}^{6+}$ were found in the drainage stream and in the Buriganga river water (Figure 5), respectively. The highest amount of chromium in the Buriganga river water was determined to be $0.192 \mathrm{mg} / \mathrm{L}$. Although, the concentration of hexavalent chromium in Buriganga river is less than Hazaribagh area drainage system-2 $(3.54 \mathrm{mg} / \mathrm{L})$ but still it is higher than the standard set by EPA 2001.

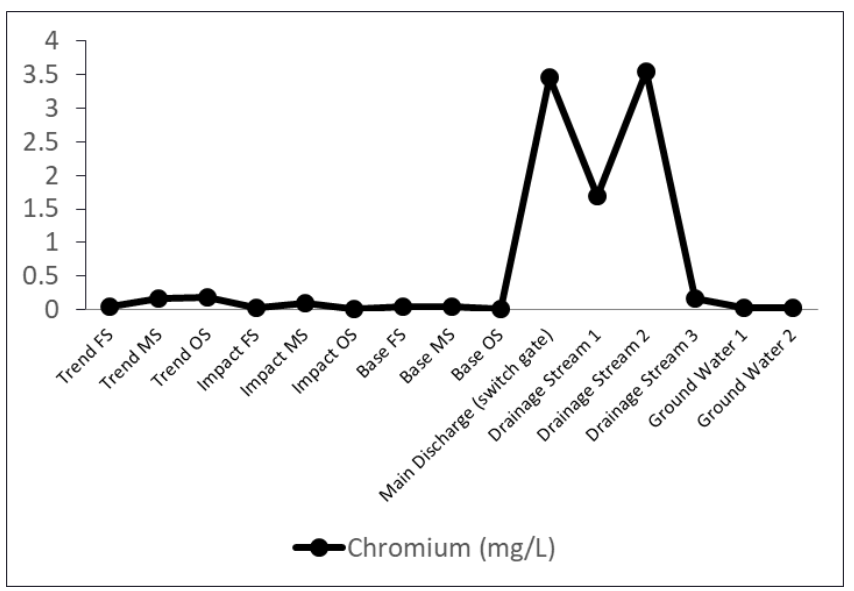

Figure 5: Concentration of $\mathrm{Cr}^{6+}$ in water bodies at different sampling locations in Hazaribagh area

On the other hand, the concentration of $\mathrm{Cr}^{6+}$ in Savar area was found in a range between $0.022 \mathrm{mg} / \mathrm{L}$ and $0.050 \mathrm{mg} / \mathrm{L}$ as shown in Table 1 and Table 2, which is identified within the standard limit set by EPA 2001. Eventually, the amount of hexavalent chromium (i.e., $0.032 \mathrm{mg} / \mathrm{L}$ ) at CETP main drop point is very reasonable. The presence of trace concentration of $\mathrm{Cr}^{6+}$ in Savar area (Figure 6) might cause due to the less efficiency of the newly established CETP or through the advection of the water flows between two rivers, the Buriganga and the Dhaleshwari. The river channels are also connected with each other, as shown in Figure 1. The distance between these two rivers is only 20 kilometers. So, the heavy metal chromium may travel through the water current by advection. Besides, chromium from the tannery waste can be leached into nearby soil and water, which could finally be the cause of the presence of $\mathrm{Cr}^{6+}$ with a meager amount in the Dhaleshwari river water. However, when all the tannery industries will be shifted to the new location and if the CETP fails to treat the effluents efficiently, the scenario would be the same as Hazaribagh.

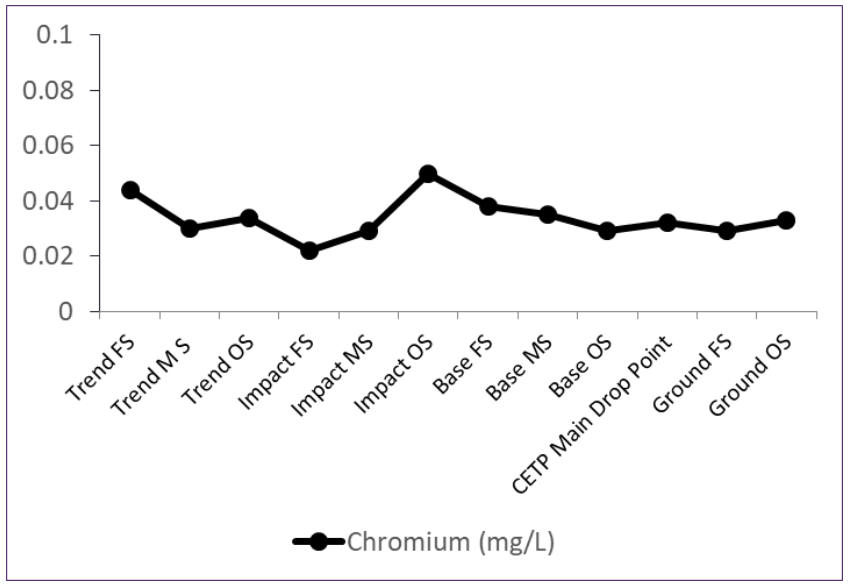

Figure 6: Concentration of $\mathrm{Cr}^{6+}$ in water bodies at different sampling locations in Savar area

\section{CONCLUSIONS}

The results of this study suggest that chromium $\left(\mathrm{Cr}^{6+}\right)$, a carcinogenic chemical released from tannery waste, is being introduced to Buriganga river water through different water bodies at Hazaribagh area. Consequently, it has been listed as one of the polluted places in Dhaka city. It is plausible that the removal of Hazaribagh tannery may reduce the Buriganga river pollution by a massive percentage. Relocation of all tanneries from Hazaribagh to Savar implemented by BSCIC (i.e., Bangladesh Small and Cottage Industries Corporation) with a properly designed and controlled new industrial estate will facilitate an ecologically friendly tannery business park in Bangladesh. So far, the results of our present study support so, especially considering the chromium contamination.

\section{ACKNOWLEDGEMENTS}

The authors are grateful to Ms. Shaheda Begum, Ms. Sonia Afsana, and Mr. Syed Ahmmed Kabir, Department of Environment, Government of the People's Republic of Bangladesh, Agargaon, Sher-e-Bangla Nagar, Dhaka-1207, Bangladesh, for their help in the sample collection and laboratory experiments. The authors would also like to thank Ms. Kazi Sunzida Lisa, Department of Environmental Management, Independent University Bangladesh (IUB), for her help to draw the GIS map.

\section{REFERENCES}

Asaduzzaman, M., Hasan, I., Rajia, S., Khan, N., \& Kabir, K. A. (2016). Impact of tannery effluents on the aquatic environment of the Buriganga River in Dhaka, Bangladesh. Toxicology and Industrial Health, 32(6), 1106-13. 
Blacksmith Institute and Green Cross Switzerland. (2013). The World's Worst 2013: The Top Ten Toxic Threats-Cleanup, Progress, and Ongoing Challenges. Retrieved February 22, 2020, from https://www.greencross.ch/wpcontent/uploads/uploads/media/pollution_report_2013_top_ten _wwpp.pdf

Hashem, M. A., Arefin, M. S., \& Ahmed, M. (2014). Estimation and Environmental Effect of Tannery Effluent from Wet Salted Goat Skin in Beam House Operations: Bangladesh Perspective. International Journal of Environment, 4(2), 3945.

Hashem, M. A., Islam, A., Mohsin, S., \& Nur-A-Tomal, M. S. (2015). Green environment suffers by discharging of highchromium containing wastewater from the tanneries at Hazaribagh, Bangladesh. Sustainable Water Resources Management, 1(4), 343-347.

Holmes, A. L., Wise, S. S., \& Wise, J. P. Sr. (2008). Carcinogenicity of hexavalent chromium. Indian Journal of Medical Research, 128(4), 353-72.

Hossain, M. A., \& Islam, L. N. (2016). Effect of Occupational Exposure on Allergic Diseases and Relationship with Serum $\operatorname{IgE}$ Levels in the Tannery Workers in Bangladesh. Bioresearch Communications, 2(1), 158-163.

Islam, M. S., Uddin, M. K., Tareq, S. M., Shammi, M., Kamal, A. K. I., Sugano, T., Kurasaki, M., Saito, T., Tanaka, S., \& Kuramitz, H. (2015). Alteration of Water Pollution Level with the Seasonal Changes in Mean Daily Discharge in Three Main Rivers around Dhaka City, Bangladesh. Environments, 2(3), 280-294.

Jolly, Y. N., Choudhury, T. R., Islam, A., \& Suravi, N. I. (2012). Background Chemical Study of Relocated Hazaribagh Tannery Complex Environment, Savar. Journal of Bangladesh Academy of Sciences, 36(1), 45-51.

Juel, M. A. I., Chowdhury, Z. U. M., Mizan, A., \& Alam, M. S. (2016). Toxicity and environmental impact assessment of heavy metals contaminated soil of Hazaribagh tannery area. In Proceedings of $3^{\text {rd }}$ International Conference on Advances in Civil Engineering, CUET, Chittagong, Bangladesh, 21-23 December 2016, (pp. 94-99).

Karim, M. R., Manshoven, S., Islam, M. R., Gascon, J. A., Ibarra, M., Diels, L., \& Rahman, M. M. (2013). Assessment of an Urban Contaminated Site from Tannery Industries in Dhaka City, Bangladesh. Journal of Hazardous, Toxic, and Radioactive Waste, 17(1), 52-61.

Mahmood, S., Nourin, F. T. J., Siddika, A., \& Khan, T. F. (2017). Encroachment of the Buriganga River in Bangladesh. Journal of Minerals and Materials Characterization and Engineering, 5, 266-273.

Onchoke, K. K., \& Sasu, S. A. (2016). Determination of Hexavalent Chromium (Cr(VI)) Concentrations via Ion Chromatography and UV-Vis Spectrophotometry in Samples Collected from Nacogdoches Wastewater Treatment Plant, East Texas (USA). Advances in Environmental Chemistry, 2016, 1-10.

River Pollution Mitigation Committee (RPMC). (2008). Mitigation of River Pollution of Buriganga and Linked Rivers-Turag, TongiKhal, Balu, Sitalakhya and Dhaleswari. A report of RPMC Dhaka, Bangladesh, 2008.

Rouf, M., Islam, M., Haq, M., Ahmed, N., \& Rabeya, T. (2013). Characterization of effluents of leather industries in Hazaribagh area of Dhaka city. Bangladesh Journal of Scientific and Industrial Research, 48(3), 155-166.

Saha, R., Nandi, R., \& Saha, B. (2011). Sources and toxicity of hexavalent chromium. Journal of Coordination Chemistry, 64(10), 1782-1806.

Sarkar, M., Rahman, A., Islam, J., Ahmed, K., Uddin, M., \& Bhoumik, N. (2015). Study of hydrochemistry and pollution status of the Buriganga river, Bangladesh. Bangladesh Journal of Scientific and Industrial Research, 50(2), 123-134.

Shams, K. M., Tichy, G., Sager, M., Peer, T., Bashar, A., \& Jozic, M. (2009). Soil contamination from tannery wastes with emphasis on the fate and distribution of tri- and hexavalent chromium. Water, Air, and Soil Pollution, 199(1-4), 123-137.

Singh, K. P., Mohan, D., Sinha, S., \& Dalwani, R. (2004). Impact assessment of treated/untreated wastewater toxicants discharged by sewage treatment plants on health, agricultural, and environmental quality in the wastewater disposal area. Chemosphere, 55(2), 227-55.

Tinni, S., Islam, M., Fatima, K., \& Ali, M. (2014). Impact of Tanneries Waste Disposal on Environment in Some Selected Areas of Dhaka City Corporation. Journal of Environmental Science and Natural Resources, 7(1), 149-156.

Wilson, B., \& Pyatt, F. B. (2007). Heavy metal dispersion, persistance, and bioccumulation around an ancient copper mine situated in Anglesey, UK. Ecotoxicology and Environmental Safety, 66(2), 224-31.

Zewdu, F., \& Amare, M. (2018). Determination of the level of hexavalent, trivalent, and total chromium in the discharged effluent of Bahir Dar tannery using ICP-OES and UV-Visible spectrometry. Cogent Chemistry, 4(1), 1534566. 



\title{
Link Budget Analysis in Designing a Web-application Tool for Military X-Band Satellite Communication
}

\author{
M. Akhtaruzzaman ${ }^{1 *}$, S. M. Sadakatul Bari², Syed Akhter Hossain³, and Md. Mahbubur Rahman4 \\ ${ }^{1}$ R\&D (Robotics) Section, DREAM Robotics Ltd., Dhaka, Bangladesh \\ 2Department of Computer Science and Engineering, Bangladesh Army University of Science and Technology, Saidpur, Bangladesh \\ 3Department of Computer Science and Engineering, Daffodil International University, Dhaka, Bangladesh \\ ${ }^{4}$ Department of Computer Science and Engineering, Military Institute of Science and Technology, Dhaka, Bangladesh \\ emails: ${ }^{* 1}$ akhter900@gmail.com; ${ }^{2}$ sadakatul@baust.edu.bd; ${ }^{3}$ aktarhossain@daffodilvarsity.edu.bd; and ${ }^{4}$ mahbub@cse.mist.ac.bd
}

\section{ART ICLE IN F O}

Article History:

Received: $14^{\text {th }}$ March 2020

Revised: 06 $6^{\text {th }}$ May 2020

Accepted: 09th May 2020

Published online: 21 st July 2020

Keywords:

Link Budget

Military X-Band

Satellite communication

Web calculator

Link budget calculator

\begin{abstract}
A B S T RACT
In satellite communication, Link Budget analysis is the most important part to determine gains and losses of signals from the transmitter to the receiver. Most importantly, it investigates system performance and optimum power which must be received at the receiver channel. In some cases, this information could be generated, saved for past data analysis, and share with peer users which are not found in existing web tools. Thus, it is obvious to design a new Link Budget calculator with users, database, and data retrieval support. This work focuses on designing a Link Budget web tool for X-band satellite communication through literature study and comparative analysis. The X-Band calculator is designed based on HTML, PHP, Javascript, and MySQL by ensuring several security issues, and can be accessed through mobile devices. This paper also focuses on the necessary equations of Link Budget for Uplink (Tx); Satellite; Downlink $(\boldsymbol{R} \boldsymbol{x})$; Azimuth, Elevation, Distance analysis; and Rain attenuation. Though, comparative assessments among various web tools show some fluctuations, overall outputs show satisfactory results with small \% of Errors (PoE) ensuring reliability and viability of the proposed X-Band tool for practical use.
\end{abstract}

(c) 2020 MIJST, All rights reserved.

\section{INTRODUCTION}

The development of satellite technology and its applications are increasing continuously. X-band, known as Super High Frequency (SHF) Satellite Communication, is widely used for military applications while beyond line-of-sight communications are required. The wavelength range of SHF is $10 \mathrm{~cm}$ to $01 \mathrm{~cm}$ where frequency shows an increasing range from $03 \mathrm{GHz}$ to $30 \mathrm{GHz}$. Satellite frequency is considered in between the range of $01-40 \mathrm{GHz}$ where Lband (uses: GPS, satellite mobile, etc.) range is $01-$ $02 \mathrm{GHz}, \mathrm{S}$-band (uses: surface ship radar) range is $02-$ $04 \mathrm{GHz}$, C-band (uses: satellite communication, TV networks, etc.) range is $04-08 \mathrm{GHz}$. X-band is primarily used by the military such as Radar application, short-range tracking, weather monitoring, missile guidance, air traffic control, mapping marine radar, battlefield surveillance, airborne intercept, weapon location, vehicle speed detection for law enforcement (Cole, 2010; Nuroddin et al., 2013; Griffiths et al., 2015). The range of X-band frequency is $08-12 \mathrm{GHz}$ (data rates: $\sim 100 \mathrm{Mbit} \times \mathrm{s}^{-1}$ ). Other bands are Ku-band (range: $12-18 \mathrm{GHz}$; usage: satellite communication), K-band (range: $18-26 \mathrm{GHz}$ ), and Ka- band (range: $26-40 \mathrm{GHz}$; data rates: $>150 \mathrm{Mbit}^{-1} \mathrm{~s}^{-1}$, uses: close-range targeting radars on military aircraft) (Griffiths et al., 2015).

Rapid access to information (RAtI) service has become a global need that can be supported through a wireless communication system. For the military state communication, RAtI is obvious which employs link budget calculations. This paper presents a link budget calculation tool to quantify link performance for military X-band satellite communication. According to the literature study, most of the tools developed so far are for research and study purpose and most of the tools need a special setup (MATLAB, VB, or Spreadsheet). Moreover, available tools are not capable to present necessary calculations in a single window, provide user support, save and retrieval facilities. As a solution to these issues, this study presents the design of a new web application tool for link budget quantification.

\section{BACKGROUND STUDY}

According to the recommendation of International Telecommunication Union (ITU) (ITU-R SA.1024), three primary bands are available at Earth Exploration-Satellite 
Service (EESS) for direct data transmission, which are, Sband $(2.200-2.290 \mathrm{GHz}), \mathrm{X}$-band $(8.025-8.400 \mathrm{GHz})$ and Ka-band $(25.500-27.000 \mathrm{GHz})$ (ITU, 2011). EESS mainly operates in NGSO (Non-geostationary Satellite Orbit) which includes Medium Earth Orbit (MEO) (altitude: $\sim 8000$ to $\sim 20000 \mathrm{~km}$ ) and Low Earth Orbit (LEO) (altitude: $\sim 400$ to $\sim 2000 \mathrm{~km}$ ). Transmission delay for Geo Stationary Orbit (GEO) Satellite is much higher $(\sim 500 \mathrm{~ms})$ comparing to EESS ( 10 ms) (Nizam, 2008; ITU, 2011; Karim, et al., 2018).

Recent research focuses on various kinds of satellites in terms of size, power, and mass, such as small-satellite $(\sim 500 \mathrm{~kg})$, mini-satellite $(500-100 \mathrm{~kg})$, micro-satellite $(100-10 \mathrm{~kg})$, nano-satellite $(10-1 \mathrm{~kg})$, and Femto- \& Pico-satellite $(<1 \mathrm{~kg})$ (Mir, et al., 2018). Several types of data are transmitted in a satellite network, which are text, voice, image, and video streaming. Link budget analysis is necessary for any kind of satellite to identify optimal parameters for link establishment as there are several gains and losses in transmitting data through free space and atmosphere. Some losses are constant, some losses depend on statistical data, and some losses vary because of weather conditions smog, snow, clouds, and specially rainfall (Mahmud \& Khan, 2009; Capela, 2012; Nuroddin et al., 2013; and Mir, et al., 2018). Classification of the main losses of satellite communication can be shown in Figure 1. Link budget presents some pre-calculations to predict performances prior to establishing links between satellite and earth station. Link budget presents acceptable links through comparisons among possible links.

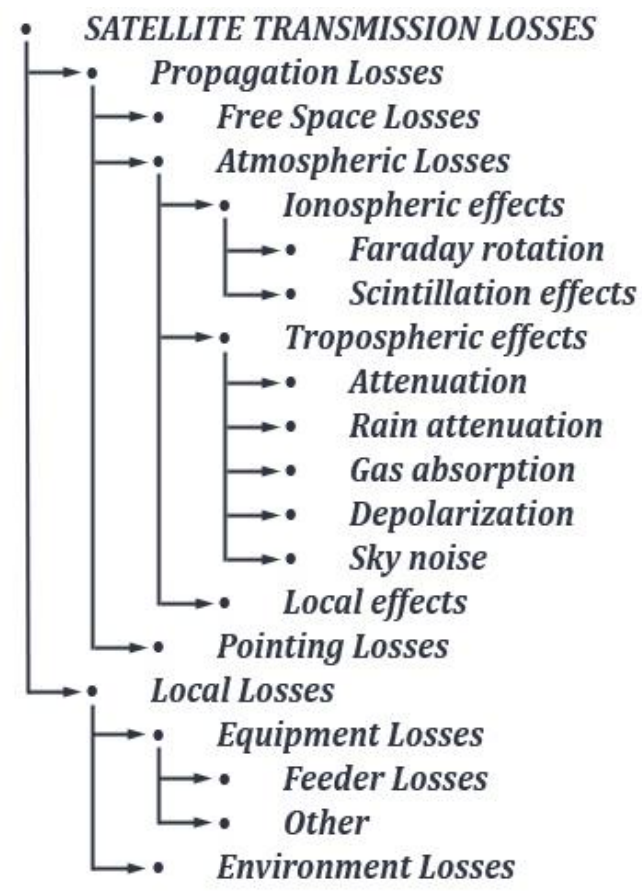

Figure 1: Classification of main losses of satellite communication (Capela, 2012; Zhiger, 2017; Ismail et al., 2017)

MATLAB based link budget calculator is presented in a recent research by Ya'acob et al. (2018) to calculate all the gains and losses of the telecommunication system from a transmitter to receiver through the used medium. This calculator is able to calculate several parameters such as Effective Isotropic Radiated Power (EIRP), effective aperture, path loss, free space path loss, physical aperture, flux density, transmit gain, transmit power, receive gain, receive power, noise temperature ratio, noise density ratio, etc. Another study on developing software tool was conducted for the configuration and calculation of link budget to broadcast multimedia services for GEO Satellite in Ka-band (Mebrek et al., 2012). This software tool was designed and developed based on MATLAB 7.8 by focusing mainly on four separate modules, Uplink, Downlink, Depointing angle, and De-pointing losses, with some other related calculation facilities. A study conducted by AlDalowi, Khoshnaw, and QasMarrogy (2017) presented another MATLAB based tool to calculate net power transmitted by the earth station where losses and attenuation were considered in the link budget calculation. The study also focused on the factors that affect the receiver signals, signal gains and losses. The MATLAB based tool is designed to get all the necessary calculated parameters in a single screen. Visual Basic (VB) programming language was used in another software development project by Yulianto (2012) where a link budget calculator was introduced which includes calculation of Receiver Signal Level (RSL), Free Space Loss (FSL), Cable Loss, EIRP, Fresnel Zone Clearance (FZC), and System Operating Margin (SOM).

The main process of transmitting a signal from earth station to satellite can be described as: signal modulation (changing the form of a signal), converting the band (L-band to C, X, or $\mathrm{Ku}$-band), amplifying signals (increasing amplitude and power), directing the signals to the satellite by using reflector antenna providing extra gain comparing with the isotropic radiation (power flux density), and the signal radiates in the given direction with antenna gain (GT) (AlDalowi, Khoshnaw, \& QasMarrogy, 2017). A detailed explanation of the theoretical calculation of the link budget of satellite communication is presented in KYMETA (2019). Depending on the flow of information, the link budget can be analyzed for three types of links: Forward (FWD) link, Simple return (RTN) link, and Complex return (RTN) link. Figure 2 presents the direction of data flow among userterminal, hub, and Satellite.

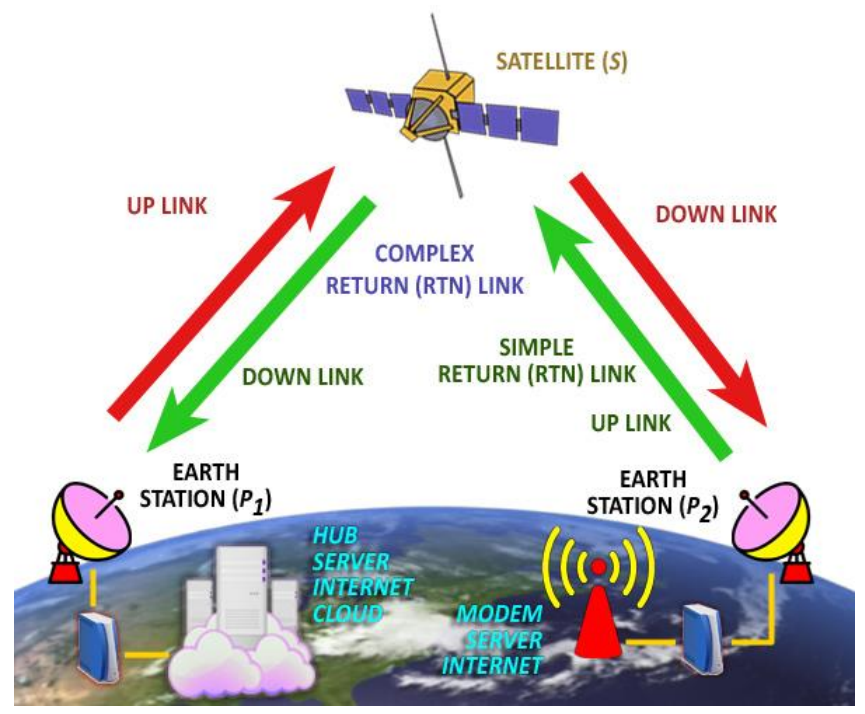

Figure 2: Direction of data flow through FWD \& RTN Links

Simplest calculation is needed for the FWD link as the hub can produce necessary uplink power to drive the FWD carrier up to the transponder limit of the satellite. As a result, for the FWD link budget analysis, only a portion of the link can be considered which basically connects the satellite and 
the user. A simple RTN link presents the up-link between user-terminal and satellite. It does not require any parameter of satellite or hub. Complex RTN link is considered as the total return link from terminal to satellite and satellite to the hub. Power received by the satellite from the terminal is not enough to drive the signal from the satellite to the hub and needs to be amplified. Signal to noise ratio (SNR) also needs to be calculated accurately for both links: terminal-satellite and satellite-hub links (KYMETA, 2019).

\section{LINK BUDGET ANALYSIS}

\section{A. Parameters of Transmitter Antenna}

Parameters of the transmitter antenna include the calculation of Wavelength, Antenna aperture, EIRP, Path loss, and C/N Ratio (CNR).

\section{i. Wavelength $(\tilde{\lambda})$}

Main properties of a wave signal (Electro-Magnetic Wave $(\operatorname{EMW}))$ are velocity $(\tilde{v})$, frequency $(f)$, and wavelength $(\tilde{\lambda})$. The velocity of EMW indicates the distance propagate over unit time, i.e. meter per second (how fast does a wave signal propagates in a certain medium). Speed of radio wave or light in a vacuum is indicated by $c$ and measured as $c=$ $299792458 \mathrm{~m} / \mathrm{s} \approx 300 \times 10^{6} \mathrm{~m} / \mathrm{s}$. Frequency indicates the number of complete vibrations of a particle of a certain medium while a wave signal is passing through, i.e. number of complete cycles per second (Hertz or $1 /$ second). Wavelength refers to the physical distance of a complete cycle of a wave signal which is measured in meters. The wavelength of a signal depends on the medium it travels through. Wavelength $(\tilde{\lambda})$ of EMW can be calculated based on the following formula as presented in Equation (1) (Mahmud \& Khan, 2009; Mir et al., 2018).

$\tilde{\lambda}=c / f$

\section{ii. Efficient Area of Transmitter Antenna}

Efficient area of Transmitter Antenna or Antenna Aperture (effective aperture, $A_{e T x}$ ) can be calculated using Equation (2) where $A_{T x}$ is the physical area, $r_{T x}$ is the radius, and $d_{T x}$ is the diameter of the antenna (Stutzman, 1998; Yaacob et $a l ., 2018)$. The efficiency of the antenna is presented by $\varepsilon_{T x}$. Antenna efficiency is determined based on the emitting capability of energy into the air.

$A_{e T x}=A_{T x} \varepsilon=\pi r_{T x}^{2} \varepsilon_{T x}=\pi\left(\frac{d_{T x}}{2}\right)^{2} \varepsilon_{T x}$

iii. Antenna Gain $\left(G_{T x}\right)$

Antenna Gain $\left(G_{T x}\right)$ can be calculated by using Equation (3) (Mahmud \& Khan, 2009; Ismail et al., 2017). Antenna gain presents the amount of radiated energy in a specific direction comparing with the amount of radiated energy of isotopic antenna in the same direction. In Equation (3), $\varepsilon_{T x}$ is antenna efficiency and $d_{T X}$ is the diameter of the transmitter antenna.

$G_{T x}=10 \log _{10}\left(\varepsilon_{T x}\left(\frac{\pi d_{T x}}{\tilde{\lambda}}\right)^{2}\right)$

\section{iv. Effective Isotropic Radiated Power (EIRP)}

The maximum amount of radiated power of the ideal isotropic antenna in a specific direction is called Effective Isotropic Radiated Power or Equivalent Isotropically Radiated Power (EIRP). EIRP can be calculated by Equation (4) which indicating summation of Antenna gain $\left(G_{T x}\right)$ and Forward power $\left(P_{f w d}\right)$ (Yulianto, 2012; Ismail et al., 2017; and Mir et al., 2018). Forward power is identified by the subtraction of Cable Loss $\left(L_{C T X}\right)$ from Transmitter output power $\left(P_{T x}\right)\left(P_{f w d}=P_{T x}-L_{C T x}\right)$. Measuring unit of EIRP is $d B i$ (decibels over isotropic).

$E I R P=G_{T x}+P_{f w d}=G_{T x}+\left(P_{T x}-L_{C T x}\right)$

\section{v. Path Loss or Free Space Path Loss (FSPL)}

FSPL is a kind of signal strength failure while electromagnetic wave travels through free space for a line of sight communication. Most of the radio frequency (RF) evaluations and dimensions are measured in the unit of decibels $(d B)$. FSPL can be calculated as presented in Equation (5) (Mahmud \& Khan, 2009; CS, 2016; and KYMETA, 2019). Here the distance of the satellite from the Earth station (Earth surface) is indicated as $d$ (or the distance from the transmitter to receiver in $\mathrm{km}$ ), and $f$ is the frequency in $\mathrm{MHz}$. Figure 3 presents behavioral graphs of FSPL on the variation of distance $(d)$ between Earth station and satellite for various frequencies of $\mathrm{X}$-band communication ranging from $8 \mathrm{GHz}$ to $12 \mathrm{GHz}$.

$F S P L=20\left(\log _{10} f+\log _{10} d\right)+32.44$

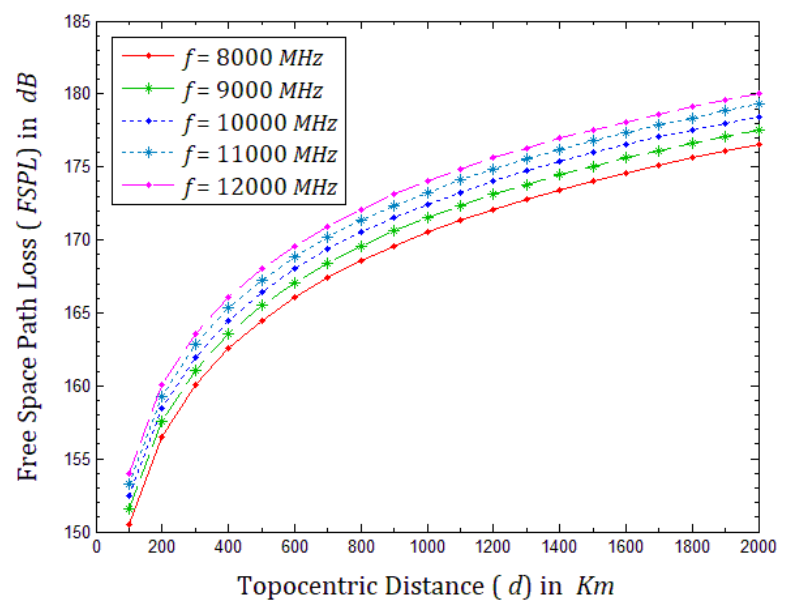

Figure 3: Behavior of FSPL over the variation of Topocentric distance (distance between Earth station \& Satellite) $(d)$ in range of X-band frequency $(f)(8 \mathrm{GHz}$ to $12 \mathrm{GHz}$ ) (Mahmud \& Khan, 2009; Song, \& Schnieder, 2019)

\section{v. Uplink C/N Ratio (CNR $\left.R_{T x}\right)$}

The carrier-to-noise ratio is written as $C N R$ or $\mathrm{C} / \mathrm{N}$ ratio. The term Signal-to-noise ratio $(S N R)$ is often used in some cases instead of $C N R$. To calculate uplink C/N Ratio $\left(C N R_{T x}\right)$ Equation (6) is used (KYMETA, 2019). Bandwidth is indicated by $b w$ in $\mathrm{Hz}, L_{a t m}$ is an atmospheric loss, $k_{\text {bolt }}$ is Boltzmann constant $\left(k_{\text {bolt }}=-228.6\right), G T_{T x}$ is gain to noise temperature or figure-of-merit of transmitter antenna, and $T_{T X}$ is system noise temperature.

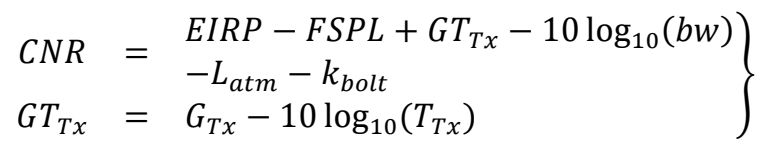

\section{B. Calculation of Satellite PFD}

Satellite power flux density (PFD) can be calculated based on the Equation (6) (Elbert, 2004; KYMETA, 2019).

$P F D=E I R P-10 \log _{10}\left(4 \pi d^{2}\right)$

Here, $d$ is the distance from the transmitter to receiver or path length and $b w$ is the reference bandwidth in $\mathrm{Hz}$. PFD 
presents the power per unit of bandwidth on the Earth surface.

\section{Azimuth ( $\alpha$ ) and Distance Analysis}

A maximum signal can be received by the earth station if it points the satellite directly. This can be ensured based on antenna look angles, which are: Azimuth angle $(\alpha)$ and Elevation angle $(\vartheta)$ (Cakaj, Keim, \& Malarić, 2007; Geyer, 2016). Azimuth is the clockwise angle created by an on-orbit satellite with North around an Earth station; and Elevation is defined as the angle at an Earth station created by the height of the on-orbit celestial body from the local horizon of the station. Figure 4 presents the concept of Azimuth angle $(\alpha)$ and Elevation angle $(\vartheta)$ of an Earth station $(P)$.

Azimuth angle $(\alpha)$ can be calculated by taking inverse tangent of the ratio of East $(e)$ and North $(n)$ as presented in Equation (7) for the $(e, n, u)$ coordinate frame.

$$
\alpha=\tan ^{-1}(e / n)
$$

Though the spherical earth model is used for analysis, the shape of the earth is mostly accepted as oblate spheroid (an ellipse moving in a circle about the minor axis) (Geyer, 2016). Because of the elliptical spheroid shape, simple calculation as in Euclidian space cannot be used, rather spherical geometry must be considered. Various methods such as, Haversine formula, Napier's cosine rule, Rightspherical triangle, Spherical trigonometry, etc. are applied by various researchers (Soler \& Eisemann, 1994; Mantoro, Akhtaruzzaman, Mahmud, \& Ayu, 2015; and Geyer, 2016).

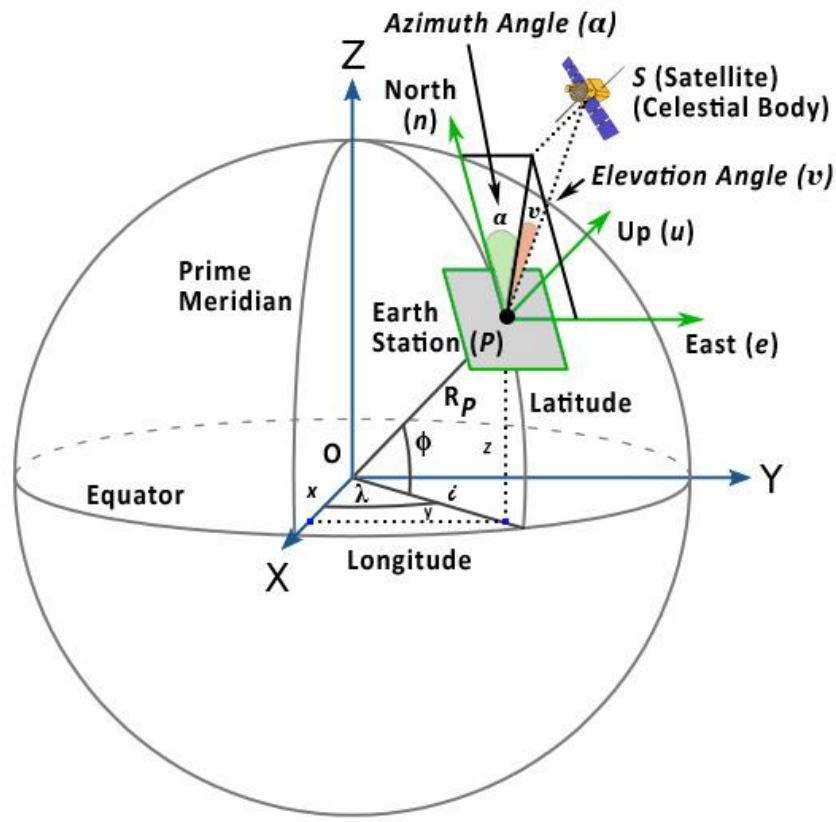

Figure 4: Conceptual Earth model for calculating Azimuth angle $(\alpha)$ and Elevation angle $(v)$ of Earth Station $(P)$ for pointing a Celestial Body $(S)$ (Soler \& Eisemann, 1994; Wang, Huynh, \& Williamson, 2013)

According to Geodetic Reference System 1980 (GRS-80) \& World Geodetic System 1984 (WGS-84), two important geometric parameters of Earth Spheroid are size $(a)$ and shape $(\zeta)$. Here $a$ is indicating the semi-major axis of Earth ( $a=6,378,137 \mathrm{~m}$ ) and $\zeta$ is indicating the flattening parameter of Earth shape $\left(\zeta^{-1}=298.257,223,563\right.$ ) (Soler $\&$ Eisemann, 1994; and Geyer, 2016). The semi-minor axis is indicated by $b(b=6,356,751 \mathrm{~m})$.
All the necessary calculations at the point of Earth station $(P)$ are with respect to the local geodetic coordinate system; East $(e)$, North $(n)$, and Up $(u)$ (Figure 4); which can be presented as $(e, n, u)$ coordinate at point $P$. Depending on the $(e, n, u)$ coordinate system, the components of PS (Earth station to Satellite in Figure 4) needs to be transformed into the components along $(x, y, z)$ coordinate frame at point $P$, which is parallel to the geocentric reference frame at point $O$. This transform can be performed by multiplying a rotational matrix $[R]$ as presented in Equation (8) (Soler, 1976; Soler \& Eisemann, 1994; and Wang, Huynh, \& Williamson, 2013).

$[R]=\left[\begin{array}{ccc}-\operatorname{Sin} \lambda & \operatorname{Cos} \lambda & 0 \\ -\operatorname{Sin} \phi \operatorname{Cos} \lambda & -\operatorname{Sin} \phi \operatorname{Sin} \lambda & \operatorname{Cos} \phi \\ \operatorname{Cos} \phi \operatorname{Cos} \lambda & \operatorname{Cos} \phi \operatorname{Sin} \lambda & \operatorname{Sin} \phi\end{array}\right]$

Thus, the equation of $(e, n, u)$ coordinate becomes, as presented in Equation (9). Here $\left(x_{s}, y_{s}, z_{s}\right)$ and $\left(x_{p}, y_{p}, z_{p}\right)$ are the coordinates of Satellite $(S)$ and Earth station $(P)$.

$\left[\begin{array}{l}e \\ n \\ u\end{array}\right]=[R]\left[\begin{array}{l}x \\ y \\ z\end{array}\right]=[R]\left\{\left[\begin{array}{l}x_{s} \\ y_{s} \\ z_{s}\end{array}\right]-\left[\begin{array}{l}x_{p} \\ y_{p} \\ z_{p}\end{array}\right]\right\}$

The rectangular coordinate $(x, y, z)$ of Earth station $(P)$ and Satellite $(S)$ can be calculated based on the well-known curvilinear geodetic expressions as presented in Equation (10) (Soler, 1976; Soler \& Eisemann, 1994; Geyer, 2016; Panou, Korakitis, \& Delikaraoglou, 2018; and Medvedev et al., 2018). Here, $N$ is indicating the principal radius (Prime Vertical Radius) of curvature which is determined using Equation (11) (Geyer, 2016; Panou, Korakitis, \& Delikaraoglou, 2018; and Medvedev et al., 2018). Geodetic height (Ellipsoidal height) is indicated by $H_{P}$.

$\left[\begin{array}{l}x \\ y \\ Z\end{array}\right]=\left[\begin{array}{c}\left(N+H_{P}\right) \operatorname{Cos} \phi \operatorname{Cos} \lambda \\ \left(N+H_{P}\right) \operatorname{Cos} \phi \operatorname{Sin} \lambda \\ {\left[N\left(1-\sigma^{2}\right)+H_{P}\right] \operatorname{Sin} \phi}\end{array}\right]$
$N=a / \sqrt{\left(1-\sigma^{2} \operatorname{Sin}^{2} \phi\right)}$

The eccentricity of the Earth ellipsoid is presenting by $\sigma$. Square of the eccentricity $(\sigma)$ is used in most of the cases of calculation and is presented in Equation (12). Equation (13) and Equation (14) are presenting necessary formulas and values of the flattening parameter of Earth shape $(\zeta)$ and other parameters.

$\sigma^{2}=\frac{a^{2}-b^{2}}{a^{2}}=\zeta(2-\zeta)$

$\zeta=\frac{a-b}{a}$

$a=$ semimajor axis $=6,378,137 \mathrm{~m}$

$\zeta^{-1}=298.257,223,563$

$b=$ semiminor axis $=(1-\zeta) a=6,356,751 \mathrm{~m}$

$\sigma^{2}=0.006,694,379,990,14$

Depending on Equation (10), geodetic longitude $(\lambda)$ and latitude $(\phi)$ of Earth station $(P)$ can be obtained from the elements of the matrix, as presented in Equation (15) where, $i$ is the horizontal projection of $R_{P}$ as shown in Figure $4, R_{P}$ (Geocentric radius) is the distance of Earth station $(P)$, and $\alpha_{\text {rad }}$ is the radian value of azimuth angle $(\alpha)$ (Panou, Korakitis, \& Delikaraoglou, 2018; and Medvedev et al., 2018). 


$$
\left.\begin{array}{l}
\lambda=\tan ^{-1}\left(\frac{y}{x}\right) \\
\phi=\tan ^{-1}\left(\frac{z}{i}\right) \\
i=\sqrt{x^{2}+y^{2}}=\left(N+H_{P}\right) \operatorname{Cos} \phi \\
R_{P}=\sqrt{i^{2}+z^{2}}=\left(N+H_{P}\right) \\
\alpha_{\text {rad }}=\alpha(\pi / 180)
\end{array}\right\}
$$

Three concepts of Earth radius can be formulated as the function of latitude $(\phi)$ as presented in Equation (16). Thus, the Earth radius varies if the $\phi$ changes. Figure 5 shows the characteristic graphs of three types of radii: Geocentric, Meridional, and Prime vertical; where latitude changes from $0^{\circ}$ to $90^{\circ}$. In this study, the prime vertical radius concept is applied for most of the calculations.

$$
\left.\begin{array}{rl}
R(\phi) & =\left(\frac{\left(a^{2} \cos \phi\right)^{2}+\left(b^{2} \sin \phi\right)^{2}}{(a \cos \phi)^{2}+(b \sin \phi)^{2}}\right)^{1 / 2} \\
M(\phi) & =\frac{a\left(1-\sigma^{2}\right)}{\left(1-\sigma^{2} \sin ^{2} \phi\right)^{3 / 2}} \\
N(\phi) & =\frac{a}{\left(1-\sigma^{2} \sin ^{2} \phi\right)^{1 / 2}}
\end{array}\right\}
$$

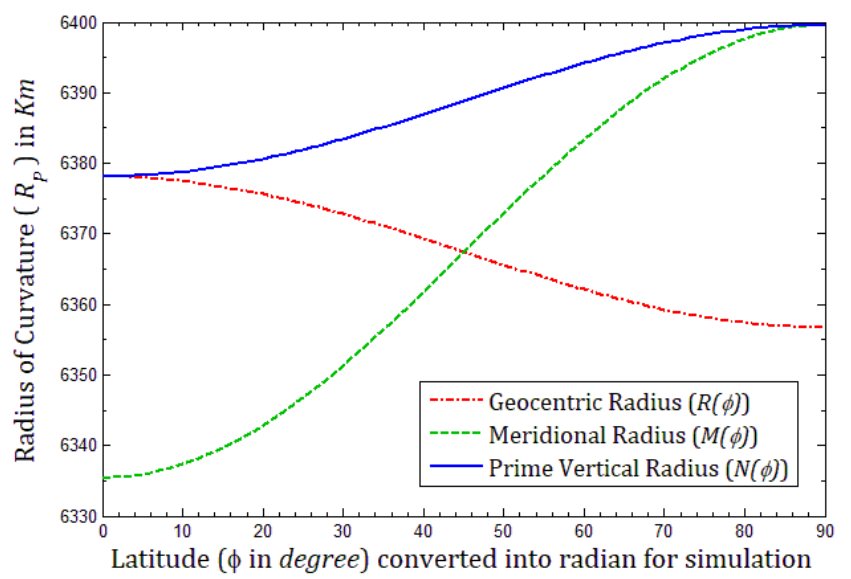

Figure 5: Characteristics of radius changes in the variation of Latitude $(\phi)$ from $0^{\circ}$ to $90^{\circ}$; Geocentric $R(\phi)$, Meridional $M(\phi)$, and Prime Vertical $N(\phi)$ Radiuses. In this study, the prime vertical radius is considered (Geyer, 2016).

Azimuth angle $(\alpha)$ and point to point distance (topocentric distance, $d$ ) between earth station $(P)$ and celestial body $(S)$ can also be determined by using the spherical geometric approximation as presented in Figure 6 . Here, $P, \lambda$, and $\phi$ are presenting the position, Longitude, and Latitude of Earth station. The straight-line distance $O S$ between Geo-center $(O)$ and Satellite $(S)$ intersects the Earth Equator at point $U$ is indicated as the sub-satellite point on Earth surface. From triangle $\triangle S O P$, distance $d$ (topocentric distance) is possible to determine by Equation (17) where $r(O S)$ and $R_{P}(O P)$ can be known from Equation (10). Here, $r$ represents the geocentric distance of Satellite $(S)$ from Earth center $(O)$.

Now, by applying Napier's rules on the spherical rightangled triangle $(\triangle U V P)$, the angle $\gamma(\angle U O P)$ can be determined by applying the cosine rule as shown in Equation (18) (Soler \& Eisemann, 1994; Hyde \& Bargellini, 2002). It is important to know that, in the triangle $\triangle U V P ; \angle P V U=$ $90^{\circ}, \angle P V O=90^{\circ}$, and $\angle P U O=90^{\circ}$. Figure 7 explains that the Azimuth angle $(\alpha)$ is a function of angle $\beta$. By applying Napier's rule, $\angle \beta$ can be calculated as presented in Equation (19) (Soler \& Eisemann, 1994; Hyde \& Bargellini, 2002; Geyer, 2016). Possible calculation of $\alpha$ as a function of
Satellite location coordinate (function of angle $\beta$ ) on the horizon of Earth station $(P)$ is presented in Figure 7; if Satellite is in $N E$ (North-East) coordinate with respect to Earth station, $\alpha$ is equal to $\beta(\alpha=\beta)$; for $S E$ (South-East) coordinate, $\alpha=180^{\circ}-\beta$; for $S W$ (South-West) coordinate, $\alpha=180^{\circ}+\beta$, and for $N W$ (North-West) coordinate, $\alpha=$ $2\left(180^{\circ}\right)-\beta$.

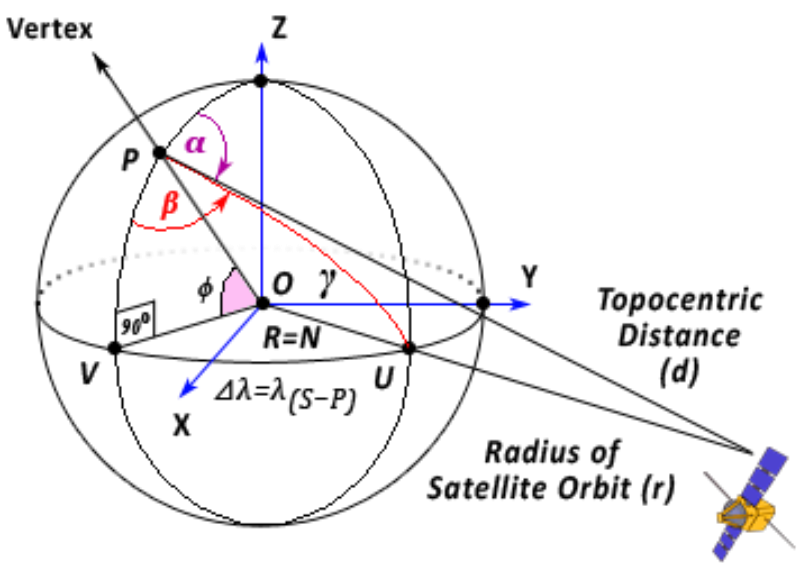

EARTH

Satellite (S)

(Conceptual Model)

\section{Spherical geometric approximation of EARTH model \\ [Determining Azimuth Angle $(\alpha)$ as a function of $\beta$ ].}

Figure 6: Spherical geometric approximation to determine Azimuth angle $(\alpha)$ as a function of angle $\beta$ and the location of Satellite $(S)$ with respect to Earth station $(P)$ (Soler \& Eisemann, 1994; Hyde \& Bargellini, 2002; Roddy, 2006)

$d=\sqrt{\left(r^{2}+R_{p}^{2}-2 r R_{p} \operatorname{Cos} \gamma\right)}$

$\operatorname{Cos} \gamma=\operatorname{Cos} \phi \operatorname{Cos}\left(\lambda_{s}-\lambda\right)$

$\beta=\operatorname{Cos}^{-1}(\operatorname{Cot} \gamma \operatorname{Tan} \phi)$

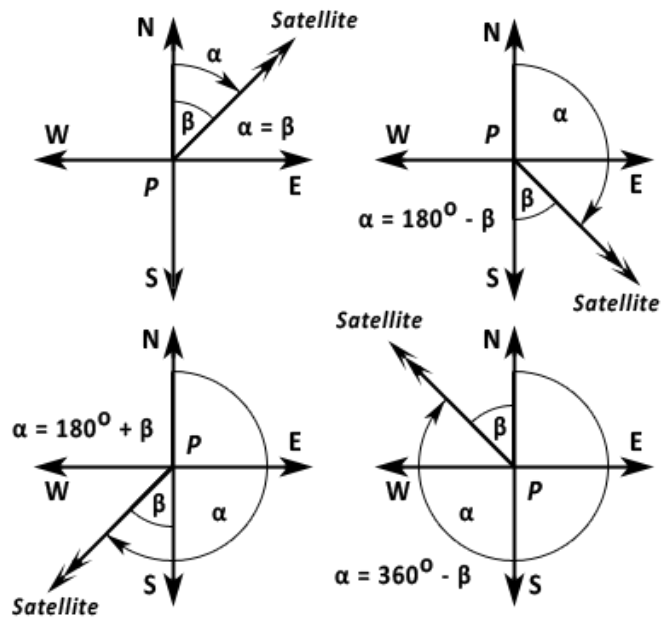

Figure 7: Concept of Azimuth angle $(\alpha)$ as a function of the location of Satellite $(S)(\angle \beta)$ with respect to Earth station $(P)$

(Soler \& Eisemann, 1994; Roddy, 2006)

\section{Rain Attenuation Analysis}

Rain attenuation refers to the degradation of Microwave Radio Frequency (MRF) signal caused by the electromagnetic interference of atmospheric rain, snow, or 
ice. Attenuation can be influenced a lot for the frequency band $10 \mathrm{GHz}$ or more by the rain and precipitation (Kestwal, 2014; Shrestha \& Choi, 2017). The phenomenon of rain attenuation is related to the amount of rainfall and frequency which leads to increasing path loss, restricting the scope of coverage, thus debasing the system performance. Communication for wireless networks depends on several parameters such as, elevation angle $(\vartheta)$ of Earth station, path loss, specific and predicted attenuation.

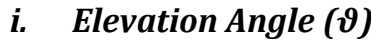

The elevation angle of the earth station is defined by the angle $v$ of the antenna created by the height of Satellite $(S)$ from the local horizon of the earth station $(P)$, the concept is presented earlier in Figure 4 (Soler \& Eisemann, 1994). Rain attenuation also depends on the Elevation angle which can be calculated by Equation (20) for the $(e, n, u)$ coordinate frame of point $P$ (Figure 4 ).

$\vartheta=\tan ^{-1}\left(\frac{u}{\sqrt{e^{2}+n^{2}}}\right)$

\section{ii. Slant Path Length $\left(L_{s}\right)$}

Slant path through rain depends on the Elevation angle of Earth station; low Elevation angle means long Slant path thus rain has more effect and causes high rain attenuation. Concept of slant path length $\left(L_{s}\right.$ in $\left.\mathrm{km}\right)$ as the function of rain height and elevation angle is presented in Figure 8. According to the figure, $L_{s}$ will be greater for lesser elevation angle $(\vartheta)$; such as, $L_{s 1}>L_{s 3}$ for Earth station $\left(P_{1}\right)$ to Satellite $S_{1}$ and $S_{2}$ as $\vartheta_{1}<\vartheta_{2}$. Slant Path Length $\left(L_{S}\right)$ can be calculated by using Equation (21) (Kanellopoulos, 2000; ITU-R, 2003a; Adhikari et al., 2011; Nuroddin et al., 2013; Lwas, et al., 2015; Shrestha, \& Choi, 2017, 2019; and Hossain \& Islam, 2017; Fadilah, \& Pratama, 2018). Rain height and the average height of Earth station $(P)$ above sea level are presented as $H_{r}$ and $H_{P}$. Horizontal projection $\left(L_{g}\right)$ of slant path length is calculated based on Equation (22) (ITU-R, 2003a; Adhikari et al., 2011; Nuroddin et al., 2013; Hossain \& Islam, 2017; Fadilah, \& Pratama, 2018).

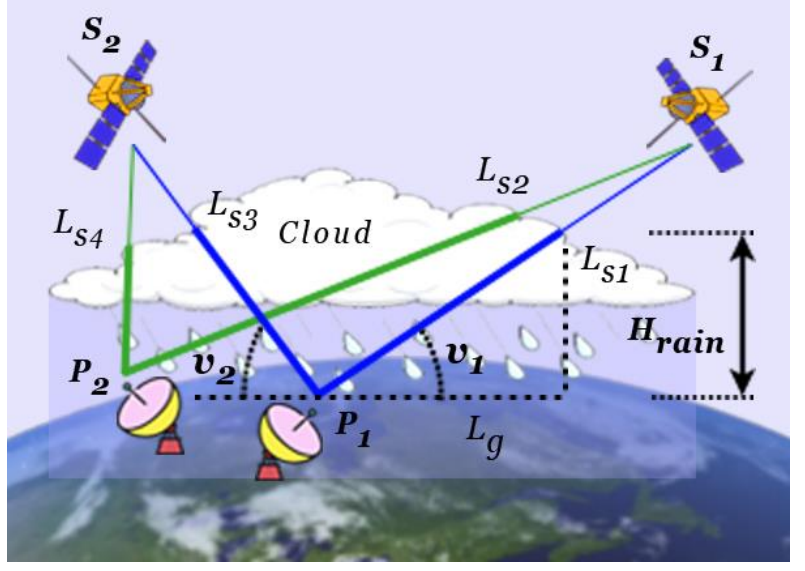

Figure 8: Concept of Slant Path and Slant Path Length $\left(L_{S}\right)$ as a function of Elevation angle $(\vartheta)$ and Rain height $\left(H_{r}\right)$ (ITU-R, 2003a; Adhikari et al., 2011; Nuroddin et al., 2013; and Hossain \& Islam, 2017)

$L_{S}=\left(H_{r}-H_{P}\right) / \sin \vartheta$

$L_{g}=L_{S} \cos \vartheta$

\section{iii. Specific Attenuation $\left(A_{S}\right)$}

Specific attenuation $\left(A_{S}\right)$ indicates the rain attenuation per unit distance $(\mathrm{dB} / \mathrm{km})$. It is a fundamental element in calculating rain attenuation for a slant path. Model of predicted rain attenuation also depends on the value of $A_{S}$. Specific attenuation can be determined by using the powerlaw as presented in Equation (23) (Ippolito, 1986; Nuroddin et al., 2013; Kestwal, Joshi, \& Garia, 2014; Hossain \& Islam, 2017; RACOM, 2018; Fadilah, \& Pratama, 2018; and Shrestha, \& Choi, 2017, 2019). Here, Rain rate presents rainfall rate in $\mathrm{mm}$ per hour exceeded for $0.01 \%$ of the average year which can be calculated from Equation (24) where Rain $_{\text {max }}$ is rainfall in $\mathrm{mm}$, and $T$ is the time interval in minutes (Kestwal, Joshi, \& Garia, 2014).

$A_{S}=k\left(\text { Rain }_{\text {rate }}\right)^{\omega}$

Rain $_{\text {rate }}=$ Rain $_{\text {max }}\left(\frac{60}{T}\right)$

If Rain $_{\text {rate }}$ is 0 (zero), there will be no attenuation (due to rainfall) for RF propagation. The values of $k$ and $\omega$ depend on frequency (range: 1 to $1,000 \mathrm{GHz}$ ) and polarization of electromagnetic (EM) wave. The values of these parameters can be calculated from Equation (25) which is derived from curve-fitting and power-law coefficients. Values of the necessary parameters can be obtained from the references included in the reference section (ITU-R, 2003b; ITU-R, 2005; Kestwal, Joshi, \& Garia, 2014).

$\left.\begin{array}{l}\log k=\sum_{j=1}^{4}\left(a_{j} \exp \left[-\left(\frac{\log f-b_{j}}{c_{j}}\right)^{2}\right]\right)+m_{k} \log f+c_{k} \\ \omega=\sum_{j=1}^{5}\left(a_{j} \exp \left[-\left(\frac{\log f-b_{j}}{c_{j}}\right)^{2}\right]\right)+m_{\omega} \log f+c_{\omega}\end{array}\right\}$

The values of $k$ and $\omega$ can also be determined through interpolation of the logarithmic scale for $k$ and linear for $\omega$. The popular equation for determining $k$ and $\omega$ is presented in Equation (26) (ITU-R, 2003b; ITU-R, 2005; Nuroddin et al., 2013; Yussuff, \& Khamis, 2013). These equations are used to determine specific rain attenuation for the designed Link Budget Tool for X-Band satellite communication as presented in this manuscript.

$\left.\begin{array}{l}k=\frac{\left(k_{H}+k_{v}+\left(k_{H}-k_{v}\right) \cos ^{2} \vartheta \cos 2 \tau\right)}{2} \\ \omega=\frac{k_{H} \omega_{H}+k_{v} \omega_{v}+\left(k_{H} \omega_{H}-k_{v} \omega_{v}\right) \cos ^{2} \vartheta \cos 2 \tau}{2 k}\end{array}\right\}$

Here $\vartheta$ is elevation angle and $\tau$ is polarization tilt angle relating to horizon values of frequency-dependent coefficients, $k_{H}, k_{v}, \omega_{H}$, and $\omega_{v}$ were determined from the listed values presented in the references; ITU-R (2003b), ITU-R (2005), Nuroddin et al. (2013), and Yussuff, \& Khamis (2013).

\section{iv. Effective Path Length $\left(L_{E}\right)$}

Effective path length $\left(L_{E}\right)$ is the average length of the slant path $\left(L_{S}\right)$ through the cell of uniform rain. Thus, $L_{E}$ is always smaller than $L_{S}$ which leads to the factors of vertical and horizontal path reduction (Mello \& Pontes, 2012). In this Link-budget tool design, the effective path length is calculated using Equation (27) (Nuroddin et al., 2013, Yussuff, \& Khamis, 2013; Abdullah, Ismail, Badron, \& Hashim, 2018).

$L_{E}=L_{R} v_{0.01}$ 
Here, $L_{R}$ is reduced path length and $v_{0.01}$ is a vertical adjustment factor (for over $0.01 \%$ of the average year). The value of $L_{R}$ depends on horizontal adjustment factor $\left(r_{0.01}\right)$ for over $0.01 \%$ of the average year and the value of new elevation angle $(\bar{\vartheta})$ which are determined from Equation (28) to Equation (32) (Nuroddin et al., 2013, Yussuff, \& Khamis, 2013; Zhiger, 2017; Abdullah, Ismail, Badron, \& Hashim, 2018). In Equation (32), $\chi$ is measured in degree and $\phi$ is the latitude of the earth station.

$$
\begin{aligned}
& r_{0.01}=\frac{1}{1+\left(0.78 \sqrt{\frac{\operatorname{Lg}_{S}}{f}}\right)-0.38\left(1-e^{-2 L g}\right)} \\
& \bar{\vartheta}=\tan ^{-1}\left(\frac{H_{r}-H_{P}}{L_{g} r_{0.01}}\right)
\end{aligned}
$$

$L_{R}= \begin{cases}\frac{L_{g} r_{0.01}}{\operatorname{Cos} \vartheta} & \text { if } \bar{\vartheta}>\vartheta \\ \frac{H_{r}-H_{P}}{\operatorname{Sin} \vartheta} & \text { if } \bar{\vartheta} \leq \vartheta\end{cases}$

$v_{0.01}=\frac{1}{1+\sqrt{\operatorname{Sin} \vartheta}\left(31\left(1-e^{-\left(\frac{\vartheta}{1+\chi}\right)}\right)\left(\frac{\sqrt{L_{R} A_{S}}}{f^{2}}\right)-0.45\right)}$

$\chi= \begin{cases}(36-|\phi|) & \text { if }|\phi|<36^{\circ} \\ 0 & \text { if }|\phi| \geq 36^{\circ}\end{cases}$

\section{ix. Predicted attenuation $\left(A_{p}\right)$}

Predicted rain attenuation $\left(A_{p}\right)$ exceeded for $0.01 \%$ of an average year can be calculated by Equation (33) where $A_{S}$ and $L_{E}$ are the specific attenuation and effective path length respectively. Effective path length vs. predicted attenuation graphs for various rain rates are presented in Figure 9.

$A_{p}=A_{S} L_{E}$

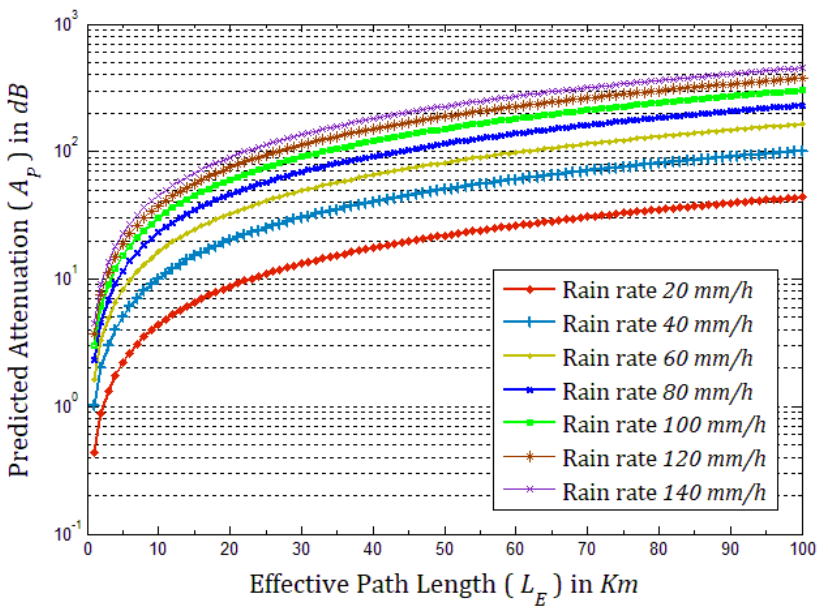

Figure 9: Predicted Attenuation $\left(A_{P}\right)$ behavior over the variation of Effective Path Length $\left(L_{E}\right)$ for various rain rate situation (Al-Saegh, et al., 2014; Panchal \& Joshi, 2016; Kestwal, Joshi, \& Garia, 2014)

\section{E. Parameters of Receiver Antenna}

Wavelength $(\tilde{\lambda})$, Efficient area of receiver antenna $\left(A_{e R x}\right)$, Receiver antenna gain $\left(G_{R x}\right)$, and Effective Isotropic Radiated Power $\left(E I R P_{S a t}\right)$ can be determined using equations from (1) to (4) where $\varepsilon_{R x}, d_{R x}$, and $P_{R x}$ should be used as efficiency, diameter of receiver antenna, and receiver power, respectively.

\section{i. Link Margin or Weather Margin $\left(W_{m}\right)$}

Link margin, Fade margin, or Weather margin $\left(W_{m}\right)$ defines the margin of safety of received signal power while a temporary attenuation or signal fading occurs at the receiver antenna. Determining the optimum link margin is very important because a small margin will make the link unstable and a large margin will make the link expensive. Though, selection of $W_{m}$ is an iterative and arbitrary process and depends on the knowledge of the designer, it is related to the receiver's sensitivity. Weather margin $\left(W_{m}\right)$ can be calculated by using Equation (34) (TRANZEO, 2010; CS, 2016; RACOM, 2018).

$W_{m}=P_{R x}-S_{R x}$

The power level $\left(P_{R x}\right)$ arrived at receiver as input signal can be derived by Equation (35). Receiver sensitivity $\left(S_{R x}\right)$ is related to the units of microvolt $(\mu V)$ which needs to be converted into unit of power $(\mathrm{dBm})$. The conversion method is presented in Equation (36) (CS, 2016), where $V$ is $r m s$ voltage of $\mu V, R_{\Omega}$ is the resistance of the system, and $\rho$ is a constant factor ( $\rho=30$ for RF320 series).

$P_{R x}=P_{T x}-L_{C T x}+G_{T x}-F S P L_{T x}+G_{R x}-L_{C R x}$

$S_{R x}=10 \log _{10}\left[\frac{\left(V 10^{-6}\right)^{2}}{R_{\Omega}}\right]+\rho$

\section{ii. Rx Antenna G/T $\left(G T_{R x}\right)$}

Earth station antenna gain-to-noise-temperature ( $G / T$ or $\left.G T_{R x}\right)$ is figure-of-merit which presents the performance of the receiver antenna (Capela, 2012). Value of $G / T$ is usually expressed in $d B K^{-1}$ and can be determined by Equation (37) (Al-Dalowi, Khoshnaw, \& QasMarrogy, 2017; KYMETA, 2019). Here $G_{R x}$ is antenna gain of receiver and $T_{R x}$ is system noise temperature.

$G T_{R x}=G_{R x}-\left(10 \log _{10} T_{R x}\right)$

\section{iii. Down Link Path Loss ( $\left.P L_{R x}\right)$}

Down link free space path loss $\left(L_{R x}\right)$ can be determined by Equation (38) (Elechi, \& Otasowie, 2016; Ranjan, et al., 2018). Here $d$ is indicating the distance of the satellite from the receiver antenna. Characteristic graphs of down link path loss of the X-band frequency range for the variation of Topocentric distance are shown in Figure 10.

$P L_{R x}=20 \log _{10}(4 \pi d / \tilde{\lambda})$

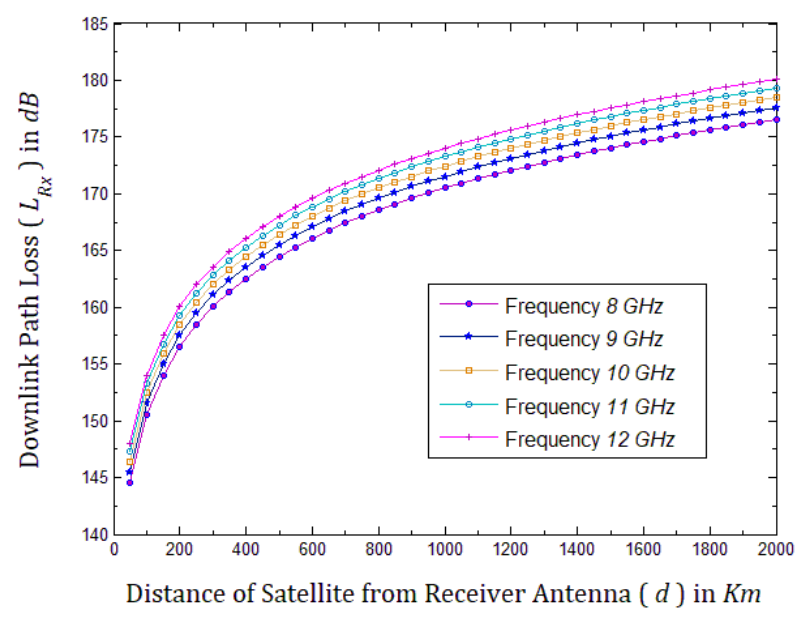

Figure 10: Characteristics of Downlink Path Loss $\left(P L_{R x}\right)$ over Topocentric distance $(d)$ for frequency ranges: $8 \mathrm{GHz}-12 \mathrm{GHz}$ (Bazzi, Giorgetti, Pasolini, \& Schena, 2005; Elechi, \& Otasowie, 2016; Ranjan, et al., 2018; Song, \& Schnieder, 2019) 


\section{iv. Down Link C/N Ratio $\left(C N R_{R x}\right)$}

Down link Career to Noise Ratio (downlink C/N Ratio or $C N R_{R x}$ ) can be ascertained by Equation (39) (Mebrek, Abderrahmane, Himeur, \& Bendoukha, 2012; KYMETA, 2019). Here, Boltzmann's constant is defined as $k_{\text {bolt }}=$ -228.6 , the atmospheric loss is indicated as $L_{a t m}$, and bandwidth is indicated as $b w$.

$$
C N R_{R x}=\begin{array}{ll}
E I R P_{S a t}-P L_{R x}-10 \log _{10}(b w) \\
-L_{C R x}+G T_{R x}-k_{b o l t}+W_{m}-L_{a t m}
\end{array}
$$

\section{DESIGN OF THE LINK-BUDGET TOOL}

Link analysis for satellite communication (link budget) is basically the theoretical study and mathematical modeling of the satellite system resembling the behavior of RF signal propagation and transmission. The analytical model comprised of some input parameters through which some output values are determined to predict some necessary parameters for the establishment of an RF satellite link. Table 1 presents input and output parameters that are necessary for satellite link budget analysis and design of the Link Budget web application tool.

Table 1

Parameters in designing Link Budget Tool for military X-band satellite communication

\begin{tabular}{|c|c|c|}
\hline $\begin{array}{l}\text { ANALYSIS } \\
\text { POINTS } \\
\end{array}$ & $\begin{array}{c}\text { INPUT } \\
\text { PARAMETERS } \\
\end{array}$ & $\begin{array}{c}\text { OUTPUT } \\
\text { PARAMETERS } \\
\end{array}$ \\
\hline $\begin{array}{l}\text { TRANSMITTER } \\
\text { ANTENNA }\end{array}$ & $\begin{array}{l}\text { Speed of light }(c) \text {, } \\
\text { Frequency }(f) \text {, } \\
\text { Diameter }\left(d_{T x}\right) \text {, } \\
\text { Efficiency }\left(\varepsilon_{T x}\right) \text {, } \\
\text { Output power }\left(P_{T x}\right) \text {, } \\
\text { Cable loss }\left(L_{C T x}\right) \text {, } \\
\text { Distance: Antenna to Satellite }(d) \text {, } \\
\text { Boltzmann cons. }\left(k_{\text {bolt }}\right) \text {, } \\
\text { Bandwidth }(b w)\end{array}$ & $\begin{array}{l}\text { Wavelength }(\tilde{\lambda}) \text {, } \\
\text { Effective area }\left(A_{e T x}\right), \\
\text { Gain }\left(G_{T x}\right) \text {, } \\
E I R P, \\
F S P L, \\
G T_{T x} \\
\text { Uplink C/N ratio } C N R_{T x}\end{array}$ \\
\hline SATELLITE & $E I R P, \& d$ & Satellite Power Flex Density $(P F D)$ \\
\hline $\begin{array}{l}\text { AZIMUTH AND } \\
\text { DISTANCE }\end{array}$ & $\begin{array}{l}\text { Antenna position }\left(x_{p}, y_{p}, z_{p}\right) \text {, } \\
\text { Satellite position }\left(x_{s}, y_{s}, z_{s}\right) \text {, } \\
\text { Rotation Matrix }[R] \text {, } \\
\text { Latitude }(\phi) \text {, } \\
\text { Longitude }(\lambda) \text {, } \\
\text { Geodetic height }\left(H_{P}\right)\end{array}$ & $\begin{array}{l}(e, n, u) \text { coordinate, } \\
\text { Azimuth angle }(\alpha) \text {, } \\
\text { Principal radius }(N) \text {, } \\
\text { Eccentricity }(\sigma) \text {, } \\
\text { Flattening }(\zeta) \text {, } \\
\text { Topocentric dist. }(d) \text {, } \\
\text { Angle }(\angle \beta)\end{array}$ \\
\hline $\begin{array}{l}\text { RAIN } \\
\text { ATTENUATION }\end{array}$ & $\begin{array}{l}(e, n, u) \text { coordinate, } \\
\text { Rain height }\left(H_{r}\right), \\
\text { Geodetic height }\left(H_{P}\right), \\
\text { Rain rate }\left(\text { Rain }_{\text {Rate }}\right) \text {, } \\
\text { Polarization factors }(k), \\
\text { Constant coefficient }(\omega) \text {, } \\
\text { Principal radius }(N)\end{array}$ & $\begin{array}{l}\text { Elevation angle }(\vartheta) \text {, } \\
\text { Slant path length }\left(L_{S}\right) \text {, } \\
\text { Horizontal projection }\left(L_{g}\right) \text {, } \\
\text { Specific attenuation }\left(A_{S}\right) \text {, } \\
\text { Effective path length }\left(L_{E}\right) \text {, } \\
\text { Reduced path length }\left(L_{R}\right) \text {, } \\
\text { Horizontal \& vertical adjustment factors }\left(r_{0.01} \& v_{0.01}\right) \text {, } \\
\text { Predicted attenuation }\left(A_{P}\right)\end{array}$ \\
\hline $\begin{array}{l}\text { RECEIVER } \\
\text { ANTENNA }\end{array}$ & $\begin{array}{l}\text { Transmitter power }\left(P_{T x}\right) \text {, } \\
\text { Transmitter \& receiver cable loss }\left(L_{C T x} \& L_{C R x}\right) \text {, } \\
\text { Transmitter gain }\left(G_{T x}\right) \text {, } \\
F S P L_{T x} \text {, } \\
\text { RMS of } \mu V(V) \text {, } \\
\text { Constant factor }(\rho) \text {, } \\
\text { System resistance }\left(R_{\Omega}\right) \text {, } \\
\text { System noise temperature }\left(T_{R x}\right) \text {, } \\
\text { Topocentric dist. }(d) \text {, } \\
\text { Boltzmann's constant }\left(k_{b o l t}\right) \text {, } \\
\text { Atmospheric loss }\left(L_{a t m}\right)\end{array}$ & $\begin{array}{l}\text { Wavelength }(\tilde{\lambda}) \text {, } \\
\text { Effective area }\left(A_{e R x}\right) \text {, } \\
\text { Gain }\left(G_{R x}\right) \text {, } \\
E I R P_{S a t}, \\
\text { Power level }\left(P_{R x}\right) \text {, } \\
\text { Sensitivity }\left(S_{R x}\right) \text {, } \\
\text { Weather margin }\left(W_{m}\right) \text {, } \\
\text { Antenna G/T }\left(G T_{R x}\right) \text {, } \\
\text { Down link path loss }\left(P L_{R x}\right) \text {, } \\
\text { Down link C/N }\left(C N R_{R x}\right)\end{array}$ \\
\hline
\end{tabular}

The web-application tool is developed based on HTML, PHP, Javascript, and MySQL. The database is designed at the back end to store user information and calculated data. The web-application tool is designed so that the tool can be used through the internet from anywhere. The tool also can be used in portable devices independently on the local server, if necessary. Javascript (scripting language) is used for necessary calculation, thus for any calculation command the tool responds very fast in producing necessary results without reloading the web tool. Ajax script is used for submitting and retrieving data to and from the server.

\section{A. Conceptual Diagrams and Design}

Users of the Link Budget tool are categorized mainly into two types; firstly, the Unregistered users, who can access the tool to perform all the available calculations without saving or retrieving any action; secondly, the Registered users, who have to login the system to perform necessary calculations. 
Registered users again categorized into two: Active-user and Peer-user. Active-user has access to change input parameters, store and retrieve data, view usages histories, and create Peer-users. On the other hand, Peer-user can only view the calculated results of its corresponding Active-user. In military activity, some troops who are connected with Earth Station through modem, hub, WiFi, or Cloud; may need to know the status and related information of satellite links. To support this notion, the Peer-user concept is adopted in this design. Active-user will be at the Earth Station while Peer-users are in mobile on the ground.

The process flow diagram of the designed web-application tool is presented in Figure 11. At the beginning stage, unregistered users have access to use the Web Tool. Registered users will $\log$ in to the system by using their username and password. Depending on the access permission, users will be directed to their corresponding page. At this stage, both users will view last updated information where Peer-users will view only the calculated information and Active-users will view all the necessary input and output parameters. Active-users will be able to change input parameter values when required and use the "Calculate" button for performing the new calculation. For a successful calculation, the system will display the updated results and send an Ajax request to store the updated information into the server. For a better understanding of the system, a conceptual Data Flow Diagram (DFD) is presented in Figure 12.

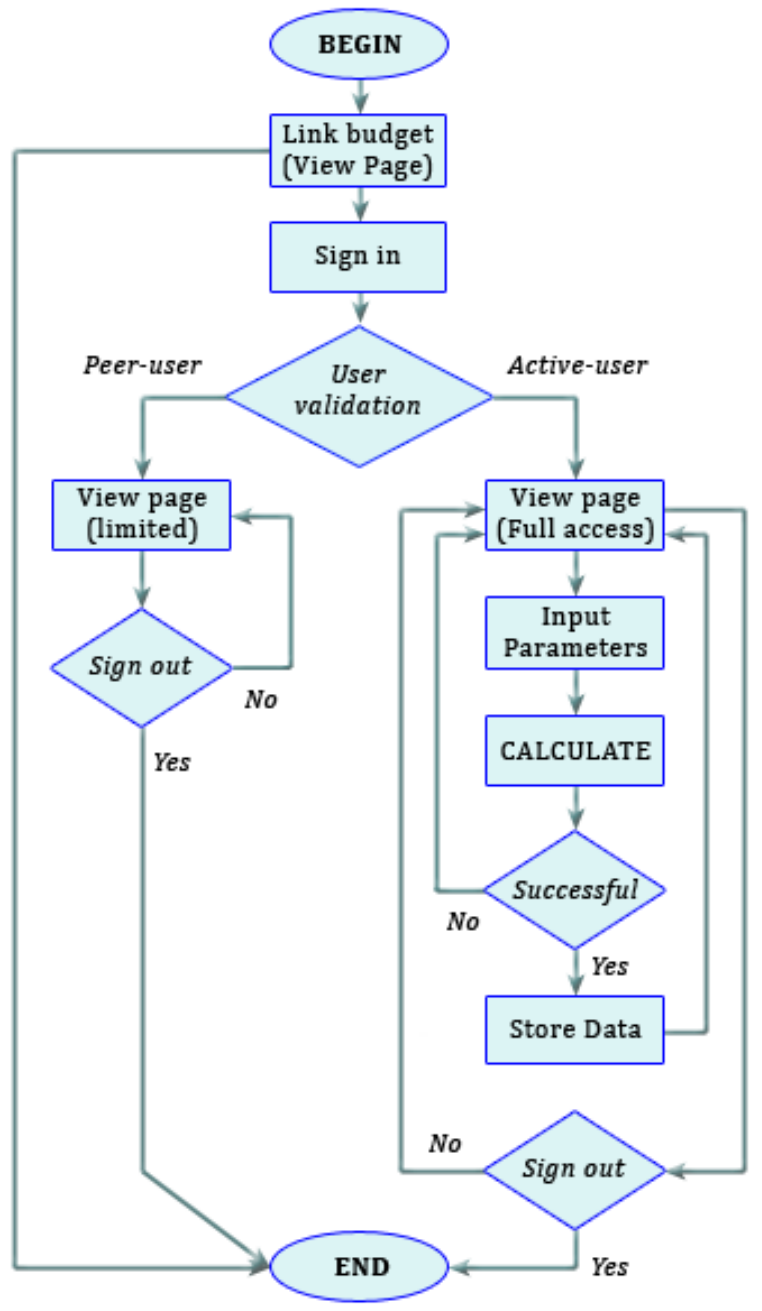

Figure 11: Process flow diagram of the designed Link Budget Tool for X-Band satellite communication

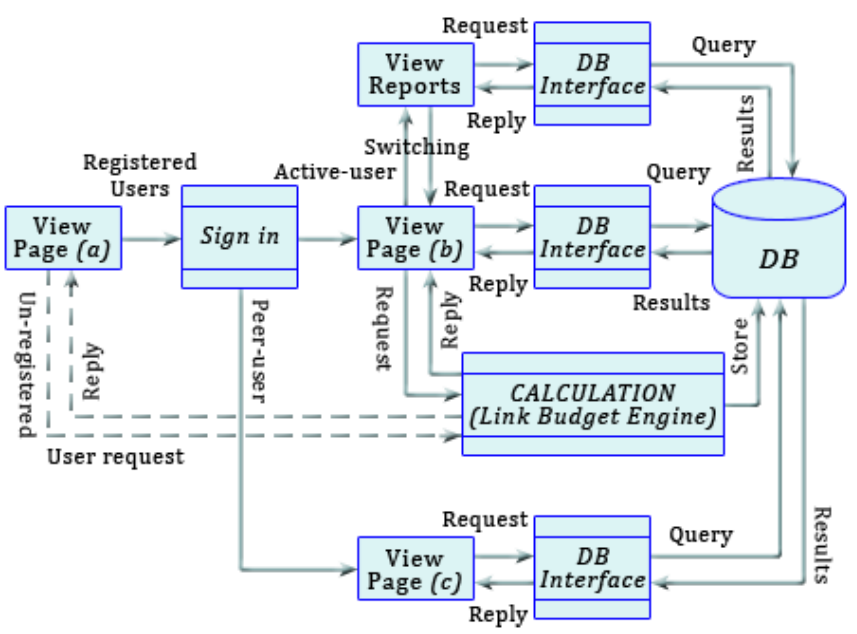

Figure 12: Data Flow Diagram (DFD) of the designed Link Budget Tool for X-band satellite communication

Detail data flow from user interfaces (view page) to Database (DB) through some processes are presented in the DFD (Figure 12). The calculation process is the Link Budget Engine (LBE) of the proposed web tool which can be accessed through View Page (a) of Unregistered users and View Page (b) of Active-users. After the process of any calculation, the LBE sends a request to DB for storing the data. The stored information can be retrieved by Activeusers (View Page (b)) and by Peer-users (View Page (c)) through DB Interface. It is to note that, View Page (c) has limited access comparing with the View Page (b) as explained in the Process Flow Diagram (PFD). Active-users can switch the View Page with View Reports to retrieve previous datasets and view usages history. At this stage, Active-user can update the user profile and create a Peeruser account.

The database schema, shown in Figure 13, is the logical view of the entire database of the proposed Link Budget tool. The schema presents the relational connectivity among seven entities. The entity "users" has one-to-many relations with other six entities, "transmitter", "receiver", "satellite", "rainatten_tx", "distance_tx", and "distance_r $x$ ". The "users" entity has a self-referential foreign key, "user_peerto", to maintain the hierarchy of Active-user and Peer-user. Basically, the Peer-user contains Active-user ID to indicate peer to that Active-user. On the other hand, Active-user may contain "NULL" for its self-referential foreign key as it is not a peer to itself. There is no weak entity in this schema.

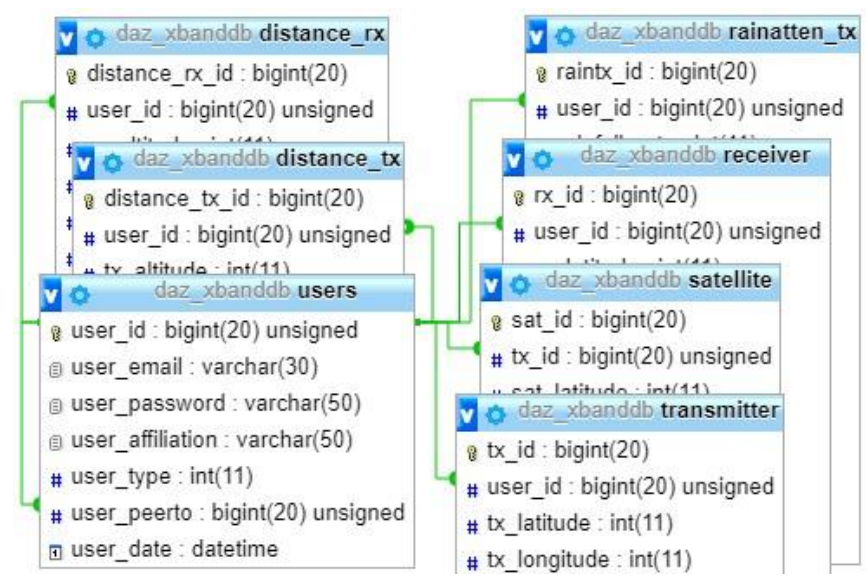

Figure 13: Database schema of the proposed web tool 


\section{B. User Interface of the Web Application Tool}

User interface for the active-user of the designed Link Budget Tool is presented in Figure 14. The interface has access to change input parameter values and calculate necessary output parameters on demand. The page is divided into six sections: TRANSMITTER $(T x)$ Earth Station, SATELLITE (Celestial Body), RECEIVER $(R x)$ Earth Station, DISTANCE $(T x)$, DISTANCE $(R x)$, and RAIN ATTENUATION. The "Calculate" button (found at the bottom of the page) can be used anytime if there is a change in input parameters and at the same time an Ajax request will be sent to the server without submitting the page which makes the system faster for calculation response. The "Reset" button (at the bottom of the interface) will help Active-users to set last updated data if necessary. At the top of the user interface, four navigation links exist through which users can perform some actions on demand. The links are: "HOME", "STATISTICS", "SIGN UP", and "SIGN IN". "HOME" links to the corresponding user home page. "SIGN $U P$ " and "SIGN IN" links are to register for new accounts and log in to the system, respectively. The link "SIGN IN" will change to "SIGN OUT" if any user is logged in the system. The navigation link "STATISTICS" will switch the user home interface to another page on which Active-user can access to the usage history, user profile (view and update), create new Peer, and update or delete existing peers.

The Peer-user interface (home page) will show limited information compare to the Active-user interface. The interface will present only the calculated parameter values. There will be no input option for changing input parameters as the user is a peer to the corresponding Active-user.

A Peer-user may be an Active-user if (s)he sign-up. Similarly, an Active-user may be a peer to another user if (s)he is chosen as a peer. In that case, the user will find a peer-list in "STATISTICS" page of the designed web tool.

\section{Features of the Web Application Tool}

In terms of design interfaces, the proposed link budget web tool is quite different compared to the other existing web tool found on the Internet. Other than calculating necessary parameters, the web tool provides some extra facilities and options for the users. The tool presents multiuser support, peer user concept, and usage history retrieval for future analysis if necessary. The following features can be highlighted for the designed web application tool.

- Necessary calculations on a single screen window

- Multiple types of user support (Registered (Activeuser \& Peer-user) and Unregistered users)

- The database is used in the back-end; thus, the tool can store user and usages data for future analysis if necessary

- $\quad$ No need a special setup like MATLAB, Visual Basic (VB), Spread sheet, etc. Just connect with the Internet and browse

- Unregistered users have instant access but no save or retrieve support

- Registered users have store and retrieve access, can create peer users, and view usages history

- Database admin can generate users and usages history reports

\section{Security Issues}

To ensure a secured web application tool, the most popular and secured MySQL database server is used with MySQLi database driver and Secure Hash Algorithm (SHA1) for encryption. While implementing, some other important issues are considered, like SQL injections, XSS (Cross-Site Scripting), Session management, Insecure Direct Object References (IDOR), Broken authentication, Exposing sensitive data, Security misconfiguration, Cross-Site Request Forgery (CSRF), and Input validation check.

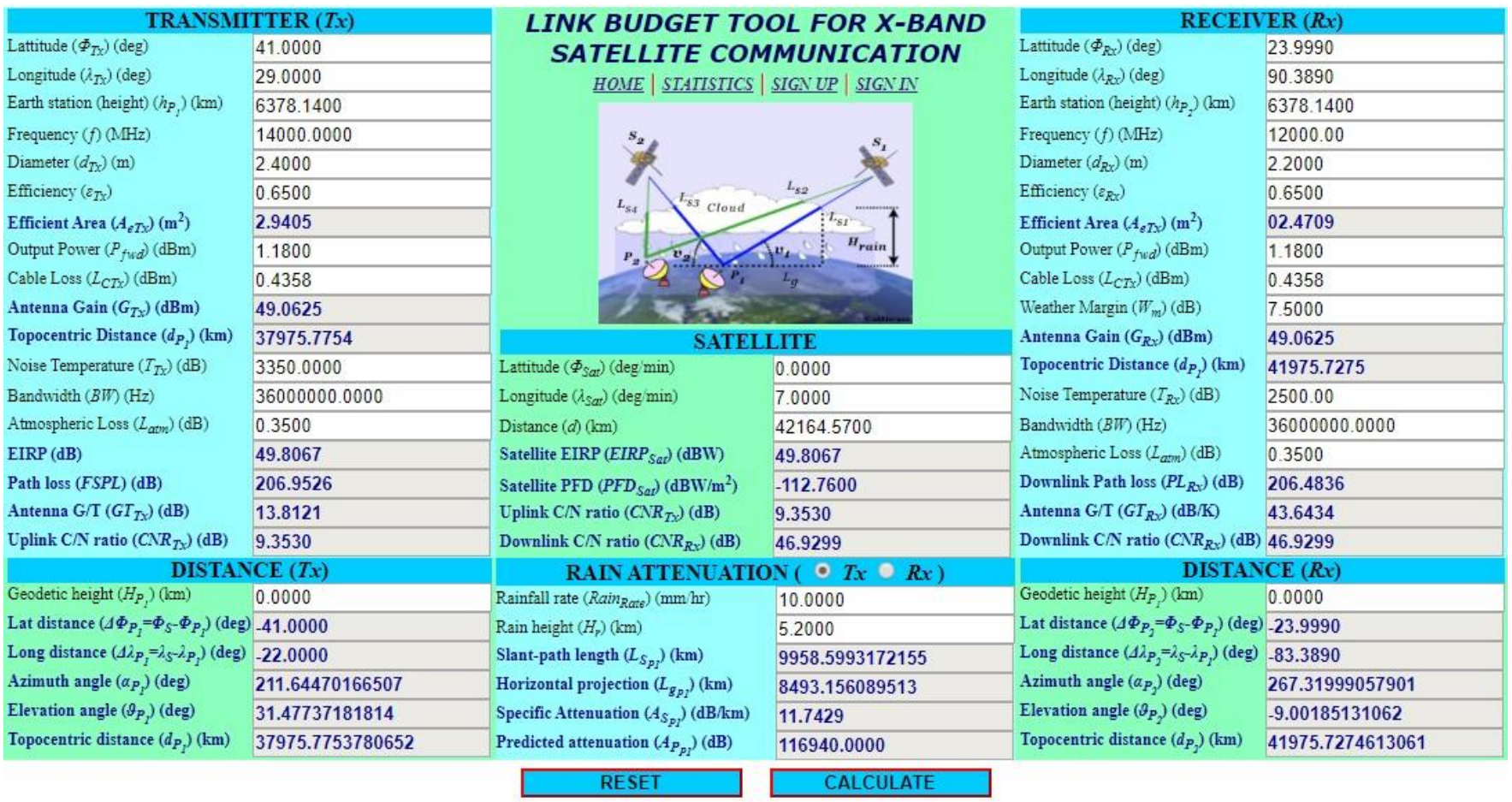

Figure 14: User interface of the proposed Link Budget Tool with six sections: TRANSMITTER (Tx) Earth Station, SATELLITE (Celestial Body), RECEIVER $(R x)$ Earth Station, DISTANCE $(T x)$, DISTANCE $(R x)$, and RAIN ATTENUATION (Tx and $R x)$. The highlighted texts and values are indicating the output parameters which cannot be changed while the un-highlighted texts and values are the input parameters that can be changed on demand. 


\section{COMPARATIVE ASSESSMENT AND RESULTS}

To evaluate the performance and validate the designed Link Budget web application tool, a comparative analysis is performed among various existing web tools and available functions of MATLAB. Results show that the applied methods are correct and viable to produce accurate results, although some minor errors are encountered. It is important to note that, not all the available web tools found on the Internet are producing the same results, there are some fluctuations in the results.

A comparative analysis is conducted focusing on some output parameters, such as: distance analysis (Topocentric distance, Azimuth angle, and Elevation angle), Uplink parameters, and Downlink parameters. For the actual error calculation, the minus ' - ' sign represents greater value and the plus ' + ' sign represents a smaller value of X-Band result than the results of compared web tools or functions. The ' $\%$ of error' (PoE) is calculated based on Equation (40).

PoE $=\frac{\text { Calculated value-Observed value }}{\text { Calculated value }} \times 100$

\section{A. Comparison of Distance Parameters}

To compare distance parameters, three important output parameters are chosen: Azimuth angle $(\alpha)$, Elevation angle $(\vartheta)$, and Topocentric distance $(d)$. Five existing web calculator tools are selected among which two web tools (Satcom Services Networks, 2020; and OMNI, 2020) present their calculation methods and equations. Three web tools (Cross, 2020; TutorialsWeb, 2020; and TRIAXMAN, 2020) do not describe any calculation methods or equations. Four different MATLAB functions are also chosen to compare and evaluate the performance of the designed X-Band web application tool. Table 2 presents the comparison results among selected and designed web tools and functions.

Calculation of $\alpha, \vartheta$, and $d$ depend on six input parameters: Latitude of earth station $\left(\phi_{P}\right)$, Longitude of earth station $\left(\lambda_{P}\right)$, Height of earth station $\left(h_{P}\right)$, Latitude of satellite $\left(\phi_{S}\right)$, Longitude of satellite $\left(\lambda_{S}\right)$, and Satellite orbital radius $\left(h_{S}\right)$. Satcom Services Networks (2020), TutorialsWeb (2020), and MATLAB functions $2 \& 3$ do not produce any results for Topocentric distance $(d)$. OMNI (2020) also does not produce Topocentric distance $(d)$, rather it produces distance on the Earth surface using Haversine formula. Results of Elevation angle $(\vartheta)$ was not found for OMNI (2020) and MATLAB function $2 \& 3$. All the chosen web tools and MATLAB functions produce results for Azimuth angle $(\alpha)$. For no output results, "Not a Number" ('NaN') is used as shown in Table 2.

The output of designed web tool (X-Band) for Topocentric distance $(d)$ shows the same result as produced in TRIAXMAN (2020), thus Percent of Error (PoE) is about $0.00 \%$. The result shows errors comparing with Cross (2020) (actual error $d_{e}=-2827.43 \mathrm{~km}$ and PoE is $-7.4454 \%$ ), and MATLAB functions $1 \& 4$ (actual error $d_{e}=-2664.68 \mathrm{~km}$ and $\mathrm{PoE}$ is $\left.-7.0168 \%\right)$.

In terms of the elevation angle $(\vartheta)$, the X-Band result shows an exact match with the outputs of MATLAB functions $1 \&$ 4. Results compared with other web tools show some errors; actual errors $+0.1366^{\circ}(+0.4340 \%), \quad+0.9911^{\circ}$ $(+3.1486 \%),-6.0153^{\circ}(-19.1100 \%)$, and $-6.0826^{\circ}$
$(-19.3240 \%)$ are found for Satcom Services Networks (2020), Cross (2020), TutorialsWeb (2020), and TRIAXMAN (2020) respectively.

PoE of Azimuth angle $(\alpha)$ is found as $0.00 \%$ for MATLAB function 1 which indicates the same output values (no actual error). The result $(\alpha)$ of X-Band compared with three web tools (Satcom Services Networks, 2020; OMNI, 2020; and TRIAXMAN, 2020) shows identical PoE $(+0.0082 \%)$ as the calculated values show same actual errors $\left(\alpha_{e}=\right.$ $+0.0174)$. MATLAB functions $2 \& 4$ show actual errors as $+0.0184^{\circ}$ and $-0.1209^{\circ}$, respectively; producing $\mathrm{PoE}$ as $+0.0087 \%$ and $-0.0571 \%$ individually. MATLAB function 3 does not produce 'Great Circle track value', rather it produces 'Rhumb Line track value'. This raise demands further analysis of these two concepts in designing the Link Budget web application tool.

Scrutinizing results shows that the outputs of $d, \alpha$, and $\vartheta$ produced by X-Band web tool are accurate in most of the cases, although there exist some little fluctuations of errors. The bigger errors found in some comparisons reflect that further study and analysis are needed for those corresponding web tools as any authenticated methods or equations are not found from their websites.

Results of Azimuth angle $(\alpha)$, Elevation angle $(\vartheta)$, and Topocentric distance $(d)$ are simulated for the variations of Longitude of a celestial body (Satellite $\lambda_{S}$ ) ranging from $5.00^{\circ}$ to $53.00^{\circ}$ as presented in Figure 15 , Figure 16 , and Figure 17. Changes in the of Azimuth angle show almost linearly decreasing characteristics (Figure 15). This is because of the chosen coordinates of the Earth station and Satellite. Variation of longitude reflects the movements of the Satellite on the Equator plane as the latitude is $0.00^{\circ}$, while the position of Earth station is at the North side of the Equator $\left(41.00^{\circ} \mathrm{N} 29.00^{\circ} \mathrm{E}\right)$. With the reference point of the chosen Earth station, the Satellite is moving from West to East, thus the changes of Azimuth angle show decreasing characteristics.

The behavior of Elevation angle $(\vartheta)$ changes with the variation of Satellite longitude $\left(\lambda_{S}\right)$ is presented in Figure 16 where dome shape characteristics are observed. This is because, when the Satellite is orbiting from West to East on the Equator plane, with the reference tangent plane of Earth station, the height of the Satellite is increasing till the longitude of $29.00^{\circ} \mathrm{E}$ and then decreasing, thus Elevation angle (look angle) shows increasing and decreasing behavior creating the dome shape characteristics. Results of compared web tools and MATLAB functions follow the same behavior pattern while the Satcom Services Networks (2020) results produce dome shape behavior but follow different path. Further analysis is necessary to explain this different characteristic.

Changes of Satellite positions from $5.00^{\circ} \mathrm{E}$ to $29.00^{\circ} \mathrm{E}$ reduces the Topocentric distance $(d)$ as it reached to its shortest distance at this point. After that, the distance is increasing to $53.00^{\circ} \mathrm{E}$. Thus, the variations of $d$ show about boat shape characteristics as presented in Figure 17. Results of compared tools and functions show similar characteristics while the results calculated in OMNI (2020) are little far from the other because it presents distance on Earth surface by using Haversine formula, not the Topocentric distance in between Satellite and Earth station. 
Table 2

Comparison of Azimuth angle $(\alpha)$, Elevation angle ( $\vartheta$ ), and Topocentric distance (d) among various methods and web tools (Satcom Services Networks, 2020; OMNI, 2020; Cross, 2020; TutorialsWeb, 2020; TRIAXMAN, 2020).

\begin{tabular}{|c|c|c|c|}
\hline $\begin{array}{c}\text { INPUT } \\
\text { PARAMETERS }\end{array}$ & $\begin{array}{c}\text { REFERENCES } \\
\& \\
\text { USED EQUATIONS OR FUNCTIONS }\end{array}$ & RESULTS & $\begin{array}{l}\text { ACTUAL } \\
\text { ERRORS }\end{array}$ \\
\hline & $\begin{array}{l}\text { Satcom Services Networks (2020): } \\
\begin{array}{l}\alpha=180+\tan ^{-1}\left(\frac{\tan \left(\lambda_{P}-\lambda_{S}\right)}{\sin \left(\phi_{P}\right)}\right) \\
\vartheta=\tan ^{-1}\left(\frac{\mu^{2}+\left(h_{p}\right)^{2}-\left(h_{s}\right)^{2}}{2 \mu h_{p}}\right) \\
\mu=\left(\left(h_{p}\right)^{2}+\left(h_{s}\right)^{2}-2 h_{p} h_{s} \cos \phi_{p} \cos \left(\lambda_{p}-\lambda_{s}\right)\right)^{1 / 2} \\
d=\text { Not available }\end{array}\end{array}$ & $\begin{array}{c}\alpha=211.6300^{\circ} \\
\vartheta=031.3408^{\circ} \\
d=N a N\end{array}$ & $\begin{array}{c}\alpha_{e}=+0.0174^{\circ} \\
\vartheta_{e}=+0.1366^{\circ} \\
d_{e}=N a N\end{array}$ \\
\hline $\begin{array}{c}\text { Earth Station }\left(P_{1}\right) \\
\text { Latitude }\end{array}$ & $\begin{array}{l}\text { OMNI (2020): } \\
\alpha=\tan ^{-1}\left(\frac{\left(\sin \left(\lambda_{S}-\lambda_{P}\right) \cos \phi_{S}\right)}{\left(\cos \phi_{P} \sin \phi_{S}-\sin \phi_{P} \cos \phi_{S} \cos \left(\lambda_{S}-\lambda_{P}\right)\right)}\right) \\
\vartheta=\text { Not Available } \\
\text { Haversine formula (use radian): } \\
\text { Distance }\left(d_{E}\right) \text { on the Earth surface. } \\
d=a\left(2 \tan ^{-1}\left(\frac{\sqrt{q}}{\sqrt{1-q}}\right)\right) \\
q=\sin ^{2}\left(\frac{\left(\phi_{S}-\phi_{p}\right)}{2}\right)+\cos \phi_{p} \cos \phi_{S} \sin ^{2}\left(\frac{\lambda_{S}-\lambda_{p}}{2}\right)\end{array}$ & $\begin{array}{c}\alpha=211.6300^{\circ} \\
\vartheta=N a N \\
d=N a N \\
d_{E}=5070.00 \mathrm{~km}\end{array}$ & $\begin{array}{c}\alpha_{e}=+0.0174^{\circ} \\
\vartheta_{e}=N a N \\
\quad d_{e}=N a N \\
d_{E e} \\
=+32905.78 \mathrm{~km}\end{array}$ \\
\hline $\begin{array}{l}\phi_{P}=41.0^{\circ} \\
\text { Longitude } \\
\lambda_{P}=29.0^{\circ}\end{array}$ & $\begin{array}{l}\text { Cross (2020): } \\
\text { Equations are not available. }\end{array}$ & $\begin{array}{c}\alpha=211.2183^{\circ} \\
\vartheta=30.4863^{\circ} \\
d=40803.21 \mathrm{~km}\end{array}$ & $\begin{array}{c}\alpha_{e}=+0.4264^{\circ} \\
\vartheta_{e}=+0.9911^{\circ} \\
d_{e}=-2827.43 \mathrm{~km}\end{array}$ \\
\hline $\begin{array}{c}\text { Earth Radius } \\
h_{P}=6378.14 \mathrm{~km}\end{array}$ & $\begin{array}{l}\text { TutorialsWeb (2020): } \\
\text { Equations are not available. }\end{array}$ & $\begin{array}{c}\alpha=211.6165^{\circ} \\
\vartheta=037.4927^{\circ} \\
d=N a N\end{array}$ & $\begin{array}{c}\alpha_{e}=+0.0282^{\circ} \\
\vartheta_{e}=-6.0153^{\circ} \\
d_{e}=N a N\end{array}$ \\
\hline & $\begin{array}{l}\text { TRIAXMAN (2020): } \\
\text { Equations are not available. }\end{array}$ & $\begin{array}{c}\alpha=211.6300^{\circ} \\
\vartheta=037.5600^{\circ} \\
d=37975.36 \mathrm{~km}\end{array}$ & $\begin{array}{c}\alpha_{e}=+0.0174^{\circ} \\
\vartheta_{e}=-6.0826^{\circ} \\
d_{e}=0000.42 \mathrm{~km}\end{array}$ \\
\hline $\begin{array}{c}\text { Satellite (S) } \\
\text { Latitude } \\
\phi_{S}=0.0^{\circ}\end{array}$ & $\begin{array}{l}\text { MATLAB Function 1: } \\
\text { wgs84 = wgs84Ellipsoid('kilometer'); } \\
{[e, n, u]=\text { geodetic2enu }\left(\phi_{S}, \lambda_{S}, h_{S}, \phi_{P}, \lambda_{P}, h_{P}, \text { wgs84); }\right.} \\
{[\alpha, \vartheta, d]=\operatorname{enu2aer}(e, n, u) ;} \\
\text { OR } \\
{[\alpha, \vartheta, d]=\operatorname{geodetic2aer}\left(\phi_{S}, \lambda_{S}, h_{S}, \phi_{P}, \lambda_{P}, h_{P}, \text { wgs84); }\right.}\end{array}$ & $\begin{array}{c}\alpha=211.6447^{\circ} \\
\vartheta=031.4774^{\circ} \\
d=40640.46 \mathrm{~km}\end{array}$ & $\begin{array}{c}\alpha_{e}=0.0000^{\circ} \\
\vartheta_{e}=0.0000^{\circ} \\
d_{e}=-2664.68 \mathrm{~km}\end{array}$ \\
\hline $\begin{array}{l}\text { Longitude } \\
\lambda_{S}=7.0^{\circ}\end{array}$ & $\begin{array}{l}\text { MATLAB Function 2: } \\
\text { \% 'gc' (Great Circle) track value... } \\
\alpha=\text { azimuth }\left(' g c^{\prime}, \phi_{P}, \lambda_{P}, \phi_{S}, \lambda_{S}\right) ;\end{array}$ & $\begin{array}{c}\alpha=211.6263^{\circ} \\
\vartheta=N a N \\
d=N a N\end{array}$ & $\begin{array}{c}\alpha_{e}=+0.0184^{\circ} \\
\vartheta_{e}=N a N \\
d_{e}=N a N\end{array}$ \\
\hline \multirow[t]{3}{*}{$\begin{array}{c}\text { Orbital Radius } \\
h_{S}=42164.57 \mathrm{~km}\end{array}$} & $\begin{array}{l}\text { MATLAB Function 3: } \\
\% \text { 'rh' (Rhumb Line) track value... } \\
\left.\alpha=\text { azimuth('rh', } \phi_{P}, \lambda_{P}, \phi_{S}, \lambda_{S}\right) ;\end{array}$ & $\begin{array}{c}\alpha=206.0401^{\circ} \\
\vartheta=N a N \\
d=N a N\end{array}$ & $\begin{array}{c}\alpha_{e}=+5.5866^{\circ} \\
\vartheta_{e}=N a N \\
d_{e}=N a N\end{array}$ \\
\hline & $\begin{array}{l}\text { MATLAB Function 4: } \\
\text { \% Available at MATLAB } R 2013 a \ldots\left(h_{p}=h_{s}=\text { meters }\right) \\
{[\vartheta, d, \alpha]=\operatorname{elevation}\left(\phi_{p}, \lambda_{P}, h_{P}, \phi_{S}, \lambda_{S}, h_{S}\right)}\end{array}$ & $\begin{array}{c}\alpha=211.7656^{\circ} \\
\vartheta=031.4774^{\circ} \\
d=40640.46 \mathrm{~km}\end{array}$ & $\begin{array}{c}\alpha_{e}=-0.1209^{\circ} \\
\vartheta_{e}=+0.0000^{\circ} \\
d_{e}=-2664.68 \mathrm{~km}\end{array}$ \\
\hline & 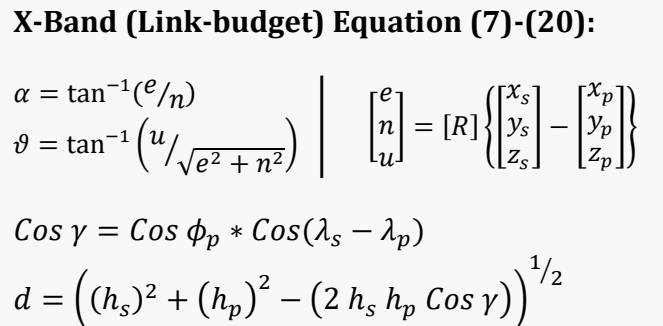 & $\begin{array}{c}\alpha=211.6447^{\circ} \\
\vartheta=031.4774^{\circ} \\
d=37975.78 \mathrm{~km}\end{array}$ & $\begin{array}{c}\alpha_{e}=0.00^{\circ} \\
\vartheta_{e}=0.00^{\circ} \\
d_{e}=0.00 \mathrm{~km}\end{array}$ \\
\hline
\end{tabular}

Note: Values in the table are obtained from direct outputs of the reference webtools, simulated MATLAB Functions 1 to 4 , and Implemented $X$-Band (Link-budget) equations. Errors are determined by comparing the obtained values with the results of the proposed Link-budget Web Tool for X-Band Satellite Communication. 


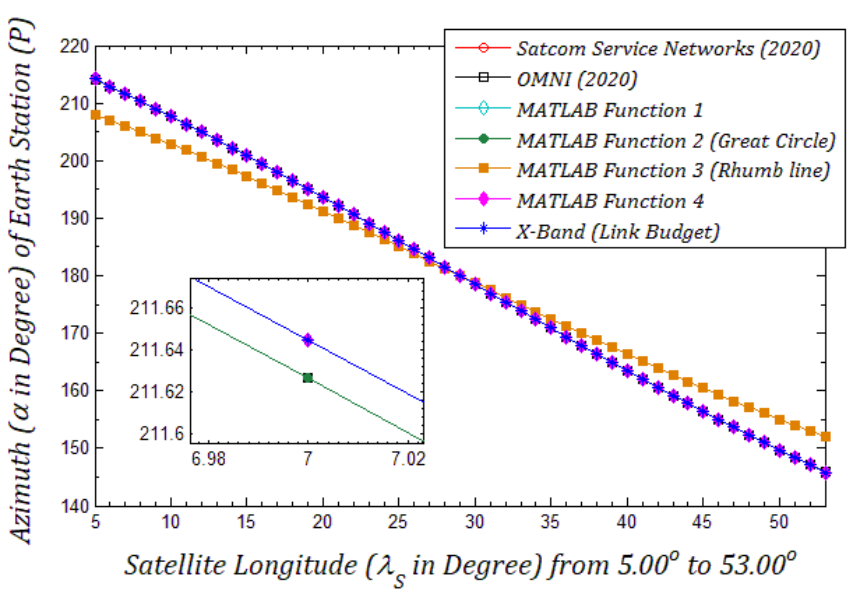

Figure 15: Changes of Azimuth angle $(\alpha)$ with the variation of Satellite longitude $\left(\lambda_{S}\right)$

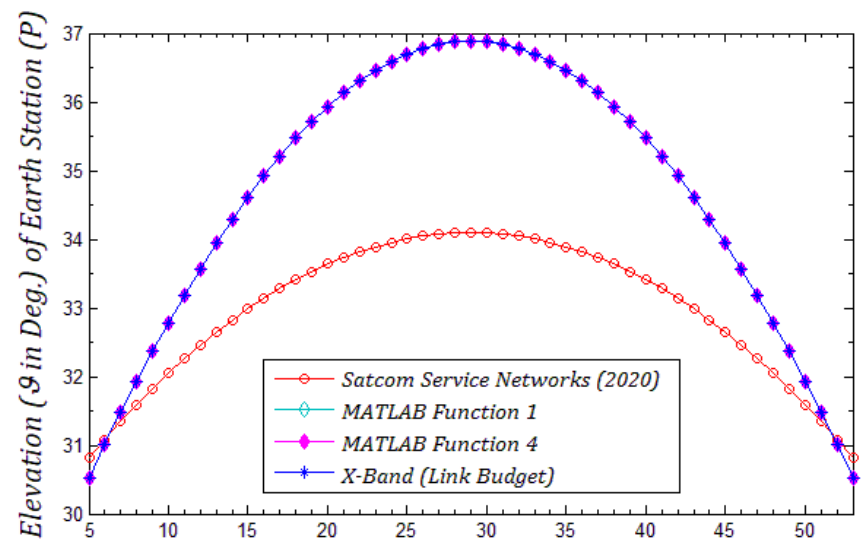

Satellite Longitude $\left(\lambda_{S}\right.$ in Degree) from $5.00^{\circ}$ to $53.00^{\circ}$

Figure 16: Behavior of Elevation angle $(\vartheta)$ changes for the variations of Satellite longitude $\left(\lambda_{S}\right)$

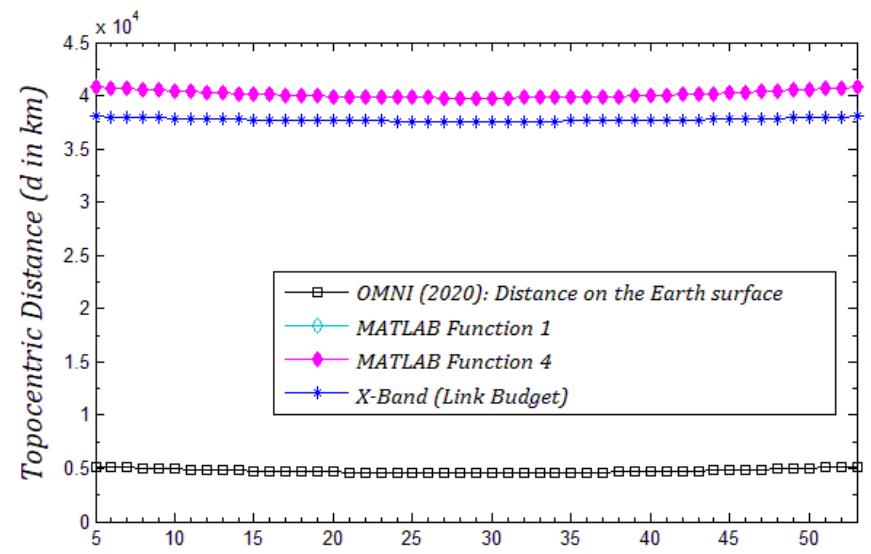

Satellite Longitude ( $\lambda_{s}$ in Degree) from $5.00^{\circ}$ to $53.00^{\circ}$

Figure 17: Characteristics of Topocentric distance $(d)$ variations with the changes of Satellite longitude $\left(\lambda_{S}\right)$

\section{B. Comparison of Uplink Parameters}

Comparison of Uplink parameters include Efficient area of transmitter antenna $\left(A_{e T x}\right)$, Antenna Gain $\left(G_{T x}\right)$, Effective Isotropic Radiated Power (EIRP), Free Space Path Loss (FSPL), Antenna G/T $\left(G T_{T x}\right)$, Career to Noise Ratio (CNR), and Satellite Power Flex Density (PFD). Results of X-Band are compared with five available Web Tools found on the Internet, which are: Satcom Services Networks (2020), SWA (2020), everithingRF (2015), Johnston (2019), and SatcomUK (2015). Comparison results are presented in
Table 3 which indicates that not all results can be generated from the available online tools comparing with the results of the proposed X-Band Link Budget tool.

Outputs of $A_{e T x}$ are not generated by any of the selected web tools. Satcom Services Networks (2020) does not produce any output for PFD. SWA (2020) does not have $G_{T x}, G T_{T x}$, CNR, and PFD calculators. The results of $G T_{T x}, \mathrm{CNR}$, and PFD are also not found in everithingRF (2015).

Table 3

Comparison of Uplink Parameters among various web tools (Satcom Services Networks, 2020; SWA, 2020; EverithingRF, 2015; Johnston, 2019, SatcomUK, 2015)

\begin{tabular}{|c|c|c|}
\hline $\begin{array}{l}\text { REFERENCES \& } \\
\text { USED EQUATIONS }\end{array}$ & OUTPUT & $\begin{array}{l}\text { ACTUAL } \\
\text { ERRORS }\end{array}$ \\
\hline \multicolumn{3}{|l|}{ Satcom Services Networks (2020): } \\
\hline $\begin{aligned} & G_{T X}= 10 \log _{10}\left(\varepsilon_{T X}\right)+20 \log _{10}\left(f d_{T x}\right) \\
&+(-159.59) \\
& \text { [Note: corrected equation] }\end{aligned}$ & $049.0659 d B$ & $-00.0030 d B$ \\
\hline$E I R P=10 \log _{10}\left(P_{T x}\right)+G_{T x}$ & $049.7847 d B$ & $-00.0010 d B$ \\
\hline $\begin{array}{l}F S P L=20 \log _{10}(f d)+92.5 \\
(\text { f is } 14 \mathrm{GHz})\end{array}$ & $207.0127 d B$ & $-00.0601 d B$ \\
\hline$G T_{T X}=G_{T X}-10 \log _{10}\left(T_{T x}\right)$ & $013.8155 d B$ & $-00.0034 d B$ \\
\hline $\begin{aligned} C N R= & E I R P-F S P L+G T_{T x}- \\
& 10 \log _{10}(B W)-k_{\text {bolt }}-L_{a t m}\end{aligned}$ & $009.2745 d B$ & $+00.0785 d B$ \\
\hline \multicolumn{3}{|l|}{ SWA (2020): } \\
\hline$E I R P=P_{T x}-L_{C T X}+G_{T x}$ & $049.8067 d B$ & $00.0000 d B$ \\
\hline $\begin{array}{l}F S P L=20 \log _{10}(4 \pi d f / c)-G_{T x}-G_{R x} \\
(\text { d in meter })\end{array}$ & $108.8355 d B$ & $+98.1171 d B$ \\
\hline \multicolumn{3}{|c|}{ everithingRF (2015): (Parabolic Antenna Gain) } \\
\hline$G_{T x}=10 \log _{10}\left(k\left(\pi d_{T x} / \tilde{\lambda}\right)^{2}\right)$ & $049.0625 \mathrm{~dB}$ & $00.0000 d B$ \\
\hline$E I R P=P_{T x}-L_{C T x}+G_{T x}$ & $049.8067 d B$ & $00.0000 d B$ \\
\hline $\begin{array}{l}F S P L=20 \log _{10}(4 \pi d f / c)-G_{T x}-G_{R x} \\
(\text { d in meter })\end{array}$ & $108.8355 d B$ & $+98.1171 d B$ \\
\hline \multicolumn{3}{|l|}{ Johnston (2019): } \\
\hline$G_{T x}$ & $049.0565 d B$ & $+00.0060 \mathrm{~dB}$ \\
\hline EIRP & $049.7753 d B$ & $+00.0314 d B$ \\
\hline FSPL & $206.9627 d B$ & $-00.0101 d B$ \\
\hline$G T_{T x}$ (as input) & $013.8121 d B$ & $00.0000 d B$ \\
\hline CNR & $009.6616 d B$ & $-00.3086 d B$ \\
\hline$P F D$ & $-112.82 d B W m^{-2}$ & $+00.04 \mathrm{dBW} \mathrm{m}^{2}$ \\
\hline \multicolumn{3}{|l|}{ SatcomUK (2015): } \\
\hline$G_{T x}$ & $049.0600 \mathrm{~dB}$ & $+00.0025 d B$ \\
\hline EIRP & $050.2400 d B$ & $-00.4333 d B$ \\
\hline$F S P L$ & $207.1600 d B$ & $-00.2074 d B$ \\
\hline$G T_{T x}$ (as input) & $013.8121 d B$ & $00.0000 d B$ \\
\hline CNR & $009.9400 d B$ & $-00.5870 d B$ \\
\hline$P F D$ & $-112.52 d B W m^{-2}$ & $-00.26 d B W m^{2}$ \\
\hline \multicolumn{3}{|l|}{ X-Band (Link-budget): } \\
\hline$A_{e T x}=\pi\left(r_{T x}\right)^{2} \varepsilon_{T x}$ & $002.9405 \mathrm{~m}^{2}$ & $00.0000 \mathrm{~m}^{2}$ \\
\hline$G_{T x}=10 \log _{10}\left(\varepsilon_{T x}\left(\pi d_{T x} / \tilde{\lambda}\right)^{2}\right)$ & $049.0625 \mathrm{~dB}$ & $00.0000 d B$ \\
\hline$E I R P=G_{T x}+P_{T x}-L_{C T x}$ & $049.8067 d B$ & $00.0000 d B$ \\
\hline $\begin{array}{l}F S P L=20 \log _{10}(f d)+32.44 \\
(f \text { in } G H z \& \text { in meter })\end{array}$ & $206.9526 d B$ & $00.0000 d B$ \\
\hline$G T_{T X}=G_{T x}-10 \log _{10}\left(T_{T X}\right)$ & $013.8121 d B$ & $00.0000 d B$ \\
\hline $\begin{aligned} C N R= & \begin{array}{l}E I R P-F S P L-10 \log _{10}(b w) \\
+G T_{T x}-L_{\text {atm }}-k_{\text {bolt }}\end{array}\end{aligned}$ & $009.3530 d B$ & $00.0000 d B$ \\
\hline$P F D=E I R P-10 \log _{10}\left(4 \pi d^{2}\right)$ & $-112.76 \mathrm{dBWm} \mathrm{m}^{2}$ & $0.00 \mathrm{dBWm} \mathrm{m}^{2}$ \\
\hline
\end{tabular}


All the output parameters except Gain $\left(G_{T x}\right)$ can be calculated in Johnston (2019) and SatcomUK (2015). Related input parameters with relevant values are presented in Table 4. Based on the results found in Table 3, PoEs are calculated and presented graphically in Figure 18.

Table 4

Uplink input parameter values for necessary calculations

\begin{tabular}{ll}
\hline \hline \multicolumn{1}{c}{ PARAMETERS } & \multicolumn{1}{c}{ VALUES } \\
\hline Speed of radio wave & $c=299792458 \mathrm{~ms}^{-1}$ \\
Frequency & $f=14 \times 10^{9} \mathrm{~Hz}$ \\
Antenna diameter & $d_{T x}=2.4 \mathrm{~m}$ \\
Wavelength & $\tilde{\lambda}={ }^{c} / f=0.021413747 \mathrm{~m}$ \\
Antenna or Aperture efficiency & $\varepsilon_{T x}=k=0.65=65 \%$ \\
Efficient area of antenna & $A_{\text {eTx }}=02.9405 \mathrm{~m}^{2}$ \\
Transmitter output power & $P_{T x}=1.18 \mathrm{dBm}$ \\
Cable loss & $L_{C T x}=0.4358 \mathrm{dBm}$ \\
Antenna gain & $G_{T x}=G_{R x}=49.0625 \mathrm{dBm}$ \\
Topocentric distance & $d_{P_{1}}=37975.7754 \mathrm{~km}$ \\
System noise temperature & $T_{T x}=3.350 \times 10^{3} \mathrm{~dB}$ \\
Bandwidth & $B W=36 \times 10^{6} \mathrm{~Hz}$ \\
Boltzmann constant & $k_{\text {bolt }}=-228.6$ \\
Atmospheric loss & $L_{a t m}=0.35 \mathrm{~dB}$ \\
\hline \hline
\end{tabular}

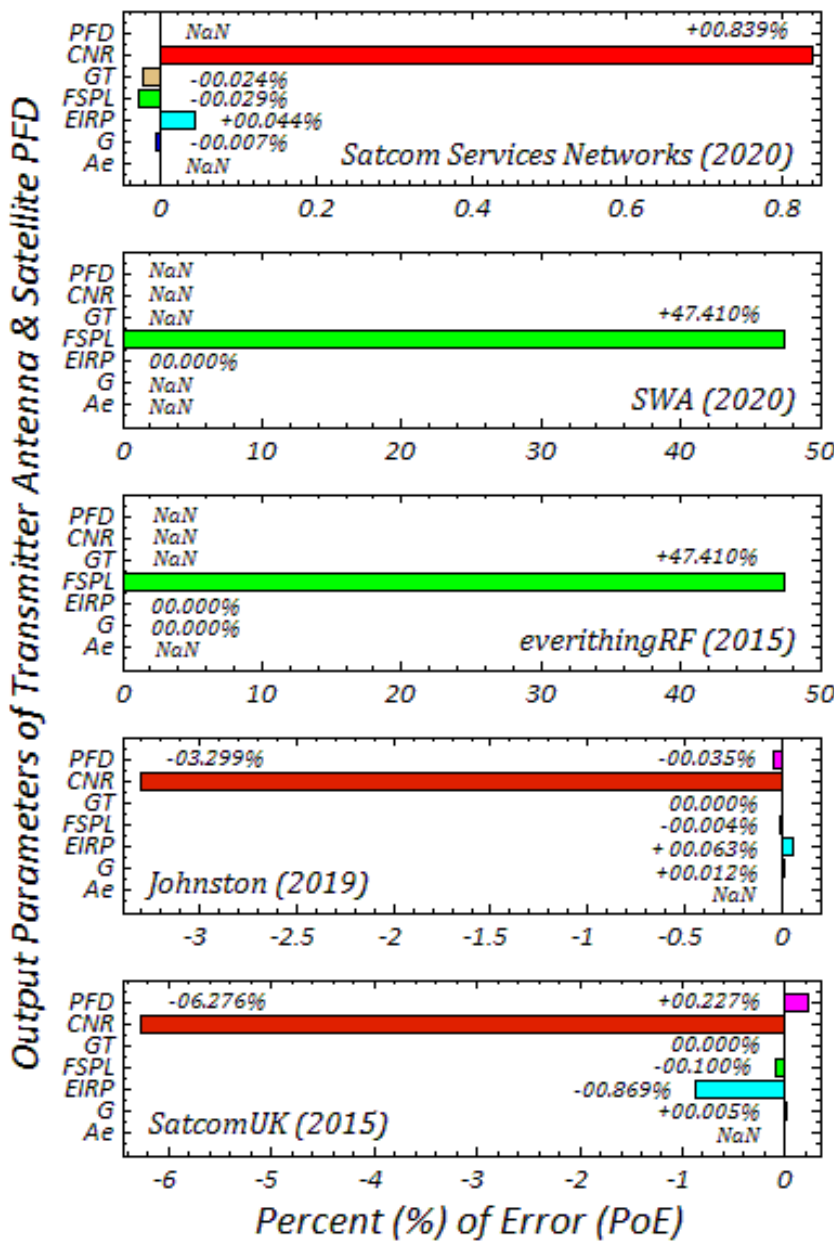

Figure 18: Output parameters of a transmitter antenna and Satellite PFD vs. Percent (\%) of Error (PoE) of various web tools compared with the proposed Link-budget tool
Johnston (2019) and SatcomUK (2015) do not provide any used methods or equations of their calculations. The other three web tools present the necessary calculation methods. Results of SWA (2020) and everithingRF (2015) show highest PoE $(+47.4100 \%)$ for FSPL as both of them use same equations with a little variation than the equation used in the proposed Link Budget tool. This issue must be considered in future study to validate the presented equation. Other results reflect very minor fluctuation in results with very little PoE as shown in Figure 18, confirming viability of designed Link Budget web tool. ' $\mathrm{NaN}$ ' in the figure indicates 'Not a Number' for unavailable results.

\section{Comparison of Downlink Parameters}

Five output parameters are considered to evaluate downlink parameter results performances of the proposed X-Band Link Budget tool, as presented in Table 5. The selected parameters are: Effective area of receiver antenna $\left(A_{e R x}\right)$, Antenna gain $\left(G_{R x}\right)$, Antenna G/T $\left(G T_{R x}\right)$, Path loss $\left(P L_{R x}\right)$, and Downlink Career to Noise Ratio $(C N R)$.

\section{Table 5}

Comparison of Downlink Parameters among various web tools (Satcom Services Networks, 2020; everithingRF, 2015; Johnston, 2019; SatcomUK, 2015)

\begin{tabular}{|c|c|c|}
\hline $\begin{array}{l}\text { REFERENCES \& } \\
\text { USED EQUATIONS }\end{array}$ & OUTPUT & $\begin{array}{l}\text { ACTUAL } \\
\text { ERRORS }\end{array}$ \\
\hline \multicolumn{3}{|l|}{ Satcom Services Networks (2020): } \\
\hline $\begin{array}{l}G_{R x}=\begin{array}{l}10 \log _{10}\left(\varepsilon_{R x}\right)+20 \log _{10}\left(f d_{R x}\right) \\
+(-159.59)\end{array} \\
\text { [Note: corrected equation] }\end{array}$ & $046.9600 d B$ & $+00.0078 d B$ \\
\hline$G T_{R X}=G_{R x}-10 \log _{10}\left(T_{R x}\right)$ & $043.6400 d B$ & $+00.0034 d B$ \\
\hline $\begin{array}{l}P L_{R x}=20 \log _{10}(f d)+92.5 \\
(\rightarrow f \text { is } 12 \mathrm{GHz})\end{array}$ & $206.5400 d B$ & $-00.0561 d B$ \\
\hline $\begin{aligned} C N R= & E I R P_{S}-10 \log _{10}(b w)-P L_{R x} \\
& +G T_{R x}-k_{\text {bolt }}-L_{\text {atm }}\end{aligned}$ & $039.5900 d B$ & $+07.3399 d B$ \\
\hline \multicolumn{3}{|c|}{ everithingRF (2015): (Parabolic Antenna Gain) } \\
\hline$G_{R x}=10 \log _{10}\left(k\left(\pi d_{R x} / \tilde{\lambda}\right)^{2}\right)$ & $046.9678 d B$ & $00.0000 d B$ \\
\hline $\begin{array}{l}P L_{R x}=20 \log _{10}(4 \pi d f / c) \\
(\rightarrow \text { din meter })\end{array}$ & $206.4914 d B$ & $-00.0078 d B$ \\
\hline \multicolumn{3}{|l|}{ Johnston (2019): } \\
\hline$G_{R x}$ & $046.9618 d B$ & $+00.0060 d B$ \\
\hline$G T_{R x}$ & $043.6374 d B$ & $+00.0334 d B$ \\
\hline$P L_{R x}$ & $205.6238 d B$ & $+00.8598 d B$ \\
\hline$C N R$ & $040.8573 d B$ & $+06.0726 d B$ \\
\hline \multicolumn{3}{|l|}{ SatcomUK (2015): } \\
\hline$G_{R x}$ & $046.9600 d B$ & $+00.0078 d B$ \\
\hline$G T_{R x}$ & $043.6100 d B$ & $+00.0334 d B$ \\
\hline$P L_{R x}$ & $206.4900 d B$ & $-00.0064 d B$ \\
\hline$C N R$ & $046.9300 d B$ & $-00.0001 d B$ \\
\hline \multicolumn{3}{|l|}{ X-Band (Link-budget): } \\
\hline$A_{e R x}=\pi\left(r_{R x}\right)^{2} \varepsilon_{R x}$ & $002.4709 d B$ & $00.0000 d B$ \\
\hline$G_{R x}=10 \log _{10}\left(\varepsilon_{R x}\left(\pi d_{R x} / \tilde{\lambda}\right)^{2}\right)$ & $046.9678 d B$ & $00.0000 d B$ \\
\hline$G T_{R X}=G_{R x}-10 \log _{10}\left(T_{R x}\right)$ & $043.6434 d B$ & $00.0000 d B$ \\
\hline $\begin{array}{l}P L_{R x}=20 \log _{10}\left(4 \pi f d_{P_{2}} / c\right) \\
\left(\rightarrow f \text { in } G H z \& d_{P_{2}} \text { in meter }\right)\end{array}$ & $206.4836 d B$ & $00.0000 d B$ \\
\hline$C N R=\begin{array}{l}E I R P_{S}-P L_{R x}-10 \log _{10}(b w)- \\
L_{C R x}+G T_{R x}-k_{\text {bolt }}+W_{m}-L_{a t m}\end{array}$ & $046.9299 d B$ & $00.0000 d B$ \\
\hline
\end{tabular}


To conduct a comparative analysis, four existing web tools are chosen depending on the availability of the targeted output parameters. The available web tools are: Satcom Services Networks (2020), everithingRF (2015), Johnston (2019), and SatcomUK (2015).

Results presented in Table 5 show that only $G_{R x}$ and $P L_{R x}$ calculators are available in everithingRF (2015). Rest of the web tools have the functionality to produce results of output parameters except the parameter $A_{e R x}$. Satcom Services Networks (2020) and everithingRF (2015) provides necessary methods to calculate output parameters, while the other two web tools do not present any equation or method. Necessary input parameters with corresponding values are presented in Table 6.

Actual errors presented in Table 5 reflect that most of the errors are 0.00 or very close to 0.00 , which proofs that the proposed X-Band Link Budget tool produces accurate results for downlink parameter calculations. This also can be confirmed form graphical representation of PoEs as shown in Figure 19.

A little deflection is identified for the PoE results of CNR produced by Satcom Services networks (2020) and Johnston (2019) as $+15.6401 \%$ and $+12.9397 \%$, respectively. This issue must keep in mind in future studies.

\section{Overall Comments}

Based on the comparative assessments, the overall comment is that the three existing web tools found reliable in terms of output parameters and results. The three web tools are: Satcom Services Networks (2020), Johnston (2019), and SatcomUK (2015). The proposed X-Band Link Budget web tool produces reliable outputs reflecting very little PoEs and viable for practical uses.

Table 6

Downlink input parameters to calculate relevant output parameter values

\begin{tabular}{ll}
\hline \multicolumn{1}{c}{ PARAMETERS } & \multicolumn{1}{c}{ VALUES } \\
\hline Speed of radio wave & $c=299792458 \mathrm{~ms}^{-1}$ \\
Frequency & $f=12 \times 10^{9} \mathrm{~Hz}$ \\
Antenna diameter & $d_{R x}=2.2 \mathrm{~m}$ \\
Wavelength & $\tilde{\lambda}={ }^{c} / f=0.021413747 \mathrm{~m}$ \\
Rx Latitude & $\phi_{P_{2}}=23.9990^{\circ}$ \\
Rx Longitude & $\lambda_{P_{2}}=90.3890^{\circ}$ \\
Rx height (Earth Radius) & $h_{P_{2}}=6378.1400 \mathrm{~km}$ \\
Antenna or Aperture efficiency & $\varepsilon_{R x}=k=0.65=65 \%$ \\
Efficient area of antenna & $A_{e R x}=02.4709 \mathrm{~m}^{2}$ \\
Cable loss & $L_{C R x}=0.2235 \mathrm{dBm}$ \\
Weather Margin & $W_{m}=7.5 \mathrm{~dB}$ \\
Satellite EIRP & $E I R P_{S}=49.8067$ \\
Antenna gain & $G_{R x}=49.0625 \mathrm{dBm}$ \\
Topocentric distance & $d_{P_{2}}=41975.7275 \mathrm{~km}$ \\
System noise temperature & $T_{R x}=2.15 \times 10^{3} \mathrm{~dB}$ \\
Bandwidth & $b w=36 \times 10^{6} \mathrm{~Hz}$ \\
Boltzmann constant & $k_{b o l t}=-228.6$ \\
\hline & $L_{a t m}=0.35$ \\
\hline Atmospheric loss & \\
\hline &
\end{tabular}

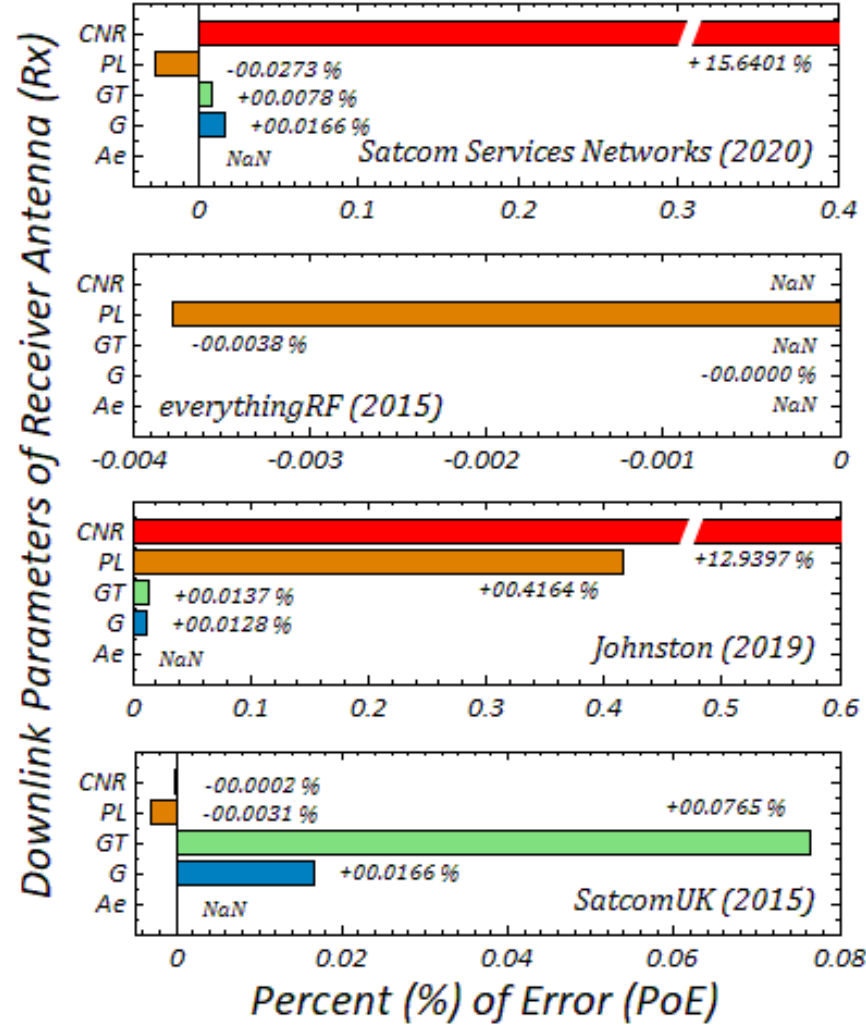

Figure 19: Percent (\%) of Error (PoE) of Downlink parameters calculated based on various web tools comparing with the proposed X-Band Link-budget tool

\section{CONCLUSIONS}

This study presents the design of a Link Budget web application tool for Military X-band satellite communication. Theoretical study on Link Budget analysis is conducted from six points of views such as transmitter antenna ( $T x)$; satellite; receiver antenna $(R x)$; azimuth $(\alpha)$, elevation $(\vartheta)$, and topocentric distance $(d)$ analysis for $T x \& R x$; and rain attenuation. Azimuth angle, elevation angle, and distance analysis are carried out based on the theory of spherical geometry. Based on the theoretical study, all input and output parameters were tabulated in designing the X-Band Link Budget web-application tool. The prototype is developed based on HTML, PHP, Javascript, and MySQL so that the tool can be used through the internet by any portable device and can store user and usage information based on the necessity of past history analysis. The designed web tool presents novel concepts in terms of user interfaces, user types, database, and usage statistics. Implementation of the peer-user concept could be considered as one of the interesting points which will enhance one step forward in the design Link Budget tool. Several security issues are considered in designing the proposed web tool. The manuscript also presents a comparative study among various tools available on the Internet and proposed X-Band web tool. Comparative results show little PoEs among various output parameters of designed X-Band Link Budget tool and other web tools which reflect the reliability and viability of the proposed system for practical use.

The system can be improved by developing apps for some specific mobile devices used in Military activities. Outcomes of this study will be more effective if this can be implemented in intelligent Earth Station control, Military vehicles in hazardous area, and Robots or autonomous systems for satellite communication. 


\section{ACKNOWLEDGEMENTS}

The authors would like to express their gratitude to the Ministry of Education Bangladesh. They also would like to present their appreciations to the R\&D (Robotics) Section at DREAM Robotics Ltd. and the departments of CSE at three highly regarded institutions, BAUST, DIU, and MIST, in Bangladesh.

\section{REFERENCES}

Abdullah, A. I., Ismail, A. F., Badron, K., \& Hashim, W. (2018). Fade Margin Estimations for Malaysian Armed Forces Military X-Band Satellite Communication Links. International Journal of Future Generation Communication and Networking, 11(3), 1-10.

Adhikari, A., Das, S., Bhattacharya, A., \& Maitra, A. (2011). Improving Rain Attenuation Estimation: Mod-Elling of Effective Path Length Using Ku-Band Measurements at A Tropical Location. Progress in Electromagnetics Research B, 34, 173-186

Al-Dalowi, A.H., Khoshnaw, A.I., \& QasMarrogy, G.A. (2017, March 29-30). Satellite Link Budget Calculator by Using $M A T L A B / G U I . \quad 1^{\text {st }}$ International Conference of Cihan University-Erbil on Communication Engineering and Computer Science (CIC-COCOS'17), Cihan University-Erbil, Kurdistan Region-Iraq, 74-78.

Al-Saegh, A. M., Sali, A., Mandeep, J. S., Ismail, A., Al-Jumaily, A. H. J., \& Gomes, C. (2014). Atmospheric Propagation Model for Satellite Communications. In Bennett, K. (Eds.), MATLAB Applications for the Practical Engineer, Chapter: 9, INTECH, (pp. 249-275), DOI: 10.5772/58238.

Bazzi, A., Giorgetti, A., Pasolini, G., \& Schena, V. (2005). Gap Fillers for Railway Tunnels: Technologies and Performance. EMC Europe Workshop, Rome, Italy, 147-150.

Cakaj, S., Keim, W., \& Malarić, K., (2007, May 30 - June 1). Communications Duration with Low Earth Orbiting Satellites. Proceedings of the Fourth IASTED International Conference on Antennas, Radar, and Wave Propagation, Montreal, Quebec, Canada, (pp. 85-88).

Capela, C. J. R. (2012). Protocol of Communications for Vorsat Satellite (Link Budget) [Master Thesis, Master Degree in Electrical Engineering]. Faculdade de Engenharia, Universidade do Porto.

Cole, C. E. (2010). Missile Communication Links. Johns Hopkins APL Technical Digest, 28(4), 324-330.

Cross, D. (2020). Azimuth/Distance calculator. Extracted on 18th Apr. 2020. Source: http://cosinekitty.com/compass.html

CS (2016). The Link Budget and Fade Margin: Application Note. Campbell Scientific Inc., Copyright 2016. App. Note Code: 3RF-F.

Elechi, P., \& Otasowie, P. O. (2016). Comparison of Empirical Path Loss Propagation Models with Building Penetration Path Loss Model. International Journal on Communications Antenna and Propagation (I.Re.C.A.P.), 6(2), 116-123. DOI: 10.15866/irecap.v6i2.8013

Elbert, B. R. (2004). The Satellite Communication Applications Handbook (Second Edition). Chapter 12: Frequency Coordination and Regulation of Services. Artech House, Inc., 685 Canton Street, Norwood, MA 02062, (pp. 445-482).

everithingRF (2015). RF Calculators. Extracted on 20th Apr. 2020. Source: https://www.everythingrf.com/rf-calculators

Fadilah, N., \& Pratama, R. (2018). Comparison of rain attenuation estimation in high frequency in Indonesia region for LAPAN communication satellite. $6^{\text {th }}$ International Seminar of Aerospace Science and Technology, IOP Conf. Series: Journal of Physics: Conf. Series 1130 (2018) 012036, IOP Publishing, (pp. 1-7), DOI: 10.1088/1742-6596/1130/1/012036

Geyer, M. (2016). Earth-referenced Aircraft Navigation and Surveillance Analysis, Project Memorandum - June 2016, DOT-VNTSC-FAA-16-12, Prepared for: Federal Aviation Administration Wake Turbulence Research Office, U.S.
Department of Transportation Research and Innovative Technology Administration, John A. Volpe Transportation Systems Center, (pp. 2.1-2.13).

Griffiths, H., Cohen, L., Watts, S., Mokole, E., Baker, C., Wicks, M., \& Blunt, S. (2015, January). Radar Spectrum Engineering and Management: Technical and Regulatory Issues. Proceedings of the IEEE, 103(1), 85-102, DOI: 10.1109/JPROC.2014.2365517

Hyde, G., \& Bargellini, P. L. (2002). Satellite and Space Communications. In Middleton, W. M., \& Valkenburg, M. E. V. (Eds.), Reference Data for Engineers: Radio, Electronics, Computer, and Communications, $9^{\text {th }}$ Edition, Elsevier Inc. (pp. $27.11-27.12)$.

Hossain, M. S. \& Islam, M. A. (2017, February 16-18). Estimation of Rain Attenuation at EHF bands for Earth-to-Satellite Links in Bangladesh. International Conference on Electrical, Computer and Communication Engineering (ECCE), Cox's Bazar, Bangladesh (pp. 589-593).

Ippolito L. J. (1986). Chapter 5: Rain Attenuation Prediction Methods. In Radiowave Propagation in Satellite Communications. Springer, Dordrecht, DOI: https://doi.org/10.1007/978-94-011-7027-7_5

Ismail, A. F., Zhiger, S., Hasan, M. K., \& Hashim, W. (2017). An Intuitive Link Budget Tool for Military Satellite Communication. International Journal of Software Engineering and Its Applications, NADIA, 11(2), 97-106.

ITU (2011). Handbook, Earth Exploration-Satellite Service. English Edition 2011, Recommendation Bureau, ITU.

ITU-R (2003a). Propagation data and prediction methods required for the design of Earth-space telecommunication systems, (Question ITU-R 206/3), RECOMMENDATION ITU-R P.618-8, Rec. ITU-R P.618-8.

ITU-R (2003b). Specific attenuation model for rain for use in prediction methods, (Question ITU-R 201/3), RECOMMENDATION ITU-R P.838-2, Rec. ITU-R P.838-2.

ITU-R (2005). Specific attenuation model for rain for use in prediction methods, (Question ITU-R 201/3), RECOMMENDATION ITU-R P.838-3, Rec. ITU-R P.838-3.

Johnston, E. (2019). Satellite Link Budget Calculator. Satellite Signals Limited. Extracted on 24th Apr. 2020. Source: https://www.satsig.net/linkbugt.htm

Kanellopoulos, J. D., Panagopoulos, A. D., \& Livieratos, S. N. (2000). Differential Rain Attenuation Statistics Including an Accurate Estimation of the Effective Slant Path Lengths. Progress in Electromagnetics Research, PIER 28, 97-120, DOI: 10.2528/PIER99060503

Karim, S. M. R., Sakib, S., Islam, M. T., \& Ahamed, F. A. S. (2018). A Review of Communications Satellite by Focusing on 'Bangabandhu Satellite-1', the First GEO Communications Satellite of Bangladesh. International Journal of Networks and Communications, $8(5), \quad 123-128, \quad$ DOI: 10.5923/j.ijnc.20180805.01

Kestwal, M. C., Joshi, S., \& Garia, L. S. (2014). Prediction of Rain Attenuation and Impact of Rain in Wave Propagation at Microwave Frequency for Tropical Region (Uttarakhand, India). International Journal of Microwave Science and Technology, Hindawi Publishing Corporation, 2014, 1-6, DOI: http://dx.doi.org/10.1155/2014/958498

KYMETA (2019). Link Budget Calculations for A Satellite Link with an Electronically Steerable Antenna Terminal. Kymeta Corporation and its affiliates.

Lwas, A. K., Islam, M. R., Habaebi, M. H., Mandeep, S. J., Ismail, A. F., Daoud, J. I., \& Zyoud, A. (2015). A Modified Effective Path Length for Predicting Rain Attenuation Based on Measurements in Penang-Malaysia. ARPN Journal of Engineering and Applied Sciences, 10(21), 10096-10100.

Mahmud, M. R. A., \& Khan, Z. S. (2009, September). Analysis and Planning Microwave Link to Established Efficient Wireless Communications [Master thesis, Master of Science in Electrical Engineering]. Department of Signal Processing, School of Engineering, Blekinge Institute of Technology. 
Mantoro, T., Akhtaruzzaman, M., Mahmud, M., \& Ayu, M. A. (2015). Design and Development of an Interactive Monitoring System for Pilgrims in Congregation of Hajj Ritual. Journal of Convergence Information Technology (JCIT), 10(1), 28-57.

Mebrek, M. A., Abderrahmane, L. H., Himeur, A., \& Bendoukha, S. (2012). Configuration and the Calculation of Link Budget for a Connection via a Geostationary Satellite for Multimedia Application in the $\mathrm{Ka}$ band. International Journal of Electronics and Communication Engineering, World Academy of Science, Engineering and Technology, 6(4), 466470.

Medvedev, P. A., Bykov, L. V., Bykov, V. L., Novorodskaya, M. V., \& Sherstneva, S. I. (2018). Methods for Transformation of Rectangular Spatial Coordinates to Geodetic Coordinates. International Journal of Engineering \& Technology (IJET), 7(4.38), 1179-1186

Mello, L. d. S., \& Pontes, M. S. (2012). Unified Method for the Prediction of Rain Attenuation in Satellite and Terrestrial Links. Journal of Microwaves, Optoelectronics and Electromagnetic Applications, 11(1), 1-14.

Mir, H., Cui, X., Shahzad, A., \& Jumani, R, (2018). Optimization of Satellite Link to Earth Station Using Satellite Tool Kit (STK). International Journal of Electrical, Electronics and Data Communication, 6(12), 48-52.

Nizam, S. J. (2008, April 19). Military Application of Satellite. The Daily Star, Bangladesh.

Nuroddin, A. C. M., Ismail, A. F., Abdullah, K., Badron, K., Ismail, M., \& Hashim, W. (2013). Rain Fade Estimations for the XBand Satellite Communication Link in the Tropics. International Journal of Computer and Communication Engineering, 2(4), 408-412, DOI: 10.7763/IJCCE.2013.V2.215

OMNI (2020). Omni Calculator: Azimuth calculator. Extracted on 18th Apr. $2020 . \quad$ Source: https://www.omnicalculator.com/other

Panchal, P., \& Joshi, R. (2016). Performance Analysis and Simulation of Rain Attenuation Models at $12-40 \mathrm{GHz}$ Band for an Earth Space Path over Indian Cities. Procedia Computer Science, ELSEVIER, 79(2016), 801-808.

Panou, G., Korakitis, R., \& Delikaraoglou, D. (2018). Cartesian to Geodetic Coordinates Conversion by an Iterative Geometrical Method. Quod Erat Demonstrandum - In quest of the ultimate geodetic insight, Special issue for Professor Emeritus Athanasios Dermanis, School of Rural and Surveying Engineering, AUTh, 274-281.

RACOM (2018). Application Notes, RACOM Radio Dato Networks, Version 1.0, 7/12/2018, 1-17.

Ranjan, A., Panigrahi, B., Rath, H. K., Misra, P., Simha, A., \& Sahu, H. B. (2018, February). A Study on Pathloss Model for UAV Based Urban Disaster and Emergency Communication Systems. IEEE Twenty Fourth National Conference on Communications (NCC), Hyderabad, India. DOI: 10.1109/NCC.2018.8600260

Roddy, D. (2006). The Geostationary Orbit (Chapter 3). In Satellite Communications, $4^{\text {th }}$ Edition, McGraw-Hill, (pp. 77-101).

SatcomUK (2015). Satellite Link Budget Calculators. Extracted on 24th Apr. 2020. Source: http://www.satcoms.org.uk/satellitelink-budget-calculator.asp

Satcom Services Networks (2020). Link Budget Calculations: Geostationary Satellite Azimuth and Elevation Calculation. Extracted on 18th Apr. 2020. Source: https://satcomservices.com/VSAT/linkbudget.html
Shrestha, S., \& Choi, D. Y. (2017). Characterization of Rain Specific Attenuation and Frequency Scaling Method for Satellite Communication in South Korea. International Journal of Antennas and Propagation, Hindawi, 2017, 1-16, DOI: https://doi.org/10.1155/2017/8694748

Shrestha, S., \& Choi, D. Y. (2019). Rain Attenuation Study at KuBand over Earth-Space Path in South Korea. Advances in Astronomy, Hindawi, 2019, 1-12, DOI: https://doi.org/10.1155/2019/9538061

Soler, T. (1976). On differential transformations between Cartesian and curvilinear (geodetic) coordinates. Rep. No. 236, Dept. of Geodetic Sci., Ohio State Univ., Columbus, Ohio.

Soler, T., \& Eisemann, D. W. (1994). Determination of Look Angles to Geostationary Communication Satellites. Journal of Surveying Engineering, 120(3), 115-127.

Song, H., \& Schnieder, E. (2019). Development and Evaluation procedure of the Train-centric Communication based System. IEEE Transactions on Vehicular Technology, 68(3), 20352043, DOI: 10.1109/TVT.2018.2868881

Stutzman, W. L. (1998). Estimating Directivity and Gain of Antennas. IEEE Antennas and Propagation Magazine, 40(4), $7-11$

SWA (2020). South West Antennas, RF Calculators and Conversion Tools. Extracted on 18th Apr. 2020. Source: https://www.southwestantennas.com/rf-calculators-andconversion-tools

TRANZEO (2010). Wireless Link Budget Analysis: How to Calculate Link Budget for Your Wireless Network. Tranzeo Wireless Technologies Inc., TR3014-01, 1-4, http://www.tranzeo.com/allowed/Tranzeo_Link_Budget_Whit epaper.pdf

TRIAXMAN (2020). SatLex: Calculator for azimuth and elevation angle. Extracted on 20th Apr. 2020. Source: https://satlex.de/en/azel_calcparams.html?satlo $=7.0 \&$ user_satlo $=7 \&$ user_satlo_dir $=E \&$ loca tion $=\& l a=41 \& l o=29 \&$ country_code $=$ ng $\&$ diam_w=70\&diam $\mathrm{h}=75$

TutorialsWeb (2020). A home for Tutorials; Satellite Look Angle Calculator: Azimuth and Elevation Angles Calculator. Extracted on 19th Apr. 2020. Source: https://www.tutorialsweb.com/satcom/calculation-of-satellitelook-angles.htm

Wangn, Y., Huynh, G., \& Williamson, C. (2013). Integration of Google Maps/Earth with microscale meteorology modelsand data visualization. Computers \& Geosciences, 61(2013), 2331

Ya'acob, N., Tajudin, N., Sarnin, S. S., Rahim, S. A. E. A., \& Manut, A. (2018). Link Budget and Noise Calculator for Satellite Communication. IOP Conf. Series: Journal of Physics: Conf. Series 1152 (2019) 012021, 1-7, DOI:10.1088/1742-6596/1152/1/012021

Yulianto, F. (2012). Link Budget Calculator Software Design with Microsoft Visual Basic. Jurusan Sistem Informasi, Sekolah Tinggi Manajemen Informatika Dan Komputer, Amikom Yogyakarta.

Yussuff, A. I. O., \& Khamis, N. H. H. (2013). Modified ITU-R Rain Attenuation Prediction Model for a Tropical Station. Journal of Industrial and Intelligent Information, Engineering and Technology Publishing, 1(3), 155-159, DOI: 10.12720/jiii.1.3.155-159

Zhiger, S. (2017). Development of an Intuitive Link Budget Tool for Military Satellite Communications [Master of Science thesis, IIUM]. International Islamic University Malaysia. 



\title{
Land-Use and Land-Cover Change in Dhaka Eastern Region and Its Impact on Surface Run-off
}

\author{
Md. Habibul Huq ${ }^{*}$ and Md. Mafizur Rahman² \\ 1Department of Civil Engineering, Military Institute of Science and Technology (MIST), Dhaka, Bangladesh \\ 2Department of Civil Engineering, Bangladesh University of Engineering and Technology (BUET), Dhaka, Bangladesh
}

emails: ${ }^{* 1}$ mdhabibulhuq4632@gmail.com; and ${ }^{2}$ mafizur@gmail.com

\section{ARTICLE INFO}

\section{Article History:}

Received: $10^{\text {th }}$ March 2020

Revised: $19^{\text {th }}$ April 2020

Accepted: 23rd April 2020

Published online: $21^{\text {st }}$ July 2020

\section{Keywords:}

Land-use

Land-cover

Dhaka Eastern Region

Regional Development Plan

Curve Number

Runoff

\begin{abstract}
A B S T RAC T
The aim of this study is to identify the impending urbanization-led land-use and land-cover (LULC) change of Dhaka Eastern Region (DER) and assessing its impact on surface runoff. Remotely sensed image data and proposed land-use plans for DER is analyzed and mapped in this study to detect the changes of LULC. A faster pace of land transformation was observed during 2016-17 from unpaved to the paved surface. Four post-developed LULC scenarios were predicted from the classified Landsat imagery of 2016-17 with increasing imperviousness. Runoff was estimated by SCS-CN method integrating RS and GIS tools. LULC changes according to land cover classes were assimilated with the hydrologic soil groups and then runoff depths were estimated for annual rainfall events in DER. Like the slower trend of urbanization, area-weighted $C N$ also increased slowly during 2016-17 but followed a moderate leap in RDP and scenario-1. However, $C N$ dropped in scenario-2 mainly due to the change in land-cover by infilling of highly permeable hydrologic soils. Predicted scenario-3 and 4 resulted in higher $C N$ respectively because of increasing imperviousness in LULC. Higher $C N$ resulted in higher runoff and more drainage requirements. RDP scenario or the predicted scenario- 1 with $C N 84$ is potentially a viable LULC option for DER by 2035 and beyond that may cause more than $30 \%$ to $50 \%$ runoff comparing to the representative 2010 LULC condition.
\end{abstract}

\section{INTRODUCTION}

Urbanization, a continuous development phenomenon across the globe is physically causing a change in the land-use and land-cover (LULC) of countries and cities with more impervious or paved surfaces. Land use planning is the broad allocation of land as per city functions in an urban area and land cover is the result of that land-use planning. Residential areas constitute a major part of urban land use in any city. Urbanization turns out to be paradoxical when urban development goals attempt to ignore environmental sustainability. Unplanned urban spatial growth with poor to no concerns about the environment is increasingly marked in the lower-middle-income countries where the pace of urbanization is the fastest. The impact of unplanned urbanization on the city environment upsets the ecological factors and leads to a gradual degradation of life-support systems including air, water, and land (Mashreque, 2009).

Since independence, Dhaka city is growing both horizontally and vertically in an unplanned manner without any systematic and effective land-use planning (Nahrin, 2008;
Kalam, 2009). Dhaka-centric development has made the capital a fast-growing megacity and a hub of urban agglomeration. Increased economic activity in Dhaka is continuing rural-urban migration and putting pressure on the city's limited land, degrading environment, and collapsing urban services (Zaman et al., 2010). As land is getting scarce in central Dhaka, peripheral land inclusion as per DAP (Detailed Area Plan) by Rajdhani Unnoyon Kartipakkha (RAJUK) makes a new provision for greater Dhaka, named as Dhaka Metropolitan Region (DMR) (RAJUK, 2015).

The primate city Dhaka with an area of 368 square $\mathrm{km}$ has the population density around 45,700 people per square kilometer, making Dhaka the most densely populated city in the world (Demographia, 2017). Recent Dhaka Structure Plan (DSP) 2016-35 provides a long-term strategic direction for an environmentally sustainable and livable greater Dhaka city with the key focus on the urban development of DMR for 20 years (RAJUK, 2015). DMR is geographically extended to Dhaka City and comprised of six regions, presented in Figure 1. 


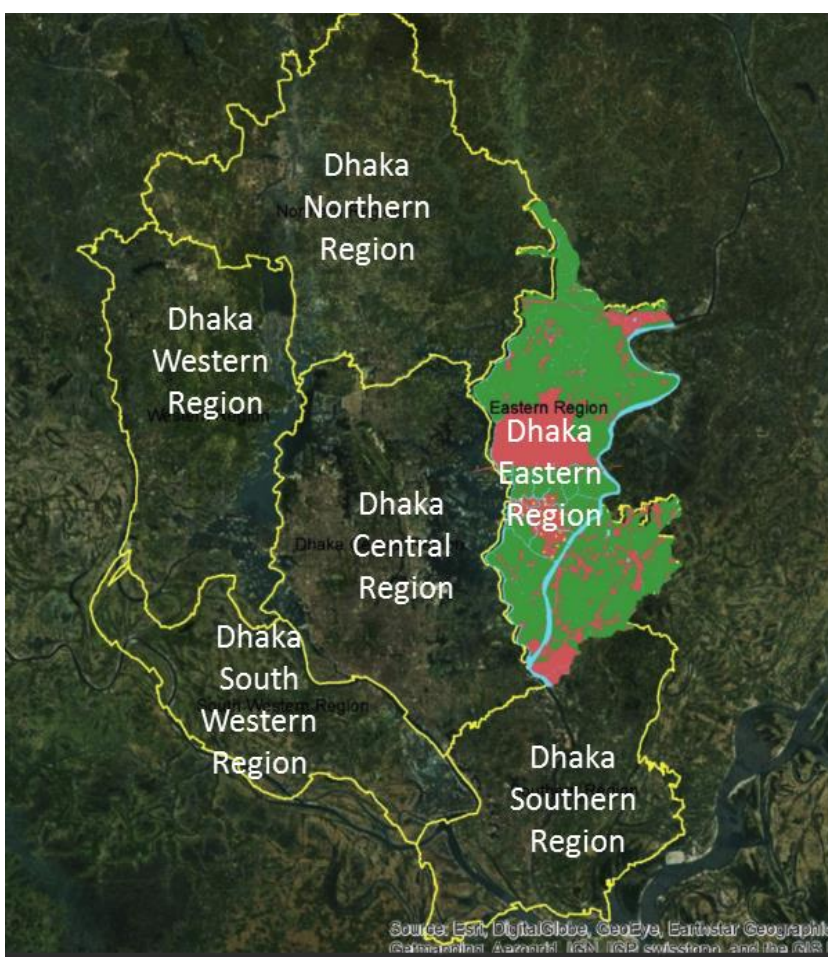

Figure 1: Dhaka Metropolitan Region (DMR) and Study Area: Dhaka Eastern Region (DER) (RAJUK, 2015)

LULC change of DMR is particularly noticeable in the case of change of Dhaka Central Region or core city Dhaka due to its unplanned spatial growth and increased imperviousness over the years without much consideration to urban development control tools relating to development intensity and density. Limited unpaved surface in central Dhaka is making the city waterlogged during monsoon because of intense rainfall and water-stressed during pre-monsoon due to over-extraction of groundwater (Shamsudduha et al., 2011; Akhter et al., 2009). Urgent focus is needed in the ongoing urban development initiatives and activities of DER which is very close to core city Dhaka and awaiting significant urban growth in the near future.

Remote Sensing (RS) and Geographical Information Systems (GIS) are now widely used to study LULC change due to urbanization. Integration of RS and GIS provides valuable information on the multi-temporal data on the processes and patterns of LULC change including mapping, analyzing and monitoring the trend of land-cover change dynamics (Shalaby \& Tateishi, 2007; Ram \& Kolarkar, 1993). While considering the case of the capital city Dhaka, the LULC change study is limited to core city Dhaka and the fringe area. One of the studies assessed the LULC changes and urban expansion dynamics of the entire central region of Dhaka using RS data in conjunction with socio-economic variables (Dewan et al., 2009).

There is no study so far on Dhaka Eastern Region (DER) that identifies and predicts LULC change and its impact on surface runoff using Soil Conservation Service (SCS) Curve Number $(C N)$ method. The integration of GIS and RS technology in the SCS-CN model is increasingly used by many researchers nowadays (Rajbanshi, 2016). The SCS-CN method developed by Soil Conservation Service (SCS) of the United States Department of Agriculture (USDA) is an empirical approach to quantify runoff of a watershed, agricultural fields or area from rainfall events (Ahmad et al.,
2015; USDA, 1972). This is a widely used hydrological model for estimating direct runoff from the relationships between rainfall, land-uses and hydrologic soil groups (Harbor et al., 2006; Gitika \& Ranjan, 2014). The $C N$ is a dimensionless index and a design tool that represents the runoff potential of watershed/drainage area/basin/ agricultural fields relying principally on hydrologic soil group (HSG), LULC, land treatment, hydrologic conditions and antecedent moisture condition (AMC) (USDA, 1986; USDA, 1989). An example of the LULC change study by integrating RS, GIS and $C N$ technology was in the Jobaru River basin of Japan. The study identified the land-use changes during 1948, 1975, and 2005 with an increase in urban area and forestry, a decrease in agricultural and barren lands, while water and others remained relatively unchanged. The average $C N$ decreased for the whole Jobaru River basin which implied a decrease in overall runoff potential (Sumarauw \& Ohgushi, 2012).

Effective land-use planning with due concerns to hydrogeological aspects can reduce runoff, ensure better drainage and enhance groundwater recharge potentiality (Harbor, 1994). This study attempts to evaluate the LULC changes of DER from pre-developed (2010) to postdeveloped context (2035 and beyond) to broadly classify the LULC changes in terms of paved and unpaved surface including water bodies. Alongside, the study also intends to provide a general hydrological forecasting due to LULCinduced impacts on the potential surface run-off of DER considering the seasonality of soil moisture. Finally, the most likely LULC change along with $C N$ is ascertained for DER that may sustain hydrological balance.

\section{LOCATION AND HYDROGEOLOGICAL SETTING OF STUDY AREA}

The location and important details of the hydrogeological setting of the study area are appended below.

\section{A. Location of Study Area}

The study area (Figure 2) involves the eastern region of greater Dhaka as per RDP. It is just on the eastern side of core city Dhaka and beside the eastern fringe area. It is selected because of its impending urban development activities and likely to have a major change of existing LULC from agricultural to urbanized areas by 2035 . As per DSP 2016-35, DER is planned to accommodate partly the population pressure of central Dhaka (RAJUK, 2015). Significant urban growth by RAJUK and others are waiting for implementation. It is situated between $23^{\circ} 42^{\prime}$ to $24^{\circ} 0^{\prime}$ North latitude and $90^{\circ} 26^{\prime}$ to $90^{\circ} 37^{\prime}$ East longitude on the eastern side of core city Dhaka. Given the area allocation of DMR, DER occupies $14.1 \%$ of the total DMR area with approximately $215.28 \mathrm{sq}$ $\mathrm{km}$. (RAJUK, 2015). It is bounded by a part of Kaliganj Upazila of Gazipur district on the northern side and Rupganj Upazila of Narayanganj district on the southern side including a part of Tarabo and Rupshi area of Narayanganj Sadar Upazila (JICA \& DTCA, 2016).

\section{B. Existing LULC and Topography}

The study area, DER is closely a riverine basin of the river Shitalakkhya and Balu except for the raised middle portion of the area. It is predominantly an agricultural area and occupying more than $80 \%$ of the entire region. The existing built-up area (mainly residential) occupies less than $10 \%$ of the total area. Water bodies comprised of less than $10 \%$ of the 
total area is also used for agriculture during the dry season (JICA \& DTCA, 2016). The LULC of the study area is a mix of agriculture, vegetation, tree-covered land, bare land, sandfilled land, and built-up area. The land adjacent to the river Shitalakkhya dominantly comprises of agricultural land. The land enclosed within the two rivers on the southern part is comparatively low lying than the northern part with bunded agriculture, bare and sand-filled land. Few low-lying areas have been observed with seasonal water within the agricultural land. From the field investigation together with recent satellite imagery i.e., Google earth and Landsat (2016) infers that the mid-portion of DER is transformed from agricultural land to residential land with urban development activities such as grading of existing lands and sand-filling of the low lying areas. Purbachal New Town (PNT), the largest urban growth by RAJUK is also located in this region. Areas planned for residential development are expected to have an average elevation of PWD (Public Works Department) reference level of 7.5 to $8 \mathrm{~m}$. Other areas are generally low, flat, fertile, and flood-prone and the elevation varies from 2 to 13 meters above sea level (JICA \& DTCA, 2016). Figure 3 shows the Digital Elevation Model (DEM) from SRTM data before urban development which signifies higher elevation in PNT areas and lower in Jolshiri and areas beside the rivers.

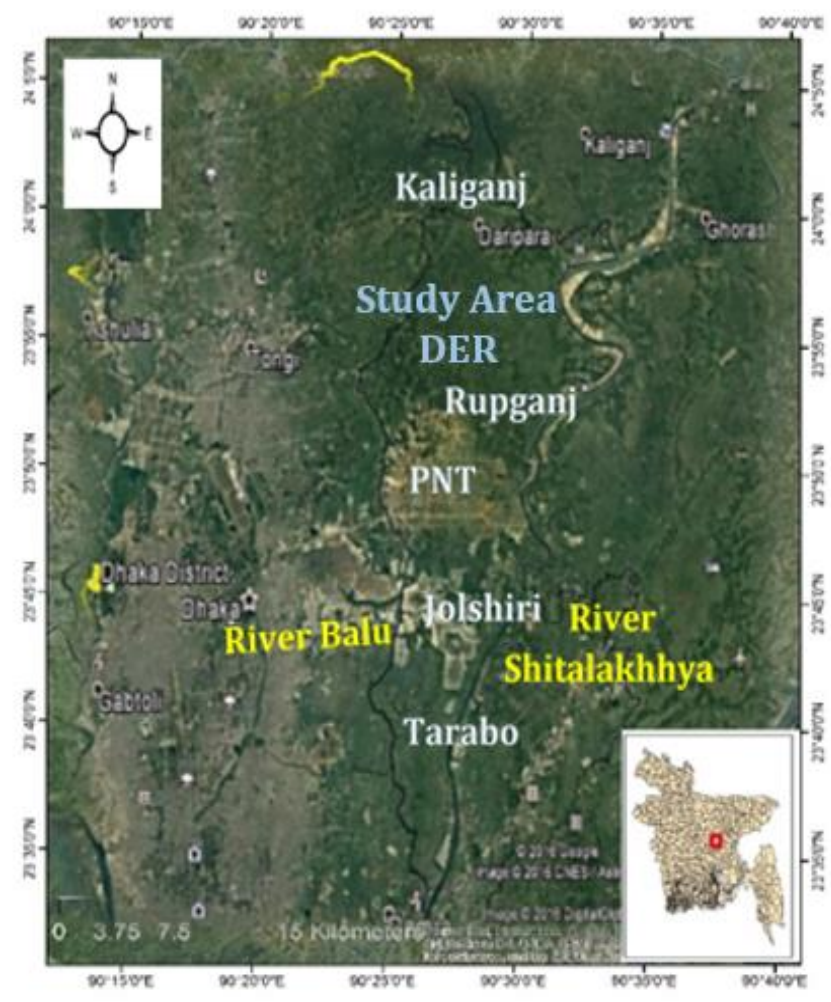

Figure 2: Location of Study Area: Dhaka Eastern Region (DER) (RAJUK, 2015)

Elevation beside the river Shitalakkhya and Balu is generally low. Few abandon channels also characterize the area being modified by human interaction as well as agricultural practice. Most of the water bodies are being used for fisheries or seasonal cultivation. As the road network is not fully developed, the industrial development covers less than $3 \%$ of the total area and mostly concentrates by the riverside of Balu and the Shitalakkhya, and Bhulta area (JICA \& DTCA, 2016). The slope of the study area varies within 0 to $3 \%$ that may have a trivial influence on runoff.

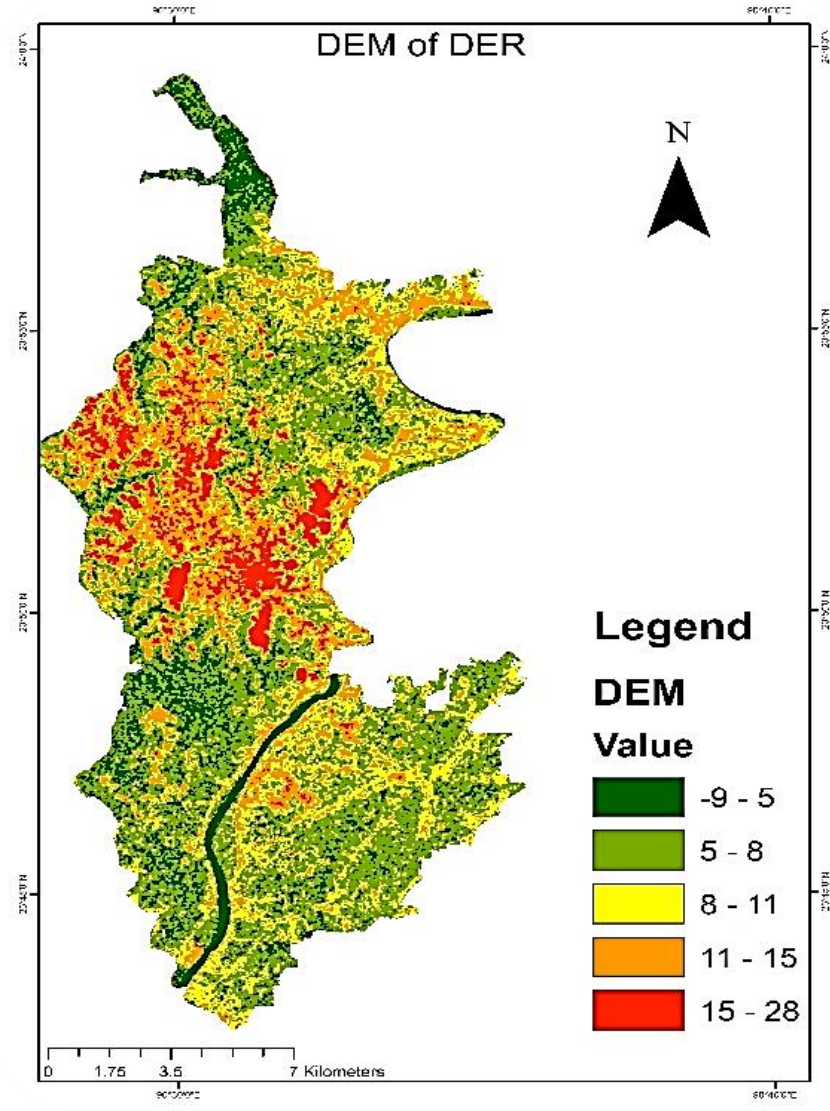

Figure 3: Digital Elevation Model (DEM) of DER (SRTM DEM Landsat Image Data of 2010)

\section{Climate}

Like the other parts of the country, Dhaka has a tropical monsoon climate (Hoque et al., 2007) and can be broadly classified into three seasons: Pre-Monsoon, Monsoon and Post Monsoon or Dry Season (Sultana, 2009). Monsoon is considered to begin from June till September and nonmonsoon from October to May with some variations (JICA \& DTCA, 2015). The humid climatic condition is characterized by short cool winters and long hot summers with high relative humidity and low active wind speed (Sultana, 2009). Dhaka has an annual precipitation of 1,400 to $2,400 \mathrm{~mm}$, and about $80 \%$ of which is concentrated during the monsoon season from June to September (JICA \& DTCA, 2015). The temperature varies from $18^{\circ} \mathrm{C}$ in January and $29^{\circ} \mathrm{C}$ in August with an annual average temperature of $25^{\circ} \mathrm{C}$.

\section{Geology of DER}

The natural geological settings of DMR is linked with the Ganges-Brahmaputra-Meghna (GBM) river system (locally known as Padma-Jamuna-Meghna river system) by the interconnecting streams and retention basins (Hoque et al., 2007, Shamsudduha et al., 2011). It is situated in the central part of Bangladesh comprises of an older flood plain having relatively flat terrain conditions with few depressions. Four rivers - the Buriganga, Turag, Balu and Tongi Khal (canal) form the area borders of Dhaka Central Region; whereas river Balu forms the western boundary and the river Shitalakkhya forms part of the eastern boundary of DER. In general, these local rivers feed the flood plains and marshy lands in and around Dhaka city (Hoque et al., 2007). The generalized surface geology of the study area is formed by the Holocene deposits of alluvial sand, marsh clay and peat, alluvial silt including Modhupur clay residuum (JICA \& DTCA, 2015) 
and the Pleistocene deposits of alluvial silt and Modhupur clay (Hoque et al., 2007; Shamsudduha et al., 2011).

Some western part of the study area bordered by river Balu has three distinct surface deposits: Floodplain and High Floodplains of Holocene age and the Madhupur clay of Pleistocene age (Hoque et al., 2007). A comprehensive geological and geotechnical investigation in the Jolshiri Housing Project area within DER to determine subsurface geology using by Standard Penetration Test (SPT) in 2014 confirmed that the project area is shielded with mostly fluvial deposits. i.e., flood plains of Holocene age and the surface deposits are the input of sediments from the river Shitalakkhya. The remnant portion is the gully of Modhupur terrace that might have been originated due to the dissection of the uplifted Modhupur terrace. The adjacent low land of the area contains recent flood plain deposits.

The lithology of the area consists of clay, silty clay, organic clay with iron concentrations and organic materials. Reddishbrown, yellowish-brown, grey colours with mottling are prominent in the clays (DU, 2014). The topsoil texture of the study area mainly consists of clay and varying as mixed clay, clay loam, silty clay and silty clay loam. The classified soil depth mostly varies between 0.60 to $1.22 \mathrm{~m}$. However, topsoil depth extends below more than $1.22 \mathrm{~m}$ in the midportion and north of the study area. The permeability is classified as mixed $\operatorname{rapid}(>7.5 \mathrm{~mm} / \mathrm{hr})$, moderate $(3.8-$ $7.5 \mathrm{~mm} / \mathrm{hr})$ and slow $(1.3-3.8 \mathrm{~mm} / \mathrm{hr})$ (BARC, 1988). However, urban development activities are continually changing the soil profile at the study area.

\section{METHODOLOGY}

The study involved five different sets of data: Thematic maps, Geospatial data, Satellite data, Hydrological data, and Geological data. LULC change analysis required the data of thematic maps, DEM, elevation, Landsat Image. Runoff analysis involved slope of the area, drainage/stream network, topsoil texture, soil depth, soil permeability, and daily rainfall data and lithological sequence of the study area. Table 1 illustrates the details of data requirements including the sources of data.

Table 1

Data Requirement of the Study

\begin{tabular}{|c|c|c|}
\hline Data Types & Details of Data & Source of Data \\
\hline \multirow{4}{*}{ Thematic Maps } & DAP (2010) of DMDP and RDP Survey 2013 & $\begin{array}{l}\text { Rajdhani Unnayan Kartripakkha (RAJUK), Dhaka Structure } \\
\text { Plan 2016-35, Japan International Cooperation Agency (JICA) }\end{array}$ \\
\hline & $\begin{array}{l}\text { Land-use Planning of Purbachol New Town (PNT) Project } \\
\text { Land-use Planning of Jolshiri Housing Project }\end{array}$ & $\begin{array}{l}\text { RAJUK } \\
\text { Jolshiri Abashon Authority }\end{array}$ \\
\hline & Surface Geology & Geological Survey of Bangladesh (GSB) \\
\hline & Soil Classification & Soil Resource Development Institute (SRDI) \\
\hline Geospatial Data & Top Soil Texture, Soil Depth, Soil Permeability & Bangladesh Agricultural Research Council (BARC) \\
\hline Satellite Data & $\begin{array}{l}\text { SRTM DEM } \\
\text { Landsat Image of } 2010,2012 \text {, and } 2016 \text { ( } 30 \mathrm{~m} \text { resolution) } \\
\text { Sentinel 2A Image of } 2017 \text { ( } 10 \mathrm{~m} \text { resolution) }\end{array}$ & $\begin{array}{l}\text { USGS (SRTM Global DEM) } \\
\text { USGS, NASA } \\
\text { European Space Agency (ESA) }\end{array}$ \\
\hline Hydrological Data & Daily, Monthly and Annual Rainfall (1995-2015) & $\begin{array}{l}\text { Bangladesh Water Development Board (BWDB) and } \\
\text { Bangladesh Meteorological Department (BMD) }\end{array}$ \\
\hline Geological Data & Lithological Sequence (Bore-log) & $\begin{array}{l}\text { BWDB, Department of Public Health Engineering (DPHE) and } \\
\text { Geological Investigation Report of Jolshiri Housing Project, } \\
2014\end{array}$ \\
\hline
\end{tabular}

\section{A. Categorization of LULC for the Study}

To simplify the different details of the LULC plan of DER and mark the changes easily from mapping, three broad categories of LULC have been taken into consideration. These are:

- Paved: Means imperviousness caused by structural (built-up) development which includes all residential, industrial, commercial, settlements, services, roads, or any other mixed urban, and other urban development and structure on the surface.

- Unpaved: Means pervious surface that includes all agricultural land, crop fields, fallow lands, low height vegetation, tree cover, bare soil or filled land, and open space.

- Waterbody: Means any surface water body which includes rivers, lake, canals, pond and/or any surface water body within the geographic boundary.

\section{B. Application of RS and GIS in LULC Change Detection}

RS and GIS were used to study LULC change due to urbanization. DEM was used to identify the original landscape and also to specifically locate the low-lying areas that are either sand-filled or underwent some changes within the study area. ArcGIS with its several built-in functions was used to turn the DEM into a derivative map of slope and drainage network. Landsat 5 (TM) of 2010, Landsat 7 (ETM+) of 2012, and Landsat 8 (OLI/TIRS) of 2016 and Sentinel-2A (MSI) of 2017 were selected as the remotely sensed image data for the study. Collected Landsat images and DEM were geo-referenced according to the geographic coordinate system (GCS_WGS_1984). Geographic coordinate systems indicate location using longitude and latitude based on a sphere (or spheroid) while projected coordinate systems use $\mathrm{X}$ and $\mathrm{Y}$ based on a plane. The projected coordinate system used for this study is WGS_1984_UTM_Zone_45N which is 
applicable to Bangladesh. Table 2 shows the data acquisition date including polygon path and row.

Table 2

Landsat and Sentinel-2A Image Acquisition Date and Polygon Path/Row

\begin{tabular}{|c|c|c|c|c|}
\hline Satellite & Sensor & $\begin{array}{c}\text { Acquisi } \\
\text { tion } \\
\text { Date }\end{array}$ & $\begin{array}{c}\text { Polygon } \\
\text { Path / } \\
\text { Row }\end{array}$ & Resolution \\
\hline Sentinel-2A & $\begin{array}{c}\text { MSI (Multi- } \\
\text { spectral } \\
\text { Imager) }\end{array}$ & $\begin{array}{c}01 \text { Feb, } \\
2017\end{array}$ & - & $10 \mathrm{~m}$ \\
\hline Landsat-8 & $\begin{array}{l}\text { Operational } \\
\text { Land } \\
\text { Imager } \\
\text { (OLI) and } \\
\text { Thermal } \\
\text { Infrared } \\
\text { Sensor } \\
\text { (TIRS) }\end{array}$ & $\begin{array}{c}16 \text { Feb, } \\
2016\end{array}$ & $137 / 44$ & $30 \mathrm{~m}$ \\
\hline Landsat-7 & $\begin{array}{l}\text { Enhanced } \\
\text { Thematic } \\
\text { Mapper + } \\
(\text { ETM+) }\end{array}$ & $\begin{array}{c}13 \text { Feb, } \\
2012\end{array}$ & $\begin{array}{c}137 / 43 \\
\text { and } \\
137 / 44\end{array}$ & $30 \mathrm{~m}$ \\
\hline Landsat-5 & $\begin{array}{c}\text { Thematic } \\
\text { Mapper } \\
\text { (TM) }\end{array}$ & $\begin{array}{c}30 \text { Jan, } \\
2010\end{array}$ & $\begin{array}{c}137 / 43 \\
\text { and } \\
137 / 44\end{array}$ & $30 \mathrm{~m}$ \\
\hline
\end{tabular}

For this particular study, a supervised classification method has been used. Focal analysis has been performed for the Landsat 7 ETM+ (2012) to remove the black stripes around the image. The geometric correction was performed on all the images using a Landsat TM image of the same area from 2010 as reference. The atmospheric effect of the imageries was corrected following López-Serrano et al. (2016). Training polygons were drawn covering the pixels having the same land-use. To train a single land-use class, 30 polygons were drawn. This process was performed for all the 5 (five) classes and saved as a signature file (.sig extension) using the classification toolbar of ArcGIS 10.2. This signature file was finally used during the supervised classification step. For the rest of the three imageries (2012, 2016, and 2017), separate three signature files were developed through training the datasets based on the above-mentioned processes. All the images were verified using Google Imagery of those dates.

Pre-Developed (2010) LULC represented in Landsat imagery of 2010 has been classified using 'Maximum Likelihood Classification' (MLC) with five land-cover types: Paved (Existing Built-up/ Settlement), Unpaved (Bare Land / Filled Land), Unpaved (Agriculture / Vegetation - Low Height 3 to $4 \mathrm{ft}$ Plantation), Unpaved (Tree Cover), and Waterbodies. Accordingly, the other three images were also classified in the same land-cover category. Non-urban land uses remained dominant in DER such as agricultural land, bare land, and tree-covered land. From the potential information content of band combination, the combination $(5,4,3)$ was used which provided the most agricultural information and it was also useful for vegetation studies. As 2016 and 2017 imageries were mostly identical in terms of land-cover classification, the image of 2016 was used to represent the LULC information of the existing 2016-2017 condition. Percentage imperviousness is an important factor for any urban growth. Higher imperviousness is likely to cause a higher population and structural density. Following four predicted scenarios were developed through the conversion of identified land-cover of existing 2016-2017 condition:

- Predicted Scenario-1: Conversion of Identified Tree-covered Land for Urban Development with 65\% Imperviousness.

- Predicted Scenario-2: Conversion of Identified Agricultural Lands for Urban Development with 65\% Imperviousness.

- Predicted Scenario-3: Conversion of Identified both Tree-covered and Agricultural Land for Urban Development with 65\% Imperviousness.

- Predicted Scenario-4: Conversion of Identified both Tree-covered and Agricultural Land for Urban Development with 85\% Imperviousness.

\section{SCS-CN Method for Runoff Estimation}

Runoff is one of the important hydrologic variables used in water resources applications and management planning (Amutha \& Porchelvan, 2009). Human-induced LULC change is very common that causes a significant impact on the hydrologic system (Bhaduri et al., 2000). The SCS-CN method is now used as the method for computing peak runoff rates and volumes for Urban Hydrology (USDA, 1986) and also for the analysis of land use changes, i.e., urbanization or low impact development of urban areas (Banasik et al., 2014).

\section{i. Application of Soil Conservation Service (SCS) - Curve Number (CN) Method for Runoff Computation}

The $C N$ parameter can represent LULC changes and their impact on surface runoff (Sumarauw \& Ohgushi, 2012; Melesse \& Shih, 2002; Harbor, 1994). Runoff estimation by $C N$ method with several years of daily rainfall data provides an initial or general estimate of the impact of LULC change on long-term annual or seasonal average runoff depths (Harbor, 1994). Although the method is the time-consuming and error-prone the impact of LULC changes on runoff due to proposed and predicted development scenarios can be ascertained quite reasonably for local planning uses (Harbor, 1994). The spatial distribution of $C N$ due to LULC change (urbanization in particular) and corresponding runoff response is likely to show a shift in the overall water cycle of the study area (Bhaduri et al., 2000; Melesse \& Shih, 2002).) A study on urban watersheds notes that the SCS-CN method appears to be sufficiently sensitive to determine the effect of urbanization on the volume of runoff (Samuel et al., 1973).

\section{ii. SCS-CN Runoff Equation}

In the SCS-CN method (USDA, 1986), runoff equation is based on infiltration losses that are combined with surface storage by the following relation:

$Q=\left(P-I_{a}\right)^{2} /\left(P-I_{a}+S\right)$

Where, $Q=$ runoff $($ in $), P=$ rainfall $($ in $), S=$ potential maximum retention after runoff begins $(\mathrm{in})$, and $I_{a}=$ initial abstraction (in).

Initial abstraction $\left(I_{a}\right)$ is all losses before runoff begins. It includes water retained in surface depressions, water intercepted by vegetation, evaporation, and infiltration. $I_{a}$ is highly variable but generally is correlated with soil and land cover parameters. Through studies of many small agricultural watersheds, $I_{a}$ was found to be approximated by the empirical equation, $I_{a}=0.2 S$ (USDA, 1986). 
Simplifying Equation (1), runoff can be estimated in inch as follows:

$Q=(P-0.2 S)^{2} /(P+0.8 S)$

Here, $Q=0$ for $P<0.2 S$

For Indian conditions (Ministry of Agriculture, India, 1972),

$I_{a}=0.3 S$ and the empirical relationship is,

$S=(25400 / C N)-254 \mathrm{~mm}$

The equation can be rewritten as,

$Q=(P-0.3 S)^{2} /(P+0.7 S)$

Knowing the value of $C N$, runoff from the watershed can be computed from Equations (3) and (4). The $C N$ is ranging from 0 when $S$ is $\infty$, up to 100 when $S=0$. Both conditions represent the extremes between total infiltration (runoff $=$ 0 ) and totally impervious watersheds $($ rainfall $=$ runoff $)$. However, many of the computations use 30 as the lowest value, even when lower values could be detected (USDA, 1986).

\section{iii. Antecedent Moisture Condition (AMC)}

The SCS introduced the AMC concept to determine soil moisture before a storm event, the condition of which could affect the calculation of runoff (USDA, 2004). There are three conditions for dry (AMC I), normal (AMC II) and saturated soils (AMC III) that are assigned as a function of the five-day antecedent rainfall (Table 3) (USDA 2004). The moisture condition could affect runoff estimates because it modifies the $C N$ whose standard values are set to the AMC II by default. For modelling purposes, watersheds are often considered as average moisture conditions, i.e., AMC II. After selecting the AMC, the standard $C N$ values, if necessary, can be converted to AMC I or AMC III using the following functions (USDA, 2004).

$$
\begin{aligned}
& C N I=(4.2 * C N I I) /(10-0.058 * C N I I) \\
& \text { CNIII }=(23 * C N I I) /(10-0.13 * C N I I)
\end{aligned}
$$

Table 3

AMC Group and Related Soil Characteristics with 5-day

\begin{tabular}{|c|c|c|c|}
\hline \multirow{2}{*}{$\begin{array}{l}\text { AMC } \\
\text { Group }\end{array}$} & \multirow{2}{*}{ Soil Characteristics } & \multicolumn{2}{|c|}{$\begin{array}{l}\text { Total 5-day Antecedent } \\
\text { Rainfall, mm }\end{array}$} \\
\hline & & $\begin{array}{l}\text { Dormant } \\
\text { Season }\end{array}$ & $\begin{array}{l}\text { Growing } \\
\text { Season }\end{array}$ \\
\hline I & $\begin{array}{l}\text { Soil is dry but not to the } \\
\text { wilting point; } \\
\text { satisfactory cultivation } \\
\text { has taken place }\end{array}$ & $<13$ & $<36$ \\
\hline II & Average condition & 13 to 28 & 36 to 53 \\
\hline III & $\begin{array}{l}\text { Heavy or light rainfall } \\
\text { and low temperature } \\
\text { have occurred within } \\
\text { the last } 5 \text { days; } \\
\text { saturated soil }\end{array}$ & $>28$ & $>53$ \\
\hline
\end{tabular}
Antecedent Rainfall (USDA, 2007)

\section{iv. Hydrologic Soil Groups (HSGs)}

Soils are classified into four HSGs (Table 4) according to the premise that soils found within a climatic region that are similar in depth to a restrictive layer or water table, transmission rate of water, texture, structure, and degree of swelling when saturated, will have similar runoff responses. Soils in group A have the lowest runoff potential, soils in group B have moderately low runoff potential, soils in group C have moderately high runoff potential and group D soils have the highest runoff potential. With urbanization, native soil profiles may be mixed or removed or fill material from other areas may be introduced (USDA, 1986). As a result of construction and other disturbances, the soil profile can be altered from its natural state and the listed group assignments generally no longer apply, nor can any supposition based on the natural soil be made that will accurately describe the hydrologic properties of the disturbed soil. In these circumstances, an onsite investigation should be made to determine the hydrologic soil group (USDA, 1986).

Table 4

\begin{tabular}{|c|c|c|c|c|}
\hline HSG & $\begin{array}{l}\text { Soil } \\
\text { Type }\end{array}$ & $\begin{array}{c}\text { Soil } \\
\text { Texture }\end{array}$ & $\begin{array}{c}\text { Runoff } \\
\text { Potential }\end{array}$ & $\begin{array}{c}\text { Infiltration } \\
\text { Rate \& } \\
\text { Water } \\
\text { Transmission } \\
\text { Capacity }\end{array}$ \\
\hline A & $\begin{array}{l}\text { Deep, well- } \\
\text { drained sand } \\
\text { and gravels }\end{array}$ & $\begin{array}{l}\text { Sand, } \\
\text { loamy } \\
\text { sand, or } \\
\text { sandy } \\
\text { loam }\end{array}$ & Low & $\begin{array}{c}\text { Rapid } \\
(>7.5 \mathrm{~mm} / \mathrm{hr}) \\
\text { High }\end{array}$ \\
\hline B & $\begin{array}{l}\text { Moderately } \\
\text { deep, well- } \\
\text { drained with } \\
\text { moderately } \\
\text { fine to coarse } \\
\text { textures }\end{array}$ & $\begin{array}{c}\text { Silt loam } \\
\text { or loam }\end{array}$ & Moderate & $\begin{array}{c}\text { Moderate } \\
(3.8-7.5 \mathrm{~mm} / \mathrm{hr}) \\
\text { Moderate }\end{array}$ \\
\hline $\mathrm{C}$ & $\begin{array}{l}\text { Clay loams, } \\
\text { shallow } \\
\text { sandy loam, } \\
\text { soil with } \\
\text { moderately } \\
\text { fine to fine } \\
\text { textures }\end{array}$ & $\begin{array}{l}\text { Sandy clay } \\
\text { loam }\end{array}$ & $\begin{array}{l}\text { Moderately } \\
\text { high }\end{array}$ & $\begin{array}{l}\text { Slow to Moderate } \\
(1.3-3.8 \mathrm{~mm} / \mathrm{hr}) \\
\text { Low to Moderate }\end{array}$ \\
\hline D & $\begin{array}{l}\text { Clay soil that } \\
\text { swells } \\
\text { significantly } \\
\text { when wet }\end{array}$ & $\begin{array}{l}\text { Clay loam, } \\
\text { silty/ } \\
\text { sandy clay, } \\
\text { or clay }\end{array}$ & High & $\begin{array}{c}\text { Very Slow } \\
(<1.3 \mathrm{~mm} / \mathrm{hr}) \\
\text { Low }\end{array}$ \\
\hline
\end{tabular}

Classification of HSGs (USDA, 1986)

\section{v. Runoff Estimation}

LULC change detection maps provided the area-based hydrologic soil groups. $C N$ was determined to identify the hydrologic soil groups of the study area. Then area-weighted $C N$ was computed for each LULC map. The data and method applied to compute runoff by SCS-CN method are appended below.

- LULC maps of the study area were prepared considering the pre-developed and post-developed LULC characteristics including identification of permeable and impermeable areas by applying GIS.

- Hydrologic soil groups (A, B, C, and D) were identified as per area coverage of each soil group.

- Then $C N$ was assigned according to the delineated area. The $C N$ relied on the area's hydrologic soil group, LULC, and hydrological condition. In this study, $C N$ was assigned following SCS Tables in USDA, 1986; USDA2007; and Subramanya, 2008.

- Area-weighted composite $C N$ for different land-use and hydrological soil conditions was computed using the following equation. 
$C N=\sum(A i * C N i) / \sum A i$

Area-weighted $C N$ represents the average moisture condition of the soil or AMC II. While considering the seasonality of rainfall, the soil was considered to have all three antecedent moisture conditions. However, the AMC III condition was considered for wet season (monsoon) and AMC I condition during the dry season. Both seasonal AMC and average AMC were considered in this study to ascertain the variation of runoff depths between the conditions. The seasonality for this study was considered as AMC I for Dec, Jan, Feb, Mar (winter or dry period); AMC II for Apr, May, Oct, Nov (just immediate pre-monsoon - Apr and May and immediate postmonsoon - Oct. and Nov.); and AMC III for Jun., Jul., Aug., Sep. (monsoon and wet Period).

Obtaining the $C N$ value for each LULC change scenario, the SCS-CN method was applied. Runoff computation involved the hydrological data, mainly the long-term daily rainfall data of 21 years from 1995 to 2015 . As there was no rainfall station within the study area, daily rainfall data of Dhaka, Gazipur and Narayanganj for 21 years (1995 to 2015) were collected from BWDB and used for this study. As the runoff estimation was data-intensive, one rainfall station closer to Eastern Region CL42 (BWDB) was selected for computing daily runoff estimation. The rainfall data of each year was then transferred to an Excel spreadsheet so that the daily values were a single column of rainfall depths (in inches). However, days with zero precipitation may be deleted from the file to reduce the size of the spreadsheet. For each LULC and areaweighted $C N$, a column was prepared for runoff depth where each cell was determined by logical input: If $P>$ $[(300 / C N)-3]$, then $Q=(P-(300 / C N)+3)^{2} /[P+$ $(700 / C N)-7]$, else $Q=O$. Where, $P$ was the rainfall depth in inches and $Q$ was the depth of runoff in inches. It is to be mentioned that initial abstraction $I_{a}$ from rainfall was considered $0.3 S$ for the study area considering the Indian condition. The above logical input and spreadsheet analysis techniques were suggested by Harbor (1994) to compute storm-water runoff depths for different LULC conditions. Runoff depths for weighted $C N$ with AMC I and AMC III were also determined in a similar way. With 21 years of rainfall data and eight study LULC conditions, a total of 336 Excel spreadsheets were prepared $[\{21 \times$ $8($ for average $A M C)+21 \times 8($ for seasonal $A M C)\}=$ $336]$ to compute annual runoff depth of 21 years.

\section{ANALYSIS OF LULC CHANGE AND ITS IMPACT ON RUNOFF}

The following paragraphs briefly state the analysis of LULC change and its impact on surface runoff for DER.

\section{A. Analysis of Remotely Sensed Image Data and Proposed RDP Scenario by RAJUK}

Figure 4 includes the generated LULC maps of study area respectively for the pre-developed 2010 and 2012, existing 2016-17 and the proposed LULC of DER as per RDP for 2016-35. The chronological evaluation of LULC change from 2010 to the RDP scenario (2016-35) simply reflected the conversion of all unpaved bare soil or bare land into the paved surface by structural development, and consequent increase in overall built-up areas including a significant decrease in agricultural lands. However, due to the unavailability of GIS-based land-use data of RDP, specific broad details of the land-use plan and the given strategic zoning map for DER were used to identify the changes in LULC. The comparison of the existing 2016-17 condition to the RDP scenario identified a remarkable shift in the overall LULC pattern of DER. In the RDP scenario, the overall percentage increase in the paved surface was almost $40 \%$ of the existing 2016-17 condition, and the overall decrease in unpaved agricultural land was around $\mathbf{2 0} \%$. However, the RDP scenario accounted for around a 1.5\% decline in water bodies than the existing condition. Though there were some marked differences in the water bodies on the image of 2012 compared to 2010 and 2016, it was assumed temporary waterlogged areas. So, the percentage area of water bodies was considered the same for all the three Landsat images.
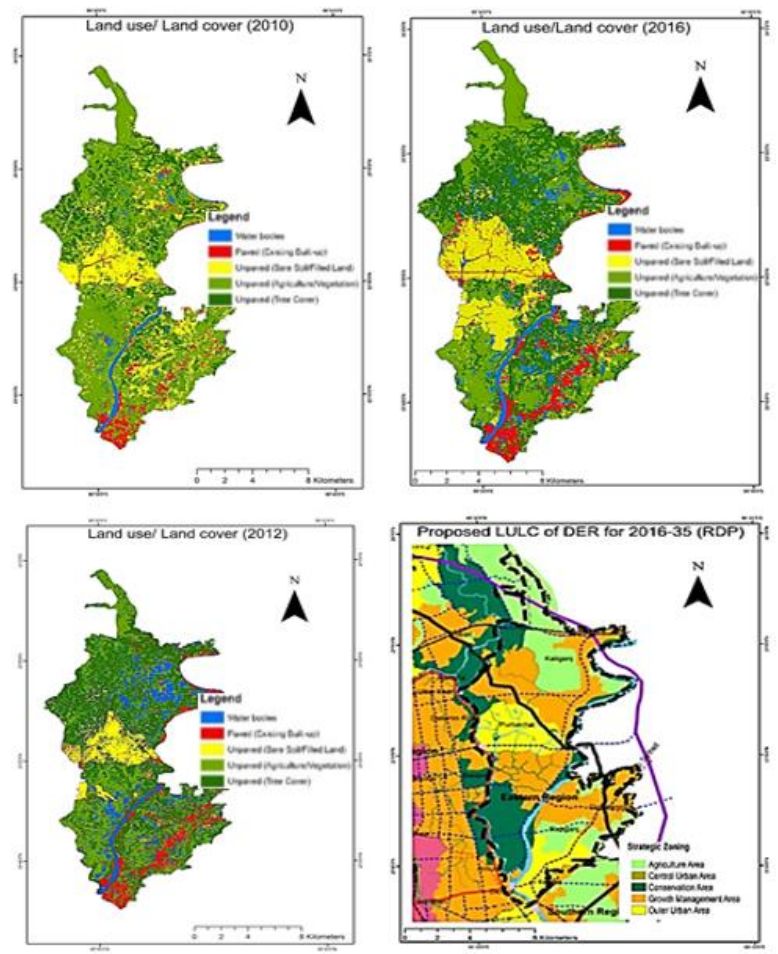

Figure 4: LULC Maps of DER from Landsat Image Data and RDP 2016-2035 (Author's Interpretation of Landsat Image Data; RAJUK, 2015)

Table 5 shows the quantified change of LULC of DER from the classified image of 2016-17 to the RDP scenario of 201635 proposed by RAJUK.

Table 5

Quantified Change of LULC of DER from 2016-17 to RDP Scenario (2016-35)

\begin{tabular}{|c|c|c|c|c|}
\hline \multirow[t]{2}{*}{ LULC Category } & \multicolumn{2}{|c|}{$\begin{array}{c}2016-17 \\
\text { (Existing Condition) }\end{array}$} & \multicolumn{2}{|c|}{$\begin{array}{c}2016-35 \\
\text { (RDP Scenario - } \\
\text { Proposed Post } \\
\text { Dev by RAJUK) }\end{array}$} \\
\hline & $\begin{array}{c}\text { Area } \\
\left(\mathrm{km}^{2}\right)\end{array}$ & $\begin{array}{l}\% \text { of } \\
\text { Land }\end{array}$ & $\begin{array}{c}\text { Area } \\
\left(\mathrm{km}^{2}\right)\end{array}$ & $\begin{array}{l}\% \text { of } \\
\text { Land }\end{array}$ \\
\hline $\begin{array}{l}\text { Paved (Built-up/ } \\
\text { Settlement) }\end{array}$ & 16.25 & 7.55 & 104.42 & 48.50 \\
\hline $\begin{array}{l}\text { Unpaved (Bare Land } \\
\text { / Filled Land) }\end{array}$ & 42.00 & 19.51 & 0.00 & 0.00 \\
\hline $\begin{array}{l}\text { Unpaved } \\
\text { (Agriculture / } \\
\text { Vegetation/ Tree } \\
\text { Cover) }\end{array}$ & 140.60 & 65.31 & 98.13 & 45.58 \\
\hline Water bodies & 16.43 & 7.63 & 12.73 & 5.91 \\
\hline Total & 215.28 & 100.00 & 215.28 & 100.00 \\
\hline
\end{tabular}




\section{B. Analysis of Imperviousness of Proposed Land-use Plan of PNT and Jolshiri Housing in DER}

To ascertain the basis of considering $65 \%$ imperviousness due to residential development, likely imperviousness of Purbachol (PNT) and Jolshiri Housing Projects (two major urban growths of DER) were investigated from the proposed land-use plan approved by RAJUK. Following the existing Floor Area Ratio (FAR) and Maximum Ground Coverage (MGC) rules of 2008 (GOB, 2008), the likely percentage imperviousness of the proposed land-use plans of both impending urban growth of study area were approximately $65 \%$ for PNT and $63 \%$ for Jolshiri Housing Area which revealed a likely high-density residential development.

\section{Analysis of Predicted LULC Scenarios of DER}

Post-developed predicted scenarios of LULC change followed a trend of increased urbanization and reduced unpaved surfaces (Figure 5).
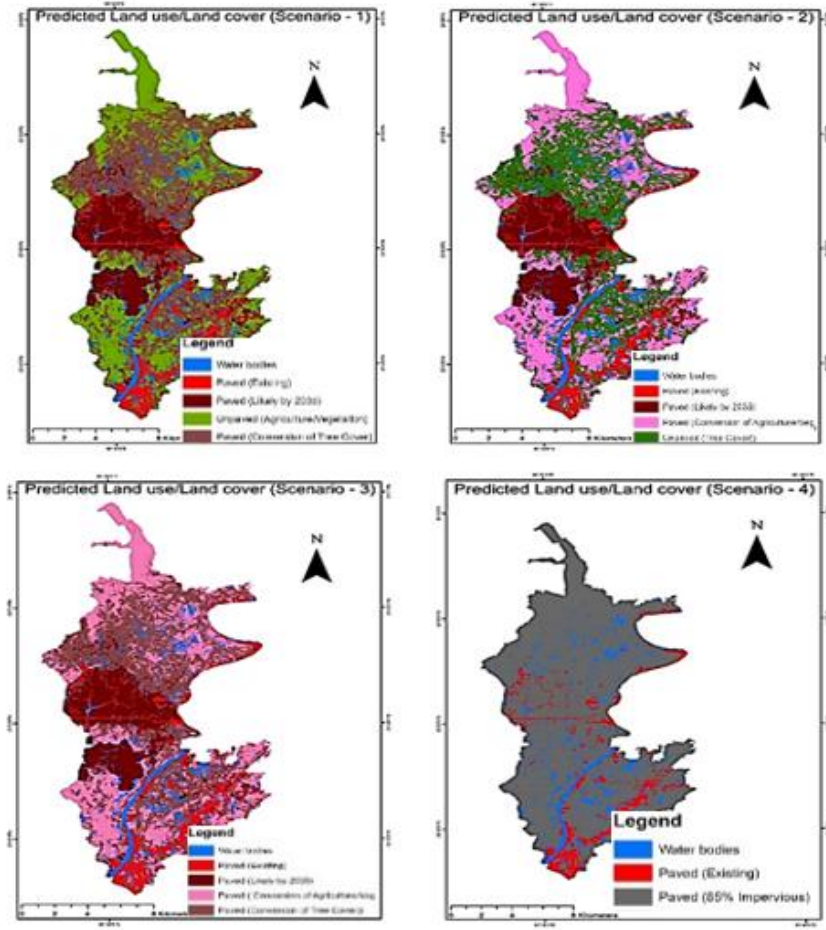

Figure 5: Predicted LULC Maps of DER from Classified Map of Existing 2016-2017 Condition

(Author's Interpretation of Landsat Image Data)

Conversion of all bare and filled land including identified agricultural or/and tree-covered land from the remotely sensed image of 2016-17 into paved built-up areas with a certain percentage of imperviousness was the key consideration of the predictions for post-developed scenarios. However, all the predictions include urban development of PNT and Jolshiri area by 2035 from the identified bare soil and filled land of existing 2016-17 LULC map. the study included general imperviousness of $65 \%$ in case of residential urban development except for scenario-4 which was predicted with $85 \%$ imperviousness and where the residential development would lead to commercial/industrial development.

\section{Analysis of Surface Runoff due to LULC Change}

The impact of LULC change on surface runoff is assessed in this study based on a total of eight LULC scenarios. Considering the soil classification map, topsoil texture, soil depth, lithology, and the detailed geological investigation of PNT and Jolshiri area; HSG 'D' was the main soil group of the study area with low permeability and infiltration capacity. The existing built-up area, mostly developed by sand-filling is verified by field visit and Google earth images and categorized as HSG ' $\mathrm{A}$ '. The trace of PNT development identified in the 2010 LULC map as bare soil or filled land was transformed with more permeable HSG 'B' soil. LULC of 2012 detected new land development activities which in fact, was infilling low-lying areas in the southern part of PNT in the Jolshiri area. Finally, LULC of 2016-17 exposed the entire area of PNT and Jolshiri area with changed soil profile. Table 6 shows the quantified area-weighted $C N$ values derived from the existing LULC map of 2016-2017. Similar area-weighed $C N$ values were deduced from maps of pre-developed 2010 and 2012, post-developed RDP and for four other predicted scenarios of 2018-35.

Table 6

Computation of Area-Weighted $C N$ for Existing 2016-2017 LULC Condition (2016 RS Image Data)

\begin{tabular}{|c|c|c|c|c|c|}
\hline $\begin{array}{l}\text { Existing LULC } \\
2016-17\end{array}$ & HSG & $\begin{array}{l}\text { Area } \\
\left(\mathrm{km}^{2}\right)\end{array}$ & $C N$ & $\%$ Area $* C N$ & $\begin{array}{c}\text { Weighted } \\
\text { CN }\end{array}$ \\
\hline $\begin{array}{l}\text { Paved (Existing } \\
\text { Built-up) }\end{array}$ & A & 16.25 & 79 & 596.32 & \\
\hline $\begin{array}{l}\text { Unpaved (Bare } \\
\text { / Filled Land) }\end{array}$ & A & 18.08 & 77 & 646.67 & $\begin{array}{l}\text { AMC (I) } \\
64\end{array}$ \\
\hline $\begin{array}{l}\text { Unpaved (Bare } \\
\text { / Filled Land) }\end{array}$ & B & 23.92 & 86 & 955.56 & AMC (II) \\
\hline $\begin{array}{l}\text { Unpaved } \\
\text { (Agriculture / } \\
\text { Veg) }\end{array}$ & D & 69.54 & 83 & 2681.08 & $\begin{array}{c}81 \\
\text { AMC (III) } \\
92\end{array}$ \\
\hline $\begin{array}{l}\text { Unpaved (Tree } \\
\text { Cover) }\end{array}$ & D & 71.06 & 73 & 2409.60 & \\
\hline Water Bodies & - & 16.43 & 100 & 763.19 & \\
\hline Total & & 215.28 & & 8052.41 & \\
\hline
\end{tabular}

\section{RESULTS AND DISCUSSION}

Important deductions have been drawn so that the results of the study are useful for practical applications and decision making for planned urban development within DER.

\section{A. Resulting Trend and Predicted Change of LULC of DER}

LULC trend from 2010 to 2016-17 revealed the significant conversion of the unpaved agricultural area of DER to the paved area due to urbanization in the near future. The classified LULC image of 2016-17 detected the direction of likely post-structural urban development as projected in RDP for DER by RAJUK for 2016-35. LULC change predicted in scenario-1 followed the RDP scenario but included more lands for urban development. Predicted scenario-2 was almost identical to scenario- 1 in terms of land-cover categories, but differed in land conversion. However, predicted scenario-3 and 4 depicted complete conversion of all unpaved land of DER except water bodies. Figure 6 broadly mirrored the overall studied trend of LULC change of DER combining the pre-developed (2010) condition to RAJUK proposed postdeveloped (2016-35) and predicted post-developed scenarios for 2018-35 and beyond.

The LULC changes in terms of classified land-cover of Landsat imageries except the given RDP scenario proposed by RAJUK quite clearly provided the direction of urban development proposed in the RDP scenario. However, extensive land-filling and changing activities including various housing development plans by real-estates that were 
observed may upset the proposed plan of RDP. While comparing the existing 2016-17 LULC with the RDP scenario, a remarkable shift was observed in terms of paved built-up areas which occupying $49 \%$ of the total land and causing a further decline in agricultural lands to approximately $46 \%$. Analysis of proposed land-use plans of PNT and Jolshiri Housing (RAJUK approved) resulted in an urban development intensity with approximately 65\% imperviousness. However, the existing FAR unless reviewed would lead to more densification within DER.
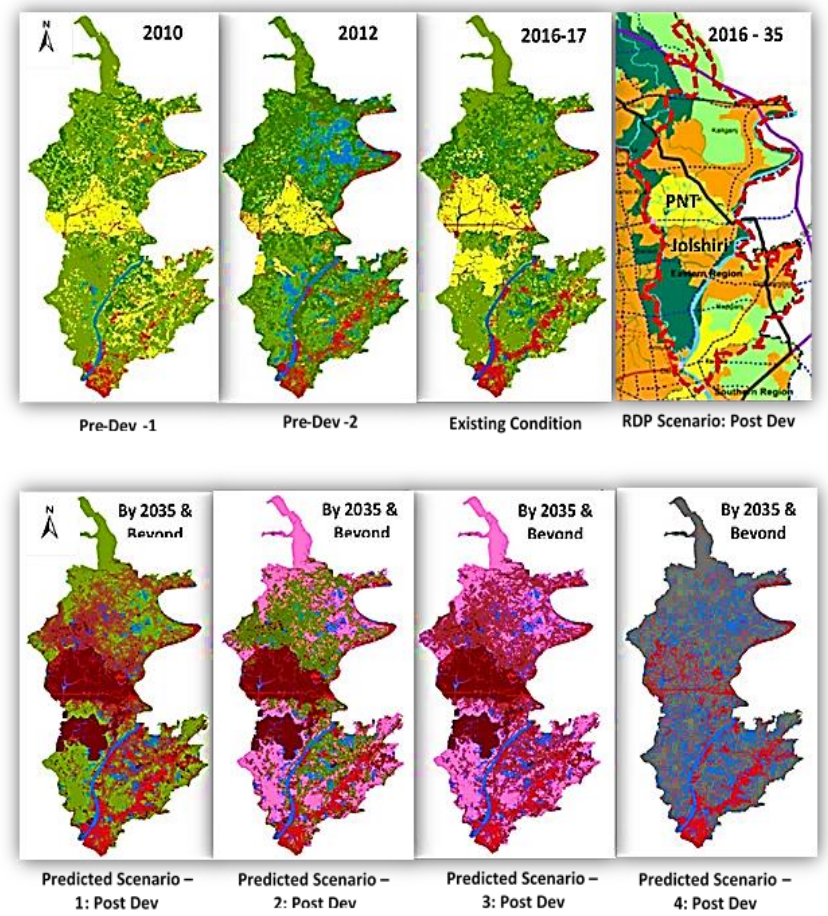

Figure 6: Trend of LULC Change of DER from 2010 and by 2035 and beyond

Figure 7 quantified the overall approximate \% change in LULC in terms of the intended study LULC category from the pre-developed 2010 condition to predicted postdeveloped scenarios for 2018-35 and beyond. In sum, the quantified paved surface increased from $4 \%$ to $94 \%$ and the unpaved surface decreased from $88 \%$ to $0.0 \%$ from 2010 to predicted scenario-4, while the water bodies reduced from nearly $8 \%$ to $6 \%$. Paved surface coverage increased as $4 \%$ in $2010,6 \%$ in $2012,8 \%$ in $2016-17$, and $49 \%$ by 2035 as proposed in RDP of DER. In predicted scenarios the increase in the paved surface is likely to be approximately $60 \%$ by 2035 and beyond for both prediction-1 and 2 and $94 \%$ for predictions 3 and 4 . Besides, the consequent decrease in the paved surface can be noted as $88 \%$ in $2010,86 \%$ in 2012 , $84 \%$ in $2016-17$ and $45 \%$ by 2035 as proposed in RDP. However, predicted scenario- 1 and 2 recorded approximately $33 \%$ of the total land as the unpaved surface which was about $12 \%$ less than RDP. However, predicted scenario-3 and 4 are likely to be without any unpaved surface.

\section{B. Impact on Runoff due to LULC Change}

The assessed LULC changes in DER would have a significant impact on surface runoff. The findings on surface runoff due to LULC changes are mentioned below.

\section{i. Area-weighted CN due to LULC Change}

Annual runoff estimation by the SCS-CN method involved the evaluation of $C N$ due to LULC change. Area-weighted
$C N$ provided an average moisture condition or the AMC II for the HSGs. Though surface prediction and assignment of $C N$ on the predicted land-cover may not be precisely accurate, it may involve an increase or decrease in the overall area-weighted $C N$. The resulting weighted $C N$ due to LULC change was graphically plotted in Figure 8. Before any urban development, HSG for the study area could be assigned as a whole as category ' $\mathrm{D}$ ' soil with the lowest permeability and infiltration capacity. However, urban development traced in this study since 2010 identified a gradual change in the soil profile. The existing 2016-17 LULC provided a combination of ' $A$ ', ' $B$ ' and ' $D$ ' category soil as classified following TR-55 (USDA, 1986) and validated by geological investigation report of Jolshiri area and also by laboratory tests of certain soil samples.

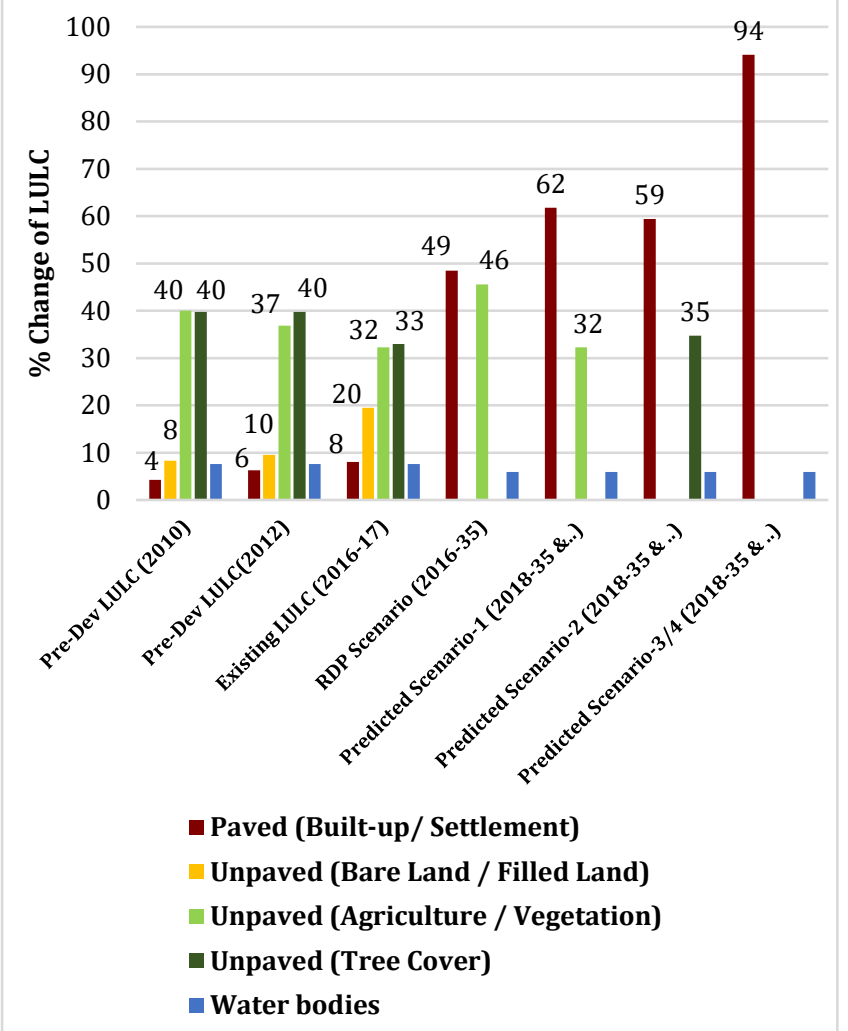

Figure 7: \%LULC Change as per Classified Land-cover of DER from 2010 and by 2035 and beyond

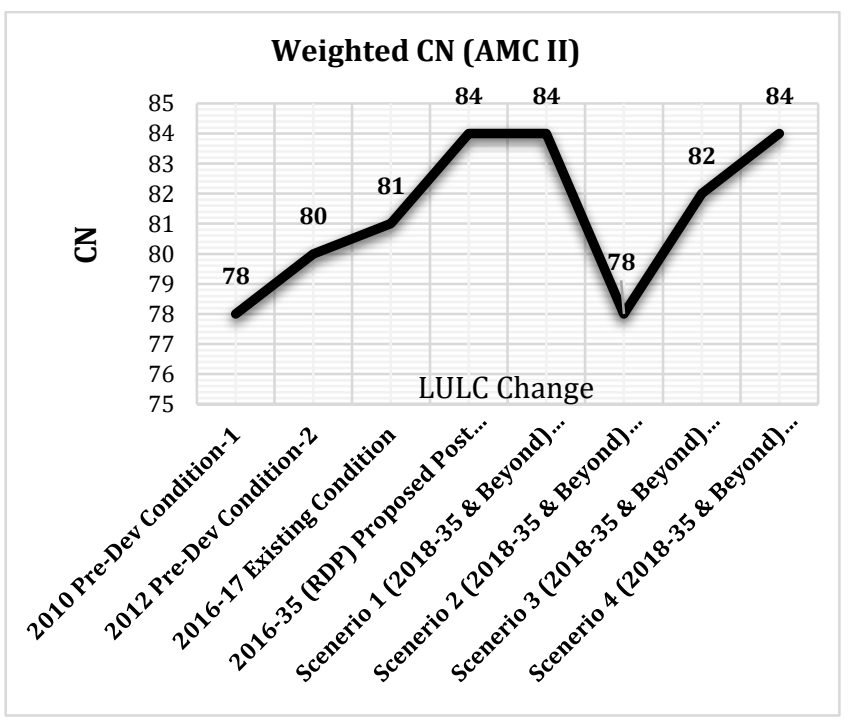

Figure 8: Variation of $C N$ due to LULC Change of DER 
The pre-developed (2010) $C N$ of the study area was 78 and 84 for the RDP scenario which is quite high to generate significant runoff. The $C N$ of the study area then remained constant up to scenario 1 and plummeted to 78 for scenario 2. Then, it again increased to 82 for scenario-3 and 90 for scenario 4. Predicted scenario-1 depicts a $C N$ similar to the RDP scenario, i.e., $C N$ 84. In fact, LULC predicted in scenario-1 was identified as a potential variant of the RDP scenario with more land inclusive to urbanization compared to RDP.

Predicted scenario- 2 was the result of the conversion of agricultural land for urban development and it followed a sharp decline in the $C N$ compared to the RDP scenario or scenario-1. Scenario-2 has an area-weighted $C N$ value 78 which was identical to pre-developed 2010 LULC. The lowlying and low-permeable HSG ' $D$ ' soil of agricultural lands required land development by $\mathrm{HSG}$ ' $\mathrm{A}$ ' category soil (mainly sand-filling) to attain reference PWD RL of 7.5 to $8 \mathrm{~m}$ prior to any structural development. Residential land development in the Jolshiri area by reclaiming low-lying agricultural land with the help of sand-filling bore the evidence of the consideration for the study area. The soil test of the Jolshiri area also confirmed that the area was filled up with highly permeable medium to fine sands. This particular change in the soil profile lowered the area-weighted $C N$ and essentially described an important inference on the LULC change of the study area. Conversion of low-lying agricultural land to attain certain elevation with more permeable soil or sand for residential development with assumed $65 \%$ imperviousness is likely to reduce the areaweighted $C N$, thereby likely to reduce runoff until it is paved.

Scenario-3 entailed LULC changes by a complete paved surface with approximately $65 \%$ imperviousness, yet the area-weighted $C N$ (82) remained below the RDP scenario or scenario-1. Overall $C N$ was decreased because of the conversion of all unpaved land of $\mathrm{HSG}$ ' $\mathrm{D}$ ' into more permeable soil (HSG ' $A$ ' and ' $B$ '). This conversion increased the $C N$ compared to scenario-2. Scenario-4, depicted scenario-3 with $85 \%$ imperviousness which increased the $C N$ to 90 . More paved surface and imperviousness of LULC would otherwise exhibit more runoff and inhibit recharge due to lesser scopes for infiltration and percolation.

\section{ii. Runoff Variation due to LULC Change and Seasonality of AMC}

Figure 9 shows the percentage of rainfall that may turn into the runoff for varying LULC scenarios including the difference in runoff due to LULC change for average (AMC II) and seasonal AMC.

Progressive runoff variations were ascertained from the representative pre-developed 2010 LULC condition. Though runoff estimation by the SCS-CN method with long term daily rainfall was increasingly data-intensive the inclusion of seasonality in soil moisture condition added further complexity in estimation. A significant runoff variation resulted between the estimates with average and seasonal AMC. Results with seasonal AMC provided approximately $14 \%$ to $17 \%$ higher runoff than average AMC. In essence, annual runoff estimation may involve seasonal AMC where there is a distinct seasonal variation of rainfall.
Figure 10 shows the percentage increases in the runoff against the representative 2010 LULC condition for both average and seasonal AMC. RDP or predicted scenario-1 resulted in $30 \%$ more runoff in the case of seasonal AMC of soil and more than $50 \%$ higher runoff from the predeveloped 2010 condition in the case of average AMC (AMC II).

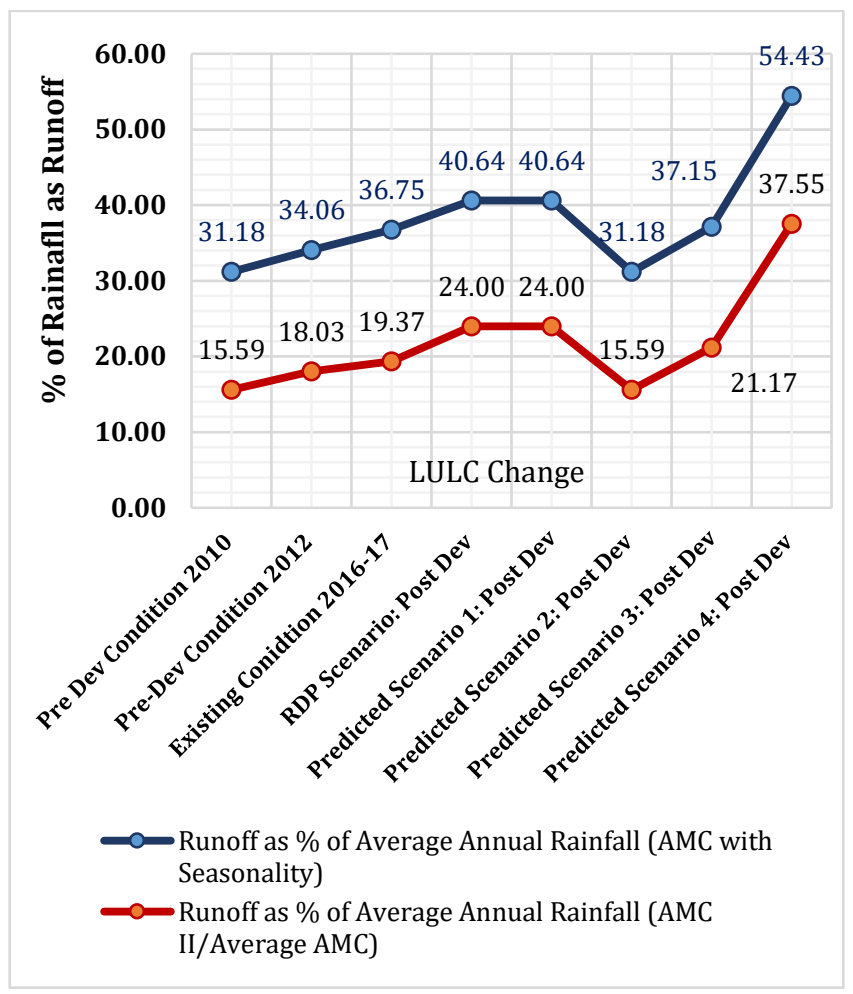

Figure 9: Percentage Runoff from Rainfall due to LULC Change of DER

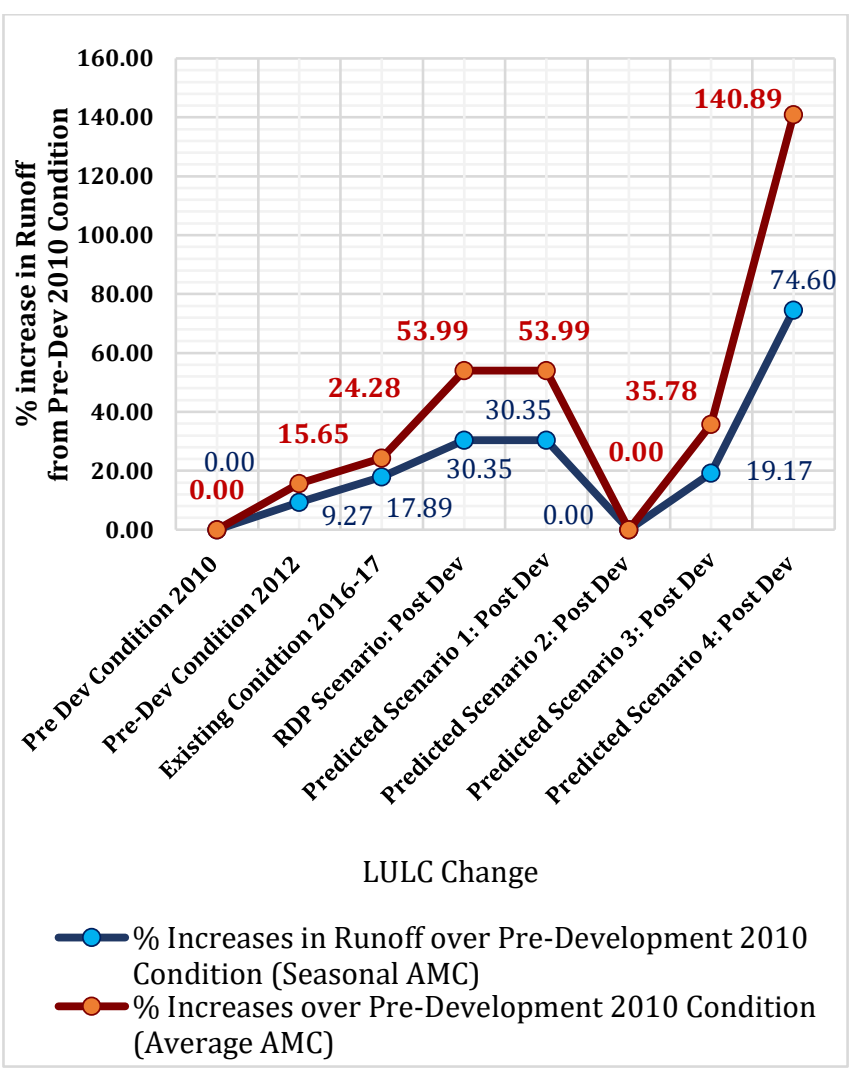

Figure 10: Percentage Increases in Runoff against the Representative 2010 LULC 


\section{Overall Assessed Impact on Runoff due to LULC Change in DER}

Figure 11 quantifies the overall impact on runoff due to LULC change which indeed is a recharge loss. Predeveloped 2010 LULC with $C N 78$ resulted in an average $31 \%$ runoff from rainfall with a runoff depth of $626 \mathrm{~mm} / \mathrm{yr}$ in the case of seasonal AMC. With $C N 80$, the runoff was nearly 34\% with a runoff depth of $684 \mathrm{~mm} / \mathrm{yr}$ in 2012 . Existing LULC (2016-17) with CN 81 generated about 37\% runoff with a runoff depth of $738 \mathrm{~mm} / \mathrm{yr}$. However, approximately $40 \%$ annual runoff was identified in both RDP and predicted scenario-1 with $C N 84$ which had an annual average runoff depth of $816 \mathrm{~mm}$.

An exception to the increase in runoff was scenario-2 which showed that all LULC change was not detrimental, rather beneficial as this change would revert the land with predeveloped runoff potential. Predicted scenario-3 with $C N 82$ again increased more than $37 \%$ runoff with a runoff depth of $746 \mathrm{~mm} / \mathrm{yr}$ when compared with scenario-2, but the impact was lesser when compared to RDP or predicted scenario. Finally, the maximum runoff nearly $55 \%$ with a runoff depth of $1093 \mathrm{~mm}$ was generated by $C N 90$ of predicted scenario-4. The overall impact followed an increasing trend up to RDP/predicted scenario-1 and had a fall in predicted scenario-2. In fact, predicted scenario- 2 revealed the LULC of DER with similar $C N$ of pre-developed 2010 condition and resulted in no impact on runoff. The hydrological impact again followed an increasing trend and resulted in a severe impact in the case of LULC with $C N 90$. This scenario resulted in more than $50 \%$ runoff and significant recharge loss.

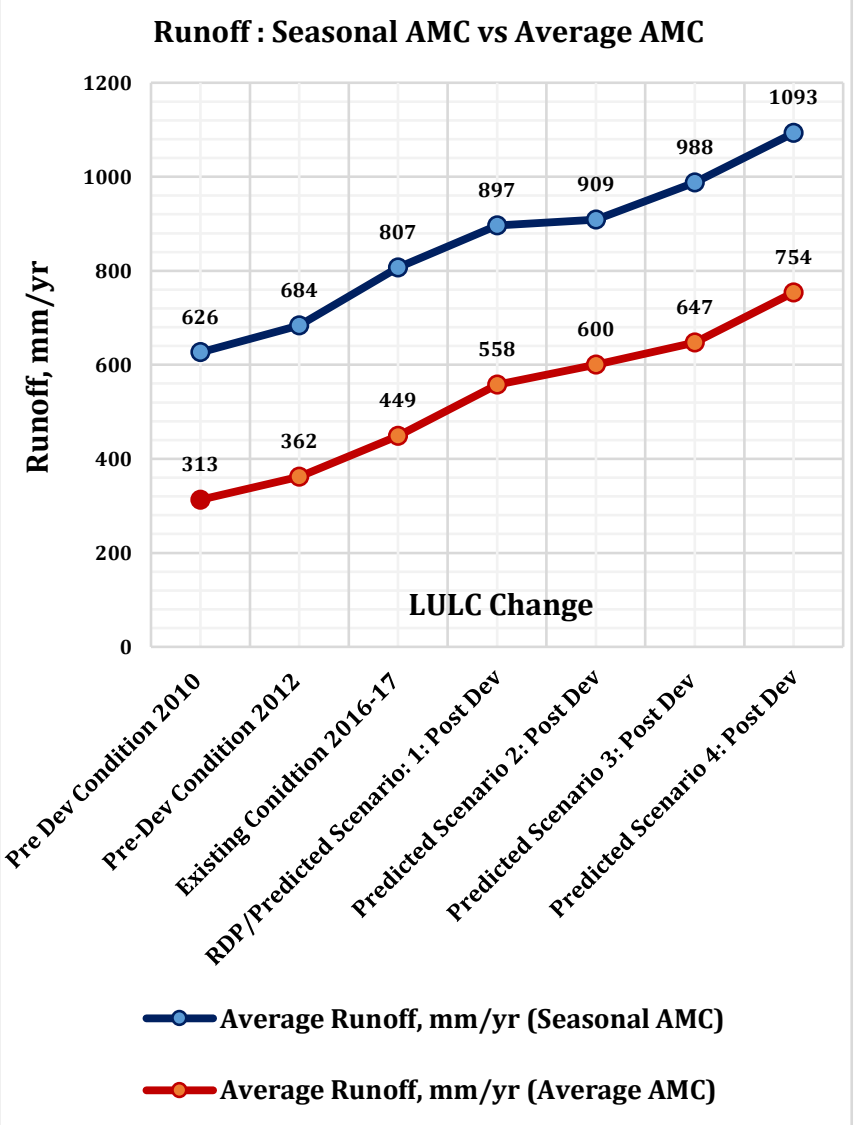

Figure 11: Impact on Runoff due to LULC Change

\section{CONCLUSIONS}

This study focused primarily on identifying the impending LULC change of DER due to urbanization and its impact on surface runoff using RS, GIS and $C N$ Technology.

Existing LULC changes of DER were mapped from Landsat 5 (TM), 7 (ETM+) and 8 (OLI-TIRS) imageries, respectively for 2010, 2012, and 2016 using supervised classification. LULC changes mapped in this study provided a total of eight scenarios of which the pre-developed condition is described by 2010 and 2012 and existing conditions by 2016-17. Out of the five post-development scenarios, one is proposed by RAJUK as per RDP and most likely to shape the future LULC of the Eastern Region of Dhaka. The other four predicted post-development scenarios derived from the Landsat imagery of existing 2016-17 LULC, in effect, represented the direction of future urban growth and mostly covered the entire urban development proposed in RDP for DER. The classified Landsat imagery of 2016-17 detected the direction of likely post-structural urban development as envisaged in RDP for DER.

A slower pace of urbanization was traced in terms of paved built-up coverage with $4.0 \%$ in $2010,6.0 \%$ in 2012 and $8.0 \%$ in $2016-17$ from the total $215.28 \mathrm{~km}^{2}$ land of DER. Conversely, a faster pace from $8.0 \%$ in 2010 to $20.0 \%$ in 2016-17 was observed in case of unpaved bare soil or filled land transformed mainly from agricultural and tree-covered areas which might be a built-up paved surface with a likely $65.0 \%$ post-developed imperviousness by 2035 or beyond as projected in RDP scenario. RDP proposed LULC had a significant increase in paved built-up areas from existing $8.0 \%$ to $49.0 \%$ by 2035 . Besides, four post-developed LULC changes were predicted from the classified Landsat 8 imagery where predicted scenario- 1 followed the RDP scenario with nearly $62.0 \%$ paved surface mainly due to conversion of the identified unpaved tree-covered area as opposed to the conversion of agricultural areas in case of scenario-2. However, predicted scenario-3 and 4 with maximum urbanization resulted in nearly $94.0 \%$ paved surface with respectively $65.0 \%$ and $85.0 \%$ imperviousness.

This study estimated runoff by the SCS-CN method of integrating RS and GIS tools. Like the slower trend of urbanization, area-weighted $C N$ also increased slowly till 2016-17 but increased substantially in RDP as well as scenario-1. Hydrological impact on runoff was assessed from the pre-developed 2010 LULC as a reference year. Two different sets of impact on runoff were observed due to average and seasonal variation of antecedent moisture condition (AMC) of soil. Distinctively, seasonal AMC generated around $14.0 \%$ to $17.0 \%$ higher runoff than average AMC.

Given the assessed impacts of LULC change on runoff, scenario- 2 is hydrologically more suitable than others. But, the direction of LULC change indicates RDP or predicted scenario-1 is an impending LULC of DER. In effect, RDP/scenario-1 ( $C N 84$ ) was considered as the limiting LULC for DER which would approximately result in $40.0 \%$ of total rainfall as runoff annually with seasonal AMC. However, predicted scenario-4 with maximum $C N 90$ would result in more than $50.0 \%$ runoff which indeed, would depict the typical landscape of core city Dhaka within DER. 
Finally, the method and results illustrated in this study on the impacts of land-use change on runoff can be used in locallevel city planning and likely to be useful for a general hydrologic forecasting as well as for understanding consequences associated with the land-use changes. Before structural development, an adequate natural drainage system should be planned to avoid excess runoff and the usual waterlogged situation observed in core city Dhaka due to intense rainfall. This would in turn lower the post-structural drainage development cost. Besides, inevitable recharge loss may be addressed.

\section{ACKNOWLEDGEMENTS}

This research must acknowledge the valuable cooperation and support received from BWDB, Water Supply and Sewerage Authority (WASA) and DPHE during data collection.

\section{REFERENCES}

Ahmad, I., Verma, V., \& Verma, M. K. (2015). Application of Curve Number Method for Estimation of Runoff Potential in GIS Environment, $20152^{\text {nd }}$ International Conference on Geological and Civil Engineering IPCBEE, vol. 80.

Akhter, H., Ahmed, M. S., \& Rasheed, K. B. S. (2009). Spatial and Temporal Analysis of Groundwater Level Fluctuation in Dhaka city, Bangladesh, Asian Journal of Earth Sciences, 2, 49-57.

Amutha, R., \& Porchelvan, P. (2009). Estimation of Surface Runoff in Malattar Sub watershed using SCS-CN Method, J. Indian Soc. Remote Sens, 37, 291-304.

Banasik, K., Krajewski, A., Sikorska, A., \& Hejduk, L. (2014), Curve Number estimation for a small urban catchment from recorded rainfall-runoff events. Archives of Environmental Protection, 40(4).

Bhaduri, B., Harbor, J., Engel, B., \& Grove, M. (2000). Assessing Watershed-Scale, Long-Term Hydrologic Impacts of Land-Use Change Using a GIS-NPS Model, Environmental Management, 26(6), 643-658, SpringerVerlag, New York.

Demographia (2017). Demographia World Urban Areas, 2017. Built-Up Urban Areas or Urban Agglomerations, $13^{\text {th }}$ Annual Edition, April 2017.

Dewan, A. M., \& Yamaguchi, Y. (2009). Land use and land cover change in Greater Dhaka, Bangladesh: Using remote sensing to promote sustainable urbanization, Applied Geography, 29, 390-401.

DU (2014). A Report on Geological and Geotechnical Engineering Survey for Proposed Jolshiri Abashon, Department of Disaster Science of Management, University of Dhaka.

Eastman, J. R. (2001). Guide to GIS and Image Processing, vol. 1, Clark Labs, Worcester, MA.

Fennessey, L. A. J., \& Hawkins, R. H. (2001). The NRCS Curve Number, a New Look at an Old Tool, Proceedings of the 2001 Pennsylvania Stormwater Management Symposium on Re-thinking Comprehensive Stormwater Management-Integrating Quality, Volume and Peak Controls, October 17-18, 2001.

Gitika, T., \& Ranjan, S. (2014). Estimation of Surface Runoff using NRCS Curve number procedure in Buriganga Watershed, Assam, India - A Geospatial Approach, International Research Journal of Earth Sciences, 2(5), 17.

GOB (2008). Government of Bangladesh, Bangladesh Gazette, 29 May 2008, Dhaka Megacity Building (Construction, Improvement, Preservation and Removal) Rules, Ministry of Housing and Public Works.

Harbor, J. M. (1994). A Practical Method for Estimating the Impact of Land-Use Change on Surface Runoff,
Groundwater Recharge and Wetland Hydrology, Journal of the American Planning Association, 60(1), 95-108.

Harbor, J., Lim, J. K., Engel, B. A., \& Muthukrishan, S. (2006). Effects of Initial Abstraction on Estimated Runoff Using CN Technology, Journal of the American Water Resources Association, 42(3), 629-643.

Hoque, M. A., Hoque, M. M., \& Ahmed, K. M. (2007). Declining Groundwater Level and Aquifer Dewatering in Dhaka Metropolitan Area, Bangladesh: Causes and Quantification, Hydrogeology Journal, 15, 1523-1534.

Huq, H. M. (2017). A Study on Land-Use and Land-Cover Change of Dhaka Eastern Region and Its Impact on Water Cycle, (Unpublished Master's Thesis), Bangladesh University of Engineering and Technology, Dhaka, Bangladesh (BUET Library).

JICA \& DTCA (2015). The Project on the Revision and Updating of the Strategic, Transport Plan for Dhaka, Draft Final Report.

JICA \& DTCA (2016). The Project on the Revision and Updating of the Strategic, Transport Plan for Dhaka, Final Report/Summary.

Kalam, A. K. M. A. (2009). Planning Dhaka as a Global City: A Critical Discourse, Journal of Bangladesh Institute of Planners, 2, 1-12.

López-Serrano, P. M., Corral-Rivas, J. J., Díaz-Varela, R. A., Álvarez-González, J. G., and López-Sánchez, C. A. (2016). Evaluation of radiometric and atmospheric correction algorithms for aboveground forest biomass estimation using Landsat 5 TM data. Remote Sens, 8, 119.

Mashreque, M. S. (2009). Dhaka's environment suffers urban impact, The Daily Star, (Extracted on 12 Jan. 2017). Source: www.thedailystar.net/news-detail-107999

Melesse, A. M. and Shih, S. F. (2002). Spatially Distributed Storm Runoff Depth Estimation using Landsat Images and GIS, Computers and Electronics in Agriculture, 37, 173183.

Ministry of Agriculture, India (1972). Ministry of Agriculture, Soil and Water Conservation Department 1972. Hand Book of Hydrology, New Delhi.

Nahrin, K. (2008). Violation of Land Use Plan and Its Impact on Community Life in Dhaka City, Jahangirnagar Planning Review, 6, 39-47.

Rajbanshi, J. (2016). Estimation of Runoff Depth and Volume Using NRCSCN Method in Konar Catchment (Jharkhand, India), J Civil Environ Eng, 6(236).

RAJUK (2015). Dhaka Structure Plan (2016-2035), Regional Development Planning (RDP), Government of Bangladesh, Ministry of Housing and Public Works.

Ram. B. B., \& Kolarkar, A. S. (1993). Remote Sensing Application in Monitoring Land-use Changes in Arid Rajasthan, International Journal of Remote Sensing, 14(17), 3191-3200.

Samuel, E. K., Fogel, M. M., \& Resnick, S. D. (1973). Hydrology and Water Resources in Arizona and the Southwest, Arizona-Nevada Academy of Science, Tucson, Arizona.

Shalaby, A., \& Tateishi, R. (2007). Remote sensing and GIS for mapping and monitoring land cover and land-use changes in the Northwestern coastal zone of Egypt, Applied Geography, 27, 28-41.

Shamsudduha, M., Taylor, R., Zahid, A., \& Ahmed, K. M. (2011). The impact of intensive groundwater abstraction on recharge to a shallow regional aquifer system: evidence from Bangladesh, Hydrogeology Journal, 19, 901-916.

Shamsudduha, M., Chandler, R. E., Taylor, R. G., \& Ahmed, K. M. (2009). Recent Trends in Groundwater Levels in a Highly Seasonal Hydrological System: the GangesBrahmaputra-Meghna Delta, Hydrol. Earth Syst. Sci., 13, 2373-2385. 
Subramanya, K. (2008). Engineering Hydrology, Third Edition, Tata McGraw-Hill, New Delhi.

Sultana, S. (2009). Hydrogeochemistry of the Lower Dupi Tila Aquifer in Dhaka City, Bangladesh. TRITA-LWR degree project $09-35,65 \mathrm{p}$.

Sumarauw, J. S. F., \& Ohgushi, K. (2012). Analysis on Curve Number, Land Use and Land Cover Changes and the Impact to the Peak Flow in the Jobaru River Basin, Japan, International Journal of Civil \& Environmental Engineering, 12( 2).

USDA (1972). Soil Conservation Service, National Engineering Handbook, Sec. 4, Hydrology, Washington D.C.
USDA (1986). Soil Conservation Service, Urban Hydrology for Small Watersheds TR-55, Washington, DC.

USDA (1989). Soil Conservation Service (1989). Runoff Curve Number Computations, Engineering Hydrologic Training Series, Module 104, Washington D.C.

USDA (2004). Estimation of direct runoff from storm rainfall. Part 630 Hydrology: National Engineering Handbook. Chapter 10. Washington, DC.

USDA (2007). National Engineering Handbook, Part 630, Section 7, Hydrology, Washington, DC.

Zaman, A. K. M. H., Alam, K. M. T., and Islam, M. J. (2010). Urbanization in Bangladesh: Present Status and Policy Implications, ASA University Review, 4(2). 



\title{
Exploring and Comparing the Performance of Design Methods Used for Information Intensive Websites
}

\author{
Tarannum Zaki1 ${ }^{*}$, Zinia Sultana², S M Anisur Rahman ${ }^{3}$, and Muhammad Nazrul Islam ${ }^{4}$ \\ Department of Computer Science and Engineering, Military Institute of Science and Technology (MIST), Dhaka, Bangladesh \\ emails: *1tarannumzaki@yahoo.com; ${ }^{2}$ sultana.hiramony@gmail.com; ${ }^{3 a n i s 972 @ g m a i l . c o m ; ~ a n d ~}{ }^{4}$ nazrul@cse.mist.ac.bd
}

\section{ART ICLE INFO}

\section{Article History:}

Received: 29th February 2020

Revised: $10^{\text {th }}$ May 2020

Accepted: $12^{\text {th }}$ May 2020

Published online: 21 st July 2020

\section{Keywords}

Human-computer interaction (HCI) Interactive dialogue model (IDM)

User experience (UX)

Card sorting

Usability

\begin{abstract}
A B S T R A C T
At present, web applications are one of the most widely used software applications in different organizations. A website is a virtual representation of the structure of any organization. Good user experience of a website is highly dependent on the content organization or design of a website. Thus, the design is a very important factor to develop a high usability standard website. Different types of design techniques are used to develop different types of websites. It is a very challenging task to develop information-intensive websites using a suitable design technique so that the website can serve its intended purpose with enhanced usability and user experience. Therefore, the objective of this research is to compare the performance of two alternate design techniques for developing an information-intensive website. To achieve this objective, the existing design techniques were explored; and selected the Card Sorting and Interactive Dialogue Model (IDM) techniques to design two websites for an orphanage system. Later, the developed orphanage web systems were evaluated with ten participants through a user study; and found that the IDM design technique performs better than the Card Sorting technique in terms of the system's usability and user experience.
\end{abstract}

(C) 2020 MIJST, All rights reserved.

\section{INTRODUCTION}

Design refers to a draft model construct or planned before developing the final product that concerns how the contents will be organized and different functions will be performed (Preece et al., 2004). System behavior is generally reflected upon the design of that system since the design is not the final product, but it determines how the final product will function or work.

Again, the design has an impact on a system's usability and user experience. Since the quality of different softwareoriented applications such as web applications, mobile applications or any other software applications are highly dependent on their usability and user experience factors. Practitioners thus concern about the design technique considered to develop a mobile or web system to improve its usability and user experience (UX) (Islam et al., 2020). The usability of a website primarily depends on some characteristics, for example, understanding the needs and expectations of users, easy and user-friendly navigation, clear requests to specific actions, complete content organization, consistent interface and operation, that is, the effectiveness, efficiency and satisfaction (Abran et al., 2003; Rabi u et al., 2012; Zhang et al., 2010). A clear concise and intuitive user interface (UI) design may lead to achieving these characteristics for a website. Thus, the design is a crucial activity to develop software systems with enhanced usability and UX.

There are several design techniques to design and develop websites such as HDM (hypertext design model), IDM (interactive dialogue model), Card Sorting, UML (unified modeling language), WSDM (website design method), SIDE (Semiotic Interface sign Design and Evaluation) etc. (Bolchini \& Paolini, 2006; Garzotto et al., 1993; Mubin et al., 2015; Troyer \& Leune; 1998; Spencer, 2009; Islam \& Bouwman, 2016). Thus, it is a very crucial concern for HCI (human-computer interaction) practitioners to understand which design approach is better and easy to follow. Though, many comparative studies are existing on HCI that focused on comparing the performance of different usability and UX evaluation techniques. But no study has been carried out focusing on the comparison among the design techniques used to develop web applications. Therefore, the objective of this research is to investigate and compare the performance of two alternate design techniques to design and develop web applications. To attain this objective, an example web application for the orphanage management system is designed and developed using the IDM and the Card Sorting techniques followed by an evaluation study that was replicated with 10 participants in a laboratory environment. 
To present the rest of the paper, it is organized as follows. Section 2 provides the theoretical concept of IDM and Card Sorting design techniques as well as some related works regarding the focused issue. The study methodology is depicted in Section 3. Section 4 illustrates the system design and development. Section 5 discusses the evaluation study including participants' profiles, study procedure, and data analysis and findings. Finally, Section 6 discusses the study outcomes highlighting the research contributions followed by limitation, future work and a brief concluding remark.

\section{BACKGROUND THEORY AND LITERATURE}

This section is divided into three parts where the initial two parts briefly discuss the theoretical concept of the two design techniques - IDM and Card Sorting and the final part describes some related research works and development published during the past few years.

\section{A. Interactive Dialogue Model (IDM)}

IDM or interactive dialogue model is a design technique focused on possible conversation exchange between users and the content of an application to identify and organize the user requirements (Bolchini \& Paolini, 2006). It is formally known as a dialogue-based model, because the features of an application are not designed based on some particular predefined design architecture rather the design is crafted based on the user interaction with that specific application which is referred to as dialogue. IDM is considered to be a convenient approach for multi-channel applications (Bolchini \& Paolini, 2006) (e.g. embedded system, web applications, android apps and so on) which means it has a fruitful result in providing similar user experience for identical content regardless of cross-platform environment. It is widely used for applications which are highly informative and interlinked and not taken into account for applications that contain a large number of operations. IDM is performed using three consecutive steps - C-IDM (conceptual IDM), LIDM (logical IDM) and P-IDM (page IDM) (Bolchini \& Paolini, 2006). C-IDM is channel independent and used to identify the main topics or concepts of a website and a necessary relation between the topics. L-IDM is channeldependent and used to identify a number of dialogue units within a specific topic for a particular development platform. $\mathrm{P}$-IDM is the page design or prototype of each topic and required navigational links. In general, the interactive dialogue model is a useful, natural, inexpensive, userfocused but a bit effortful design technique and applicable for all types of applications developed in different platforms (Bolchini \& Paolini, 2006).

\section{B. Card Sorting}

Card Sorting is a design technique used to build the information architecture of an application, that is, how the content of an application is identified, categorized and organized in accordance with users' convenience by labeling and classifying the entire content of an application (Spencer, 2009). This design technique is mostly used for web applications that are rich in information, traversable but less operative and not considered as a convenient approach for multi-channel applications. A group of participants usually perform a Card Sorting session (Spencer, 2009) where they use a number of small colorful cards. All the participants individually identify the user requirements of the application (i.e. what should be on the homepage, the hierarchy of content and the navigational structure etc.) by labeling the cards accordingly and further grouping them into different categories. The hierarchy of different topics might be interpreted using cards with different colors. This design technique eventually helps to design an application where similar user requirements can be recognized with a lot of variation. This Card Sorting session can be also performed using different software tools available online. It is indeed a very simple, inexpensive, widely used and user-centered design process that used mainly to design the structure of web applications regarding how the content will be organized but may not provide a strong analysis regarding the end to end navigation process.

\section{Related Works}

Previously, different hypertext applications used to be designed using the "page by page" design approach (Bolchini \& Garzotto, 2008), that means an application containing several interconnected links were developed by designing a particular page and then moving on to the next hyper-linked page. This approach is usually unable to reflect the user requirements completely as designing an individual page successively results in a partial content representation of an application. As a result, to fulfill the user requirements for interactive hypertext applications, HDM (hypertext design model) has been introduced (Garzotto et al., 1993), where the authors have presented a design and browsing schema that help to understand how the user requirements can be organized in a user interactive way by classifying the requirements into different entities and structural links from different perspectives. Next, to deal with the increasing and complex user requirements, the IDM has been proposed in (Bolchini \& Paolini, 2006; Bolchini \& Garzotto, 2008). Bolchini and Paolini (2006) highlighted the usage of IDM for designing multi-channel applications. Perrone et al. (2005) have introduced a "Stakeholders Centered Approach" and showed that IDM is an effective design model that supports user requirements and goals. Some academic projects have been carried out on interactive and contentintensive applications at Indiana University by Craske (2010). Spagnolo et al. (2010) integrated the concept of IDM with the concept of rich internet applications (RIA) to propose a new design strategy named SEE-IA (SEarch Enhanced Information Architecture). Coppola et al. (2015) proposed the Mobile-IDM as the extension of the IDM technique and the usages of Mobile-IDM are discussed through a case study of designing a tourism mobile application. In another study, Islam et al. (2017) showed the applicability of the IDM design technique to design and develop a multi-channel military application to facilitate communication between the higher commanders and the front-line troops during a military operation. Thus, along with multi-channel features, IDM design technique has received much acceptance for interactive and contentintensive applications.

Again, among all the traditional techniques available for designing interactive applications, Card Sorting is one of the widely used ones. Rugg and McGeorge (2005) have discussed different sorting techniques. For example, card sorts to identify user requirements for any application. The authors have also given necessary guidelines for choosing sorting techniques along with an example of a sorting session and concluded that sorting techniques are a useful part of requirements analysis. Card Sorting has gained popularity for designing information-intensive applications. 
Zimmerman and Akerelrea (2002) have summarized the Card Sorting technique and verified the derived classification for informative websites. They have also suggested an approach towards it and concluded that Card Sorting techniques must be enhanced using social science concepts. Card Sorting can be conducted physically or using online software, while the effectiveness of its result using either approach has been compared (Petrie et al., 2011). The comparison has been carried out on two types of websites museum and news and found that the information architecture of the respective website drawn using card sorting differs from the typical ones depending on the cultural differences of the participants.

Another study has been conducted by Faiks and Hyland (2000) using the Card Sorting technique to identify and organize the concepts of an online library system, and then showed that this design technique is useful enough before developing an application as the concepts are gathered from a users' point of view. The card sorting technique is used in a number of other studies to design the websites, including a website for the electronic banking system (French et al., 2007), Utah State University's library website (Duncan \& Holliday, 2007), e-commerce websites in Kuwait (Al-Fadhli, 1997), websites for the health care worker and the general public (Wentzel et al., 2016), and usable website for an aging population (Kurniawan \& Zaphiris, 2007). Again, card sorting is also used to evaluate the usability and information architecture of web systems (Tullis, 2007; Ebenezer, 2003).

A suitable and effective design technique for a particular application depends on evaluating some usability factors such as its content organization, user-friendly navigational structure, performance, responsiveness and on the likes (Kumar \& Goundar, 2019; Razzak \& Islam, 2020). These usability factors or parameters are measured through a number of existing Usability Evaluation Methods (UEM) that includes, for example, task-analysis, heuristic evaluation, think-aloud, interviews, cognitive walkthrough, etc. (Park et al., 2020; Sagar \& Saha, 2017; Palmer, 2002; Bolchini \& Garzotto, 2007).

These methods have been compared with each other to assess the performance of various usability evaluation methods in (Matera et al., 2002; Ternauciuc \& Vasiu, 2015; Jeffries et al., 1991; Karat et al., 1992; Gray \& Salzman, 1998; Brejcha \& Marcus, 2013; Marcus, 2015). For example, two analytical evaluation methods were compared in (Matera et al., 2002), where an educational computer game developed for young children was evaluated by two different evaluation methods and then their performances were compared. Similarly, Conte et al. (2007) proposed a usability evaluation technique for web application and then compared its performance with Nielsen's heuristics.

Based on the above discussion, it was found that the earlier work mainly discussed the procedure of applying the design techniques with example cases, assessing the performance of a design technique to design and develop different types of software systems, and how a design technique can improve the system usability to end-users. On the other hand, in HCI, several studies focus to compare the performance of different usability evaluation methods (UEMs) in a different context. But none of the studies is yet conducted to compare the performance of different design techniques in respect of system usability and UX. Usability and UX are strictly related to system design. Therefore, it is of utmost importance and an open issue to explore whether choosing a specific design technique provides any impact on systems' usability and UX. Similarly, it is not yet revealed which kind of design technique would be a better choice for UI practitioners to achieve enhanced usability and UX for information-intensive websites.

\section{METHODOLOGY}

The research was carried out by following three phases as shown in Figure 1. Firstly, a number of design techniques were identified through a literature survey. Each design technique has its own merits and demerits. The features of design techniques have been explored and found that only a few are explicitly focused to design information-intensive multi-channel (web and mobile) applications. The objective of this research is to observe the performance of different design techniques and thus, this research has preliminarily selected the IDM and Card Sorting design techniques. Among a few others, both the Card Sorting and IDM are old and widely used to design information intuitive web application. Again, designing information-intensive websites mainly focuses on the content and navigation structure and the selected design techniques are addressing the same issues. Moreover, both the card sorting and IDM techniques are focusing on the end-users and their requirements; and not dependent on some predefined design model.

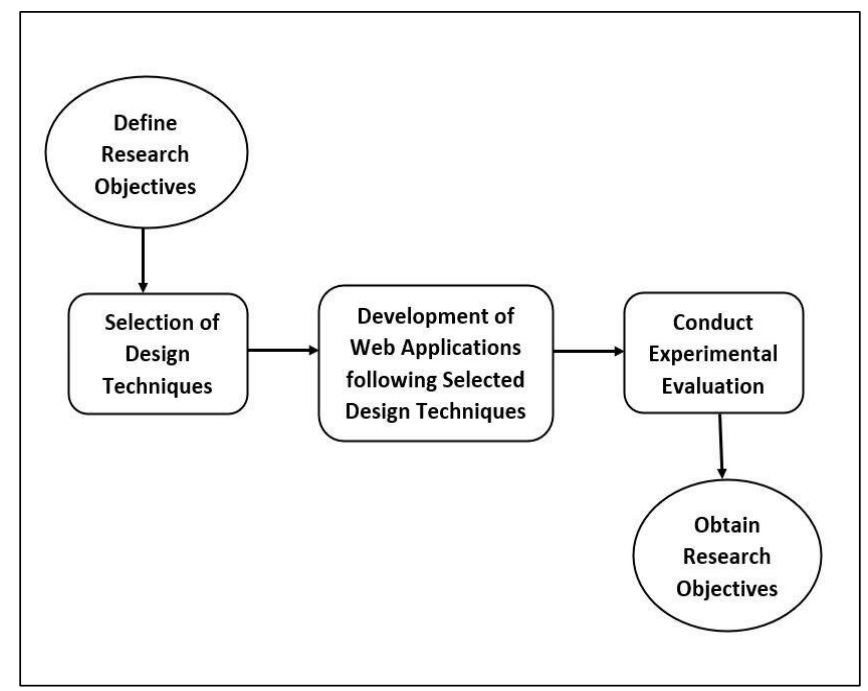

Figure 1: Phases of research methodology

Secondly, two websites for an orphanage management system were designed and developed following the selected design techniques. The orphanage system can be considered as an information-intensive website and presumed to provide information regarding different orphanages and accommodated orphans worldwide, adoption and admission information and processes, donation information, and other relevant online services.

Finally, a within-subject experiment was conducted to compare the performance of design techniques in terms of the usability and user experience of the developed systems. A number of participants were recruited and asked them to perform a set of tasks for both websites. During the experiment a number of metrics have been measured and analyzed using descriptive statistics and qualitative approach. A more detailed discussion of the study procedure and data analysis is presented in Section 5. 


\section{DESIGN AND DEVELOPMENT}

Two web portals for the orphanage system were designed using the Card Sorting and IDM techniques. A total of four designers participated to design and develop the web portals. All participants (designers) were graduated in Computer Science, highly expert in the respective design techniques, had practical experiences of applying the design techniques in real-world projects, all had teaching and research experiences in the field of human-computer interaction. Each portal was designed by two designers following either IDM or Card Sorting design technique. However, before starting the design task, all participants discussed together to understand the objectives and requirements of an orphanage system so that participants can design the orphanage system based on a common paradigm related to system requirements, and to reduce the effect of confounded variable.

\section{A. Design Using Card Sorting}

An open Card Sorting technique (Garzotto et al., 1993) is used to design the orphanage system, where participants of Card Sorting make assumptions on the content of a particular website theme and label them into a particular group. At first, they individually labeled different topics of the content on a number of small cards, then grouped altogether into different clusters and finally organized the subgroups into required clusters. A total of nine primary groups were found, that includes: About Us, Orphanage Info, Orphan Info, Contribute Now, Admission, Adoption, Site map, Privacy Policy and FAQ. Each group consists of several construct or topic, for example, s About Us consisted of Mission \& Vision, Our Service, Board of Directors and Contact. Orphanage Info consisted of an Orphanage List, that contained a number of orphanages, while each orphanage is represented through its' Name, Contact, Photos, Brief Introduction and Latest Donation News. Similarly, the
Contribute Now consisted of Donation Form and Volunteer Form, while the Adoption consisted of Eligibility Document and Adoption Form. The overall information architecture derived from the Card Sorting technique is presented in Figure 2.

\section{B. Design Using IDM}

The IDM-based design is discussed in three steps, namely CIDM, L-IDM, and P-IDM.

\section{i. Conceptual IDM (C-IDM)}

The first phase is C-IDM and does not depend on the channel or platform type. Conceptual IDM consists of three design parameters (Bolchini \& Paolini, 2006) - topic, relevant relation, group of topics and a parametric group of topics (optional). The topic is of two types - single topic and kind of topic. A single topic is a concept which can be an issue of an interactive discussion between human and web application and does not contain multiple instances in the application. In the orphanage portal website, single topics were About Us, Contact Us, Admission, Donate Now, Online Counseling, Site map, FAQ and Privacy Policy. For example, About $U s$ was a single instance and only contained some introductory information. Kind of topic is the same as a single topic except that it contains multiple instances in the application. In this website, the topics covered included Explore Orphanage, Donation Report, Know Orphans and Adoption Form. For example, Explore Orphanage had multiple instances because it contained some information of a number of orphanages. Next, relevant relation only exists for a kind of topic and indicates the change of conversation from one kind of topic to another with necessary cardinality (1:1, 1: $n$, etc.). Again, there are five relevant relations showed in this design (see Figure 3), for example, Explore Orphanage is related with Donation Report through "provides", while, Explore Orphanage is related with Know Orphans through

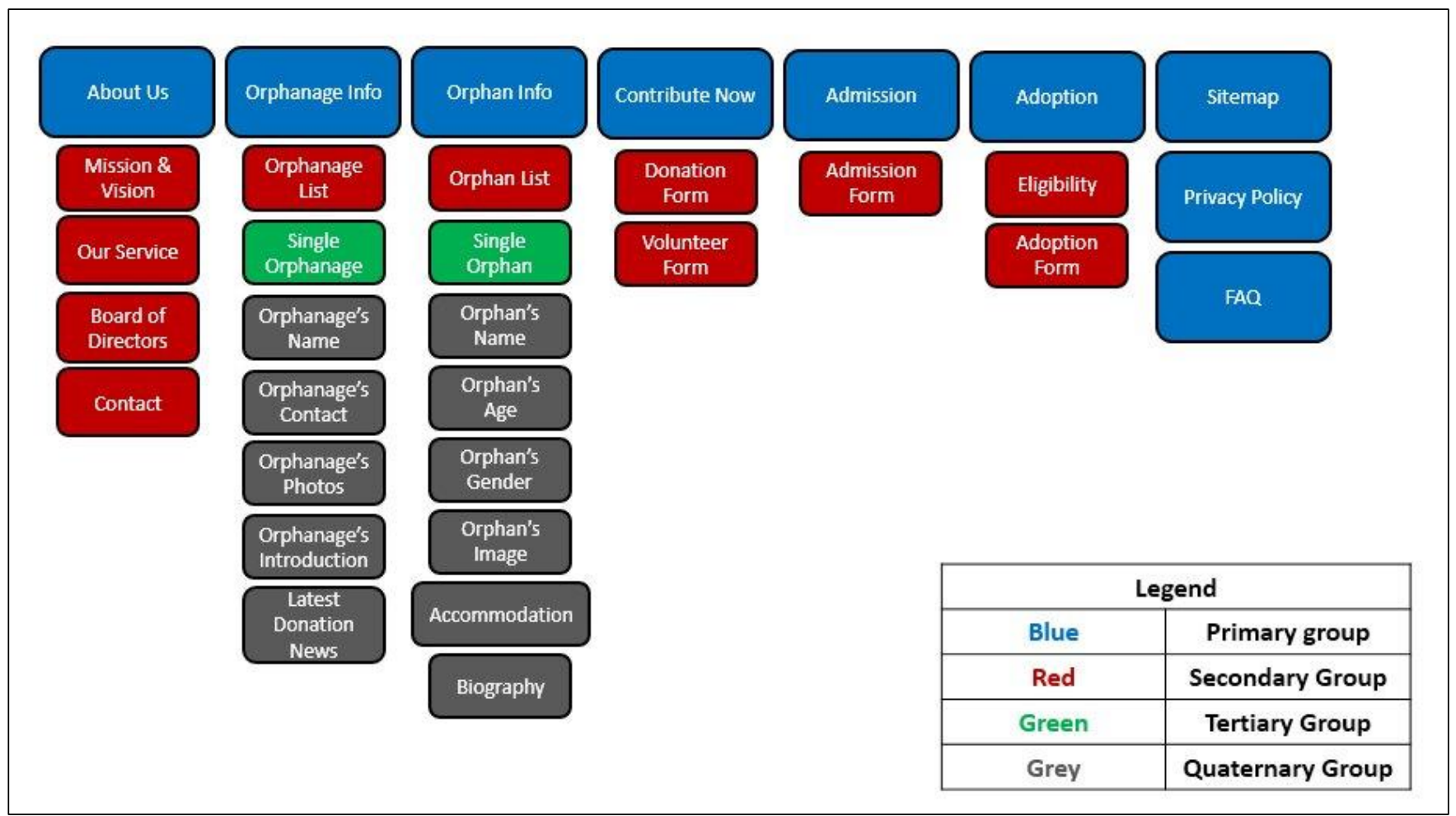

Figure 2: Card sorting for orphanage portal 


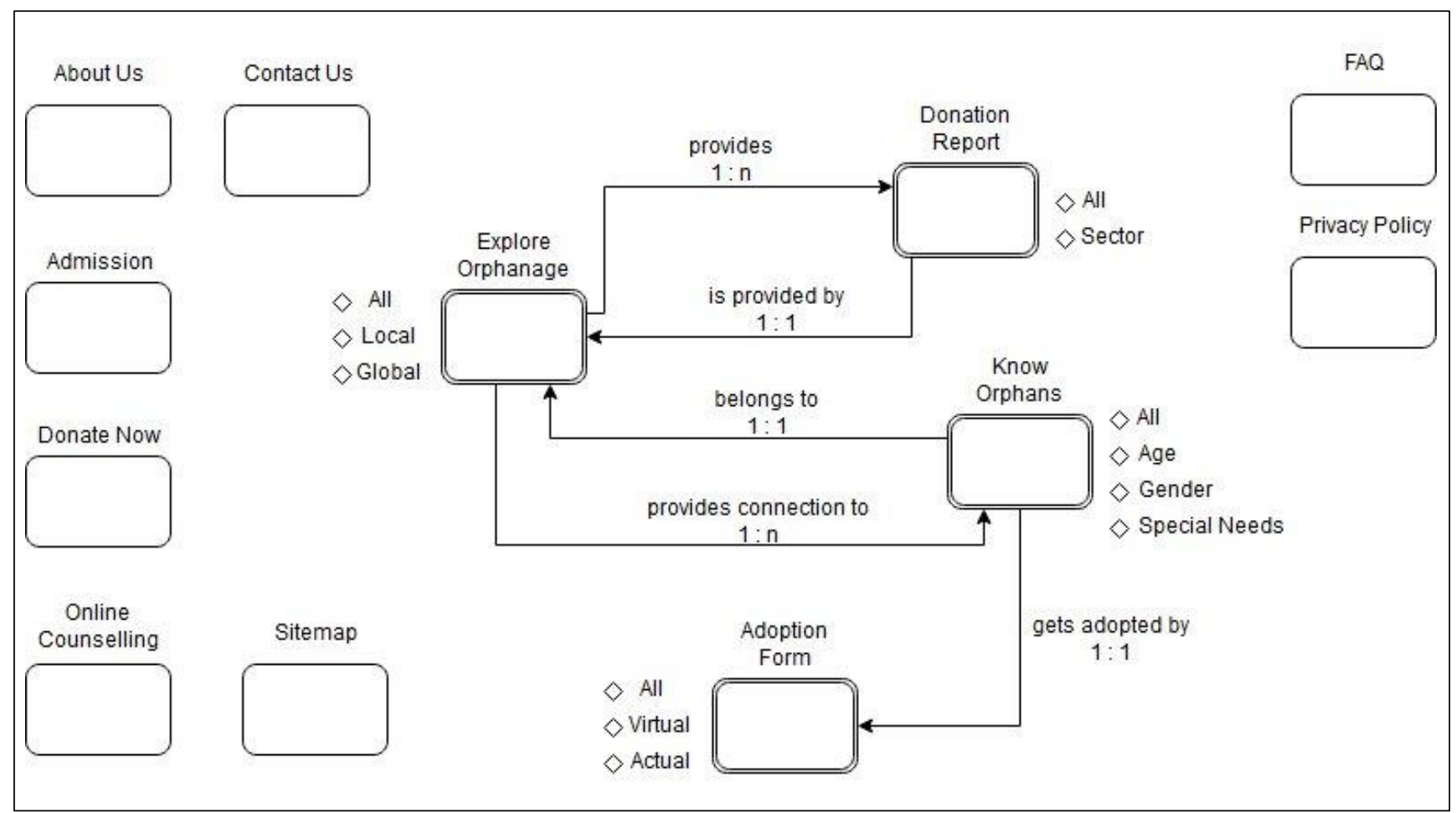

Figure 3: C-IDM of orphanage portal

"provides a connection to". For instance, someone might want to know about donations types of a particular orphanage, and so there should be a relation between Explore Orphanage and Donation Report. Finally, a group of topics is a particular list of topics and a parametric group of topics is a collection of groups of topics. In this design, orphanages could be searched under the topic Explore Orphanage by "all category", by "local category" or by "global category". So, All, Local and Global were indicated as a group of topics for the topic Explore Orphanage. Other groups of topics and the entire schema of C-IDM are represented in Figure 3 with necessary symbols.

\section{ii. Logical IDM (L-IDM)}

Logical IDM consists of three mandatory parameters and an optional design parameter, which include dialogue act, transition act, introductory act and multiple introductory acts (optional) (Bolchini \& Paolini, 2006). The content of a topic is divided into a number of units which is known as a dialogue act. In the orphanage portal website, the dialogue acts for the topic Explore Orphanage were Name, Location, Contact, Gallery, Description, Events and Promotional Activity. The dialogue acts Name and Gallery were underlined which presents the structural strategy of this topic, that is, initially these two dialogue acts were visible on the interface and others can be navigated using a different pattern of structural strategies (see Figure 4). Next, the relevant relation in $\mathrm{C}$-IDM that had cardinality of 1: $\mathrm{n}$ was specified as transition act in L-IDM and the relevant relations having other cardinalities were kept unchanged. A transition act mainly indicates a list of instances when the topic is multiple and the navigation of this list can also be structured using a different pattern of transitional strategy. In this website, there existed a transition act between Explore Orphanage and Know Orphans because a particular orphanage can accommodate a lot of orphans. So, before knowing about an orphan of a particular orphanage, this transition act helps to go through a list of orphans of that orphanage. Finally, a group of topics of C-IDM was specified as an introductory act in L-IDM. Each group of topics is linked to a list of possible instances when the topic is multiple and the navigation of the list can also be structured using a different pattern of subject strategy. In this website, the introductory acts of the topic Know Orphans were indicated as All, Age, Gender and Special Needs, that is before knowing a particular orphans' details, the orphans can be searched "by a list of all category", by "a list of age", by "a list of gender" or by "a list of special needs". The entire schema of L-IDM is represented in Figure 4.

\section{iii. Page IDM (P-IDM)}

Page IDM is the final phase of IDM and involves designing the prototypes for each design parameter discussed above. Figure 5 shows the P-IDM for the homepage of the website orphanage portal. This phase consists of some pages (Bolchini \& Paolini, 2006) where each dialogue act, transition act and the introductory act becomes a page, relevant topics and relevant group of topics become landmarks. For each dialogue act, there should be the content of a kind of topic, structural links of other dialogue acts of the same topic, transition links for transition acts, group of topic links to go from one instance to another, orientation info to indicate the current position of user and landmarks. On the other hand, for a single topic, there is no need for transition links and a group of topic links.

Figure 6 shows a P-IDM for a single topic About Us where the topics' content Aim is displayed by default and contained structural links for Founders' Profile, Our Team and History; the breadcrumbs indicated the orientation info that the users' current position is in Aim inside About Us; the header and footer menu bar and other info links, logo and name are the landmarks. The Explore Orphanage, Know Orphanage, Admission, Adoption Form, Donation Report, and Online Counseling are landmarks used as the header menu, while the About Us, Contact Us, and Donate Now are the landmarks used as a footer menu. 


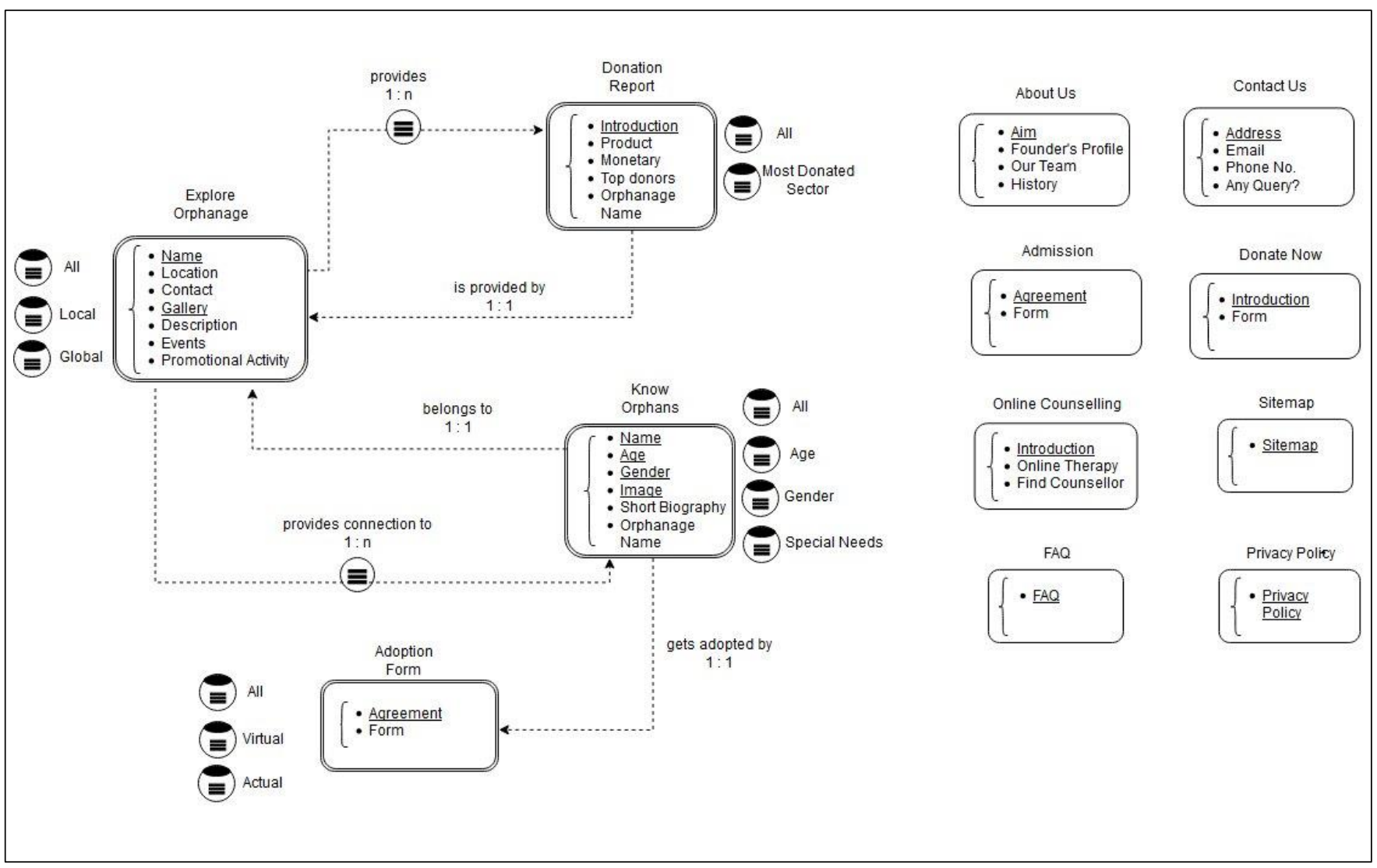

Figure 4: L-IDM of orphanage portal

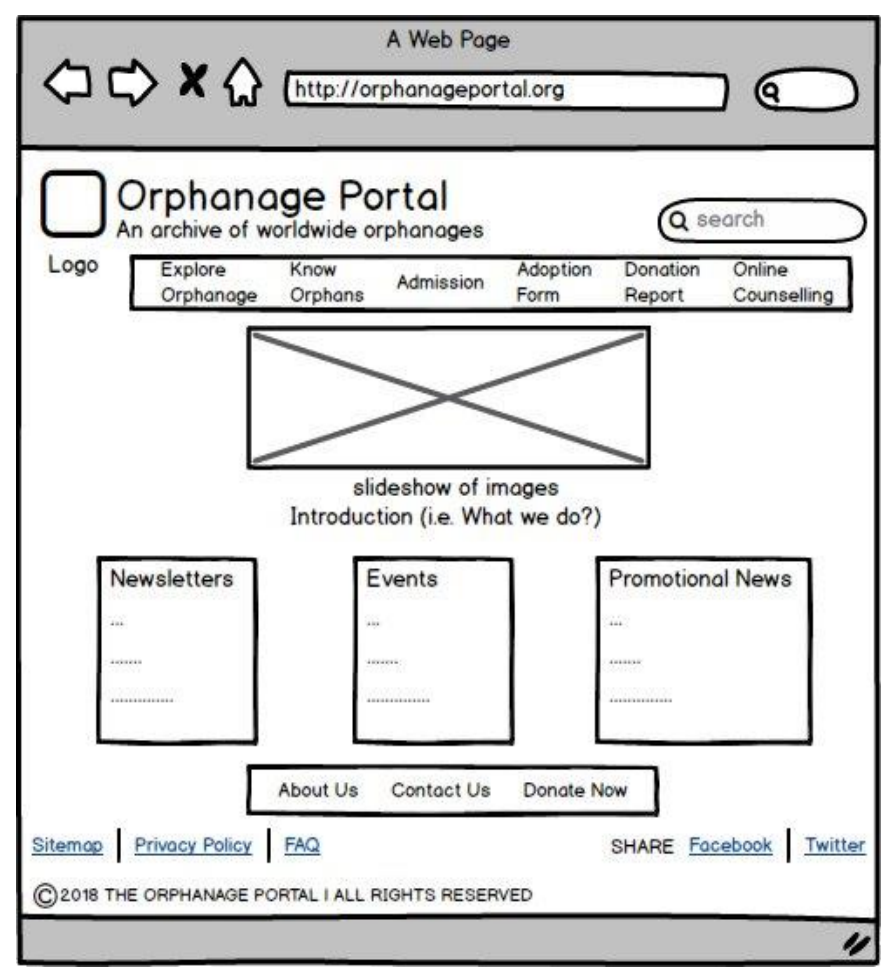

Figure 5: P-IDM of homepage in orphanage portal

Figure 7 shows a P-IDM for a kind of topic Explore Orphanage that is a page displaying the lists for all orphanages by default and links to local and global orphanages list. Selecting a particular orphanage led to a page displaying the topics' content Gallery and Name by default and structural links to other dialogue acts; transition links and the introductory acts were presented as before.

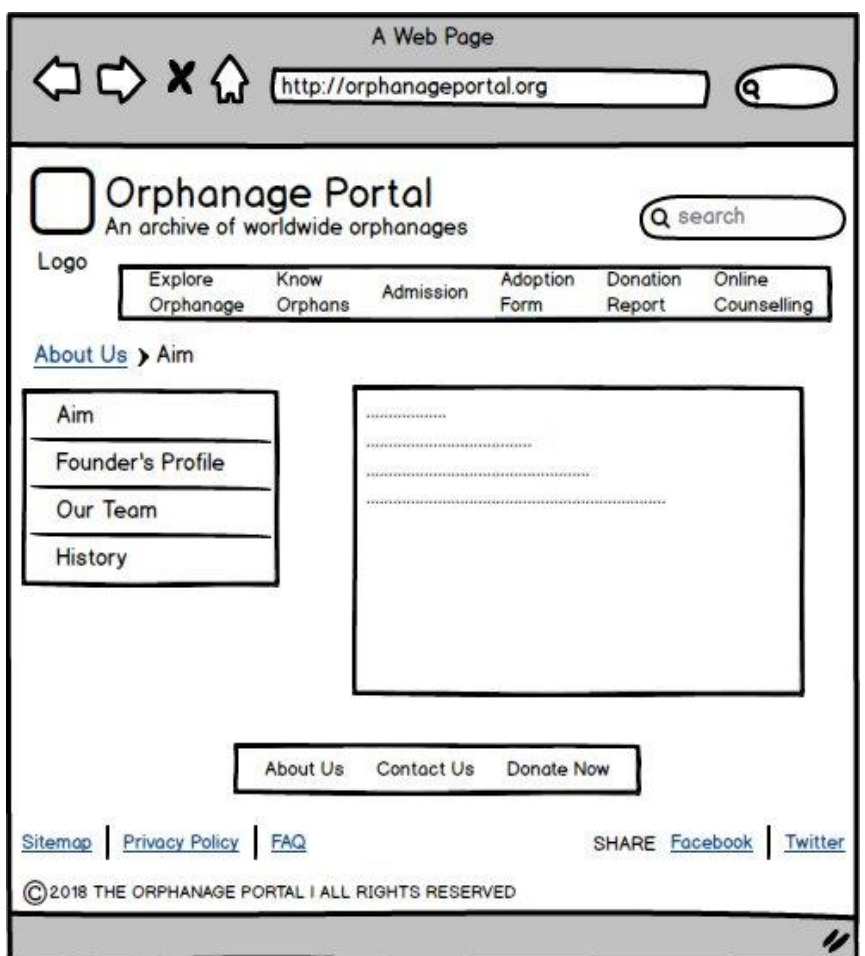

Figure 6: P-IDM of About Us in orphanage portal

There existed a group of topic links on this page to navigate to the next or previous orphanage details. The transition link "connect with orphans" on this page led to a page containing a list of orphans from where a particular orphan can be selected for details and furthermore. The landmarks and orientation info were as before. 

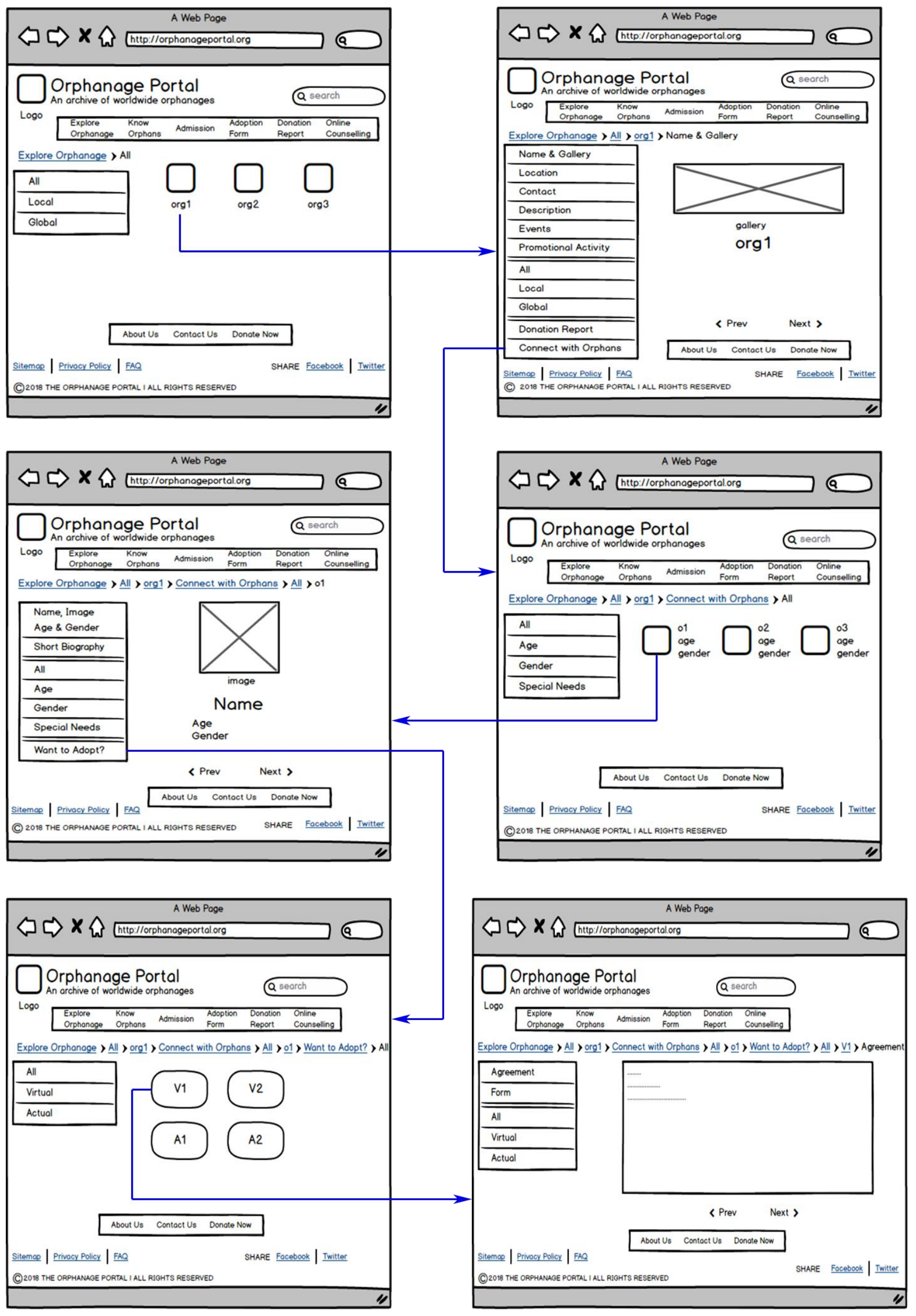

Figure 7: P-IDM steps of Explore Orphanage in orphanage portal 


\section{Development of Web Portals}

For each design, a separate web portal was developed. For the front-end development; HTML, CSS, JavaScript and PHP were used. The Apache server and MySQL database of the XAMPP platform were used to deploy the portals to a local server. Figure 8 shows a user interface of the homepage which has been developed using the Card Sorting design technique. On the other hand, Figure 9 shows a user interface of the homepage which has been developed using the IDM design technique.

\section{COMPARATIVE EVALUATION STUDY}

To evaluate the usability of the two developed websites, an experiment has been conducted. The independent variable of this experiment is the web systems: the website designed using the IDM and the website designed using the card sorting. Dependent variables are some metrics which are chosen to ensure that the goal is reached such as task completion time, success/fail, number of clicks, number of attempts and number of asking help to perform the given task. The experiment has been designed following the within-subjects' concept that means all participants performed the given tasks for both websites. The following subsections describe briefly about the profile of participants, how the experiment has been conducted and the findings of this experiment.

\section{A. Participant Profile}

About fourteen individuals were invited through email and social media to participate in the experiment and ten of them participated in the experiment. There were four female participants and six male participants. The age of the participants varied from 22 to 31 years. All the participants were graduated from various disciplines. All of them had experiences of using the internet and three of them were undergraduate students major in the computer science discipline and others were major in a non-computer science discipline. None of the participants had familiarity with the orphanage system. The participants were assured that their participation is of their own accord and none of their provided information would be used other than experiment purposes. Moreover, participation in the study was completely voluntary and as such, no incentive or compensation has given to the participants.

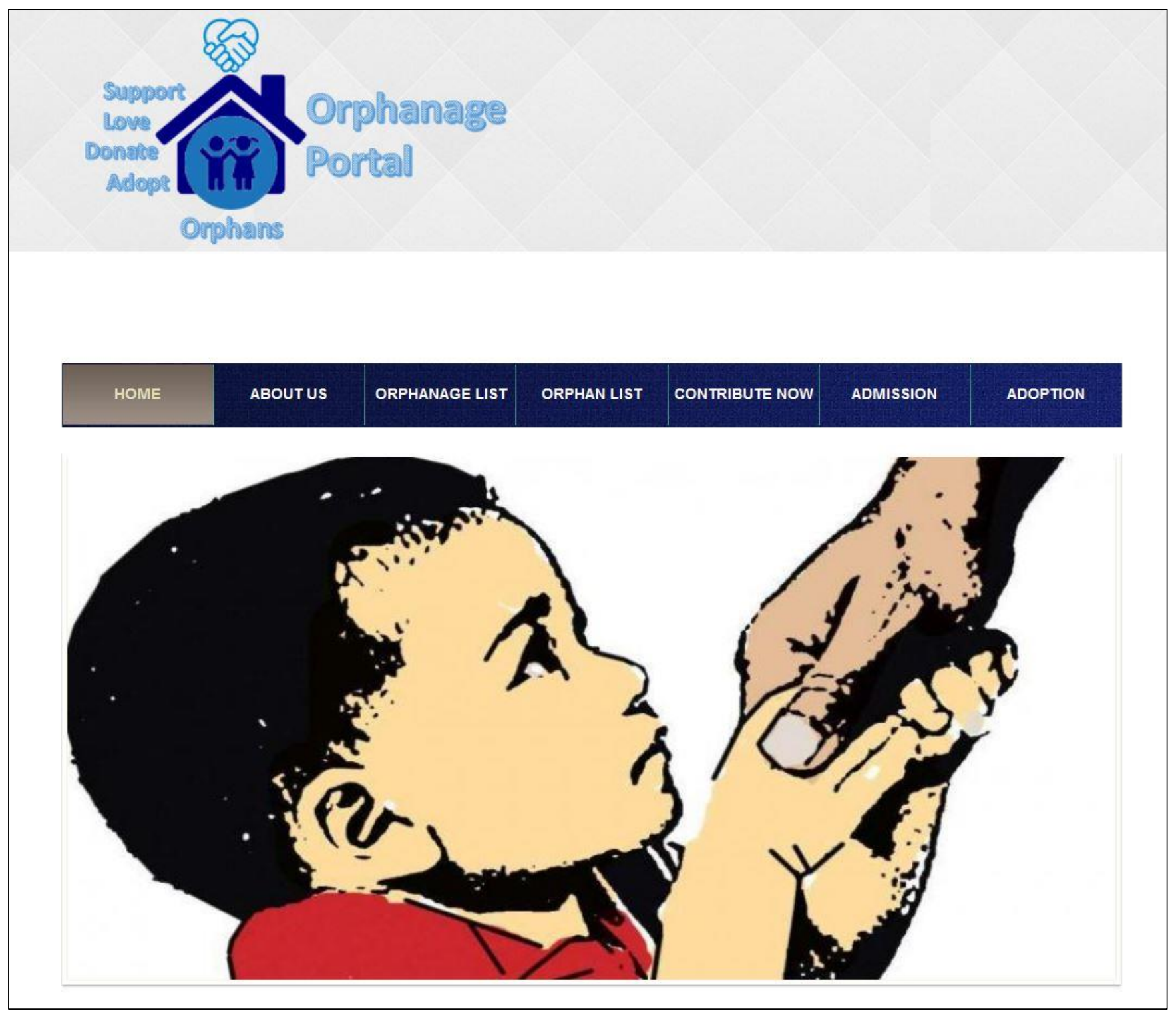

Figure 8: User interface of Homepage of orphanage portal using Card Sorting 


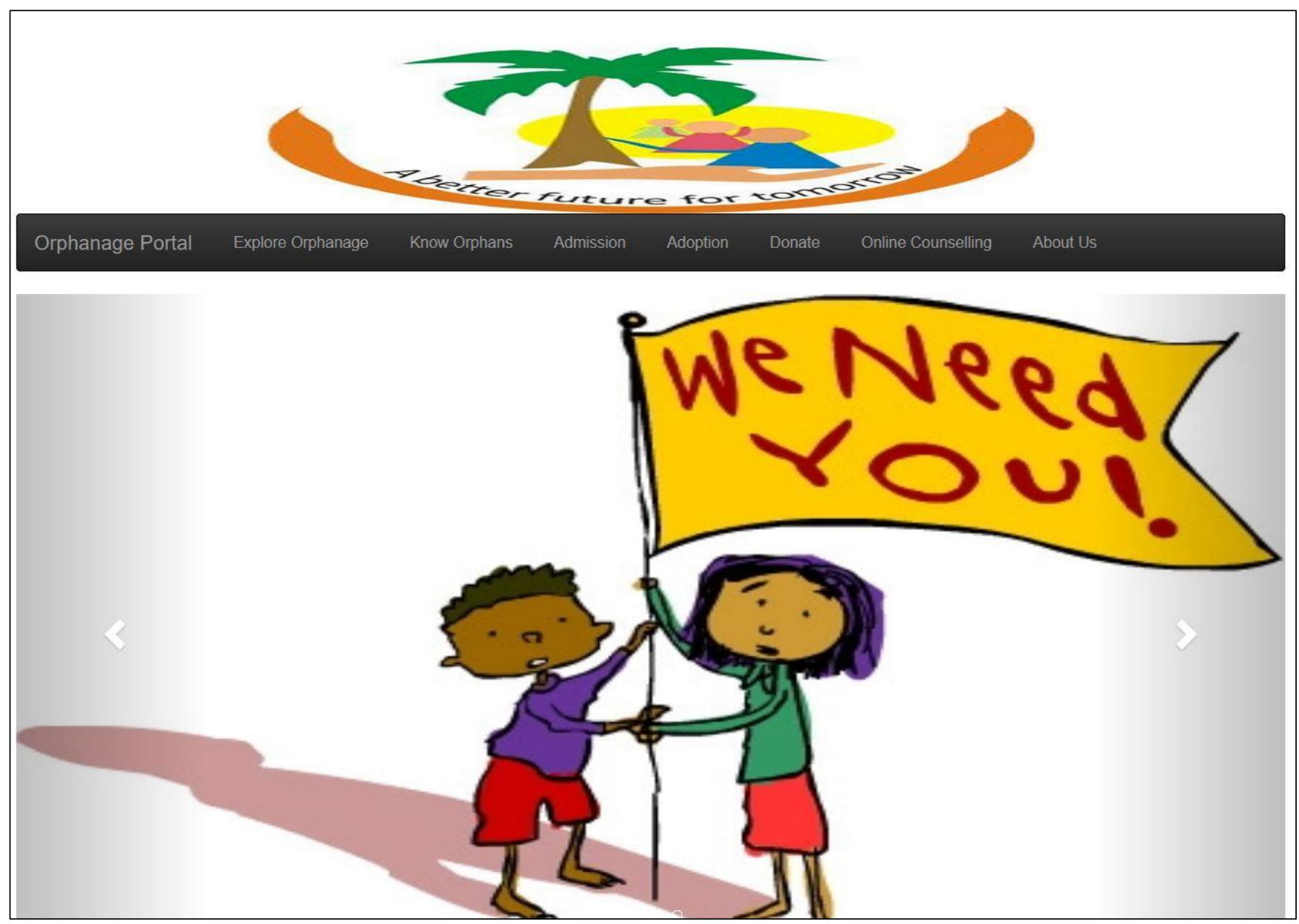

Figure 9: User interface of the Homepage of orphanage portal using IDM

\section{B. Study Procedure}

The experiment was performed in the Software Engineering Laboratory of the authors' institute. A written informed consent was taken from each participant to inform them that participation is voluntary and at any moment they can choose to stop participation in the evaluation study; while the data collected from them will be used anonymously solely for the research and research publications. A total of ten test-sessions were conducted, each with an individual participant. For each test-session, initially, an introduction along with a short demonstration was given to the participants regarding their role and objective of this experiment. After the demonstration, each participant was provided with two sheets - participant's biographical information sheet, and a task sheet followed by a post-test. The tasks were firstly to find details of a local orphanage (Task 01), then to find a female orphan of any local orphanage (Task 02) and finally to adopt the female orphan of that local orphanage that has been found (Task 03). At first, the participants filled up their biographical information sheet and signed the consent form. Then they performed the assigned tasks for each website. While the participants were performing the tasks, required data (data related to the dependent variables) were collected for each participant through observation. After completing the tasks, the participants filled up the post-questionnaire sheet to provide their overall opinion (qualitative feedback) about the experimented websites along with a subjective rating on their overall satisfaction in a range of 1 (strongly dissatisfied) to 5 (strongly satisfied).

\section{Analysis and Findings}

This subsection briefly discusses the analysis and study findings in a different perspective as presented below:

- Number of clicks: The average number of clicks for each task has been calculated for both IDM and card sorting design techniques. The minimum number of clicks required to perform a specific task is considered here as the optimal (number of clicks) value. The difference between the optimal number of clicks and the average number of clicks has been calculated and the deviations are presented in Table 1. It shows that for Task 01 and Task 03, IDM differs slightly less than card sorting but for Task 02 , IDM differs a bit greater than card sorting.

Table 1

Comparison between optimal number of clicks and average number of clicks

\begin{tabular}{cccc|ccc}
\hline \hline & \multicolumn{3}{c}{ IDM } & \multicolumn{3}{c}{ Card Sorting } \\
\cline { 2 - 7 } Tasks & $\begin{array}{c}\text { Optimal } \\
\text { Clicks }\end{array}$ & $\begin{array}{c}\text { Average } \\
\text { Clicks }\end{array}$ & Deviation & $\begin{array}{c}\text { Optimal } \\
\text { Clicks }\end{array}$ & $\begin{array}{c}\text { Average } \\
\text { Clicks }\end{array}$ & Deviation \\
\hline $\begin{array}{c}\text { Task } \\
\mathbf{0 1}\end{array}$ & 3.0 & 3.4 & 0.4 & 2.0 & 2.8 & 0.8 \\
$\begin{array}{c}\text { Task } \\
\mathbf{0 2}\end{array}$ & 2.0 & 2.7 & 0.7 & 2.0 & 2.2 & 0.2 \\
$\begin{array}{c}\text { Task } \\
\mathbf{0 3}\end{array}$ & 2.0 & 2.4 & 0.4 & 3.0 & 3.5 & 0.5 \\
\hline \hline
\end{tabular}


- Number of attempts and asking for help: While the optimal value for the number of attempts is one, the IDM based website showed almost optimal value except Task 02. The Card Sorting based website showed on average 2 to 3 more attempts than the optimal value as shown in Figure 10(a). Again, for each task the number of attempts showed higher value for Card Sorting based website than the IDM based website. Almost similar results are observed in case of number of times asking for help (see Figure 10(b)). Since, the optimal value for the number of asking help is zero, the results showed that none of the tasks was completed with optional (number of times asking for help) value for both websites. Again, the average number of times asking for help does not vary for Task 01 for both design techniques, while the Card Sorting based website differs most in the case of Task 03 and slightly greater for Task 02 comparing to the IDM based website.

- Task completion time: The participants were able to complete each task successfully for both websites. The TCT for the assigned tasks varied from 8 seconds to 24 seconds for IDM based website, while for the Card Sorting based website the TCT was 12 seconds to 26 seconds. That is, on average, the IDM based website taken comparatively less task completion time (TCT) to complete each of the assigned tasks than the Card Sorting based website (see Figure 10(c)).

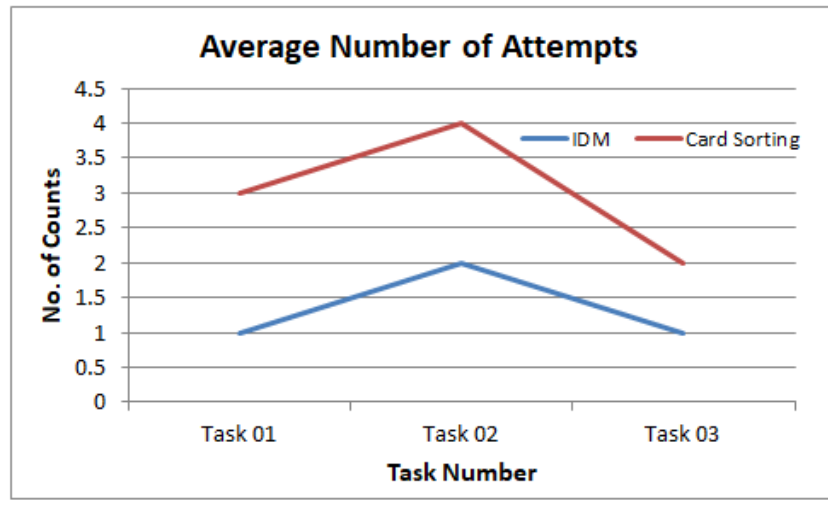

(a) Average number of attempts

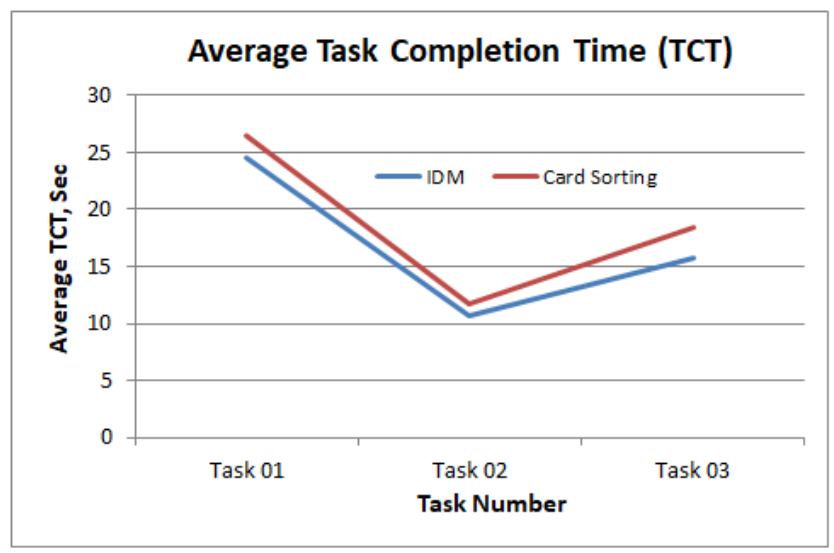

(c) Average task completion time
- Overall satisfaction scores and qualitative feedback: The overall satisfaction score rated by the participants has got much support for the website designed by using IDM than the website designed using card sorting (see Figure 10(d)). As qualitative feedback, participants recommend some features that can enhance the usability of the websites in the future. For the web site designed using IDM, the participants suggested that the icons should be more user-friendly and the interface should be attractive, Google Map should be integrated to find the location of an orphanage. They have commented that the website provides the required functionality to perform the given tasks but it is a little complex to use. On the other hand, for the website designed using card sorting, the participants suggested that the navigation system for the list of the orphanage and orphan information requires much improvement, different pages of the website should be linked up in a user-friendly way, Google Map should be integrated to find the location of an orphanage and necessary information of a child should be provided on the adoption page. They have also agreed to the fact that such a website for an orphanage is helpful and trustworthy for the adoption process. Moreover, most of the participants recommend the IDM design technique over card sorting for designing such an informative website in the future.

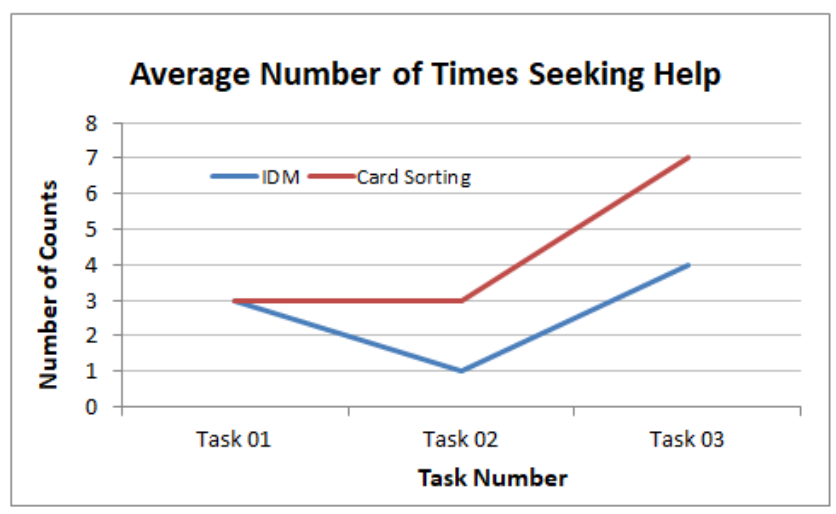

(b) Average number of times asking help

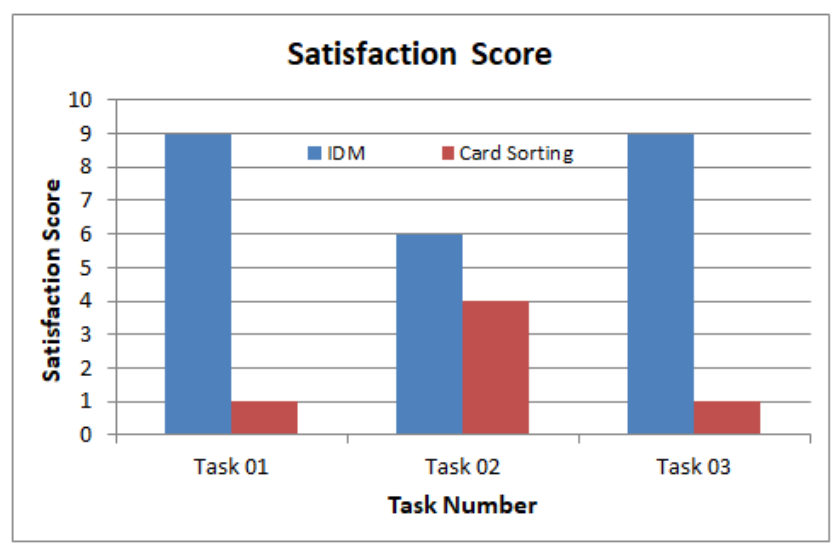

(d) Satisfaction score

Figure 10: Graphical representation of chosen metrics for Task 01, Task 02 and Task 03 


\section{CONCLUSIONS}

This research showed that the IDM based websites performed well than the Card Sorting based website from the usability perspective. The outcome of this research thus contributes to the HCI practitioners by making them aware that the UX and usability of a website depend on an appropriate selection of a design technique to design and develop the website; and by showing them that the IDM is performed better in design information-intensive website. Again, while the existing research mainly focused on the UX and usability evaluation (Park et al., 2020), and comparing the performance of different UX and evaluation methods (Ternauciuc \& Vasiu, 2015), this research explored a new concept, which was not only the UX and usability evaluation approach but also the design choice had a strong impact on the development of a usable website for end-users. However, this research had a few limitations. The number of participants was not adequate from whom the data were collected. Since an orphanage portal website was developed, and the assigned task includes the adoption process of orphans, so the participants should have been adults who are interested in child adoption or are concerned of children. But, most of the participants were not as desired. Again, only one website (i.e., the orphanage web system) was developed here as an experiment purpose, developing multiple information-intensive websites would give more generalize outcomes. Moreover, to analyze the evaluation data, the concept of Fitts' law was not considered to assess the number of clicks with respect to the time to measure the RMS values. The future work of this study would be firstly, to develop the concrete versions of the websites by including more features or functionality, and by making the websites dynamic in nature. Secondly, to conduct a further experiment with more desired participants and conducting an in-depth analysis of the study data to measure more usability factors. Thirdly, potential future research may consider other available design techniques to compare with the CS and IDM techniques to provide a more generalize and effective outcome for the HCI practitioners.

\section{ACKNOWLEDGEMENTS}

The authors would like to acknowledge the contribution of the participants who have voluntarily participated in the experiment of this research work.

\section{REFERENCES}

Abran, A., Khelifi, A., Suryn, W., \& Seffah, A. (2003). Usability meanings and interpretations in ISO standards. Software Quality Journal, 11(4), 325-338.

Al-Fadhli, S. (1997). Critical success factors influencing ECommerce in Kuwait. Journal of Internet Banking and Commerce, 16(1), 1-7.

Bolchini, D. \& Garzotto, F. (2008). Designing multichannel web applications as "Dialogue Systems": The IDM Model. In: Rossi G., Pastor O., Schwabe D., Olsina L. (Eds.), Web Engineering: Modelling and Implementing Web Applications. (pp. 193-219). London, United Kingdom: Springer-Verlag.

Bolchini, D., \& Garzotto, F. (2007, December 3-7). Quality of web usability evaluation methods: An empirical study on MiLE+. Proceedings of the International Conference on Web Information Systems Engineering (WISE'07), Berlin, Heidelberg. (pp. 481-492).

Bolchini, D., \& Paolini, P. (2006). Interactive dialogue model: A design technique for multichannel applications. Journal of IEEE Transactions on Multimedia, 8(3), 529-541.
Brejcha, J., \& Marcus, A. (2013, July 21-26). Semiotics of interaction: Towards a UI alphabet. Proceedings of the 15th International Conference on Human-Computer Interaction (HCII'13), Las Vegas, Nevada, USA. (pp. 13-21).

Conte, T., Massollar, J., Mendes, E., \& Travassos, G. H. (2007, September 20-21). Usability evaluation based on web design perspectives. Proceedings of the 1st international symposium on Empirical Software Engineering and Measurement (ESEM '07), Madrid, Spain. (pp. 146-155).

Coppola, G., Fiore, A., Mainetti, L. \& Pandurino, A. (2015, June 23-26). Mobile-IDM: A design method for modeling the new interaction style of mobile applications. Proceedings of the 15th International Conference on Web Engineering (ICWE'15), Rotterdam, Netherlands. (pp. 101-115).

Craske, D. J. (2010). Conceptual, logical \& page designs for a proposed website for golf courses of Central Indiana and Indiana Microbrews [Technical report], Indiana University School of Informatics, Indiana, USA.

Duncan, J., \& Holliday, W. (2008). The role of information architecture in designing a third-generation library website. Journal of College and Research Libraries, 69(4), 301-318.

Ebenezer, C. (2003). Usability evaluation of an NHS library website. Health Information and Libraries Journal, 20(3), 134-142.

Faiks, A., \& Hyland, N. (2000). Gaining user insight: A case study illustrating the card sort technique. Journal of College and Research Libraries, 61(4), 350-357.

French, T., Liu, K., \& Springett, M. (2007, September 3-7). A cardsorting probe of E-Banking trust perceptions. Proceedings of the 21st British HCI Group Annual Conference on People and Computers (BCS-HCI'07), University of Lancaster, United Kingdom. (pp. 45-83).

Garzotto, F., Paolini, P., \& Schwabe, D. (1993). HDM-a modelbased approach to hypertext application design. Journal of ACM Transactions on Information Systems (TOIS), 11(1), 126.

Gray, W. D., \& Salzman, M. C. (1998). Damaged merchandise? a review of experiments that compare usability evaluation methods. Journal of Human-Computer Interaction, 13(3), 203-261.

Islam, M. N., \& Bouwman, H. (2016). Towards user-intuitive web interface sign design and evaluation: A semiotic framework. International Journal of Human-Computer Studies, 86, 121137.

Islam, M. N., Oishwee, S. J., Mayem, S. Z., Mokarrom, A. S. M. N., Razzak, M. A., \& Kabir, A. B. M. H. (2017, December 79). Developing a multi-channel military application using Interactive Dialogue Model (IDM). Proceedings of the 3rd International Conference on Electrical Information and Communication Technology (EICT'17), Khulna, Bangladesh. (pp. 1-6).

Islam, M. N., Bouwman, H. \& Islam, A. K. M. N. (2020). Evaluating Web and Mobile User Interfaces with Semiotics: An Empirical Study. IEEE Access, 8(1), 84396-84414. DOI: 10.1109/ACCESS.2020.2991840

Jeffries, R., Miller, J. R., Wharton, C., \& Uyeda, K. (1991, April 27-May 2). User interface evaluation in the real world: A comparison of four techniques. Proceedings of the SIGCHI Conference on Human factors in Computing Systems (CHI'91), New Orleans, Louisiana, USA. (pp. 119-124).

Karat, C. M., Campbell, R., \& Fiegel, T. (1992, June 3-7). Comparison of empirical testing and walkthrough methods in user interface evaluation. Proceedings of the SIGCHI Conference on Human factors in Computing Systems (CHI'92), Monterey, California, USA. (pp. 397-404).

Kumar, B. A., \& Goundar, M. S. (2019). Usability heuristics for mobile learning applications. Education and Information Technologies, 24(2), 1819-1833.

Kurniawan, S., \& Zaphiris, P. (2005, October 9-12). Researchderived web design guidelines for older people. Proceedings of the 7th International ACM SIGACCESS Conference on 
Computers and Accessibility (Assets'05), Baltimore, Maryland. (pp. 129-135).

Marcus, A. (Ed.) (2015). Design, User Experience, and Usability: Users and Interactions. Proceedings of the $4^{\text {th }}$ International Conference, DUXU 2015, Held as Part of HCI International 2015, Los Angeles, CA, USA, August 2-7, 2015, Proceedings (Vol. 9187), Springer.

Matera, M., Costabile, M. F., Garzotto, F., \& Paolini, P. (2002). SUE inspection: An effective method for systematic usability evaluation of hypermedia. Journal of IEEE Transactions on Systems, Man, and Cybernetics-Part A: Systems and Humans, 32(1), 93-103.

Mubin, S. A., Jantan, A. H. Jantan, \& R. Abdullah (2015, December 16-17). UML-based navigational design approach for modeling complex interactions in web applications. Proceedings of the $9^{\text {th }}$ Malaysian Software Engineering Conference (MySEC'15), Kuala Lumpur, Malaysia. (pp. 6063).

Nielsen, J. (1995). 10 usability heuristics for user interface design. (Extracted on Apr. 23, 2020). Source: https://www.nngroup.com/articles/ten-usability-heuristics.

Park, K., Jeong, M., \& Kim, K. (2020). Usability evaluation of menu interfaces for smartwatches. Journal of Computer Information Systems, 60(2), 156-165.

Palmer, J. W. (2002). Web site usability, design, and performance metrics. Journal of Information Systems Research, 13(2), 151167.

Perrone, V., Bolchini, D., \& Paolini, P. (2005, September 21-23). A stakeholders centered approach for conceptual modeling of communication-intensive applications. Proceedings of the 23rd Annual International Conference on Design of Communication: Documenting \& Designing for Pervasive Information (SIGDOC'05), Coventry, United Kingdom. (pp. 25-33).

Petrie, H., Power, C., Cairns, P., \& Seneler, C. (2011, September 59). Using card sorts for understanding website information architectures: Technological, methodological and cultural issues. Proceedings of the $13^{\text {th }}$ IFIPTC13 International Conference on Human-Computer Interaction (INTERACT'11), Lisbon, Portugal. (pp. 309-322).

Preece, J., Rogers, Y., \& Sharp, H. (2004). What is interaction design? In S. Kurniawan (Ed.), Interaction design: Beyond human-computer interaction (Vol. 3, pp. 1-18). Sussex, United Kingdom: John Wiley \& Sons Ltd.
Razzak, M. A., \& Islam, M. N. (2020). Exploring and Evaluating the Usability Factors for Military Application: A Road Map for HCI in Military Applications. Human Factors and Mechanical Engineering for Defense and Safety, 4(4), 1-18.

Rabi'u, S., Ayobami, A. S., \& Hector, O. (2012, November 2). Usability characteristics of mobile applications. Proceedings of First International Conference on Behavioural \& Social Science Research (ICBSSR), Kampar, Malaysia. (pp. 1-5).

Rugg, G. \& McGeorge, P. (2005). The sorting techniques: A tutorial paper on card sorts, picture sorts and item sorts. Journal of Expert Systems, 22(3), 94-107.

Sagar, K., \& Saha, A. (2017). A systematic review of software usability studies. International Journal of Information Technology, 9 (4), 1-24. DOI: 10.1007/s41870-017-0048-1

Spagnolo, L., Bolchini, D., Paolini, P., \& Blas, N.D. (2010). Search-enhanced information architecture for contentintensive rich internet applications. Journal of Information Architecture, 2(1), 19-36.

Spencer, D. (2009). Card sorting: Designing usable categories. Rosenfeld Media, Brooklyn, New York.

Ternauciuc, A., \&Vasiu, R. (2015). Integrated usability testing. TEM Journal, 4(4), 388 -395.

Tullis, T. S. (2007). Using closed card-sorting to evaluate information architectures. Proceedings of the Usability Professionals Association (2007) Conference, Austin, TX. (pp. 11-15).

Troyer, O. D., \& Leune, C. J. (1998). WSDM: A user-centered design method for web sites. Journal of Computer Networks and ISDN Systems, 30 (1-7), 85-94.

Wentzel, J., Müller, F., Beerlage-de Jong, N., \& van GemertPijnen, J. E. W. C. (2016). Card sorting to evaluate the robustness of the information architecture of a protocol website. International Journal of Medical Informatics, 86, 7181.

Zhang, T., Rau, P. L. P., \& Salvendy, G. (2010). Exploring critical usability factors for handsets. Behaviour \& Information Technology, 29(1), 45-55.

Zimmerman, D. E., \& Akerelrea, C. (2002, September 17-20). A group card sorting methodology for developing informational websites. Proceedings of the International Professional Communication Conference (IPCC'02), Portland, Oregon, USA. (pp. 437-445). 


\section{CALL FOR PAPERS}

MIJST invites to submit Unpublished, Original, and Innovative research works from any branch of Engineering, applied sciences, and related areas.

Submitted manuscripts will undergo a double-blind peer-review process. For submission of Manuscript template and authors' instructions, please visit journal website at:

https://mijst.mist.ac.bd/mijst/index.php/mijst/

MIJST offers a faster peer-review process. There will be no charges for Registration, Online submission, Publication of manuscripts, and access to the published articles. Best selected papers will also be awarded by MIJST.

\section{ABOUT MIJST}

MIST International Journal of Science and Technology (MIJST), published biannually (June and December), is a peer-reviewed open-access journal of the Military Institute of Science and Technology (MIST). This journal is a continuation of the 'MIST Journal of Science and Technology', published by MIST, under ISSN 1999-2009 from 2009 to 2011, ISSN 2224-2007 from 2012 to 2019, \& ISSN 2707-7365 since 2020.

MIJST publishes original research findings as regular papers, review papers (by invitation). The Journal provides a platform for Engineers, Researchers, Academicians, and Practitioners who are highly motivated in contributing to the Engineering, Science, and Technology and Applied Sciences disciplines. MIJST welcomes contributions that address solutions to the specific challenges of the developing world.

The Journal will be indexed under the "Bangladesh Journal Online", "Creative Common" and "Open Journal System" databases and will be accessible through Google Scholar. The journal is also planned to be registered under the Asian Citation Indexing, Directory of Open Access Journals (DOAJ), SCOPUS, and Emerging Source Citation Indexing (ESCI) in course of time. The Journal aims to be one of the leading journals of the Country and the Region for its contributions in the advancement of Science and Technology. Unpublished innovative world-class research papers under the following subject areas are invited. Contributions from other areas of Engineering and Applied Sciences are also welcome.

SUBJECT AREAS:

$\begin{array}{ll}- & \text { AEROSPACE AND AVIONICS ENGINEERING } \\ - & \text { APPLIED PHYSICS \& SCIENCE } \\ \text { - } & \text { ARCHITECTURE } \\ \text { BIOMEDICAL ENGINEERING } & \text { CHEMISTRY } \\ - & \text { CIVIL ENGINEERING } \\ \text { COMPUTER SCIENCE AND ENGINEERING } \\ \text { ELECTRICAL, ELECTRONIC AND COMMUNICATION ENGINEERING } \\ \text { ENVIRONMENTAL, WATER RESOURCES, AND COASTAL ENGINEERING } \\ \text { INDUSTRIAL AND PRODUCTION ENGINEERING } \\ \text { MATERIALS SCIENCE \& ENGINEERING } \\ \text { MECHANICAL ENGINEERING } \\ \text { NAVAL ARCHITECTURE AND MARINE ENGINEERING } \\ \text { NUCLEAR SCIENCE \& ENGINEERING } \\ \text { PETROLEUM AND MINING ENGINEERING }\end{array}$

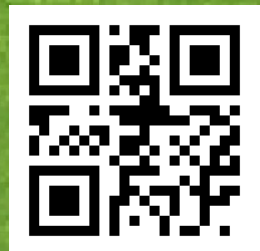

ISSN: 2707-7365 
